UNIVERSIDADE DE BRASÍLIA

FACULDADE DE TECNOLOGIA

DEPARTAMENTO DE ENGENHARIA CIVIL E AMBIENTAL

\title{
MÉTODO DE ANÁLISE DE VULNERABILIDADE UTILIZANDO REDES COMPLEXAS: APLICAÇÃO NA REDE DE TRANSPORTE AÉREO BRASILEIRA
}

RAFAEL RODRIGUES DIAS PEREIRA

ORIENTADOR: PASTOR WILLY GONZALES TACO COORIENTADOR: GLAUCO ESTÁCIO GONÇALVES

DISSERTAÇÃO DE MESTRADO EM TRANSPORTES

PUBLICAÇ̃̃O: T.DM-008/2016

BRASÍLIA / DF: 03/2016 


\title{
UNIVERSIDADE DE BRASÍLIA \\ FACULDADE DE TECNOLOGIA \\ DEPARTAMENTO DE ENGENHARIA CIVIL E AMBIENTAL
}

\author{
MÉTODO DE ANÁLISE DE VULNERABILIDADE UTILIZANDO \\ REDES COMPLEXAS: APLICAÇÃO NA REDE DE TRANSPORTE \\ AÉREO BRASILEIRA
}

RAFAEL RODRIGUES DIAS PEREIRA

DISSERTAÇÃO DE MESTRADO SUBMETIDA AO DEPARTAMENTO DE ENGENHARIA CIVIL E AMBIENTAL DA FACULDADE DE TECNOLOGIA DA UNIVERSIDADE DE BRASÍLIA COMO PARTE DOS REQUISITOS NECESSÁRIOS PARA A OBTENÇÃO DO GRAU DE MESTRE EM TRANSPORTES.

APROVADA POR:

PASTOR WILLY GONZALES TACO, Doutor (ENC-UnB) (ORIENTADOR)

MICHELLE ANDRADE, Doutora (ENC-UnB)

(EXAMINADOR INTERNO)

MARCELO PEREIRA QUEIROZ, Doutor (ANAC) (EXAMINADOR EXTERNO)

BRASÍLIA/DF, 23 DE MARÇO DE 2016. 


\section{FICHA CATALOGRÁFICA}

\section{PEREIRA, RAFAEL RODRIGUES DIAS}

Método de Análise de Vulnerabilidade Utilizando Redes Complexas: Aplicação na Rede de Transporte Aéreo Brasileira [Distrito Federal] 2016.

xiii 146p. 210 x 297 mm (ENC/FT/UnB, Mestre, Transportes, 2016).

Dissertação de Mestrado - Universidade de Brasília. Faculdade de Tecnologia.

Departamento de Engenharia Civil e Ambiental.

1. Análise de Vulnerabilidade

3. Teoria de Redes Complexas

2. Infraestruturas Críticas

I. ENC/FT/UnB

4. Redes de Transporte Aéreo

II. Título (série)

\section{REFERÊNCIA BIBLIOGRÁFICA}

PEREIRA, R. R. D. (2016). Método de Análise de Vulnerabilidade Utilizando Redes Complexas: Aplicação na Rede de Transporte Aéreo Brasileira. Dissertação de Mestrado em Transportes, Publicação PPGT/ENC. T.DM-008/2016, Departamento de Engenharia Civil e Ambiental, Universidade de Brasília, Brasília, DF, 146p.

\section{CESSÃO DE DIREITOS}

AUTOR: Rafael Rodrigues Dias Pereira.

TÍTULO: Método de Análise de Vulnerabilidade Utilizando Redes Complexas: Aplicação na Rede de Transporte Aéreo Brasileira.

GRAU: Mestre

ANO: 2016

É concedida à Universidade de Brasília permissão para reproduzir cópias desta dissertação de mestrado e para emprestar ou vender tais cópias somente para propósitos acadêmicos e científicos. O autor reserva outros direitos de publicação e nenhuma parte dessa dissertação de mestrado pode ser reproduzida sem autorização por escrito do autor.

Rafael Rodrigues Dias Pereira

rafaelrodriguesx@gmail.com

SRIA, Guará II, QI 29, Condomínio SQA, B1. H, Apt. 804

Brasília - DF - Brasil. 


\section{AGRADECIMENTOS}

A conclusão deste trabalho é resultado de uma jornada de estudos e reflexões iniciada em março de 2014, que contou com a orientação, o apoio e a amizade de pessoas especiais.

Agradeço aos professores do PPGT-UnB pelo conhecimento e experiência compartilhados. À professora Michelle que, durante as reuniões do grupo de estudo de segurança em transportes, pode dar as primeiras lições acerca da importância de um procedimento sistemático para realizar um levantamento bibliográfico. Ao meu orientador, professor Pastor, que me recepcionou de forma prazerosa no grupo GCTNT, alertou constantemente sobre os procedimentos metodológicos para a elaboração de uma dissertação e me incentivou a investigar o tema de análise de vulnerabilidade em transportes.

Agradeço ao meu coorientador, professor Glauco, da UFRPE, pela imensa atenção e apoio dados desde o primeiro contato por mensagem eletrônica, em meados de 2014. Sem dúvida, a curva de aprendizado para manipulação das ferramentas computacionais e para compreensão de parte das referências bibliográficas foi um pouco menos acentuada em virtude da sua constante presença (online) e colaboração.

Agradeço aos amigos do PPGT-UnB pelo apoio e companheirismo sempre presentes e essenciais para caminharmos no universo acadêmico. Agradeço à amiga Thays, da UFRPE, pelas discussões sobre a teoria de redes e suas aplicações no transporte aéreo e pelo trabalho colaborativo que realizamos na elaboração e manipulação dos códigos em R.

Agradeço à ANAC pelo apoio concedido para a realização do curso de mestrado e a produção desta dissertação. Aos amigos da SIA/ANAC, na pessoa da Michelle, que motivou o meu ingresso no curso e sempre esteve incentivando a condução deste projeto. Aos amigos Luiz Gustavo (SIA) e Susane (SPO), pela revisão proporcionada ao texto.

Agradeço aos meus familiares, em especial, aos meus pais e minhas queridas irmãs por fazerem parte de mais essa etapa. Agradeço à minha esposa, Priscila, pela constante atenção e carinho com que permaneceu ao meu lado nas horas de cansaço e pelos momentos de alegria que serviram para recarregar as energias.

Agradeço à minha pequena filha, Ana Luisa, por fazer dos últimos cinco meses um período especial em minha vida.

Por fim, agradeço a Deus pela oportunidade de enfrentar esse desafio e por colocar pessoas tão importantes no meu caminho. 


\section{RESUMO}

\section{MÉTODO DE ANÁLISE DE VULNERABILIDADE UTILIZANDO REDES COMPLEXAS: APLICAÇÃO NA REDE DE TRANSPORTE AÉREO BRASILEIRA}

As redes de transporte aéreo são consideradas uma das infraestruturas críticas que sustentam a dinâmica da sociedade econômica atual, ao lado de diversos outros sistemas essenciais que operam sob uma estrutura de rede, tais como, sistemas de transmissão de energia elétrica, sistemas de abastecimento de água ou de telecomunicações. Nesse contexto, existe a necessidade de melhorar a compreensão da vulnerabilidade dessas redes quando sujeitas a eventos de interrupção. Uma condição climática severa, um acidente na pista de pouso, uma sabotagem do terminal de passageiros ou de uma aeronave em solo, são exemplos da variedade de eventos que podem causar interrupção ou redução da capacidade operacional de um aeroporto e, portanto, podem impactar negativamente uma rede de transporte aéreo. O cenário de interrupção de uma instalação ou serviço componente de um sistema que opera em rede é um ponto de partida para a análise da vulnerabilidade do sistema. Em sistemas de transportes, essa análise pode ser entendida como uma avaliação do comportamento da rede de transporte quando esta sofre interferências de eventos inesperados ou não desejáveis nos elementos que a compõem. Considerando o conjunto de preocupações decorrentes dessa perspectiva, a pesquisa investiga as formas de avaliar a vulnerabilidade de uma rede de transporte aéreo e propõe um método para essa avaliação em cenários de interrupção operacional de aeroportos. A teoria das redes complexas proporciona um ferramental teórico e técnico que tem se mostrado adequado pela capacidade de integração de diferentes abordagens metodológicas. O método foi implementado na linguagem e ambiente $\mathrm{R}$ e aplicado para análise da rede de transporte aéreo brasileira, onde foi possível: (1) descrever as características topológicas e funcionais da rede; (2) avaliar o seu grau de vulnerabilidade (3) identificar a importância e criticidade dos aeroportos que compõe a rede e (4) avaliar a validade do método proposto. Por fim, destaca-se o potencial do método em contribuir para o aprimoramento do processo de gerenciamento de risco das organizações públicas e privadas do setor de aviação.

Palavras chave: análise de vulnerabilidade, infraestruturas críticas, teoria de redes complexas, rede de transporte aéreo. 


\section{ABSTRACT}

\section{METHOD OF VULNERABILITY ANALYSIS USING THE COMPLEX NETWORK APPROACH: CASE STUDY OF BRAZILIAN AIR TRANSPORTATION NETWORK}

Air transport networks are considered one of the critical infrastructure that support the dynamics of the current economic society, along with many other essential systems that operate under a network structure, such as electric power transmission systems, water supply systems or telecommunications systems. In this context, there is a need to enhance the understanding of the vulnerability of these networks when subjected to events of interruption. A severe weather condition, an accident on the runway, and a sabotage of the terminal or of the aircraft on the ground are examples of the variety of events that may cause interruption or reduction of the operational capacity of an airport and therefore may negatively impact an air transport network. The scenario of interruption of a facility or service that is part of a networked system is a starting point for the analysis of the system's vulnerability. In transport systems, this analysis may be seen as an assessment of the behavior of the transport network when it is interfered by unexpected or undesirable events on the elements that compose it. Considering the set of concerns arising from this perspective, the research investigates ways to evaluate the vulnerability of an air transport network and proposes a method for this assessment in scenarios of operational disruption of airports. The theory of complex networks provides a theoretical and technical tool that has been shown to be suitable because of the integration capacity of different methodological approaches. The method was implemented on the $\mathrm{R}$ language and environment and applied in the analisys of the Brazilian air transport network, where it was possible: (1) to describe the topological and functional characteristics of the network; (2) to assess the network's level of vulnerability (3) to identify the importance and criticality of the airports that make up the network and (4) to evaluate the validity of the proposed method. Finally, it is important to highlight the potencial of the method in contributing to the improvement of the risk management process in public and private aviation organizations.

Key words: analysis of vulnerability, critical infrastructure, theory of complex network, air transportation network. 


\section{SUMÁRIO}

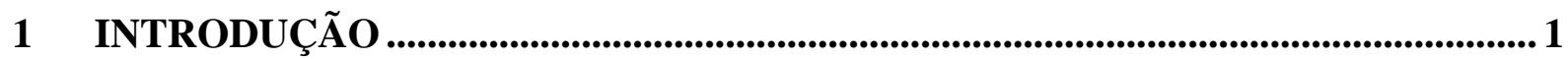

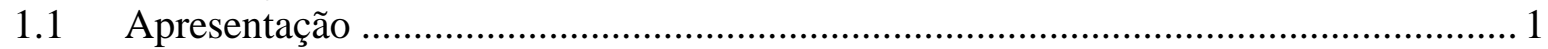

1.2 Problematização............................................................................................... 2

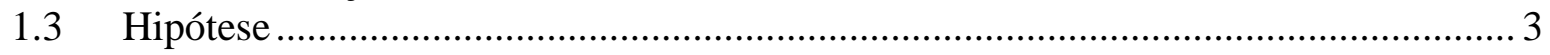

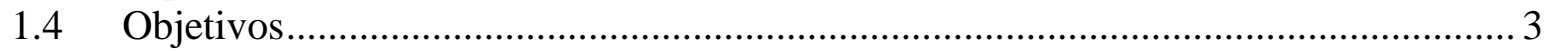

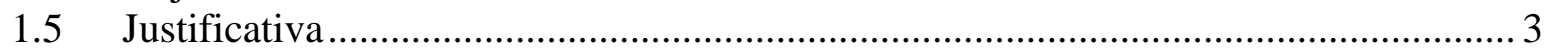

1.5.1 Aspectos de ordem acadêmica ......................................................................... 3

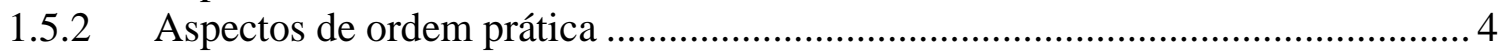

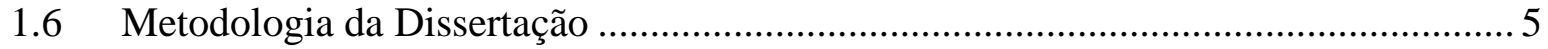

2 VULNERABILIDADE DE SISTEMAS DE TRANSPORTE ................................. 8

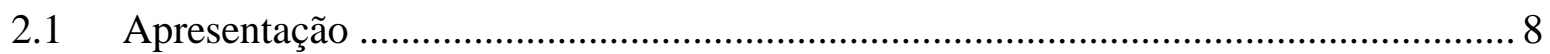

2.2 Abordagens conceituais ................................................................................... 8

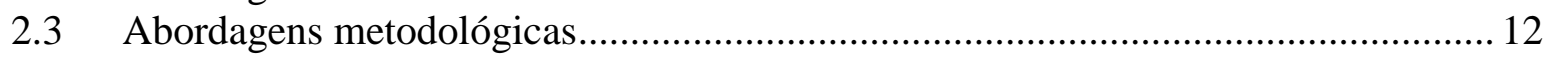

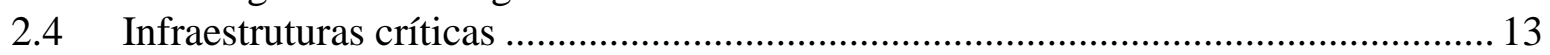

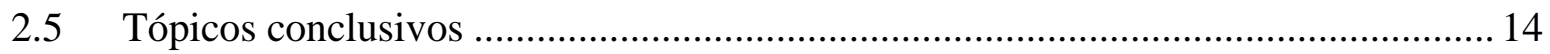

3 TEORIA DE REDES COMPLEXAS........................................................................... 15

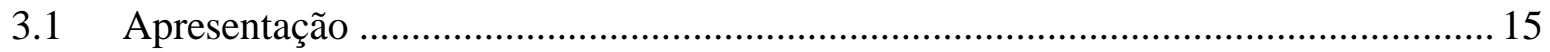

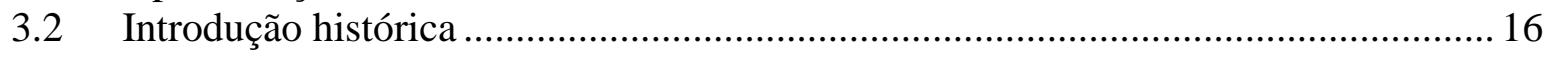

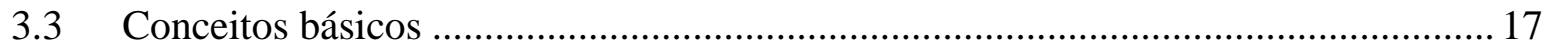

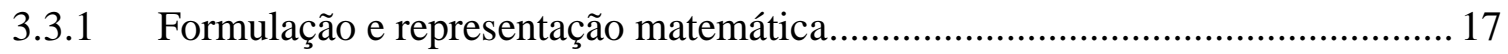

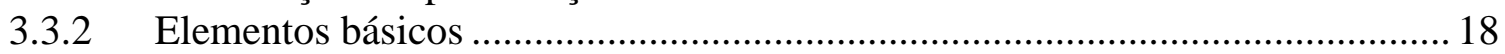

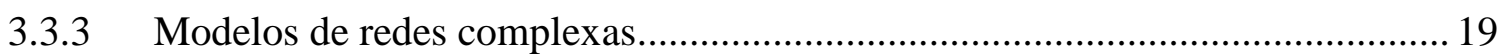

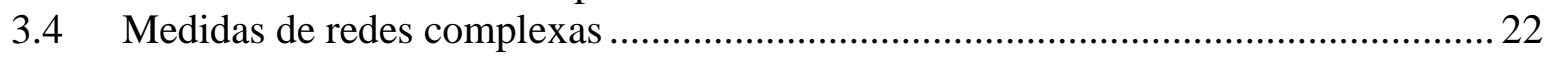

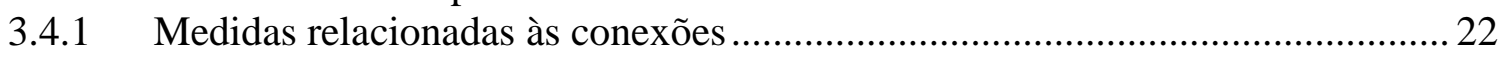

3.4.2 Medidas Relacionadas à Distância .................................................................. 26

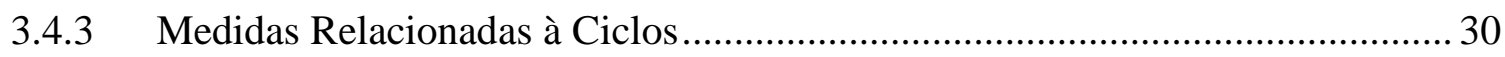

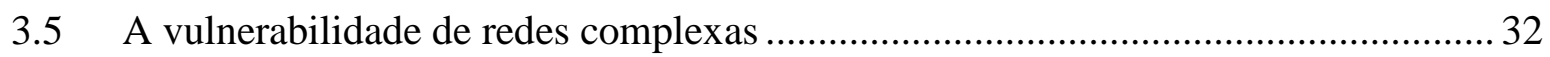

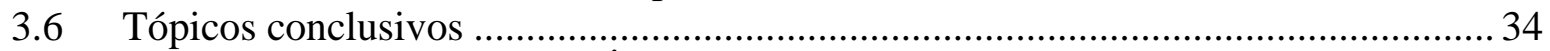

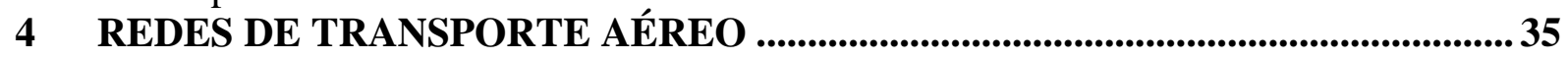

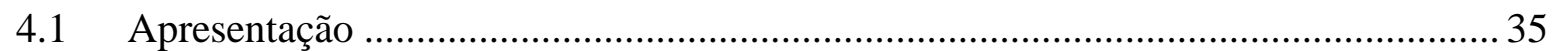

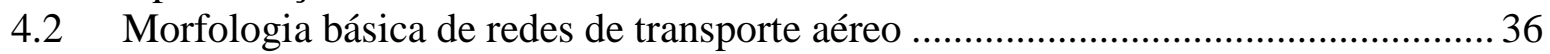

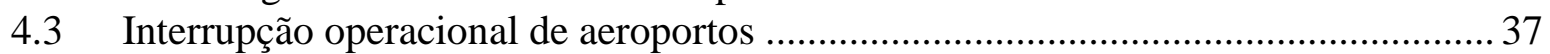

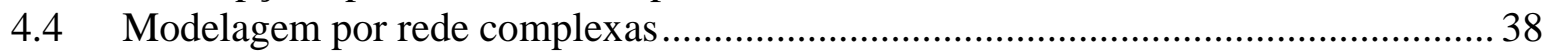

4.5 Análise da vulnerabilidade da rede de transporte aéreo .......................................... 42

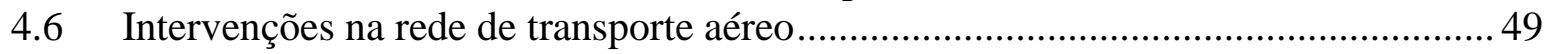

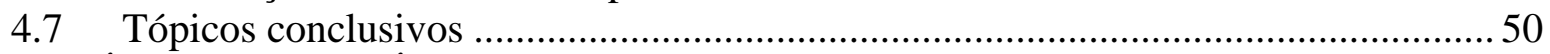

5 MÉTODO DE ANÁLISE DE VULNERABILIDADE DE REDES DE

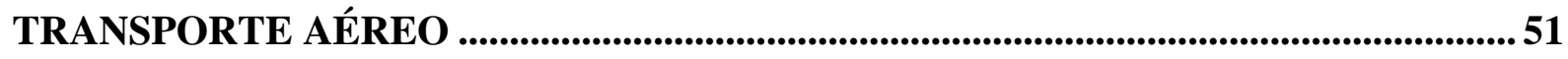

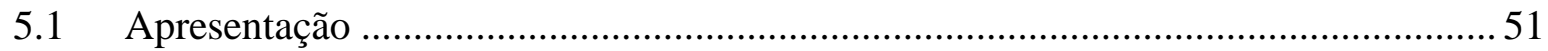

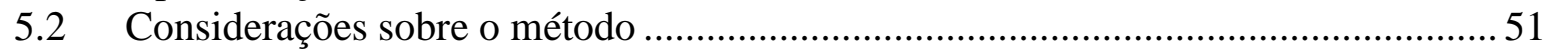

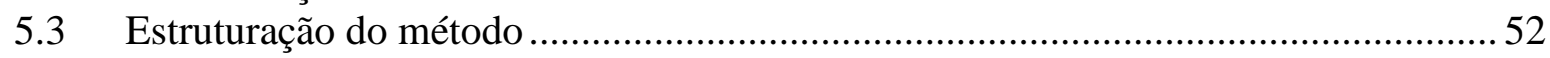

5.3.1 Etapa I: caracterização do sistema de transporte aéreo ..................................... 52

5.3.2 Etapa II: processo de modelagem da rede de transporte aéreo ..........................54

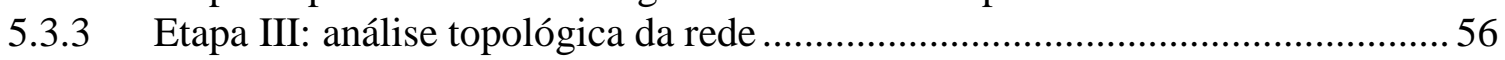

5.3.4 Etapa IV: simulação de ataque sequencial .................................................... 57

5.3.5 Etapa V: simulação de interrupção individual ............................................ 59

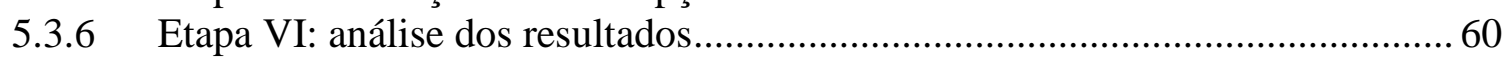




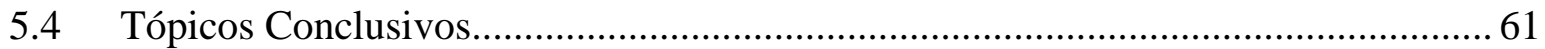

6 APLICAÇÃO DO MÉTODO NA MALHA AÉREA BRASILEIRA ......................... 62

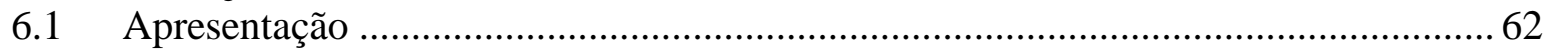

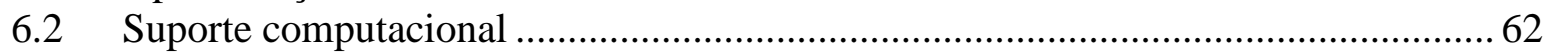

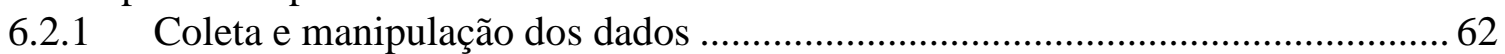

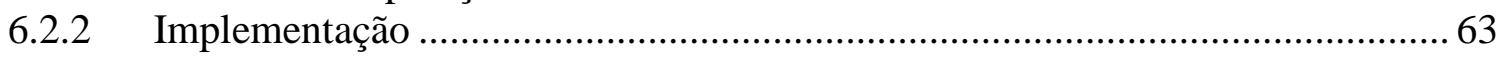

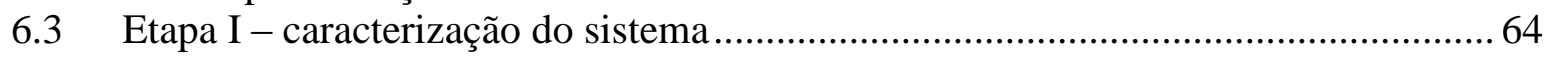

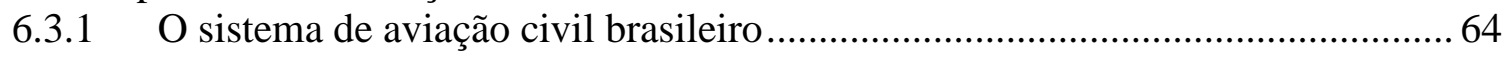

6.3.2 Delimitação das redes de transporte aéreo ..................................................... 71

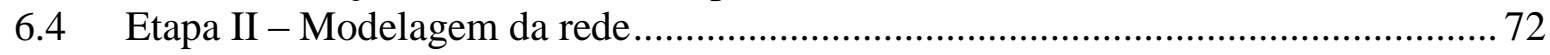

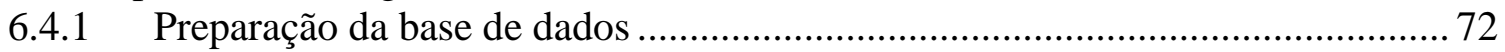

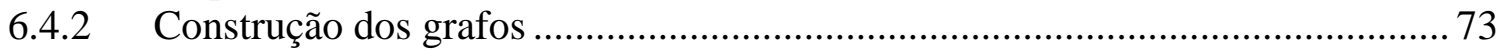

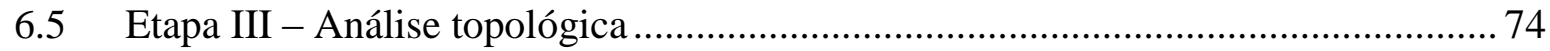

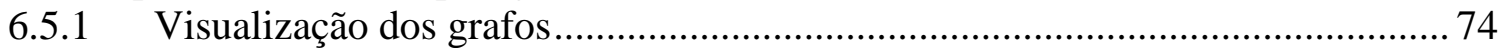

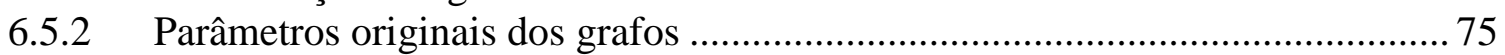

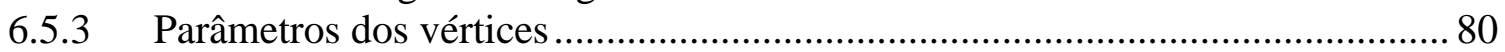

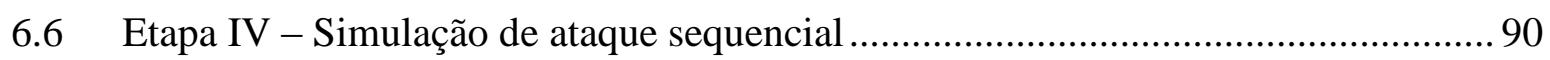

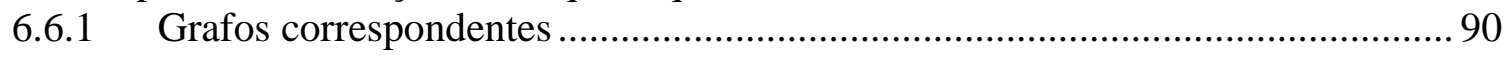

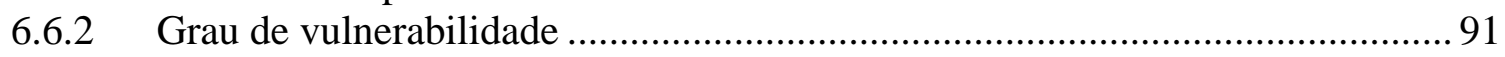

6.6.3 Aeroportos críticos determinados pela literatura ........................................... 93

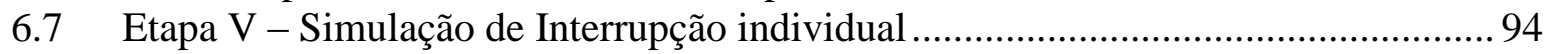

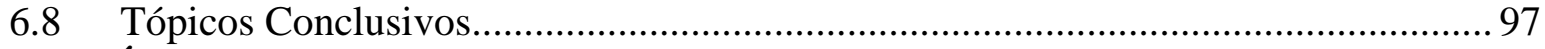

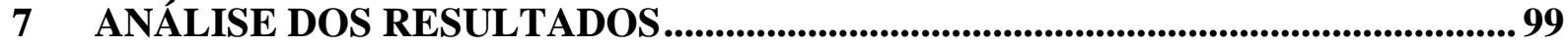

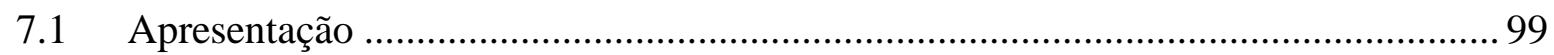

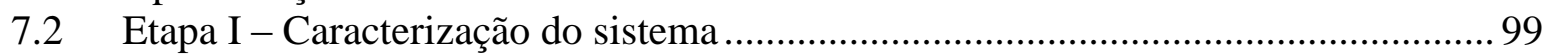

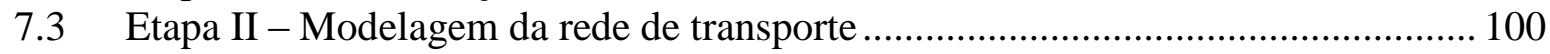

7.4 Etapa III - Análise topológica da rede ................................................................ 100

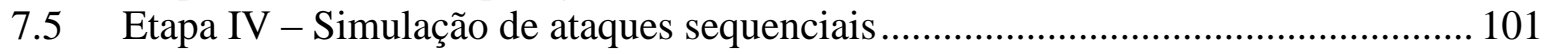

7.6 Etapa V - Simulação de interrupções operacionais individuais ............................... 103

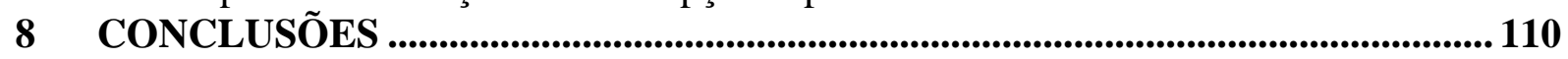

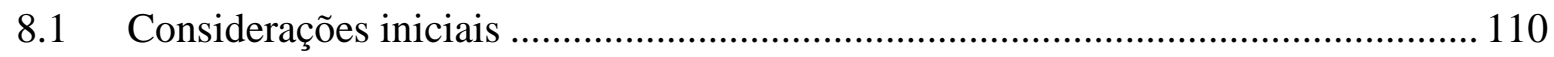

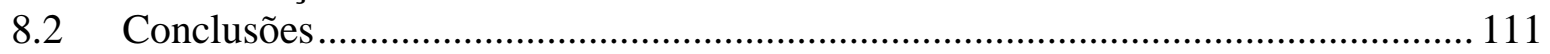

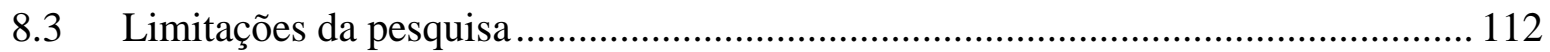

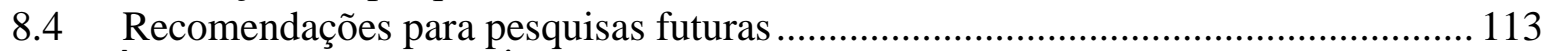

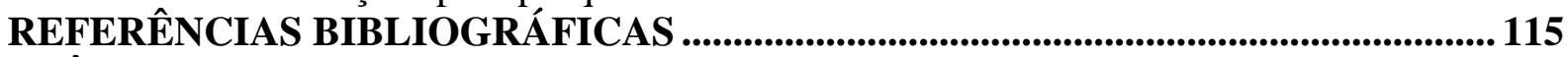

APÊNDICE A - Principais códigos implementados no R .............................................. 125

APÊNDICE B - Resultados dos parâmetros de vértices ..................................................... 131

APÊNDICE C - Resultados das variações dos parâmetros dos grafos............................ 137

APÊNDICE D - Dendrograma da análise de agrupamento .......................................... 143

ANEXO 1 - Descrição de variáveis da base de dados do transporte aéreo brasileiro... 144 


\section{LISTA DE TABELAS}

Tabela 6.1. Delimitação das redes de transporte aéreo. 72

Tabela 6.2. Representatividade das amostras da base delimitada e da base final. ................... 73

Tabela 6.3. Medida da reciprocidade dos grafos direcionados. ............................................ 74

Tabela 6.4. Parâmetros originais de grafos não direcionados da rede brasileira. ..................... 76

Tabela 6.5. Parâmetros de grafos não direcionados obtidos na literatura pesquisada. ............ 76

Tabela 6.6. Parâmetros originais de grafos direcionados da rede brasileira. ............................ 77

Tabela 6.7. Lista de 17 aeroportos brasileiros que atenderam voos domésticos e

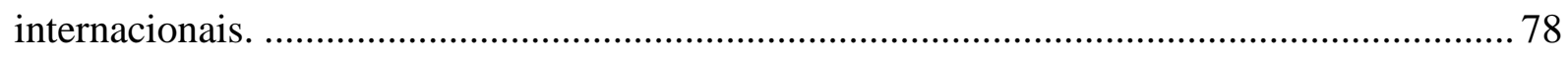

Tabela 6.8. Diâmetro e ligações entre aeroportos mais distantes das redes............................. 79

Tabela 6.9. Correlação linear entre os parâmetros de vértices da rede $R \_b r a \_d o m$................ 84

Tabela 6.10. Parâmetros de 25 aeroportos mais importantes da rede $R \_b r a \_d o m$................. 86

Tabela 6.11. Os cinco aeroportos com maiores indicadores de importância em cada rede. .... 89

Tabela 6.12. Comparação dos parâmetros dos grafos originais e dos grafos correspondentes.

Tabela 6.13. Dominância do ponto central das RTAer. ....................................................... 93

Tabela 6.14. Ordenação dos aeroportos que seriam críticos, segundo Lordan et al., (2014b). 94

Tabela 6.15. Impactos dos 25 aeroportos mais críticos da rede $R \_b r a \_d o m$......................... 96

Tabela 6.16. Os cinco aeroportos com maiores indicadores de criticidade em cada rede. ...... 97

Tabela 7.1. Matriz de correlação das variações nos parâmetros do grafo que representa a rede

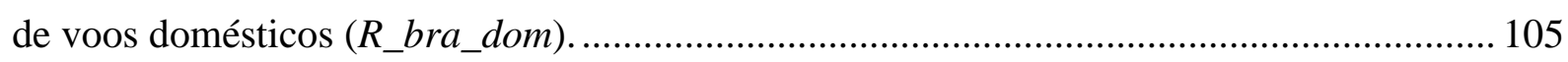

Tabela 7.2. Grupos de aeroportos da rede de voos domésticos $\left(R \_b r a \_d o m\right)$ definidos pela análise de agrupamento. 


\section{LISTA DE FIGURAS}

Figura 1.1. Estrutura Metodológica do Projeto de Pesquisa. ................................................... 7

Figura 2.1. Diferenças e relacionamentos entre termos correlatos . ...................................... 10

Figura 3.1. Representação de um grafo pela forma visual e pela matriz de adjacência. Grafo

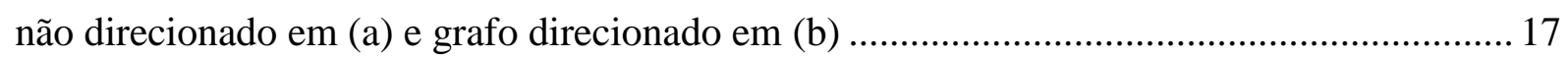

Figura 3.2. Ilustração da representação visual de modelos de rede e suas curvas de distribuição da quantidade de conexões $(k)$ dos vértices ....................................................... 21

Figura 3.3. Visualização do grau topológico e grau valorado de vértices .............................. 25

Figura 3.4. Relação entre vértice $h u b$ e vértice de alto grau de intermediação ....................... 29

Figura 3.5. Visualização do coeficiente de aglomeração do vértice i em três diferentes redes .

Figura 4.1. Morfologia básica de redes de transporte aéreo ................................................ 36

Figura 4.2. Níveis de estudo para redes de transporte aéreo ................................................ 42

Figura 4.3. Vulnerabilidade da rede de transporte aéreo mundial . ........................................ 48

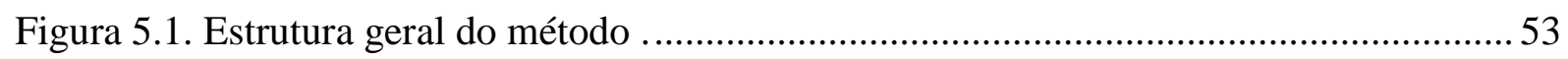

Figura 5.2. Ilustração do procedimento de remoção sequencial dos vértices. ..........................58

Figura 5.3. Procedimento de remoção dos vértices, com reposição. ....................................... 59

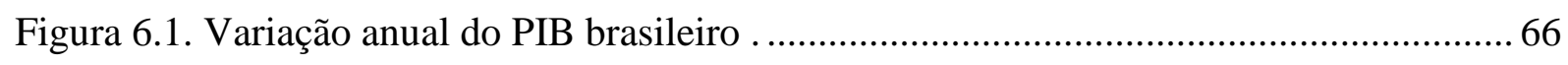

Figura 6.2. Variação anual da demanda por transporte aéreo (RPK), mercado doméstico e internacional

Figura 6.3. Participação no mercado doméstico, em RPK, das principais empresas aéreas brasileiras .

Figura 6.4. Exemplos de etapas básicas e etapa combinada de um voo . 70

Figura 6.5. Representação visual das redes de voos domésticos e internacionais do Brasil.... 74

Figura 6.6. Representação visual das redes de voos das empresas aéreas brasileiras.............. 75

Figura 6.7. Histograma e distribuições do grau topológico da rede $R \_b r a \_d o m$. 82

Figura 6.8. Histogramas dos graus valorados pelas distâncias, voos, assentos e RPK da rede

R_bra_dom. 82

Figura 6.9. Diagramas de dispersão entre grau topológicos e os graus valorados para a rede $R \_b r a \_d o m$. .83

Figura 6.10. Visualização da relação de linearidade entre os parâmetros de vértices. ............ 84

Figura 6.11. Representação visual dos grafos correspondentes à rede $R \_b r a \_d o m$. .90 
Figura 6.12. Resultados da simulação de ataque sequencial. Cores das curvas: preto para a rede original, azul para a rede aleatória e vermelho para a rede livre de escala.

Figura 6.13. Resultados da simulação de ataque sequencial. Cores das curvas: preto para a rede original, azul para a rede aleatória e vermelho para a rede livre de escala.

Figura 7.1. Histogramas das variações nos parâmetros do grafo da rede de voos domésticos. (a) histograma do impacto na densidade; (b) histograma do impacto na componente conectada; (c) histograma do impacto na conectividade da rede e (d) histograma do impacto na eficiência.

Figura 7.2. Histogramas das variações nos parâmetros do grafo da rede de voos domésticos. (a) histograma do impacto na acessibilidade; (b) histograma do impacto no tráfego de aeronaves; (c) histograma do impacto na oferta de assentos e (d) histograma do impacto no atendimento à demanda.

Figura 7.3. Representação em elipses dos coeficientes da matriz de correlação das variações nos parâmetros do grafo que representa a rede de voos domésticos $\left(R \_b r a \_d o m\right)$. 105 


\section{LISTA DE QUADROS}

Quadro 2.1. Termos e definições . ........................................................................... 9

Quadro 4.1. Literatura: abordagem do sistema de transporte aéreo como rede complexa ...... 40

Quadro 4.2. Elementos básicos da literatura de vulnerabilidade de rede de transporte aéreo .44

Quadro 4.3. Critério de seleção de vértices no grafo . .......................................................... 44

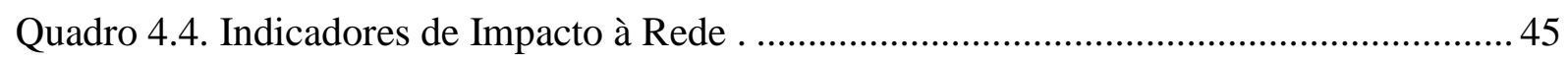

Quadro 5.1. Elementos de valoração nos grafos com pesos. ................................................ 54

Quadro 5.2. Característica operacional considerada na medição dos parâmetros. ...................56

Quadro 6.1. Códigos produzidos no R para implementação do método.................................. 63

Quadro 6.2. Variáveis da base de dados utilizadas no estudo.................................................. 70 


\section{LISTA DE SÍMBOLOS, NOMENCLATURA E ABREVIAÇÕES}

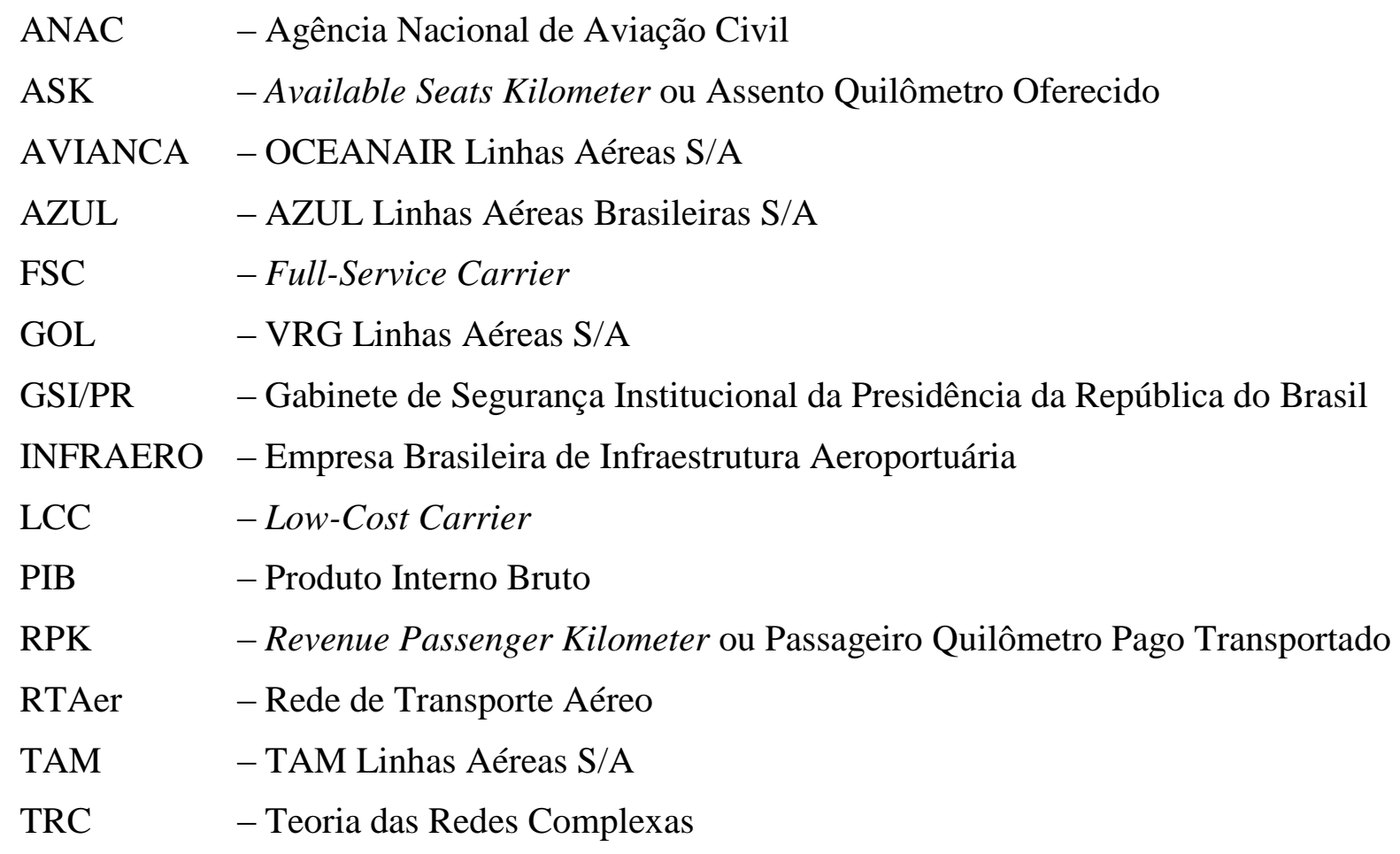




\section{INTRODUÇÃO}

\subsection{APRESENTAÇÃO}

O transporte aéreo tem assumido um papel de relevância na sustentação do desenvolvimento econômico e social das sociedades globalizadas. Nota-se que essa importância é mais evidente em países de dimensões continentais como o Brasil, onde as necessidades de integração nacional e de longos deslocamentos de pessoas e mercadorias, de forma rápida e segura, podem ser adequadamente atendidas pelo modal aéreo. A exploração do potencial econômico de uma cadeia de negócios e de turismo internacionais também passa pelo desenvolvimento do transporte aéreo, inclusive em países de menor dimensão territorial.

Assim como em outros sistemas de transporte, tais como o rodoviário (ERATH, 2011), ou sistemas essenciais que operam em rede (MURRAY; MATISZIW; GRUBESIC, 2008), há uma preocupação quanto ao entendimento do grau de vulnerabilidade presente nas operações do transporte aéreo (LORDAN et al., 2014a). Um nevoeiro, uma forte chuva, um incidente ou acidente na pista de pouso e decolagem, uma sabotagem do terminal de passageiros ou de uma aeronave em solo ou mesmo uma greve de funcionários são exemplos da variedade de eventos que podem causar interrupção ou redução da capacidade operacional de um aeroporto e, portanto, podem impactar negativamente o funcionamento normal de uma rede de transporte aéreo (RTAer).

A circulação ágil de pessoas e mercadorias por grandes distâncias pode ser considerada a função fundamental de uma rede de transporte aéreo. Tal função é fortemente dependente da operação normal dos aeroportos, sendo que a interrupção temporária dos serviços aeroportuários, de maneira que impeçam os pousos e decolagens programados, geram impactos à funcionalidade da malha aérea. Em 13/10/2012, por exemplo, o pouso malogrado de uma aeronave cargueira provocou o cancelamento das operações de pousos e decolagens no Aeroporto Internacional de Viracopos (SBKP), em Campinas/SP, por quase dois dias (JORNAL DA GLOBO, 2012).

A análise da vulnerabilidade em sistemas de transporte pode ser entendida como uma avaliação do comportamento da rede de transporte quando esta sofre interferências de eventos adversos (eventos inesperados ou não desejáveis) nos elementos que a compõem (MURRAY; GRUBESIC, 2007). 
Uma recente publicação do Instituto de Pesquisa Econômica Aplicada propõe a aplicação de metodologias associadas ao campo de sistemas complexos para lidar com os problemas e desafios que envolvem o desenvolvimento e a avaliação de políticas públicas (IPEA, 2015). A coletânea de textos trazidos pela publicação fornece, dentre outros aspectos, uma descrição das principais ferramentas de sistemas complexos que são aplicados em análises de políticas públicas em áreas como meio ambiente, economia, educação, zoneamento urbano e transportes. A teoria de redes complexas está entre aquelas metodologias que fornecem mecanismos para o estudo de sistemas complexos.

Desde a origem da teoria e aplicações de redes complexas (ALBERT; BARABÁSI, 2002), essa metodologia tem sido aplicada em diferentes sistemas de transportes, incluindo o urbano, rodoviário e o metroviário. Recentemente, cresceu o interesse do uso de tal teoria com a finalidade de modelagem e estudo de sistemas do transporte aéreo, como pode-se perceber das revisões produzidas por Zanin \& Lillo (2013), Lordan et al. (2014a) e Cook et al., (2015).

Uma perspectiva dessa modelagem é a representação da rede de transporte aéreo por meio de um grafo, sendo os vértices equivalentes aos aeroportos e as arestas equivalentes às rotas aéreas. Esse tipo de abstração para análise de uma infraestrutura é tradicionalmente aplicado nos estudos de transportes em geral, conforme ensina Rodrigue (2013).

\subsection{PROBLEMATIZAÇÃO}

MURRAY et al. (2008) apontam que a questão da interrupção de uma instalação ou serviço que compõem um sistema de operação em rede é um ponto de partida para a análise da vulnerabilidade do sistema. Sob essa perspectiva, o autor sugere diversas questões que podem ser levantadas: (a) quão vulnerável é a rede frente a uma interrupção de um de seus elementos? (b) quais são os potenciais impactos de um cenário de interrupção específico? (c) quais elementos causariam maiores impactos quando desativados? (d) a estrutura topológica da rede amplia a sua vulnerabilidade ou contribui para minimizá-la? (e) qual a abordagem metodológica mais adequada para avaliar a vulnerabilidade desse sistema?

Considerando esse conjunto de preocupações, para condução desta pesquisa questiona-se de que maneira é possível analisar a vulnerabilidade da rede de transporte aéreo, identificar os seus aeroportos críticos e os impactos ocasionados pela interrupção operacional de tais aeroportos. 


\subsection{HIPÓTESE}

O processo de análise de vulnerabilidade da rede de transporte aéreo por meio da teoria de redes complexas permite dimensionar impactos à rede, decorrentes de interrupções operacionais, e identificar os aeroportos críticos do sistema.

\subsection{OBJETIVOS}

Desenvolver um método para analisar a vulnerabilidade de RTAer em cenários de interrupção operacional de aeroportos. De forma específica, objetiva-se:

(1) aplicar o método na RTAer brasileira e nas redes individuais das principais empresas aéreas nacionais, considerando os voos de passageiros;

(2) quantificar impactos estruturais e funcionais, decorrentes da interrupção de aeroportos;

(3) estimar o grau de vulnerabilidade da rede e identificar os seus aeroportos críticos.

\subsection{JUSTIFICATIVA}

Os motivos que justificam a condução de um projeto de pesquisa podem ser amplos e estarem associados a diferentes naturezas, de ordem acadêmica, prática e pessoal (DESLADES, 2007).

\subsubsection{ASPECTOS DE ORDEM ACADÊMICA}

No âmbito do Programa de Pós-Graduação em Transportes (PPGT) da UnB, desenvolvem-se estudos na linha de pesquisa de confiabilidade e vulnerabilidade de sistemas de transportes. Até o momento, as investigações concentraram-se em redes de transporte terrestre: o transporte urbano de passageiros (ERICH, 2012; PIPICANO, 2014; PRICINOTE, 2008) e o transporte rodoviário de cargas (CUNHA FILHO, 2014; JUNIOR, 2015). Assim, de um primeiro ponto de vista, esta pesquisa traz uma contribuição de ordem acadêmica, ao agregar um esforço adicional na formação de conhecimento sobre o tema, direcionando a linha de pesquisa para o modo de transporte aéreo.

A investigação do problema de pesquisa apontado também é motivada pela coordenação iniciada com o professor Dr. Glauco Estácio Gonçalves, da Universidade Federal Rural de Pernambuco (UFRPE), e que poderá contribuir para a construção de uma cooperação científica entre pesquisadores do PPGT/UnB e do Departamento de Estatística e Informática da UFRPE. 


\subsubsection{ASPECTOS DE ORDEM PRÁTICA}

Segundo o Anuário do Transporte Aéreo de 2013 (BRASIL, 2014), a demanda doméstica do transporte aéreo de passageiros foi recorde em 2013 e mais do que triplicou no período de 2004 a 2013, em termos de passageiros-quilômetros pagos transportados (Revenue Passenger Kilometers - RPK). De fato, a demanda teve alta de $203 \%$ nesse período, representando um crescimento médio de $13,1 \%$ ao ano, ao passo que o crescimento médio da economia brasileira foi de $3,5 \%$ ao ano e o da população foi de $1 \%$ ao ano.

Esses dados evidenciam o forte crescimento do setor e o importante papel assumido pelo transporte aéreo no desenvolvimento econômico e social brasileiro. No entanto, tal relevância, também traz desafios para o governo e os agentes econômicos envolvidos, na medida em que são necessárias ações com o objetivo de manter a qualidade dos serviços aéreos prestados. Neste contexto, são positivos os estudos que objetivam dimensionar os potenciais efeitos negativos gerados por interrupções nas operações aéreas e as proposições de ações para mitigar esses efeitos.

Os potenciais impactos na prestação dos serviços de transporte aéreo, decorrentes de eventos adversos causadores de interrupções em aeroportos é uma preocupação já tradicionalmente considerada pelas organizações do setor aéreo. Em geral, um operador do sistema de transporte aéreo, seja ele um operador aéreo, um operador aeroportuário ou um operador de serviço de navegação aérea, aplica um processo de gestão de forma a identificar, avaliar e controlar os riscos associados à sua operação.

A gestão de risco é aplicada pelas organizações através de um processo cíclico e contínuo que inclui, dentre outras medidas, a identificação do nível de risco (ABNT, 2009). Este nível de risco é avaliado, fundamentalmente, por meio de duas variáveis: a probabilidade de ocorrência de um evento adverso e a severidade das consequências do evento na operação ou no negócio da organização.

O estudo da vulnerabilidade da malha aérea, constituída por voos de passageiros no Brasil, deve permitir identificar os aeroportos críticos do sistema, ou seja, aqueles que, em decorrência de uma interrupção temporária ou permanente, produzem maiores impactos negativos à malha aérea. A identificação dos aeroportos críticos está associada a um melhor conhecimento do fator severidade, podendo contribuir para o aprimoramento do processo de gerenciamento do risco nas organizações do setor. 
Os resultados que podem ser obtidos por meio da análise de vulnerabilidade da RTAer são, também, de interesse dos programas nacionais de proteção de infraestruturas críticas. Consideram-se infraestruturas críticas aquelas instalações, serviços, bens e sistemas que, se forem interrompidos ou destruídos, provocarão sério impacto social, econômico, político, internacional ou à segurança do Estado e da sociedade (BRASIL, 2010).

A elaboração e implementação de programas de segurança de infraestruturas críticas é uma tendência mundial (CANADA, 2014; EUROPEAN UNION, 2005; U.S., 2013) e o Brasil inseriu-se nesse grupo de países, através da aprovação da sua Estratégia Nacional de Defesa (BRASIL, 2008). Nota-se, assim, os benefícios que podem ser alcançados pela proposição de um método eficaz e sistemático que permita analisar a vulnerabilidade de redes de transporte aéreo, em particular, a rede brasileira.

\subsection{METODOLOGIA DA DISSERTAÇÃO}

Definidos os objetivos e as motivações deste trabalho, é necessário estabelecer e descrever como os objetivos foram alcançados. Em linhas gerais, a pesquisa foi desenvolvida pelo método hipotético-dedutivo e delineada em quatro fases principais, conforme apresentado na Figura 1.1 e descrito a seguir.

Na Fase 01 - Revisão Bibliográfica - foram levantados e adquiridos os conhecimentos necessários para construção do embasamento teórico e condução dessa pesquisa. O levantamento bibliográfico incluiu conceitos e temas relacionados à: vulnerabilidade em sistema de transportes, infraestrutura crítica, teoria de redes complexas e modelagem de redes de transporte aéreo.

Na Fase 02 - Formulação do Método - procedeu-se o desenvolvimento do método de análise de vulnerabilidade da rede de transporte aéreo, constituindo-se de seis etapas básicas: (i) caracterização do sistema; (ii) processo de modelagem; (iii) análise topológica; (iv) simulação de ataque sequencial aos aeroportos; (v) simulação da interrupção individual de aeroporto e (vi) análise dos resultados.

Na Fase 3 -Aplicação e Validação do Método - avaliou-se a validade do método através da sua aplicação na malha aérea brasileira, fazendo-se uso de base de dados reais de voos realizados. Neste estudo de caso, considerou-se a malha aérea nacional e individual das principais empresas aéreas brasileiras, tanto de voos domésticos como internacionais. 
Na Fase 4 - Análise dos Resultados - buscou-se a interpretação dos resultados obtidos e a análise das informações no sentido de propor um delineamento para compor o planejamento setorial, tanto a nível de políticas públicas como a nível regulatório e operacional.

O documento final está estruturado em oito capítulos. Este primeiro capítulo apresenta os elementos básicos que guiaram e motivaram o desenvolvimento da pesquisa. O capítulo 2 resgata o arcabouço teórico e metodológico produzido nos últimos anos pelas pesquisas sobre vulnerabilidade de sistemas de transporte. O capítulo 3 apresenta uma breve revisão sobre a teoria de redes complexas e comenta as principais medidas de caracterização de rede aplicadas na análise de sistemas de transporte aéreo. O capítulo 4 traz um panorama sobre redes de transporte aéreo, em especial sobre o processo de modelagem dessas redes utilizando a teoria de redes complexas. A partir dessa revisão bibliográfica, o capítulo 5 detalha a proposta do método para análise de vulnerabilidade de redes de transporte aéreo. No capítulo 6 é feita a aplicação do método a partir de uma base de dados do transporte aéreo brasileiro. $\mathrm{O}$ capítulo seguinte se destina à análise dos resultados levantados com a aplicação do método. Por fim, no capítulo 8 são expostas as conclusões e recomendações finais sobre o desenvolvimento da pesquisa. 


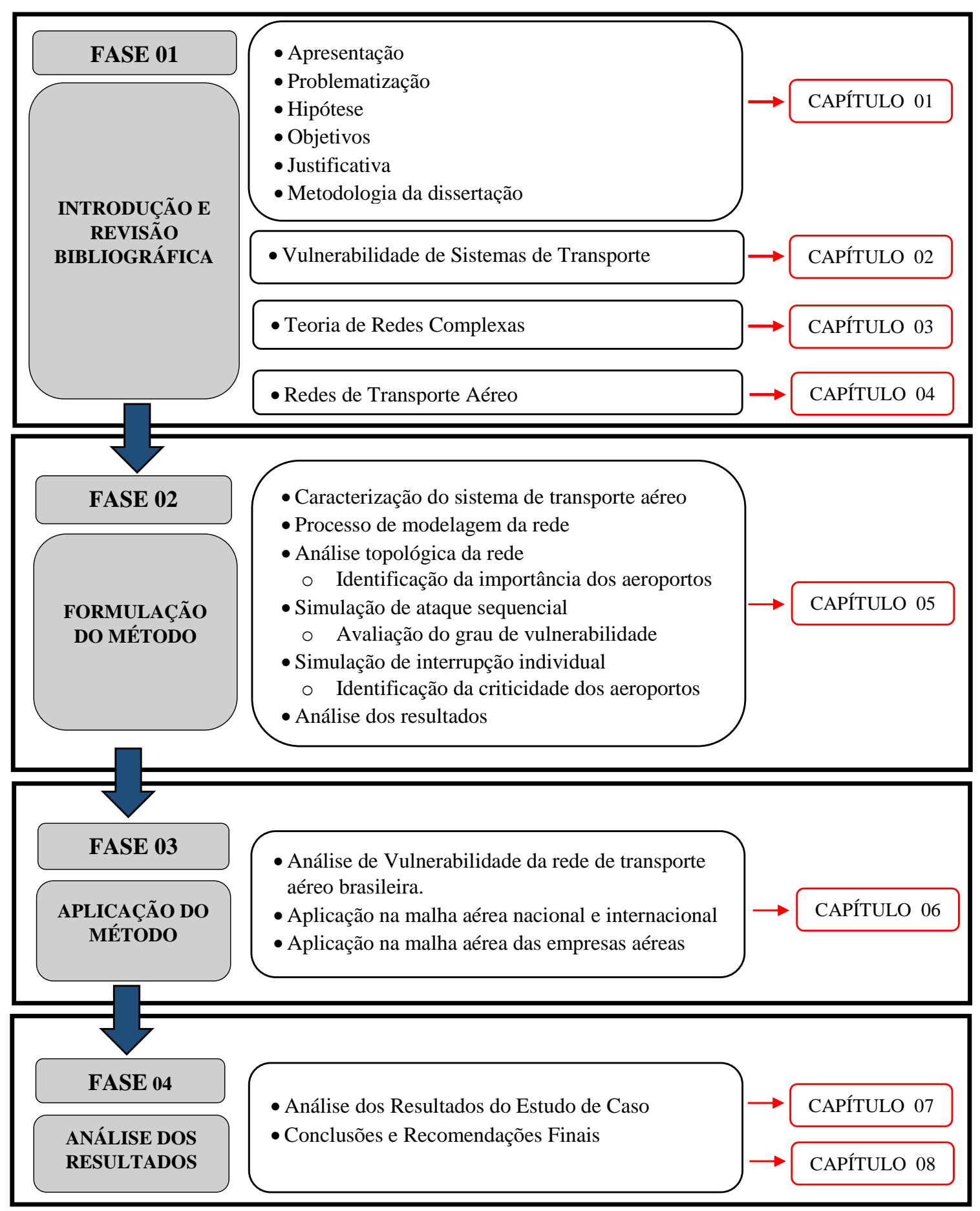

Figura 1.1. Estrutura Metodológica do Projeto de Pesquisa. 


\section{VULNERABILIDADE DE SISTEMAS DE TRANSPORTE}

\subsection{APRESENTAÇÃO}

De acordo com autores especializados (BERDICA, 2002; NICHOLSON, 2003) as pesquisas sobre confiabilidade de sistemas de transportes foram precursoras dos trabalhos que focaram na vulnerabilidade desses mesmos sistemas. À época, D’Este \& Taylor (2001) destacaram que as pesquisas desenvolvidas sobre confiabilidade de redes de transportes preocuparam-se essencialmente com redes urbanas concentradas e na probabilidade de esse tipo de rede ser capaz de fornecer um determinado nível de serviço ou de desempenho.

Em um nível mais amplo e fora dos grandes centros urbanos, entretanto, a cobertura regional, a acessibilidade e a conectividade interurbana se mostram como considerações mais primárias (D’ESTE; TAYLOR, 2001). Em tais redes esparsas, os autores visualizam a vulnerabilidade da rede como um atributo de maior importância que a confiabilidade, devido à severidade das consequências ao serviço de transporte caso um determinado elemento ou componente da rede seja interrompido.

Neste capítulo pretende-se resgatar o arcabouço teórico desse tema, de forma que seja possível compreender as relações existentes entre vulnerabilidade e outros atributos correlatos, delimitar o conceito e o escopo da análise de vulnerabilidade dos sistemas de transporte, das metodologias empregadas para condução dessa análise e visualizar sua importância no contexto do planejamento de transportes e da proteção de infraestruturas críticas.

\subsection{ABORDAGENS CONCEITUAIS}

O conceito de vulnerabilidade é aplicado em diferentes campos do conhecimento, mas em aplicações técnicas não há um conceito geral amplamente aceito (HOLMGREN, 2007). Verificou-se em alguns trabalhos que buscam analisar a vulnerabilidade de infraestruturas em rede, que os autores não se preocuparam em estabelecer uma definição prévia do termo vulnerabilidade ou de outras expressões similares. Em contrapartida, outros pesquisadores trazem uma discussão relativamente ampla do escopo conceitual abrangido pelo termo vulnerabilidade, como ocorre em Erath (2011).

No estudo de Holmgren (2007), o autor busca introduzir um framework para avaliação quantitativa da vulnerabilidade de infraestruturas críticas, e aponta que a vulnerabilidade de um 
sistema pode ser descrita como a susceptibilidade (sensibilidade) a ameaças ou perigos que reduzirá, substancialmente, a habilidade do sistema em manter a sua funcionalidade pretendida.

Taylor \& D’Este (2007) discutem a proximidade e a relação entre os termos vulnerabilidade, confiabilidade e risco. Segundo Erath (2011), o conceito também pode estar associado à robustez e à resiliência de sistemas.

Uma recente revisão da literatura conduzida por Wang et al. (2015), trouxe uma síntese apropriada da definição de diversos conceitos aplicados no processo de análise de vulnerabilidade de sistemas de transportes, conforme mostrado na Quadro 2.1.

Quadro 2.1. Termos e definições (Fonte: tradução livre, adaptado de Wang et al., 2015).

\begin{tabular}{|c|c|}
\hline Termo & Definição \\
\hline Risco & $\begin{array}{l}\text { Risco é o efeito da incerteza nos objetivos ou nas } \\
\text { funções da rede, sendo representado em termos da } \\
\text { probabilidade de ocorrência de um dado evento Erath et al., (2009), } \\
\text { adverso, multiplicada pela probabilidade de falha de ABNT (2009) } \\
\text { um dado componente da infraestrutura e pela } \\
\text { consequência dessa falha. }\end{array}$ \\
\hline Confiabilidade & $\begin{array}{l}\text { Confiabilidade é um atributo da rede representado } \\
\text { pela probabilidade de a rede ser capaz de } \\
\text { disponibilizar um nível de performance requerido, } \\
\text { durante um determinado intervalo de tempo. }\end{array}$ \\
\hline Resiliência & $\begin{array}{l}\text { Resiliência é um atributo da rede que indica a sua } \\
\text { capacidade em resistir e se recuperar de uma } \\
\text { interrupção ou outro evento adverso. }\end{array}$ \\
\hline Robustez & $\begin{array}{l}\text { Robustez é um atributo da rede que indica o quanto, } \\
\text { sob determinadas circunstâncias adversas, a rede é } \\
\text { capaz de manter suas funções para as quais foi } \\
\text { originalmenter et. al., (2012) } \\
\text { orojetada. }\end{array}$ \\
\hline Flexibilidade & $\begin{array}{l}\text { Flexibilidade é um atributo da rede representado } \\
\text { pela habilidade de expansão da sua capacidade de } \\
\text { tráfego para acomodar mudanças na demanda, } \\
\text { enquanto mantem nível satisfatório de performance. }\end{array}$ \\
\hline Vulnerabilidade & $\begin{array}{l}\text { Vulnerabilidade é um atributo da rede que indica a } \\
\text { susceptibilidade a eventos adversos que resultam Holmgren (2007) } \\
\text { em redução significativa da sua funcionalidade. }\end{array}$ \\
\hline
\end{tabular}


Em geral, os termos referem-se a eventos ou incidentes que forçam a transição da operação normal do sistema para uma situação anormal. Os mesmos autores propõem um esquema, mostrado na Figura 2.1, para interpretação das relações dos termos correlatos.

A análise de conteúdo desses estudos possibilita sintetizar os principais conceitos relacionados à pesquisa de vulnerabilidade em sistemas de transportes e delimitar o entendimento acerca do termo vulnerabilidade que será adotado nesta pesquisa.

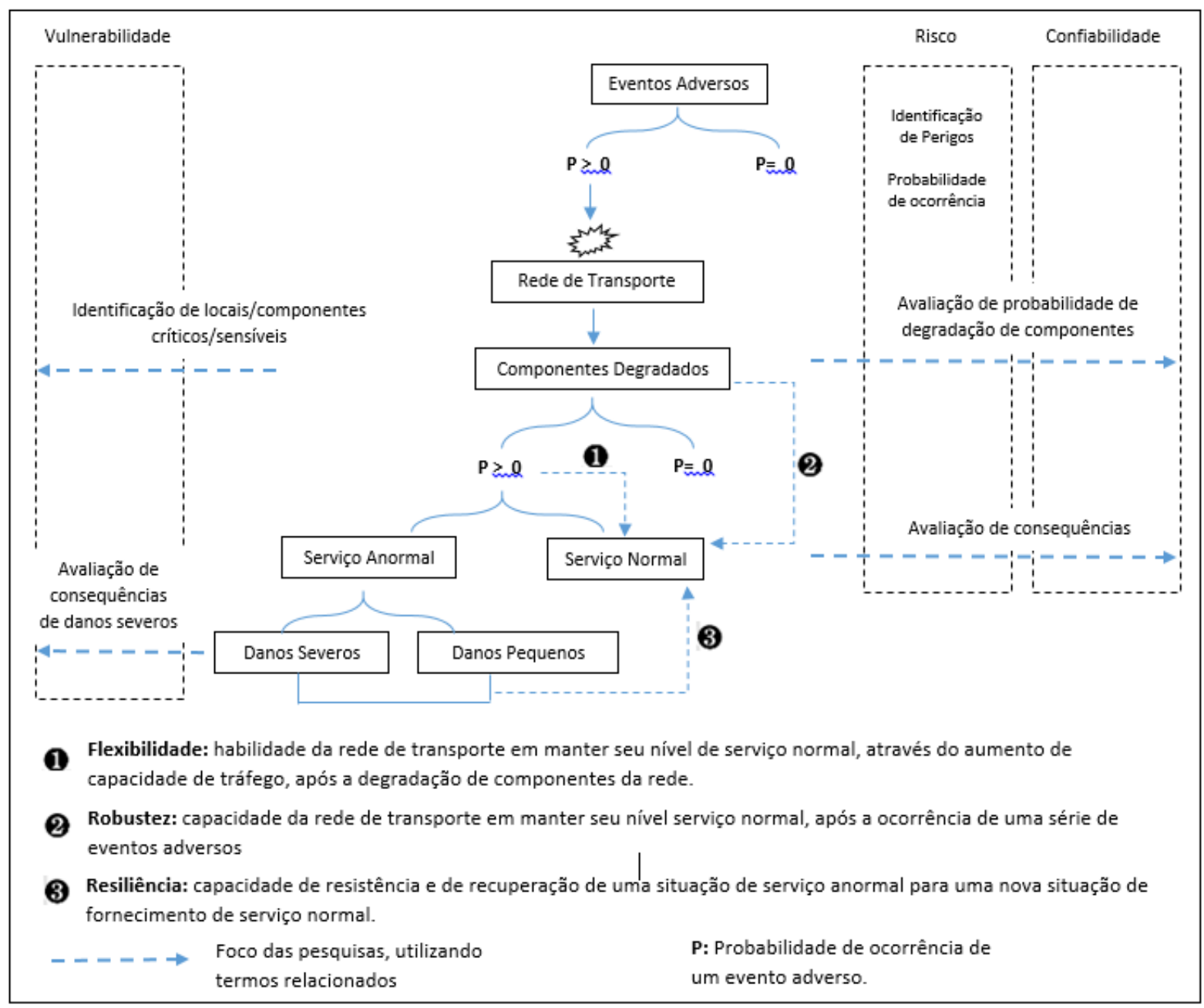

Figura 2.1. Diferenças e relacionamentos entre termos correlatos (Fonte: tradução livre, adaptado de Wang et al., 2015).

Todo sistema possui um objetivo a ser alcançado ou uma função a ser exercida. A função de uma rede de transporte é proporcionar a fluidez adequada da demanda por deslocamentos. A Figura 2.1 denomina esse estado de atendimento adequado da demanda, sob determinados critérios de níveis de serviço, como um estado de "serviço normal". No entanto, a operação da rede de transporte está sujeita a perigos que, se concretizados, podem afetar negativamente esse 
estado de "serviço normal". Um evento adverso abrange a concretização de um determinado perigo.

Em geral, os perigos podem advir de fontes naturais ou humanas. Os primeiros estão relacionados a eventos da natureza como condições meteorológicas que prejudicam o tráfego de veículos por uma rede de transporte. As fontes humanas de perigo podem ser de natureza não intencional, em geral, causadoras de acidentes ou falhas no funcionamento da rede. Mas também podem ser de natureza intencional, quando o perigo está relacionado a ações criminosas ou terroristas que objetivam causar dano à rede de transporte. No contexto do transporte aéreo, os perigos advindos de fonte humana e de natureza intencional recebem a denominação específica de ameaça.

Conforme apresentado na Figura 2.1, o risco envolve a identificação de perigos, a avaliação da probabilidade de ocorrência ou concretização desses perigos, além da avaliação da probabilidade dessa ocorrência ser capaz de degradar componentes da rede de transporte e as respectivas consequências dessa degradação.

Na hipótese de um evento adverso atingir a rede de transporte, há dois atributos que poderiam, ainda assim, garantir nível normal de serviço: o grau de flexibilidade ou de robustez da rede. A flexibilidade reflete a habilidade da rede em acomodar eventual aumento de demanda, sem prejuízo do nível de serviço. Já a robustez descreve a capacidade de uma rede de transporte em manter seu funcionamento, mesmo após a ocorrência de uma série de eventos adversos que degradem seus componentes.

Na hipótese de um evento adverso atingir a rede de transporte, provocar a degradação de componentes e levar o sistema a uma situação de funcionamento anormal, os danos causados podem ser pequenos ou grandes. Em princípio, dois fatores que podem influenciar na dimensão desses danos são os atributos de resiliência e de vulnerabilidade da rede de transporte.

A resiliência existe quando as características estruturais e operacionais da rede lhe conferem capacidade de resistência às degradações de seus componentes, a tal ponto de ser capaz de retornar para uma situação normal de funcionamento. Por outro lado, a rede de transporte pode ser mais susceptível aos eventos adversos que causem degradações aos seus componentes, estando sujeita a maiores impactos negativos. Essa susceptibilidade é, então, caracterizada pelo atributo da vulnerabilidade da rede de transporte. 


\subsection{ABORDAGENS METODOLÓGICAS}

A análise da vulnerabilidade em sistemas de transporte pode ser entendida como uma avaliação do comportamento da rede de transporte quando esta sofre interferências de eventos adversos (eventos inesperados ou não desejáveis) nos elementos que a compõem (MURRAY \& GRUBESIC, 2007). Esse processo de análise pode ser estudado por meio de diferentes abordagens.

Murray et al. (2008) identificaram e analisaram as abordagens metodológicas empregadas na análise de vulnerabilidade de sistemas que se estruturam em rede e estabeleceram a seguinte tipologia:

(a) Avaliação baseada em cenário específico (Scenario-specific assessment): essa abordagem avalia os potenciais efeitos de um cenário de interrupção específico ou de um pequeno conjunto de cenários. Este tipo de abordagem ajuda a responder questões do tipo "what if " relacionada a uma interrupção em particular e pode facilitar comparações entre cenários de interesse previamente selecionados;

(b) Avaliação baseada em estratégia específica (Strategy-specific assessment): a abordagem de uma estratégia específica está associada à avaliação por meio de cenários específicos, acrescida, entretanto, de uma estratégia de definição do cenário. Busca responder questões do tipo “quão vulnerável é a rede a uma perda coordenada/estruturada de instalações?”. Na abordagem de estratégica específica, os cenários de interesse são aqueles que seguem uma estratégica hipotética de interrupção, por exemplo, o caso de ataques às instalações mais relevantes da rede;

(c) Avaliação baseada em simulação (Simulation assessment): se não há nenhuma consideração prévia quanto à instalação ou cenário mais importante ou crítico, então a análise de cenários de interrupção baseada em simulações pode ser útil. A abordagem baseada em simulação objetiva comparar os cenários de interrupção em relação à capacidade de causar impactos a operação do sistema; e

(d) Avaliação baseada em modelagem matemática (Mathematical modeling assessment): na análise de vulnerabilidade, a capacidade de caracterizar uma variedade de cenários de interrupção é importante. No entanto, em vários casos, o cenário que pode gerar os maiores impactos negativos à rede é a situação de maior interesse. É este cenário que os planejadores e 
formadores de políticas buscam conhecer quando precisam decidir sobre a alocação de investimentos para melhorias da rede. A modelagem matemática busca identificar tais cenários.

Murray et al. (2008) avaliam que a integração das abordagens metodológicas é certamente desejável dado a riqueza de informações que elas poderiam produzir quando usadas em conjunto.

\subsection{INFRAESTRUTURAS CRÍTICAS}

Os riscos associados aos desastres naturais e às ameaças do terrorismo internacional têm, nos últimos anos, conduzido muitos países a formularem programas de proteção de suas infraestruturas críticas (YUSTA et al., 2011).

O plano de proteção de infraestrutura norte-americano (UNITED STATES, 2013) define a infraestrutura crítica como sistemas ou ativos, sejam físicos ou virtuais, tão essenciais aos Estados Unidos, que a incapacidade ou destruição de tais sistemas ou ativos geraria um impacto debilitante na segurança do Estado, na segurança da economia nacional, na seguridade e saúde pública ou qualquer combinação desses elementos. Os documentos brasileiros (BRASIL, 2010) consideram como infraestruturas críticas aquelas instalações, serviços, bens e sistemas que, se forem interrompidos ou destruídos, provocarão sério impacto social, econômico, político, internacional ou à segurança do Estado e da sociedade.

Os países que já se alertaram acerca dessas infraestruturas produziram plataformas e programas de proteção baseadas na conceituação e implementação de programas de gerenciamento de risco, com a incorporação de análises das vulnerabilidades e procedimentos de mitigação de perigos. Além disso, os documentos que consolidam as diretrizes para a proteção das infraestruturas críticas de cada país são unânimes em classificar os sistemas de transportes como uma infraestrutura crítica da sociedade atual (BRASIL, 2008; CANADA, 2014; EUROPEAN UNION, 2005; UNITED STATES, 2013).

Como destacado anteriormente na Figura 2.1, o processo de caracterização da vulnerabilidade de sistemas de transportes deve ser capaz de identificar os locais ou componentes tidos como críticos ou sensíveis para o funcionamento do sistema, podendo constituir-se como um método integrante dos programas de proteção de infraestruturas críticas do país. 


\subsection{TÓPICOS CONCLUSIVOS}

O capítulo apresentou um panorama de abordagens conceituais e metodológicas aplicadas nas pesquisas sobre vulnerabilidade de sistemas de transportes. Foi possível reconhecer a vulnerabilidade como um atributo das redes de transporte que mede a sua susceptibilidade a eventos adversos que causam danos significativos na sua funcionalidade. Verificou-se, também, os benefícios que podem ser produzidos pela integração de duas ou mais metodologias de análise de vulnerabilidade.

O processo de análise de vulnerabilidade deve ser capaz de identificar os elementos críticos constituintes do sistema e, além disso, deve propiciar levantamento de informações prévias para formulação de um planejamento estratégico adequado do sistema de transporte e do seu gerenciamento de risco. 


\section{TEORIA DE REDES COMPLEXAS}

\subsection{APRESENTAÇÃO}

A análise de sistemas complexos tem sido uma tendência crescente nos últimos anos (COOK et al., 2015; IPEA, 2015) e uma forma de explorar e entender esses sistemas é através do mapeamento da sua estrutura de conexões (BARABÁSI, 2012). A estrutura de conexões pode resultar numa representação em rede do sistema, constituída por um conjunto de suas partes componentes, geralmente denominados de vértices (ou nós), e suas interações diretas, denominadas de arestas (ou links).

A representação em rede permite o desenvolvimento de uma linguagem comum para o estudo de sistemas com naturezas bastante diferentes (BARABÁSI, 2012). Essa linguagem ou framework é denominada por alguns autores como teoria ou ciência das redes complexas (CAVALCANTE, 2009; BARABÁSI, 2012). Assim, o objeto de estudo dessa teoria são os sistemas complexos que nos cercam com foco nas relações entre as partes componentes desses sistemas.

As redes reais consideradas complexas, quando modeladas com base nessa linguagem, geram grafos que apresentam propriedades topográficas bastante particulares, não encontradas em grafos mais simples (METZ et al., 2007). Seu estudo abrange temas interdisciplinares, provenientes de diversas áreas do conhecimento, tais como física, biologia, computação, psicologia, sociologia e engenharia (BARABÁSI, 2009).

Considerando esse amplo leque, Costa et al. (2011) realizaram um levantamento das aplicações da teoria de redes complexas para caracterização, modelagem e análise de diversos fenômenos do mundo real, inclusive no âmbito dos transportes.

No que se refere aos fenômenos e desafios presentes em sistemas de transporte aéreo, Cook et al. (2015) discutem os benefícios que a abordagem da teoria de redes tem oferecido. Essa abordagem também tem sido uma das bases teóricas na condução de recentes pesquisas acadêmicas capitaneadas pela EUROCONTROL ${ }^{1}$, através do projeto SESAR (Single European

\footnotetext{
${ }^{1}$ Organização Europeia para a Segurança da Navegação Aérea, fundada em 1960 (https://www.eurocontrol.int/).
} 
Sky ATM Research) ${ }^{2}$, que busca gerar conhecimento para redesenhar a estrutura de controle de tráfego aéreo europeia e melhorar a sua gestão.

É considerando esse contexto, que o presente capítulo expõe os principais elementos acerca da origem da teoria de redes, sua evolução e algumas aplicações, além de apresentar a formalização matemática e as medidas de rede a serem empregadas na consecução dos objetivos deste estudo.

\subsection{INTRODUÇÃO HISTÓRICA}

A teoria dos grafos foi a base matemática para a formação da teoria das redes complexas (LEWIS, 2009). Os primeiros conceitos de grafos surgiram a partir do método utilizado por Leonhard Euler, em 1736, para solucionar o famoso problema das Sete Pontes de Konisberg (BARABÁSI, 2009). Desde então, a teoria dos grafos desenvolveu-se principalmente no campo da matemática que tinha o objetivo de descrever as propriedades de diferentes grafos regulares, que são estruturas onde todos os seus elementos possuem o mesmo número de conexões.

Em meados do século XX, os matemáticos Erdós e Rényi introduziram a visão randômica/probabilística na abordagem de redes, estabelecendo os paradigmas que fundamentaram o primeiro mecanismo teórico de formação de redes, denominado de modelo de rede aleatória. No final da década de 1990, com o avanço da capacidade de simulação computacional, os pesquisadores puderam investigar melhor a organização estrutural de redes formadas por sistemas reais. A teoria de redes complexas surgiu então, especialmente devido à investigação e elaboração de dois modelos de formação de redes denominados: modelo de mundos pequenos e modelo livre de escala (BARABÁSI, 2009).

Apesar das semelhanças, Rodrigues (2007) nos esclarece que a teoria de redes complexas se difere da teoria dos grafos em três aspectos básicos: (i) ela está relacionada com a modelagem de redes reais, por meio de análise de dados empíricos; (ii) as redes estudadas não são estáticas, mas evoluem no tempo, modificando sua estrutura e (iii) as redes, muitas vezes, não são consideradas apenas objetos topológicos, mas constituem estruturas onde fluxos ou processos dinâmicos podem ser simulados. Cabe ainda mencionar que embora as redes reais sejam dinâmicas, elas podem ser analisadas como estáticas dentro de um intervalo de tempo em que as variações sejam inexistentes ou pouco importantes (RODRIGUES, 2007).

\footnotetext{
${ }^{2}$ Projeto colaborativo entre a Eurocontrol e a European Comission (http://www.sesarju.eu/).
} 


\subsection{CONCEITOS BÁSICOS}

\subsubsection{FORMULAÇÃO E REPRESENTAÇÃO MATEMÁTICA}

Um sistema real estruturado em rede pode ser formalmente representado por um grafo (LEWIS, 2009; BARABÁSI, 2012). Um grafo pode ser definido como $G=(V, E, f)$, onde $V$ é um conjunto de vértices $i(i=1,2, \ldots, N)$ e $E$ é um conjunto de arestas que conectam os vértices na forma de duplas $(i, j)$, com $i$ e $j$ pertencente à $V$, segundo um determinado tipo de interação ou regra de combinação $f$ (LEWIS, 2009). O resultado é uma estrutura de grafo simples ou grafo sem pesos (não valorado), conforme exemplo (a) da Figura 3.1.

De acordo com o fenômeno de rede que se queira modelar, as arestas que formam um grafo podem assumir uma direção específica. Quando isto ocorre, dizemos tratar-se de um grafo direcionado, conforme exemplo (b) da Figura 3.1.

Outra forma bastante usual de representação matemática de um grafo é através da denominada matriz de adjacência, $A_{i j}$, uma matriz quadrada $N$ x $N$, onde $N$ é igual ao número de vértices da rede e:

$$
\begin{aligned}
& a_{i j}=1 \text {, se há uma aresta que conecta o vértice } i \text { ao vértice } j \\
& a_{i j}=0 \text {, se não há uma aresta que conecta o vértice } i \text { ao vértice } j .
\end{aligned}
$$

Para um grafo não direcionado, temos que $a_{i j}=a_{j i .}$ Já para um grafo direcionado, é possível termos $a_{i j}=1$ e $a_{j i}=0$, tendo em vista que podemos encontrar uma par de vértices com ligação em apenas um dos sentidos. É possível quantificar o grau de assimetria do grafo direcionado através da proporção de arestas bidirecionais, isto é, a razão do número de arestas bidirecionais pelo número total de arestas presentes no grafo. Essa medida pode ser denominada de índice de reciprocidade (ROCHA, 2009; KOLACZYK \& CSÁRDI, 2014).

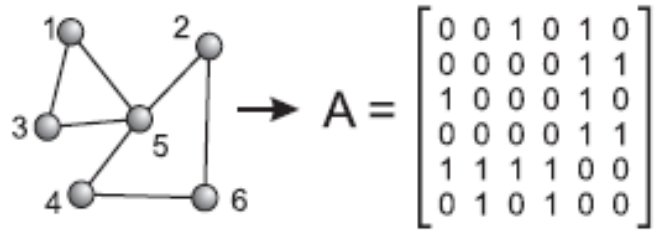

(a)

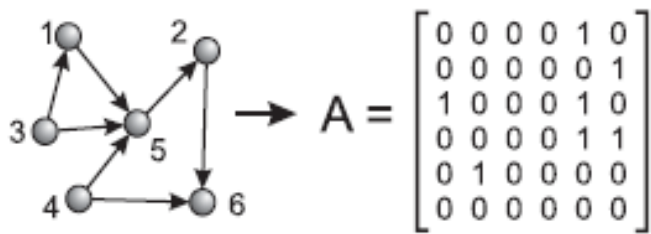

(b)

Figura 3.1. Representação de um grafo pela forma visual e pela matriz de adjacência. Grafo não direcionado em (a) e grafo direcionado em (b), (Fonte: Rodrigues, 2007). 
BARRAT et al. (2004) mostrou que as redes oriundas de sistemas reais não podem ser especificadas estritamente pela sua estrutura topológica, mas devem ser caracterizadas pelas características dinâmicas dos processos que ocorrem nas redes, tais como o fluxo de informações ou de tráfego entre os componentes constituintes do sistema.

Essas características são representadas por meio de pesos às arestas do grafo. Assim, quando estamos tratando de redes com pesos ou redes valoradas (weighted networks), os elementos unitários da matriz de adjacência são substituídos pelos valores dos pesos entre os respectivos vértices.

Verifica-se, portanto que a representação de uma rede de transporte aéreo como um grafo sem pesos possibilita uma análise dos aspectos topológicos das conexões da rede. Já numa representação que faz uso de um grafo com pesos, é possível estudar elementos que formam a dinâmica de fluxos presente nesse tipo de rede de transporte.

\subsubsection{ELEMENTOS BÁSICOS}

Neste tópico serão apresentadas noções de elementos essenciais para o estudo de redes: conectividade (connectedness), componente, distância, caminho, diâmetro, raio, centralidade e aglomeração.

Diz-se que um grafo é fortemente conectado (ou conexo) se partindo de cada vértice é possível alcançar qualquer outro vértice, como é o caso do exemplo (a) da Figura 3.1. Nessa situação, afirma-se que o grafo possui apenas uma componente conectada. Quando um grafo $G$ possui duas componentes conectadas $G_{l}$ e $G_{2}$, os vértices da componente $G_{l}$ não apresentam nenhuma conexão com os vértices da segunda componente (LEWIS, 2009). A distribuição da quantidade de conexões que cada vértice possui é uma característica básica para análise estrutural do grafo e representa a probabilidade de um vértice escolhido aleatoriamente ter uma determinada quantidade de conexões (a seguir, essa característica será de denominada de grau topológico).

A distância entre os vértices é um elemento importante que está relacionado ao transporte e comunicação em redes (RODRIGUES, 2007). A propriedade da distância é avaliada por meio de um caminho. Um caminho é uma sequência de vértices conectados em um grafo e seu tamanho é dado pelo número de arestas ao longo do caminho que conecta dois vértices (LEWIS, 2009). 
Em outras palavras, num grafo sem pesos, o caminho entre dois vértices é medido em saltos e pode haver mais de um caminho entre dois vértices. O comprimento ou tamanho do menor caminho entre dois vértices $i$ e $j, d_{i j}$, é dado pela extensão dos caminhos que conectam estes vértices cujos comprimentos são mínimos. Em grafos com pesos, a medida do caminho entre dois vértices é dada pela soma dos pesos das arestas do caminho (RODRIGUES, 2007).

Um caminho que se inicia e termina no mesmo vértice é denominado circuito, ciclo ou loop. Se não há caminho entre dois vértices (no caso de o grafo ser desconexo), então assumimos que o tamanho do caminho entre aqueles vértices é infinito $\left(d_{i j}=\infty\right)$. A menor distância entre um par de vértices é denominada de menor caminho ou caminho geodésico. O maior caminho geodésico entre todos os pares de vértices de um grafo conectado $\mathrm{G}$ é denominado de diâmetro do grafo (LEWIS, 2009).

Já o maior caminho geodésico entre um vértice $i$ e qualquer outro vértice do grafo $G$ é chamado de raio do vértice $i$. O vértice que possui o menor tamanho de raio situa-se na posição mais central do grafo (LEWIS, 2009). Dessa noção de raio surgem as medidas de centralidade que serão vistas na seção 3.4 .

A propriedade de aglomeração ou clusterização está relacionado a uma estrutura de três vértices conectados entre si, denominada de loop ou ciclo de ordem três. Numa rede social, por exemplo, a presença de um loop de ordem três é identificada quando dois amigos quaisquer A e B possuem um amigo C em comum (RODRIGUES, 2007).

Do ponto de vista da organização estrutural, pode-se classificar as redes de acordo com a distribuição das suas conexões. Para isso, é importante conhecer um pouco sobre os três modelos clássicos da literatura de redes complexas.

\subsubsection{MODELOS DE REDES COMPLEXAS}

As pesquisas sobre a aleatoriedade em grafos foram iniciadas por Paul Erdos e Alfréd Rényi na década de 1950 e resultaram na formulação da teoria dos grafos aleatórios (IZAWA, 2010). Basicamente, um grafo aleatório é aquele formado a partir de um conjunto inicial de $N$ vértices isolados que são conectados, par a par, sob uma probabilidade $p$ de conexão. Uma outra forma é visualizar a formação de um grafo aleatório como um processo Binomial em que, a cada passo, você tem uma probabilidade $p$ de efetuar a conexão e uma probabilidade (1-p) de não concretizar a ligação (RODRIGUES, 2007 e BARABÁSI, 2012). 
Quando $N$ é grande e a conectividade média é mantida constante, a distribuição de grau de um grafo aleatório tende a uma curva de Poisson, como ilustrado na Figura 3.2. Apesar de Erdos e Rényi terem explorado bastante os fundamentos matemáticos dos modelos de redes aleatórias, mostraram-se pouco interessados em possíveis aplicações práticas. Apesar disso, hipóteses foram levantadas acerca da possibilidade de a estrutura de conexões de redes reais poderem ser modeladas como redes aleatórias (RODRIGUES, 2007).

Em 1998, as pesquisas de Ducan Watts e Steven Strogatz começaram a gerar resultados que questionavam a abordagem única da aleatoriedade para modelagem de redes reais. Eles observaram que em algumas redes reais a presença de loops (caminhos fechados) de ordem três era muito maior do que nas redes aleatórias com mesmo número de vértices e arestas. Isso seria um indício que de as redes reais não seriam completamente aleatórias, mas poderiam apresentar algum padrão de formação. Baseado nesta descoberta, eles propuseram um modelo alternativo aos grafos aleatórios, denominado modelo mundo pequeno ou small-world, no qual apresentava uma distribuição das conexões similar à rede aleatória, mas com a presença de loops. Passouse a entender que as redes presentes na natureza se situam entre dois extremos definidos, de um lado, pela estrutura completamente regular e, de outro, pela estrutura aleatória (RODRIGUES, 2007).

Em 1999, os pesquisadores Albert-Lásló Barabási e Reka Albert buscaram investigar se o fenômeno small-world estava presente na Teia Mundial (World Wide Web). Além de observarem o efeito de mundo pequeno na estrutura topológica da rede, eles verificaram que a distribuição das conexões não era aleatória, mas seguia um comportamento do tipo livre de escala (scale-free) que, posteriormente, também se mostrou presente em outras redes reais (RODRIGUES, 2007).

A distribuição livre de escala segue uma curva conhecida como lei de potência ou curva de Pareto, que foi proposta no início do século 20 para explicar fenômenos encontrados na economia. Trata-se de uma curva continuamente decrescente sem um pico característico e descrita por um único expoente $\left(P(k) \sim k^{-a}\right)$, como ilustrado na Figura 3.2. As variáveis ou quantidades geradas de forma aleatória resultam numa escala típica, sendo descritas por curvas caracterizadas por uma média e um desvio padrão, conforme mostrado na Figura 3.2 (RODRIGUES, 2007). 


\section{Modelo de rede aleatória}
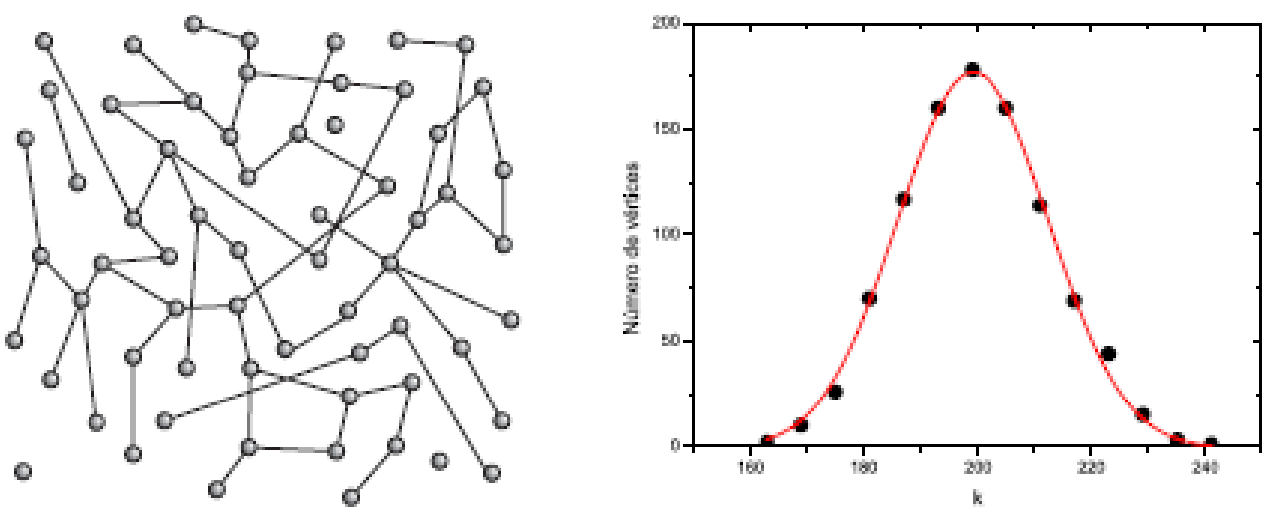

Modelo de rede mundo pequeno
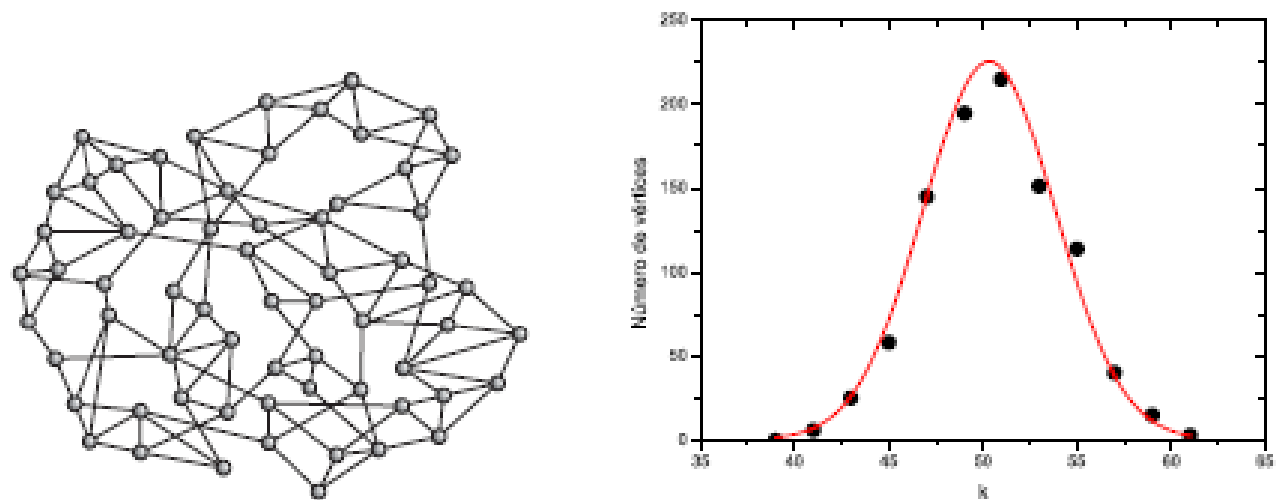

Modelo de rede livre de escala
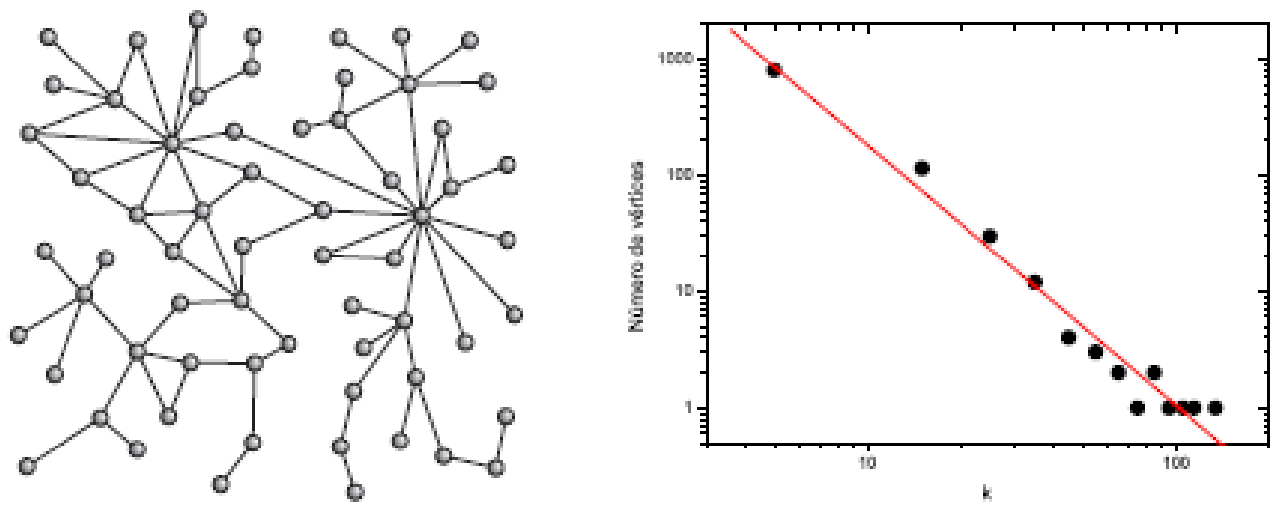

Figura 3.2. Ilustração da representação visual de modelos de rede e suas curvas de distribuição da quantidade de conexões $(k)$ dos vértices (Fonte: adaptado de Rodrigues, 2007).

Motivados por essas descobertas, Barabási e Albert propuseram um modelo de formação que resulta em redes com distribuição de conexões livre de escala. Assim, o trabalho de Watts e Strogtaz indicou a primeira limitação do modelo de Erdos e Rényi, que foi a ausência de ciclos de ordem três, embora tenha mantido o caráter aleatório. Já o modelo de Barabási e Albert 
descartou a predominância da aleatoriedade e mostrou que há padrões ou leis que regem a estrutura das redes reais (RODRIGUES, 2007).

\subsection{MEDIDAS DE REDES COMPLEXAS}

A análise e caracterização de redes complexas é feita através do uso de diversas métricas que podem ser resumidamente agrupadas em três categorias: medidas relacionadas às conexões, às distâncias e aos ciclos (RODRIGUES, 2007).

Algumas dessas principais medidas são denominadas de centralidade e foram propostas, originalmente, nas pesquisas de redes sociais, buscando identificar quão importante é determinada pessoa (vértice) no âmbito da rede e, posteriormente foram utilizadas para caracterizar redes de natureza diversas (OKAMOTO et al., 2008).

Por fim, tem-se que uma forma de avaliar o resultado ou o tamanho de uma determinada métrica de uma rede real é comparar com os valores das mesmas medidas obtidas em redes aleatória, mundo pequeno ou livre de escala correspondentes. Redes correspondentes ou equivalentes são aquelas formadas pelo mesmo número de vértices e arestas, mas cuja organização estrutural é diferente (LEWIS, 2009; SAPRE, 2011)

Neste tópico serão apresentadas as definições das medidas de redes complexas a serem utilizadas no desenvolvimento do método proposto e seus significados quando aplicadas ao contexto do transporte aéreo. Para maiores informações sobre métricas e aplicações da teoria de redes complexas pode ser consultado (COSTA et al., 2011).

\subsubsection{MEDIDAS RELACIONADAS ÀS CONEXÕES}

A literatura traz duas medidas básicas relacionadas às conexões no grafo: grau topológico (degre ou degree centrality), grau valorado (weighted degree).

\subsubsection{GRAU TOPOLÓGICO, GRAU MÉDIO E DENSIDADE}

A centralidade ou grau topológico (ou simplesmente, grau) é uma propriedade básica de um vértice e representa o número de arestas (direcionadas ou não) que conectam um vértice específico. O grau indica, ao mesmo tempo, o número de outros vértices a qual um determinado vértice está conectado ou, de forma mais simples, a quantidade de vizinhos do vértice. Partindo da representação matricial, o grau do vértice $i, k_{i}$, é obtido da seguinte equação, onde $a_{i j}$ 
representa um elemento da matriz de adjacência (BAGLER, 2008b; BARABÁSI, 2012; LEWIS, 2009; RODRIGUES, 2007):

$$
k_{i}=\sum_{j=1}^{N} a_{i j}
$$

Numa rede não direcionada, o número total de arestas, $E$, pode ser expresso pela soma dos graus dos vértices, divido pelo fator $1 / 2$, que corrige a soma duplicada da mesma aresta, conforme seguinte equação (BARABÀSI, 2012):

$$
E=\frac{1}{2} \sum_{i=1}^{N} k_{i}
$$

Numa rede direcionada há dois tipos de graus. O grau de entrada (in-degree) de um vértice, $k_{i n}$, representa o número de arestas que partem de outros vértices e se direcionam ao respectivo vértice. Da maneira similar, o grau de saída (out-degree), $k_{\text {out }}$, representa a quantidade de arestas que partem de um dado vértice. De acordo com a natureza das interações entre os vértices de um grafo, o grau de entrada de um vértice pode ser diferente do seu grau de saída.

O número total de arestas numa rede direcionada é indicada na Equação 3. Neste caso, o fator $1 / 2$ não aparece, tendo em vista que o somatório na equação contabiliza separadamente as arestas de entrada e de saída (BARABÁSI, 2012):

$$
E=\sum_{i=1}^{N} k_{\text {in }}=\sum_{i=1}^{N} k_{\text {out }}
$$

Uma medida que caracteriza globalmente a rede, o grau médio da rede, 〈k〉, pode ser obtido pela seguinte equação, para a rede não direcionada:

$$
\langle k\rangle=\frac{1}{N} \sum_{j=1}^{N} k_{i}=\frac{2 * E}{N}
$$

Na rede direcionada, o grau médio de entrada é igual ao grau médio de saída, resultando num grau médio da rede igual a $\langle k\rangle=E / N$.

Ainda com base nas conexões básicas de um grafo, Lewis (2009) define a densidade de um grafo como resultado da razão do número de arestas existentes no grafo pelo número de arestas 
que existiria caso todos os vértices estivessem conectados entre si (grafo completo). Desta forma, o número de arestas em um grafo não direcionado completo com $N$ vértices é de $N^{*}(N$ 1)/2. Em um grafo direcionado este valor é $N^{*}(N-1)$.

No contexto de uma rede de transporte aéreo, o grau indica a quantidade de aeroportos a que um determinado aeroporto está conectado através de um voo direto (BAGLER, 2008b; QUARTIERI et al., 2008). É entendido como uma medida da conectividade de cada aeroporto (LORDAN et al., 2014b), ou seja, um aeroporto de alto grau significa que é bem conectado à rede e possui uma importância relativamente alta para o tráfego de pessoas e bens pelo sistema (SAPRE, 2011).

\subsubsection{GRAU VALORADO}

Quando determinadas características (pesos) estão associadas às conexões de uma rede real, pode-se utilizar um grafo valorado como modelo do sistema. Assim, uma métrica que reflita tais pesos é recomendada, sendo utilizado, nesse caso, o grau valorado, que também é denominado de força (strength) de um vértice $i$ (BARRAT et al., 2004; RODRIGUES, 2007).

O grau valorado do vértice pode ser definido da seguinte forma, onde $w_{i j}$ representa a característica (peso ou intensidade) associada à aresta que liga os vértices $i$ e $j$, sendo que, por definição, $w_{i j}$ é igual a zero, quando $a_{i j}$ é igual a zero:

$$
s_{i}=\sum_{j=1}^{N} w_{i j}
$$

A respectiva medida global é denominada de grau valorado médio da rede, $\langle S\rangle$ :

$$
\langle s\rangle=\frac{1}{N} \sum_{j=1}^{N} s_{i}
$$

As medidas de grau (topológico e valorado), apesar de simples, podem ser usadas na identificação de hubs do grafo (vértices altamente conectados) e para quantificar a densidade de conexões. Os hubs têm importância fundamental na formação da estrutura das redes 
complexas, já que sua remoção pode causar a fragmentação da rede, resultando em componentes não conectados ${ }^{3}$ (RODRIGUES, 2007).

A Figura 3.3 traz um exemplo de duas redes formadas por 10 vértices e 15 arestas. Na rede sem peso (a), o vértice 1 é considerado um $h u b$, por concentrar grande parte das conexões $\left(k_{i}=8\right)$. Já na rede com pesos (b), o vértice 6 deveria ser o hub, pois possui ligações com maior intensidade (neste caso, a intensidade da ligação está sendo representada pela largura da aresta).

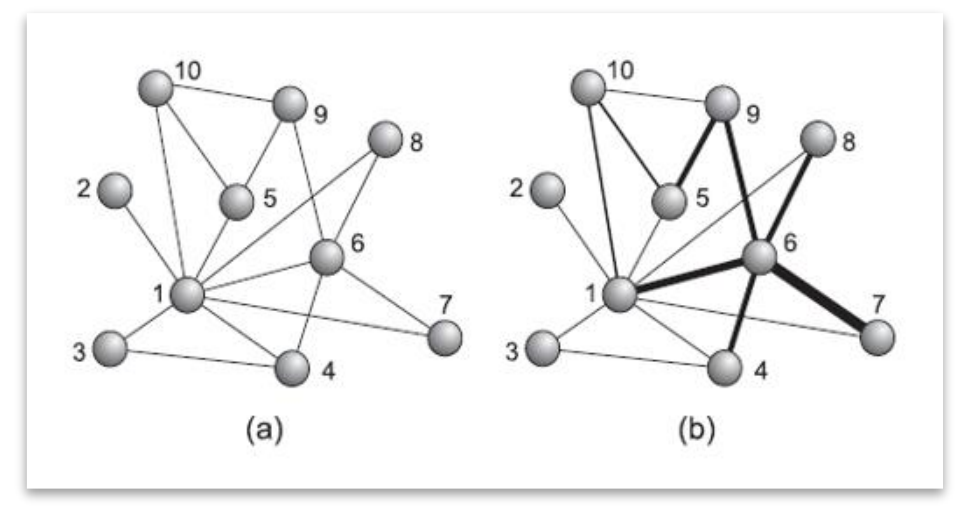

Figura 3.3. Visualização do grau topológico e grau valorado de vértices (Fonte: Rodrigues, 2007).

Numa rede de transporte aéreo, a intensidade ou a força das conexões pode estar associada à capacidade ou oferta de tráfego aéreo entre dois aeroportos ou à demanda existente. Esses atributos são, usualmente, representados pelo número de voos ofertados em cada par de aeroportos (HOSSAIN et al., 2013; LI-PING et al., 2003) ou pela quantidade de assentos disponíveis na rota (BARRAT et al., 2004; DALL'ASTA et al., 2006), ou ainda pela capacidade de transporte de carga (ROCHA, 2009; ZHANG et al., 2010), considerando um período de análise específico (horas, dias, semanas, meses ou anos). Assim, o resultado é uma métrica que indica a oferta/demanda total de tráfego aéreo existente em um determinado aeroporto (BAGLER, 2008b; BARRAT et al., 2004).

Através do grau médio e da sua distribuição é possível caracterizar diversos tipos de redes, assim como determinar se uma configuração específica de conexões é definida de forma aleatória ou se possui alguma lei de formação (RODRIGUES, 2007).

\footnotetext{
${ }^{3}$ Componentes não conectados são formados por vértices sem conexões ou grupos de vértices conectados entre si e não conectados ao restante da rede.
} 
A distribuição das conexões ou distribuição de grau topológico, $\mathrm{P}(k)$, representa a probabilidade de um vértice escolhido aleatoriamente ter grau $k$. Da mesma forma é definida a distribuição de grau valorado, $\mathrm{P}(s)$, onde são consideradas as forças dos vértices.

O grau de um vértice é, por si só, um parâmetro muito importante, no entanto, não fornece uma informação completa do papel exercido pelo vértice na rede (QUARTIERI et al., 2008). Para entender melhor o papel de cada vértice dentro da rede é necessário conhecer algumas medidas relacionadas à distância no grafo, dentre elas a denominada centralidade de intermediação, mencionada no tópico seguinte.

\subsubsection{MEDIDAS RELACIONADAS À DISTÂNCIA}

A literatura traz quatro medidas básicas relacionadas às distâncias no grafo: tamanho do menor caminho médio (average shortest path length), eficiência topológica (efficiency), grau de proximidade (closeness) e grau de intermediação (betweenness).

\subsubsection{MENOR CAMINHO MÉDIO}

Os menores caminhos entre todos os vértices de uma rede podem ser representados através de uma matriz de distâncias $D$, cujos elementos $d_{i j}$, expressam o valor do menor caminho entre os vértices $i$ e $j$. A média entre os valores na matriz de distâncias (caminhos mínimos) exprime o caminho característico da rede (ou menor caminho médio ou, ainda, tamanho do menor caminho médio), sendo calculada por:

$$
L=\frac{1}{N(N-1)} \sum_{i \neq j} d_{i j}
$$

Numa rede de transporte aéreo, o tamanho do menor caminho médio reflete o número médio de escalas necessárias para ligar dois pares de aeroportos. Se numa determinada rede há tamanho de menor caminho médio iguais a 1, 2, 3 e 4, isso implicaria que um voo de um aeroporto qualquer $i$ para um aeroporto qualquer $j$, não teria mais do que três escalas (o tamanho de caminho médio igual a 1 significa um voo direto) (LI-PING et al., 2003).

\subsubsection{EFICIÊNCIA TOPOLÓGICA}

Um problema na definição do menor caminho médio é que seu valor diverge, caso haja vértices desconectados no grafo, já que $d_{i j}$ é considerado infinito quando não há um caminho entre $i$ e $j$ (RODRIGUES, 2007). Uma alternativa para evitar tal problema foi proposta por Latora \& 
Marchiori (2001), que introduziram uma medida chamada eficiência global (global efficiency), cujo cálculo é realizado da seguinte forma:

$$
E=\frac{1}{N(N-1)} \sum_{i \neq j} \frac{1}{d_{i j}}
$$

Essa medida é um indicador da capacidade de transporte ou comunicação de uma rede, podendo, ainda, ser empregada para determinar quais dos vértices são mais importantes para obtenção de um transporte mais eficiente pela rede. Em muitos casos, os hubs correspondem a esses vértices. No entanto, pode haver uma hierarquia de importância entre vértices, mesmo quando eles têm aproximadamente o mesmo grau (RODRIGUES, 2007).

\subsubsection{GRAU DE PROXIMIDADE}

A centralidade ou grau de proximidade (closeness centrality) de um vértice é definido como o inverso do tamanho do menor caminho médio do vértice para todos os demais vértices do grafo (OKAMOTO et al., 2008). Outras definições ligeiramente diferentes existem (FREEMAN, 1979), mas não serão consideradas neste trabalho.

Essa propriedade pode ser vista como uma medida do quão eficientemente um vértice conseguirá compartilhar informações ou processar fluxos com outros vértices da rede. Quanto maior a centralidade de aproximação de um vértice, menor é a distância média entre esse vértice e os demais e, portanto, mais bem posicionado está o vértice para realização de trocas com outros vértices (OKAMOTO et al., 2008).

O grau de proximidade é calculado pelo inverso da soma de todos os menores caminhos de um vértice $i$ para cada um dos outros vértices da rede:

$$
C l_{i}=\frac{N-1}{\sum_{i \neq j \in V} d_{i j}}
$$

Sendo que $V$ é a componente conectada que contém todos os vértices alcançáveis pelo vértice $i$. Os vértices que possuem alto valor de proximidade apresentam maior centralidade na rede, isto é, todos os outros vértices da mesma componente conectada podem ser facilmente alcançados a partir do vértice com alto grau de proximidade. 
$\mathrm{Na}$ rede de transporte aéreo, a identificação de tais vértices pode ajudar no planejamento do crescimento da rede e na promoção do turismo em cidades que possuem aeroportos que não são alcançáveis facilmente pelos demais (SAPRE, 2011).

\subsubsection{GRAU DE INTERMEDIAÇÃO}

A centralidade ou grau de intermediação (betweenness centrality) é uma propriedade que pode estar associada tanto ao vértice quanto à aresta. Ela mede a razão entre o número de menores caminhos que passam por um determinado vértice/aresta e o total de menores caminhos da rede, ou seja, o quanto um vértice ou aresta está no caminho entre outros vértices (RODRIGUES, 2007).

O cálculo é feito conforme Equação 10, onde $d_{u j}(i)$ é o número de menores caminhos entre os vértices $u$ e $j$ que passam pelo vértice (ou aresta) $i$ e $d_{u j}$ é o número total de menores caminhos entre $u$ e $j$. A soma é feita sobre todos os pares distintos $u, j$ de vértices (RODRIGUES, 2007).

$$
B_{i}=\sum_{u \neq j} \frac{d_{u j}(i)}{d_{u j}}
$$

A média do grau de intermediação pode ser utilizada como uma medida de caracterização global da rede:

$$
\langle\mathrm{B}\rangle=\frac{1}{N} \sum_{i} \mathrm{~B}_{i}
$$

A partir do grau de intermediação pode-se ainda obter uma medida global chamada dominância do ponto central, que é calculada pela seguinte equação, onde $\mathrm{B}_{\max }$ é o maior valor da betweenness na rede (FREEMAN, 1977, 1979):

$$
C_{D}=\frac{1}{N-1} \sum_{i}\left(\mathrm{~B}_{\max -} \mathrm{B}_{i}\right)
$$

Inicialmente introduzida para análise de redes sociais, essa medida tem sido considerada útil, também, para a análise de redes de transportes (MONECHI, 2015). Quando o valor do betweenness $\left(\mathrm{B}_{\mathrm{i}}\right)$ é calculado de forma normalizada, a dominância do ponto central assume o valor 0 quando a rede é completamente conectada e assume o valor 1 quando se trata de uma rede tipo estrela, na qual um vértice central está incluso em todos os caminhos da rede. 
Numa rede de transporte aéreo, os aeroportos que possuem alto valor de grau de intermediação podem ser críticos para a integridade da rede, já que a maioria dos voos que envolva uma ou mais paradas (escalas ou conexões) passam por eles. Além disso, esses aeroportos podem representar relevância socioeconômica para a região ou país. Assim, um funcionamento ineficiente nesses vértices pode levar a fragmentação da rede (DALL'ASTA et al., 2006; SAPRE, 2011).

A Figura 3.4 demonstra a relação entres duas características importantes presente em redes complexas. $\mathrm{O}$ vértice $5 \mathrm{faz}$ a interligação de dois blocos relativamente grandes, sendo o vértice de maior grau de intermediação. Já os vértices 3 e 7 são considerados hubs, pois são os vértices com maior número de conexões.

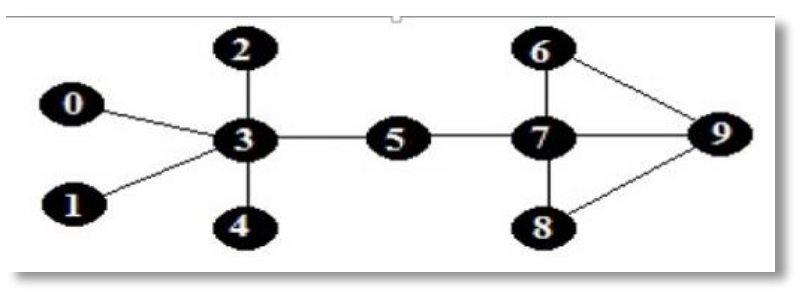

Figura 3.4. Relação entre vértice $h u b$ e vértice de alto grau de intermediação (Fonte: Silva \& Otazu, 2011).

Sobre o cálculo do grau de intermediação numa rede de transporte aéreo, DALL'ASTA et al. (2006) fizeram uma importante contribuição ao proporem o uso do conceito de "distância efetiva". Os autores partiram do fato, inicialmente discutido por BARRAT et al. (2004), de que em redes com pesos, a heterogeneidade do atributo das arestas faz com que alguns caminhos sejam mais favoráveis ou eficazes do que outros para promover o fluxo entre as conexões da rede. Isso tornou natural a generalização da noção da centralidade de intermediação para outra da centralidade de intermediação valorada, na qual os menores caminhos, medidos em saltos/arestas, seriam substituídos por caminhos que refletissem os pesos das arestas.

Uma maneira direta de generalizar a distância por saltos (ou por número de arestas), proposta pelos autores, consistiu em atribuir à cada aresta um comprimento $l_{i j}$ que fosse uma função da característica associada à aresta.

Para o caso da rede de transporte aéreo, uma característica natural que influencia a distância entre aeroportos é a separação geográfica entre eles. Por outro lado, seria razoável assumir que quanto maior a oferta de transporte, melhores e mais frequentes são as oportunidades de deslocamento de pessoas e mercadorias entre um par de aeroportos. Assim, a distância efetiva 
$\left(l_{i j}{ }^{\mathrm{w}}\right)$ entre dois pares de aeroportos conectados é função da distância geográfica $\left(d^{w}{ }_{i j}\right)$ e inversamente proporcional à oferta de tráfego $\left(\mathrm{w}_{i j}\right)$, conforme Equação 13 (DALL'ASTA et al. 2006).

$$
l_{i j}^{w}=\frac{d_{i j}^{w}}{w_{i j}}
$$

Dessa forma, para quaisquer dois nós $h$ e $j$, o menor caminho valorado entre eles $\left(\sigma^{w}\right)$ é aquele em que a soma dos valores da distância valorada ( $\left.l^{w}\right)$ é mínima, independentemente do número de arestas percorridas no caminho. O grau de intermediação valorado passa a ser calculado da seguinte maneira (DALL'ASTA et al. 2006)

$$
B_{i}^{w}=\sum_{u \neq j} \frac{\sigma_{h j}^{w}(i)}{\sigma_{u j}^{w}}
$$

No capítulo 5, quando se descreve sobre a formulação do método de análise de vulnerabilidade da rede de transporte aéreo, o conceito de distância efetiva será resgatado e empregado no processo de cálculo de outros parâmetros valorados e que precisam reconhecer o menor caminho entre pares de nós: tamanho do menor caminho médio, diâmetro, grau de proximidade e eficiência da rede.

\subsubsection{MEDIDAS RELACIONADAS À CICLOS}

A literatura traz duas medidas básicas relacionadas aos ciclos presentes num grafo: coeficiente de aglomeração ou clusterização (clustering coefficient) e coeficiente de aglomeração valorado (weigthed clustering coefficient).

\subsubsection{COEFICIENTE DE AGLOMERAÇÃO}

O coeficiente de aglomeração busca indicar a fração de ocorrência de loops numa rede. Assim calcula-se a razão do número de arestas entre os vizinhos de um dado vértice i, denotado por $e_{i}$, pelo número máximo possível de arestas entre esses vizinhos, que é dado por $k_{i}\left(k_{i}-1\right) / 2$. Em termos de matriz de adjacência, o coeficiente de aglomeração é calculado por (RODRIGUES, 2007):

$$
C C_{i}=\frac{2 e_{i}}{k_{i}\left(k_{i}-1\right)}=\frac{\sum_{j=1}^{N} \sum_{m=1}^{N} a_{i j} a_{i m} a_{j m}}{k_{i}\left(k_{i}-1\right)}
$$


Numa rede de transporte aéreo, o coeficiente de aglomeração $C C_{i}$ do aeroporto $i$ que está ligado com voos diretos a $V$ aeroportos, indica o quão conectados os $\mathrm{V}$ aeroportos estão entre eles (LI $\&$ CAI, 2004). Assim, quando um determinado aeroporto possui alto valor de $C C_{i}$ significa que o aeroporto $i$ tem um sistema de conexão mais compacto com os seus aeroportos vizinhos. Para uma rede hipotética totalmente conectada, o $C C_{i}$ de todos os vértices é igual a 1 , conforme mostrado na Figura 3.5. Por outro lado, se um vértice possui apenas um vizinho (grau 1) ou nenhum de seus vizinhos se conectam, o $C C_{i}$ é igual a 0. Veja a ilustração da Figura 3.5.

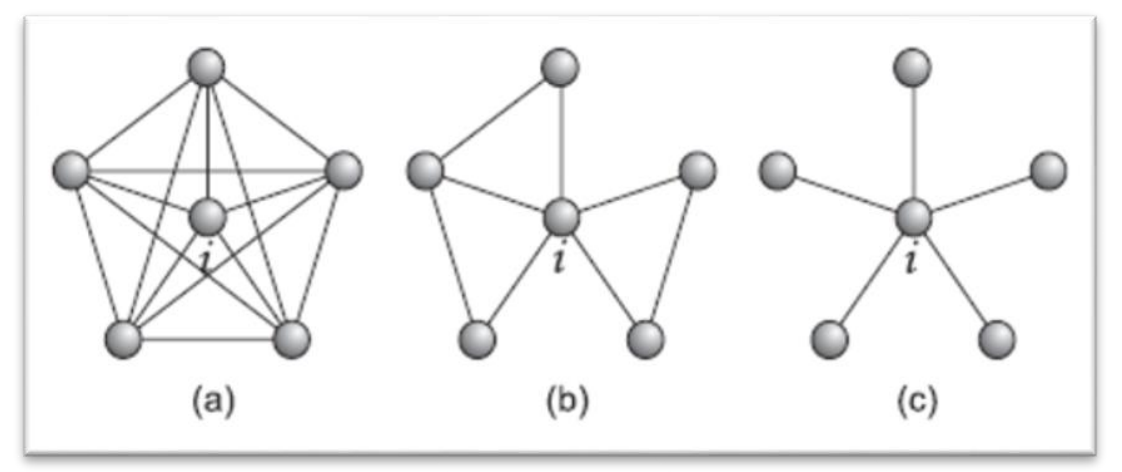

Figura 3.5. Visualização do coeficiente de aglomeração do vértice i em três diferentes redes (Fonte: Rodrigues, 2007).

\subsubsection{COEFICIENTE DE AGLOMERAÇÃO VALORADO}

A definição do coeficiente de aglomeração provê uma clara assinatura da organização estrutural da rede (BARRAT et al., 2004). No entanto, a inclusão de pesos nas arestas pode mudar a visão da estrutura da rede. Considere, por exemplo, um subgrafo de uma rede em que os vértices desse subgrafo estão conectados em ciclos de ordem três e possuem pequenos pesos associados às conexões. Neste caso, a definição acima do coeficiente de aglomeração resultaria no valor de 1 para todos esses vértices. Mesmo com um alto coeficiente de aglomeração, é evidente que esses ciclos apresentam um papel menor na organização e dinâmica da rede, quando comparados com subgrafos conectados por meio de arestas de pesos elevados (BARRAT et al., 2004).

Assim, para uma rede com pesos, o coeficiente de aglomeração (weighted clustering coefficient) é definido por (RODRIGUES, 2007):

$$
C C_{i}^{w}=\frac{1}{s_{i}\left(k_{i}-1\right)} \sum_{j>m} \frac{w_{i j}+w_{i m}}{2} a_{i j} a_{i m} a_{j m}
$$


O coeficiente de agrupamento global da rede pode ser representado pela média dos coeficientes dos vértices (RODRIGUES, 2007). Então, como medida global temos, a Equação 17 para grafo sem peso e a Equação 18 para grafo com pesos:

$$
\begin{gathered}
\langle C C\rangle=\frac{1}{N} \sum_{i=1}^{N} C C_{i} \\
\left\langle C C^{w}\right\rangle=\frac{1}{N} \sum_{i=1}^{N} C C_{i}^{w}
\end{gathered}
$$

Numa rede de transporte aéreo, um alto coeficiente de aglomeração global implica alto grau de concentração ou conectividade que, por sua vez, sugere uma alta probabilidade de se poder "viajar" pela rede através de poucas paradas.

\subsection{A VULNERABILIDADE DE REDES COMPLEXAS}

Uma das questões centrais no estudo de redes complexas é a avaliação da segurança e estabilidade da rede, tendo como principal objetivo o entendimento, a prevenção e um possível controle do comportamento de um sistema em rede quando está sujeito a falhas ou ameaças de qualquer tipo (ZANIN \& LILLO, 2013).

No desenvolvimento dos fundamentos da teoria de redes complexas, quando os especialistas se referiam a eliminação/remoção de elementos constituintes da rede (vértices ou arestas), diferentes termos já foram empregados: tolerância, robustez, vulnerabilidade, fragilidade e resiliência. Em alguns estudos é possível verificar certa correspondência com as expressões utilizadas no campo de conhecimento dos sistemas de transportes, discutidas no capítulo 2. No entanto, outros trabalhos são omissos quanto à definição dessas expressões ou as usam de forma ligeiramente diversa.

Albert et al. (2000) devem ter sido os primeiros a explorarem a ocorrência de erros (falhas) e ataques aos elementos componentes de uma rede complexa. Os autores fizeram uso dos termos tolerância e robustez para indicar a capacidade de certos tipos de redes reais em manter sua estrutura de conexão e comunicação entre os vértices integrantes da rede, mesmo numa situação hipotética de alta taxa de falhas (remoção) de alguns vértices. Réka Albert e seus colegas observaram que as redes complexas do tipo scale-free apresentavam uma tolerância incomum às falhas aleatórias dos vértices da rede. Por outro lado, também mostraram grande 
vulnerabilidade à ataques (isto é, à hipótese de seleção e remoção de determinados vértices que exercem um papel relevante na manutenção da conectividade da rede).

Interessante notar como se deu o processo de simulação computacional realizado por Albert et al. (2000). A avaliação da tolerância às falhas foi feita a partir da remoção aleatória e sequencial dos vértices da rede e da observação do momento de fragmentação da rede. Ou seja, em geral, a questão foi a seguinte: quantos vértices eram necessários serem removidos da rede para dividila em vértices isolados que não poderiam comunicar-se entre si (BARABÁSI, 2009)? No próximo capítulo, veremos que esse processo de simulação continuou sendo amplamente utilizado em estudos posteriores.

O conceito de eficiência da rede (network efficiency) foi proposto por Latora \& Marchiori (2001) para caracterizar as propriedades de redes do tipo small-world. Como visto no tópico anterior, a propriedade de eficiência é entendida como um indicador da capacidade de transporte ou comunicação de uma rede.

Mais tarde, Latora \& Marchiori (2005), ao discutirem a vulnerabilidade e proteção de sistemas tecnológicos em rede, fizeram uso de métricas da teoria de redes complexas, considerando a medida de eficiência como um índice de performance da rede. Propuseram um método para encontrar componentes críticos de uma rede de infraestrutura, isto é, os componentes (vértices ou arestas) fundamentais para o perfeito funcionamento de uma rede. O método foi avaliado através de estudos de caso aplicados em redes de internet e uma rede de transporte metroviário. Latora \& Marchiori (2005) perceberam que o nó mais crítico de uma rede de infraestrutura nem sempre é aquele nó mais bem conectado, denominado por alguns autores como nó hub, e mais simples de ser encontrado.

Crucitti et al. (2003) também utilizaram essa medida para estudar o efeito que erros e ataques provocariam em redes livres de escala. Dois tipos de rede complexas livres de escala, isto é, redes cuja distribuição de conexões segue uma lei de potência $\mathrm{P}(k)$, foram consideradas. As propriedades dessas redes foram comparadas com as de redes aleatórias e demonstrou-se que a eficiência global da rede é uma medida mais apropriada que o tamanho do menor caminho médio quando se pretende descrever a resposta de redes complexas a fatores externos. Além disso, quando comparadas com grafos aleatórios, as redes complexas apresentam, tanto a nível local como global, um alto grau de tolerância a erros e uma vulnerabilidade extrema a ataques, de forma similar ao que já havia sido encontrado por Albert et al. (2000). A eficiência global e 
local não são afetadas pela falha aleatória de alguns vértices, mas são extremamente sensíveis à remoção de alguns poucos vértices que desempenham um papel crucial na manutenção da conectividade da rede.

\subsection{TÓPICOS CONCLUSIVOS}

Neste capítulo foi apresentada a base matemática da teoria de redes complexas e a discussão sobre a área de pesquisa que envolve o estudo da "vulnerabilidade" em redes complexas. Os estudos desse campo, em geral, não buscam explicar um sistema em particular, mas objetivam produzir generalizações sobre as redes complexas a partir de estudos empíricos aplicados em redes específicas. No próximo capítulo, é apresentado o desenvolvimento dos estudos de análise de vulnerabilidade de redes de transporte aéreo, com base na teoria de redes complexas. 


\section{REDES DE TRANSPORTE AÉREO}

\subsection{APRESENTAÇÃO}

O sistema de transporte aéreo pode ser considerado como um sistema complexo (COOK et al., 2015). Vários sistemas complexos podem, naturalmente, ser representados por uma ou mais redes. A Internet, por exemplo, poderia ser representada como um conjunto de páginas (vértices) conectadas por hiperlinks (arestas) ou poderia ser modelada considerando os roteadores como vértices e suas conexões físicas como arestas (BARABÁSI, 2009).

Essa propriedade de múltiplas representações de rede presente em alguns sistemas complexos é, também, compartilhada pelo sistema de transporte aéreo e, portanto, o pesquisador tem, primeiramente, que decidir qual rede será investigada (ZANIN \& LILLO, 2013). O sistema de transporte aéreo é composto por um grande número de diferentes elementos que se interagem e trabalham conjuntamente.

A revisão trazida por Zanin \& Lillo (2013) apresenta diferentes possibilidades de abordagem por redes quando se estuda fenômenos no contexto do transporte aéreo. As redes de voos (flight networks) ou rede de aeroportos (airports network) foram, até recentemente, as mais estudadas por diferentes trabalhos. Mas outras redes podem ser formuladas e analisadas, dentre as quais pode-se exemplificar: (i) a rede de auxílios a navegação aérea (airways networks or airspace networks), considerando os auxílios como vértices e as aerovias como arestas de um grafo (KAI-QUAN et al., 2012); (ii) a rede formada por tripulantes como vértices que são ligados por compartilharem uma mesma aeronave em sequência e (iii) a rede de aeronaves que são conectadas quando se envolvem num evento de segurança de voo denominado Short Term Conflict Alert (LILLO et al., 2009; ZANIN, 2014).

Para as finalidades desta dissertação, a rede de transporte aéreo considerada é aquela formada por aeroportos (vértices) conectados por voos (arestas). Este capítulo pretende discorrer sobre as configurações usuais da malha de voos planejada pelas empresas aéreas e apresentar um panorama das pesquisas que modelaram as redes de transporte aéreo com base na teoria de redes complexas. Em seguida, serão discutidos os estudos que buscaram avaliar a vulnerabilidade de redes de transporte aéreo, sob a abordagem da teoria de redes. 


\subsection{MORFOLOGIA BÁSICA DE REDES DE TRANSPORTE AÉREO}

Do ponto de vista da morfologia, as redes de transporte aéreo podem ser caracterizadas por dois tipos básicos, conforme ilustrado pela Figura 4.1. A topologia denominada Point-to-Point é formado por rotas aéreas que ligam dois aeroportos de forma direta, sem escalas. Já topologia denominada Hub-and-Spoke é resultado das ligações aéreas que são distribuídas para diferentes aeroportos a partir de um ou mais aeroportos centralizadores. Não se pode afirmar que a malha aérea real das empresas aéreas são estritamente de um tipo ou outro, mas, geralmente em função de sua estratégia de negócio, podem apresentar alguma predominância a um dos modelos (SOUTELINO, 2006).

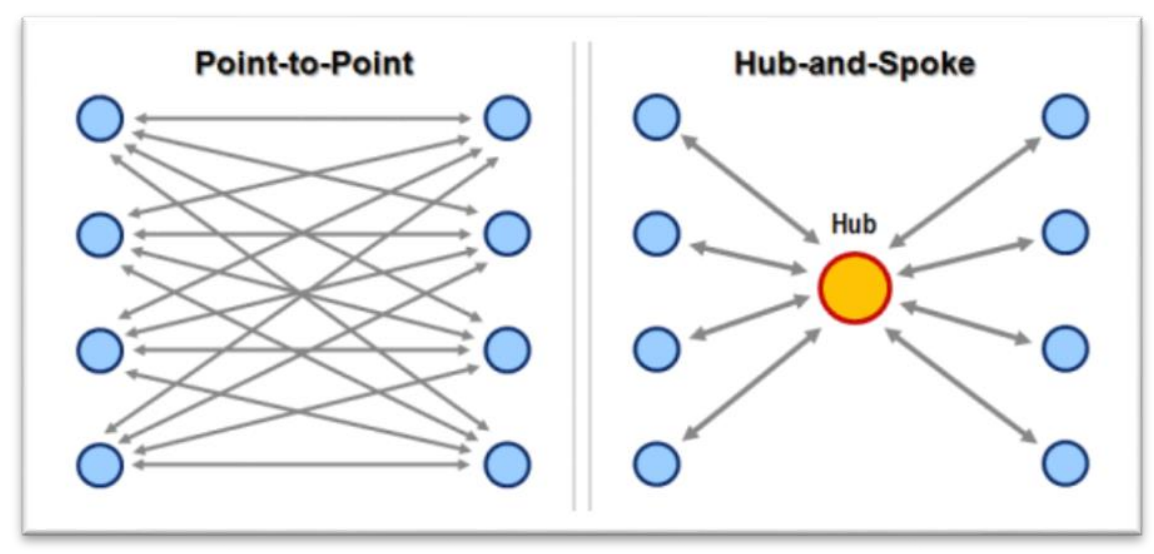

Figura 4.1. Morfologia básica de redes de transporte aéreo (Fonte: Soutelino, 2006).

A evolução da rede de rotas das empresas aéreas está sujeita a diversos fatores, especialmente, econômicos e operacionais. Os processos regulatórios de liberalização do setor iniciados no final da década de 70, nos Estados Unidos, e acompanhado pela Europa no final da década seguinte provocaram uma significativa reorganização da indústria do transporte aéreo (LORDAN et al., 2014a). Os elevados custos operacionais e o aumento da competitividade trouxeram impactos também na configuração da malha aérea das empresas. A tipologia $\mathrm{Hub}$ and-Spoke passou a dominar as estratégias de negócio, especialmente das empresas denominadas Full-Service Carrier (FSC), em substituição à tipologia Point-to-Point, atualmente de uso mais comum das empresas conhecidas como Low-Cost Carrier (LCC) (LORDAN et al., 2014a).

De um lado, argumenta-se que o sistema Hub-and-Spoke aumenta a eficiência das empresas aéreas e, portanto, num mercado competitivo, isso leva a preços mais baixos. Por outro lado, é claro que as cidades denominadas spoke ficam com o risco de se marginalizarem, sendo conectadas de forma mais indireta com o resto do sistema. O surgimento de companhias Low- 
Cost, graças a desregulação do mercado, criou oportunidades mais baratas de voar e sub-redes Hub-and-Spoke adicionais, onde os hubs são diferentes daqueles usados pelas principais empresas. Essas considerações qualitativas dos efeitos do sistema Hub-and-Spoke sob os passageiros tem sido investigada recentemente de uma maneira mais quantitativa, através do uso da teoria das redes (ZANIN \& LILLO, 2013).

Pode-se observar que a estrutura morfológica que caracteriza redes do tipo hub-and-spoke, mostrada na Figura 4.1, é similar à estrutura de estrela que aparece na Figura 3.5 do Capítulo 3. Isso indica que as redes de transporte aéreo cujas topologias seguem a arquitetura $h u b$-andspoke deverão apresentar baixos coeficientes de aglomeração por parte dos aeroportos e, consequentemente, da medida global da rede, quando comparados com redes formadas pelos princípios das ligações diretas (point-to-point).

\subsection{INTERRUPÇÃO OPERACIONAL DE AEROPORTOS}

A operabilidade dos aeroportos é elemento essencial para o funcionamento e disponibilidade normal dos serviços aéreos. No entanto, há diversos eventos que podem provocar a interrupção operacional desses aeroportos. A preocupação em avaliar fenômenos de interrupção que podem impactar o bom funcionamento dos serviços de transporte aéreo, em identificar as formas como esses impactos são sentidos pelos operadores e usuários do sistema e, principalmente, em estimar a extensão e dimensionamento desses prejuízos, está presente em um variado conjunto de estudos (AZIZI et al., 2016; CLAUSEN et al., 2010; JANIĆ, 2005; MAERTENS, 2013; PEJOVIC et al., 2009).

Janic (2005) desenvolveu um modelo analítico, baseado na teoria de filas, para quantificação das consequências econômicas decorrentes de uma ocorrência de interrupção de grande escala numa malha aérea do tipo hub-and-spoke. Pejovic et al. (2009) tentam, também, analisar os impactos causados pelo fechamento de um aeroporto. Em ambos os estudos, as consequências estavam associadas aos custos por motivo de atrasos e cancelamentos de voos. As aplicações se dão na análise de um único aeroporto, através de dados operacionais detalhados sobre horários de chegada e saída de aeronaves, suas origens e destinos, categorias de voos e categorias de aeronaves.

Clausen et al. (2010) fazem uma revisão sobre o gerenciamento de interrupções na indústria do transporte aéreo, apresentando os modelos mais comumente usados para problema de otimização dos recursos das empresas. As três representações de rede frequentemente utilizadas 
pelas empresas para lidar com problemas de planejamento e retorno (replanejamento) após um evento de interrupção são descritas como: rede de conexões (connection network), rede de linha de tempo (time-line network) e rede faixa de tempo (time-band network). Em geral, as técnicas são aplicadas para o planejamento do uso das aeronaves e da tripulação disponível. Os autores mencionam estudos recentes que buscam abordar o gerenciamento de interrupções através de um planejamento robusto (robust planning) ou uma programação robusta (schedule robustness). O objetivo de um planejamento robusto seria tornar a programação de voos e da tripulação e o revezamento de aeronaves menos sensível a eventos adversos que afetam a malha aérea. A busca por uma maior robustez do planejamento de voos pode ser vista como uma maneira proativa de lidar com as possíveis interrupções de serviço.

Verifica-se, portanto, a diversidade de metodologias e abordagens que tem sido aplicada na formação de entendimentos acerca do comportamento da malha aérea, no contexto de interrupção de aeroportos e sob pontos de vista de diferentes atores da cadeia do transporte aéreo (passageiros, operadores aéreos, operadores aeroportuários e provedores de serviços de controle de tráfego). A seguir discute-se as aplicações da teoria de redes complexas para análise do transporte aéreo, em especial, para análise da vulnerabilidade da rede.

\subsection{MODELAGEM POR REDE COMPLEXAS}

O uso da teoria de redes complexas para abordagem de problemas no contexto do sistema de transporte aéreo iniciou-se a partir dos trabalhos de Li-Ping et al., (2003), Li e Cai (2004); Chi \& Cai (2004); Barrat et al., (2004); Guimera \& Amaral (2004) e Guimera (2005). Desde então, houve um interesse considerável do uso dessa abordagem para análise de diversos aspectos do transporte aéreo, com foco na análise estatística e estrutural, análise da vulnerabilidade da rede, além da observação de diferentes processos dinâmicos pela rede.

A análise estatística e estrutural da rede, de maneira geral, envolveu a caracterização de medidas ou propriedades topológicas, a identificação de fatores que influenciam a organização e evolução das redes e, finalmente, a proposição de modelos teóricos que explicam o comportamento emergente identificado.

A avaliação da vulnerabilidade de redes de transporte aéreo foi estudada, especialmente, nos cenários de falhas (tidos como eventos aleatórios) e sob cenários de ataques (vistos como eventos determinísticos) direcionados aos aeroportos componentes da rede. 
Muitos sistemas complexos, incluindo as redes, não são estáticos, mas apresentam variação da sua estrutura no tempo (RODRIGUES, 2007). Assim, a caracterização da dinâmica da evolução estrutural em redes complexas é uma tarefa importante para o entendimento dessas redes e dos processos dinâmicos que ocorrem nelas (GAUTREAU et al., 2009). Diferentes processos dinâmicos que ocorrem numa rede de transporte aéreo já foram objetos de estudo, tais como, a disseminação de doenças (COLIZZA et al., 2006), os efeitos de congestionamentos (LACASA et al., 2009) e a propagação de atrasos (LILLO et al., 2011; FLEURQUIN et al., 2014).

O Quadro 4.1 apesenta uma visão geral do direcionamento da literatura produzida nos últimos treze anos, mostrando, por exemplo, uma ênfase de aplicações para análise da rede de transporte mundial, dos Estados Unidos e da China.

Li-Ping et al., (2003) analisaram algumas propriedades estruturais da rede de voos doméstica dos Estados Unidos, considerando os aeroportos como vértices e a presença de voos que conecte dois aeroportos como arestas. Foi mostrado que tal rede apresenta duas importantes características também encontradas em redes do tipo mundo pequeno (small-world): um valor reduzido do menor caminho médio $(l)$ e um coeficiente de aglomeração $(\langle C C\rangle)$ relativamente elevado, quando comparados com uma rede randômica correspondente. Analisando as distribuições das propriedades estruturais da rede, os autores também identificaram que a distribuição de grau segue uma lei de potência de dois segmentos; a distribuição de voos (flight weight distribution) apresenta uma cauda de lei de potência com expoente aproximadamente igual a 2 e a distribuição do coeficiente de aglomeração segue uma distribuição linear.

As propriedades da rede de voos norte-americana foram comparadas com as propriedades observadas em redes aleatórias, redes mundo pequeno e redes livre de escala. Para isso, Li-Ping et al. (2003) utilizaram uma base de dados de voos de um período diário e semanal (de segunda a domingo). Isso permitiu-lhes verificar diferenças de alguns parâmetros observados para a estrutura da rede durante os dias úteis da semana e durante o final de semana. Por fim, concluíram que a rede de voos norte-americana tem um comportamento de rede mundo pequeno, com alto coeficiente de aglomeração e baixo tamanho do menor caminho médio.

Barrat et al. (2004) estudaram a arquitetura de redes complexas valoradas, fazendo uso de observações empíricas relacionadas à rede mundial de aeroportos (world-wide airport network - WAN). 
Quadro 4.1. Literatura: abordagem do sistema de transporte aéreo como rede complexa (Fonte: adaptado de LORDAN et al., 2014a).

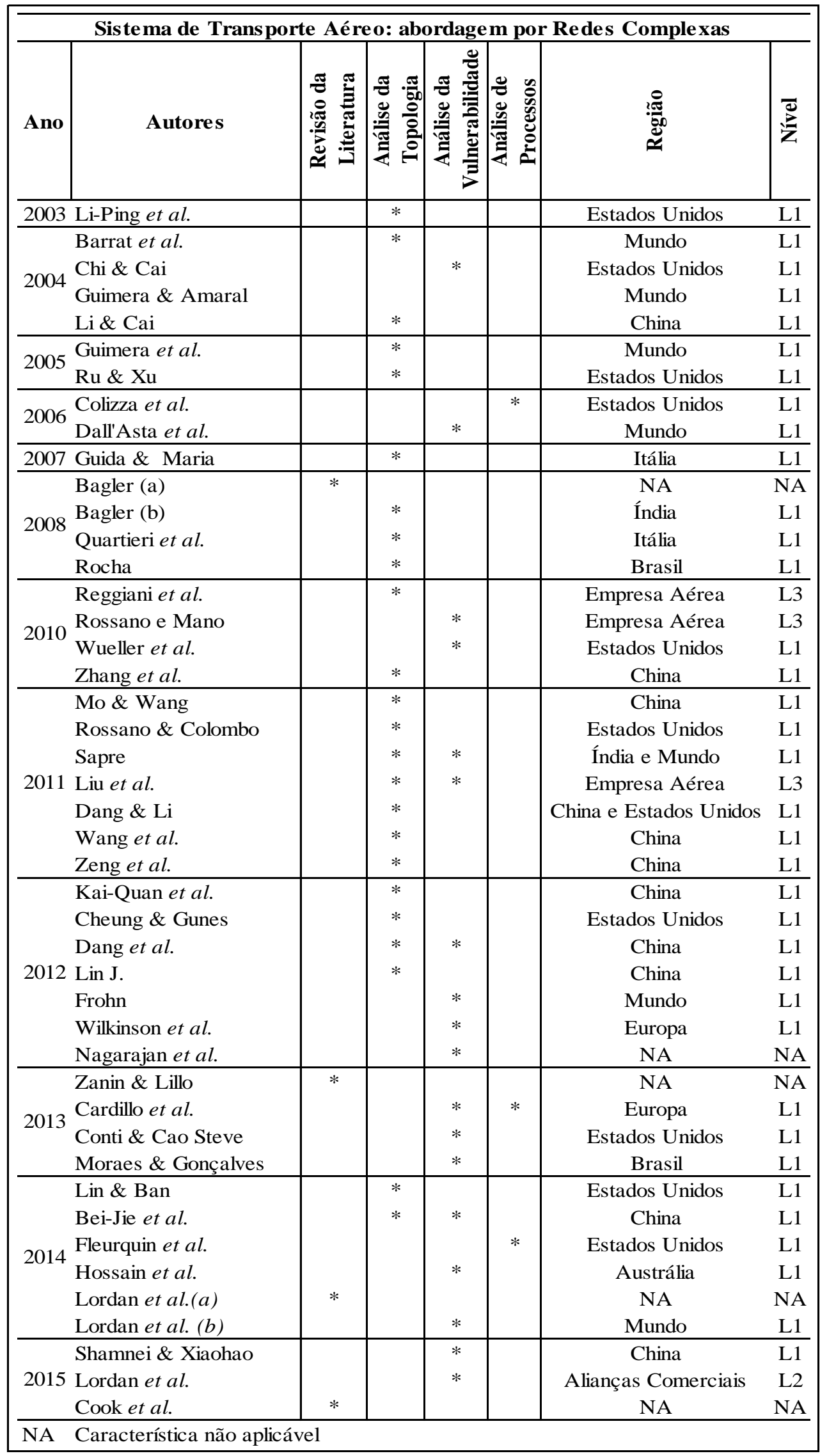


Apesar de estudos anteriores que analisaram algumas redes de aeroportos por meio da teoria de redes complexas, foi Guimera (2004 e 2005) e seus colegas, provavelmente, os primeiros a promoverem uma investigação profunda da estrutura da rede mundial de aeroportos fazendo uso dessa teoria, modelando as conexões a partir da existência de voos regulares de passageiros entre dois aeroportos. A rigor, a análise partiu de uma rede de cidades, tendo em vista que os aeroportos que atendiam uma mesma região metropolitana foram representados como um único vértice do grafo. Foi o caso, por exemplo, dos três aeroportos presentes na cidade de Nova York.

Neste estudo pioneiro, os autores verificaram a presença do comportamento mundo pequeno e livre de escala na rede de aeroportos, constatando a caracterização da rede de aeroportos como uma rede complexa. Por outro lado, verificaram uma característica incomum até então: a presença de vértices de baixo grau topológico, mas com elevado grau de intermediação. A partir desta observação, os pesquisadores passaram a acreditar que os modelos teóricos de formação de rede não conseguiriam gerar redes com tal característica. De fato, isso foi observado. Mas além disso, verificaram que o mecanismo de anexação preferencial, dos modelos teóricos, e as restrições geográficas, inerentes a rede de aeroportos, não eram critérios suficientes para explicar o comportamento visto na rede. As condições ou restrições geopolíticas foi um fator que influenciou a formação e evolução da rede mundial de aeroportos.

É importante notar que alguns resultados de estudos da literatura não são passíveis de comparação ou, no máximo, permitem uma comparação com ressalvas. Há estudos que usaram métricas com a mesma denominação, mas com uma definição matemática sutilmente diferente. A aplicação de métricas com denominação diferenciada, mas com mesma definição matemática, também ocorre, exigindo atenção do leitor. Observa-se isso, por exemplo, nos artigos de Chi \& Cai (2004), quando aplicam a medida de diâmetro de rede e de caminho médio.

Um aspecto importante da rede de voos é que ela pode ser, naturalmente, decomposta em várias sub-redes (subgrafos). Por exemplo, a rede formada pela malha aérea de um país pode ser decomposta através da consideração de sub-redes formadas por voos exclusivos de cada uma das empresas aéreas. A análise de redes que abrangem uma única empresa aérea foi realizada ao menos por Han et al., (2009) e por Reggiani et al., (2010).

Nesta mesma linha, Lordan et al., (2014a) propôs uma estrutura de sub-redes para guiar o planejamento e delimitar a aplicação das futuras pesquisas. Como mostrado na Figura 4.2, o 
nível L1 representa a modelagem de uma rede de transporte aéreo de abrangência mundial, regional ou nacional (isto é, no âmbito de um determinado país). O nível L2 representa redes formadas por alianças comerciais entre empresas aéreas, de abrangência regional ou mundial. Por fim, o nível L3 indica as redes formadas apenas pela malha aérea de uma única empresa.

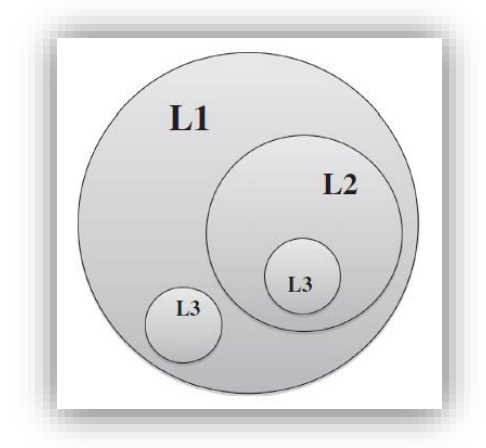

Figura 4.2. Níveis de estudo para redes de transporte aéreo (Fonte: Lordan et al., 2014a).

\subsection{ANÁLISE DA VULNERABILIDADE DA REDE DE TRANSPORTE AÉREO}

Foi visto que nos últimos anos, alguns pesquisadores envidaram esforços para analisar a vulnerabilidade de redes de transporte aéreo, tentando identificar e avaliar os impactos causados à rede, em decorrência de fechamento de aeroportos ou de cancelamento de voos. Situações essas que ocorrem devido a uma diversidade de eventos, tais como, condições meteorológicas adversas, greves de funcionários, acidentes aeronáuticos e atentados terroristas.

No âmbito desse objeto de estudo, destaca-se na literatura científica recente o uso da teoria de redes complexas (LORDAN et al., 2014a; LORDAN et al., 2014b; COOK et al., 2015). Através da análise dos estudos que partiram dessa abordagem para analisar a vulnerabilidade de redes de transporte aéreo, é possível levantar algumas de suas características principais e elementos em comum. Basicamente, os estudos se estruturam partindo de uma base de dados de voos realizados numa determinada região e período. Procedem a modelagem dos dados representando o sistema por meio de um grafo, definem uma estratégia de simulação de cenários e utilizam um conjunto de métricas como indicadores de impacto à rede. 
Em alguns estudos não há informação suficiente para identificar que tipos de voos foram incluídos na análise (voo regular ${ }^{4}$ ou voo não regular ${ }^{5}$ ), entretanto, a maioria das bases de dados, consideraram voos regulares de passageiros. Apenas Moraes \& Gonçalves (2013) consideraram, também, dados de voos exclusivamente de cargas.

Na modelagem foi comum a representação por meio de rede não direcionada. Isso se deve ao fato de as redes de transporte aéreo apresentarem um grau de simetria entre voos de ida e volta relativamente elevado (GUIMERA \& AMARAL, 2004; ROCHA, 2009). Conti et al., (2013), Hossain et al., (2013) e Moraes \& Gonçalves (2013) fizeram uso de rede direcionada nas suas análises.

O uso de um modelo de grafo com pesos para representação da RTAer se mostrou comum, considerando as discussões trazidas por Barrat et al., (2004) e Dall'Asta et al., (2006) e a necessidade de refletir de forma mais apropriada a realidade operacional da rede. Para a valoração das arestas, os estudos fizeram uso de ao menos um dos seguintes atributos operacionais: número de voos, número de passageiros, número de assentos disponíveis, assento-quilômetro oferecido (ASK) e distância geográfica entre os pares de aeroportos, conforme apontado no Quadro 4.2.

Para o processo de simulação, foram adotadas as estratégias de eventos aleatórios, associados às falhas no sistema, e eventos determinísticos, para simular ataques direcionados a pontos específicos da rede. A maioria das simulações consistiram na retirada sequencial de vértices ou arestas. Para o caso de ataques, a escolha dos vértices obedecia algum critério relacionado a sua importância. Apesar da variedade de critérios utilizados, alguns estudos identificaram maior eficácia no processo de simulação para o caso em que os critérios envolviam as medidas de grau topológico e grau de intermediação topológico e valorado (DALL'ASTA et al., 2006; LORDAN et al., 2014b). Conti et al., (2013) e Hossain et al., (2013) simularam, também, cenários de interrupção de pares de aeroportos. Por fim, o indicador de impacto mais comum foi o tamanho da maior componente conectada da rede, mas, também, outras diferentes métricas foram empregadas.

\footnotetext{
${ }^{4}$ Operação regular significa uma operação de transporte aéreo público para o qual é informado previamente o horário e local de partida e o local de chegada (BRASIL, 2014b).

${ }^{5}$ Operação não regular significa uma operação de transporte aéreo público para o qual o horário, o local de partida e o local de destino são função da demanda e cujo preço pode ou não ser especificamente negociado com os usuários (BRASIL, 2014b).
} 
O Quadro 4.2 indica os elementos básicos que delinearam os estudos de vulnerabilidade de redes de transporte aéreo, a partir da abordagem de redes complexas. Em seguida, os quadros 4.3 e 4.4 apresentam, respectivamente, os critérios de seleção de vértice do grafo que foram utilizados na simulação de ataques à rede e os indicadores de impacto.

Quadro 4.2. Elementos básicos da literatura de vulnerabilidade de rede de transporte aéreo (Fonte: elaborado pelo autor).

\begin{tabular}{|c|c|c|c|c|c|c|}
\hline \multirow[t]{2}{*}{ Autor e Ano } & \multirow[t]{2}{*}{ Região } & \multirow[t]{2}{*}{ Nível } & \multicolumn{2}{|c|}{$\begin{array}{l}\text { Características da } \\
\text { Modelagem }\end{array}$} & \multicolumn{2}{|c|}{$\begin{array}{l}\text { Estratégia de } \\
\text { Simulação }\end{array}$} \\
\hline & & & Direção & Pesos & Falhas & Ataques \\
\hline Chi \& Cai (2004) & Estados Unidos & L1 & $\mathrm{ND}^{(1)}$ & Voos & Sequencia $^{(2)}$ & Sequencia \\
\hline Dall'Asta et al. (2006) & Mundo & L1 & Não & $\begin{array}{c}\text { Assentos/ } \\
\text { Distância/ASK }\end{array}$ & Não & Sequencia \\
\hline Wuellner (2010) & Estados Unidos ${ }^{(3)}$ & L1 & Não & Voos & Sequencia & Sequencia \\
\hline Sapre (2011) & Mundo & L1 & Não & Voos & Sequencia $^{(4)}$ & Sequencia \\
\hline Conti (2013) & Estados Unidos & L1 & Sim & Passageiros & Reposição & Reposição \\
\hline $\begin{array}{l}\text { Moraes \& Gonçalves } \\
\text { (2013) }\end{array}$ & Brasil & L1 & Sim & Não & Sequencia & Sequencia \\
\hline Hossain (2013) & Austrália & L1 & Sim & Voos & $\begin{array}{l}\text { Sequencia e } \\
\text { Reposição }\end{array}$ & Sequencia \\
\hline Lordan et al. (2014b) & Mundial & L1 & NA & Não & Sequencia & Sequencia \\
\hline Lordan et al. (2015) & Alianças Comerciais & L2 & NA & Não & Não & Sequencia \\
\hline $\begin{array}{l}\text { Shanmei \& Xiaohao } \\
(2015)\end{array}$ & $\begin{array}{l}\text { Estados Unidos e } \\
\text { China }\end{array}$ & L1 & $\mathrm{ND}^{(1)}$ & Voos & Não & Sequencia \\
\hline \multicolumn{7}{|c|}{ (1) ND - Informação não disponível } \\
\hline \multicolumn{7}{|c|}{$\begin{array}{l}\text { (2) Em Chi \& Cai (2004) a estratégia para simulação das falhas na rede não foi implementada de forma aleatória. Houve } \\
\text { uma ordenação prévia dos aeroportos e seleção sequencial a partir do nó de menor grau. E ainda, apenas uma } \\
\text { determinada percentagem de nós foram eliminados. }\end{array}$} \\
\hline \multicolumn{7}{|c|}{$\begin{array}{l}\text { (3) Em Wuellner et al. (2010) a base de dados compreende os voos das } 7 \text { maiores empresas aéreas dos Estados Unidos } \\
\text { (por número de passageiros transportados). }\end{array}$} \\
\hline
\end{tabular}

Quadro 4.3. Critério de seleção de vértices no grafo (Fonte: elaborado pelo autor).

\begin{tabular}{|c|c|c|}
\hline $\begin{array}{c}\text { Critérios de Seleção de Vértices do } \\
\text { Grafo }\end{array}$ & Estudos & Referências \\
\hline Grau topológico & 7 & $\begin{array}{l}\text { Chi e Cai (2004); Dall'Asta et al. (2006); Wuellner } \text { et al. (2010); Sapre(2011); } \\
\text { Hossain et al. (2013); Lordan et al. (2014b); Shanmei e Xiaohiao (2015) }\end{array}$ \\
\hline Grau valorado & 2 & Dall'Asta et al. (2006); Hossain et al. (2013) \\
\hline Grau de intermediação topológico & 7 & $\begin{array}{c}\text { Dall'Asta et al. (2006); Wuellner et al. (2010); Conti (2013); Moraes \& } \\
\text { Gonçalves (2013); Hossain et al. (2013); Lordan et al. (2014b); Lordan et al. } \\
\text { (2015) }\end{array}$ \\
\hline Grau de intermediação valorado & 2 & Dall'Asta et al. (2006); Hossain et al. (2013) \\
\hline Grau de Proximidade & 1 & Conti (2013) \\
\hline Grau de Hub (Hub Score) & 1 & Conti (2013) \\
\hline $\begin{array}{l}\text { Grau de Autoridade (Authority } \\
\text { Scores) }\end{array}$ & 1 & Conti (2013) \\
\hline Ranking de página (Page Rank) & 1 & Conti (2013) \\
\hline Ponto de Articulação & 1 & Conti (2013) \\
\hline Dano (Damage) & 2 & Lordan et al. (2014b); Lordan et al. (2015) \\
\hline Análise Modal (Modal Analysis) & 2 & Lordan et al. (2014b); Lordan et al. (2015) \\
\hline $\begin{array}{l}\text { Centralidade de Bonacich } \\
\text { (Bonacich Power })\end{array}$ & 2 & Lordan et al. (2014b); Lordan et al. (2015) \\
\hline $\begin{array}{l}\text { Eficiência invertida (Inverted } \\
\text { Eficiency) }\end{array}$ & 1 & Lordan et al. (2015) \\
\hline Índice de importância (AIFSS) & 1 & Shanmei \& Xiaohao (2015) \\
\hline
\end{tabular}


Quadro 4.4. Indicadores de Impacto à Rede (Fonte: elaborado pelo autor).

\begin{tabular}{|c|c|c|}
\hline Indicador de Impacto na Rede & Estudos & Referências \\
\hline Grau médio & 1 & Chi \& Cai (2004) \\
\hline Coeficiente de aglomeração & 1 & Chi \& Cai (2004) \\
\hline Diâmetro & 2 & Chi \& Cai (2004); Conti (2013) \\
\hline Eficiência topológica & 3 & Chi \& Cai (2004); Sapre (2011); Hossain et al. (2013) \\
\hline Eficiência valorada & 1 & Hossain et al. (2013) \\
\hline Componente conectada & 7 & $\begin{array}{l}\text { Dall'Asta et al . (2006); Wuellner et al . (2010); Conti (2013); Moraes \& Gonçalves } \\
\text { (2013); Hossain et al. (2013); Lordan et al. (2014b); Lordan et al . (2015) }\end{array}$ \\
\hline Grau valorado & 1 & Dall'Asta et al. (2006) \\
\hline Custo de viagem global & 1 & Wuellner et al. (2010) \\
\hline Caminho médio & 1 & Conti (2013) \\
\hline Subgrafos & 1 & Hossain et al. (2013) \\
\hline $\begin{array}{c}\text { Métrica de vulnerabilidade multi- } \\
\text { escala }\end{array}$ & 1 & Lordan et al. (2015) \\
\hline
\end{tabular}

Chi \& Cai (2004) podem ter sido os pioneiros na análise da tolerância da rede de aeroportos norte-americana a erro e ataques, por meio da avaliação das mudanças estruturais sob esses cenários.

Os ataques à rede foram simulados por meio da retirada sequencial de uma parcela de aeroportos mais bem conectados. A remoção de um aeroporto significa, também, a eliminação das rotas que fazem conexão com esse aeroporto. Para simular as falhas ou erros aleatórios que ocorrem na rede, eles selecionaram e removeram, de forma também sequencial, os aeroportos menos conectados à rede.

Essa estratégia de simulação, onde concentra os erros (falhas) nos pequenos aeroportos e os ataques nos grandes aeroportos, se diferencia da adotada por Albert et al. (2000), com o objetivo de destacar a diferença de papéis entre grandes e pequenos aeroportos.

Para analisar o impacto das remoções, quatro propriedades topológicas foram monitoradas: grau médio, coeficiente de aglomeração, tamanho do menor caminho médio e eficiência. Além disso, foi feita uma avaliação acerca da alteração nas curvas de distribuição de grau e distribuição do grau valorado (rede valorada por número de voos em cada rota). Comparou-se a forma das curvas de distribuição originais com as curvas resultantes no fim das simulações de erros e ataques.

Os estudos dos autores demonstraram um surpreendente alto grau de tolerância a erros e, ao mesmo tempo, uma extrema vulnerabilidade a ataques. Isso reside nas seguintes razões: a remoção dos pequenos aeroportos não altera a estrutura dos aeroportos remanescentes. $\mathrm{Na}$ verdade, promove até uma melhoria na distância média do menor caminho e na eficiência da rede. Diferentemente, a remoção dos grandes aeroportos, altera drasticamente a topologia da 
rede e diminui a habilidade dos aeroportos remanescentes de se comunicarem um ao outro. $\mathrm{Na}$ rede norte-americana considerada, quando um grande aeroporto era eliminado sob ataque, isso causava, em média, o fechamento de outros oito aeroportos menores. Quando a proporção de remoções alcança um valor irreal de $10 \%$, mais da metade dos aeroportos remanescentes são fechados. Isso explica porque, apesar do fechamento de alguns pequenos aeroportos, as viagens praticamente não são afetadas, e porque quando um grande aeroporto é interrompido, há grandes preocupações sobre os passageiros preteridos e as perdas econômicas.

Ainda sobre o estudo de Chi \& Cai (2004), foi observado o grau de vulnerabilidade à ataques da rede de aeroportos dos EUA era similar ao observado em redes livres de escala. Eles conjecturaram que a rede de aeroportos americana apresenta a característica livre de escala. Ao mesmo tempo, um pequeno tamanho do menor caminho médio e grande coeficiente de aglomeração mostram que a rede de aeroportos também se comporta como uma rede mundo pequeno. Assim, a topologia da rede de aeroportos exibe tanto propriedades de mundo pequeno como de livre de escala.

Dall'Asta et al. (2006) exploraram a vulnerabilidade de redes complexas valoradas através de um estudo empírico aplicado à rede de transporte aéreo mundial, construída a partir de dados fornecidos pela IATA (International Air Transportation Association). Para conduzir esse estudo, os autores consideraram duas informações que já haviam sido identificadas na literatura sobre redes complexas.

Primeiro, o fato de que em sistemas reais a diversidade de interações entre seus elementos se associam a estrutura topológica da rede, sendo representadas por pesos nas arestas do grafo (BARRAT et al., 2004). Somado aos processos de interação, especialmente em sistemas de infraestrutura, tem-se as restrições geográficas que resultam numa inter-relação entre topologia, pesos e geografia. O segundo aspecto considerado foi a característica marcante de vulnerabilidade das redes complexas às situações de ataque direcionados aos componentes mais importantes do sistema (ALBERT et al., 2000). Esta última observação, no entanto, foi inicialmente verificada pela literatura através de um processo de modelagem de uma rede sem pesos.

Dall'Asta e seus colegas julgaram relevante analisar como a introdução de pesos ao modelo de rede poderia alterar ou confirmar as verificações mencionadas acerca da vulnerabilidade de redes complexas. Para isso, realizaram testes empíricos no modelo da rede de transporte aéreo 
mundial, considerando dois atributos (pesos): o tráfego existente e a distância geográfica entre dois pares de aeroportos. De fato, os autores concluíram que as redes reais se mostravam ainda mais vulneráveis à ataques do que a simples análise topológica prévia indicava.

Conti et al., (2013) investigaram o problema de ruptura na rede de aeroportos dos Estados Unidos através da teoria de redes complexas, utilizando métricas de centralidade e parâmetros de rede para a identificação de aeroportos críticos e avaliação do fechamento de tais aeroportos.

Lordan et al., (2014b) realizaram simulações na rede de transporte aéreo mundial buscando alcançar, basicamente, dois objetivos: (i) apresentar um método de identificação de aeroportos críticos e (ii) avaliar a efetividade dos critérios de seleção de aeroportos no que se refere a capacidade de provocar a degradação da conectividade da rede.

A sistemática de simulação foi a mesma aplicada por Dall'Asta et al., (2006), isto é, observação do comportamento da rede em cenários de falhas ou ataques sequenciais sob os aeroportos. Essa sistemática foi originalmente proposta por Albert et al. (2000), conforme exposto no Capítulo 3. A diferença é que no caso do cenário de ataques à rede, o parâmetro associado à importância do vértice era novamente calculado após cada remoção de vértice. Essa estratégia foi denominada como "recursive re-calculation" por Dall'Asta et al., (2006) e como "adaptative selection criteria” por Lordan et al., (2014b).

Ambos os estudos identificaram que o grau de intermediação dos vértices (betweenness), quando usado como critério de seleção de aeroportos mais importantes, gerava danos à conectividade da rede de forma mais efetiva.

A Figura 4.3 apresenta os resultados das simulações feitas na rede de transporte aéreo, mostrando as curvas de decréscimo do tamanho da maior componente conectada em função da quantidade de aeroportos removidos da rede. Cada curva em declínio representa um método de seleção. Como esperado, em virtude de estudos anteriores, a rede é muito menos vulnerável a remoção aleatória de vértices do que a ataques. A remoção aleatória de $13 \%$ dos aeroportos reduz em $22 \%$ o tamanho da maior componente. Por outro lado, o mesmo número de aeroportos removidos é suficiente para desconectar quase toda a rede, caso a remoção seja feita com base no grau de intermediação (betweenness).

Um aspecto interessante da curva do grau de intermediação é a ocorrência de quedas abruptas no tamanho da maior componente em determinados estágios, como por exemplo, a que ocorre 
no ponto de 2,5\% de aeroportos removidos. Inclusive, antes dessa taxa de remoção, o critério de dano à rede (damage) se mostrou mais efetivo para prejudicar a sua conectividade. Esse critério foi adaptado pelos autores com base no estudo de Dall'Asta et al. (2004) que empregou o somatório dos graus valorados de cada vértice do grafo para caracterizar a situação de integridade da rede de transporte.

Portanto, esse comportamento de vulnerabilidade ao critério denominado damage é importante para cenários que envolvam pequenas porcentagens de interrupção de aeroportos e será considerada na formulação do método apresentado no capítulo seguinte.

Mais recentemente, Shanmei \& Xiaohao (2015) propuseram uma análise de vulnerabilidade de rede de aeroportos combinando a teoria das redes complexas com a teoria de conjuntos suaves fuzzy (fuzzy soft sets), através de uma perspectiva estrutural e funcional.

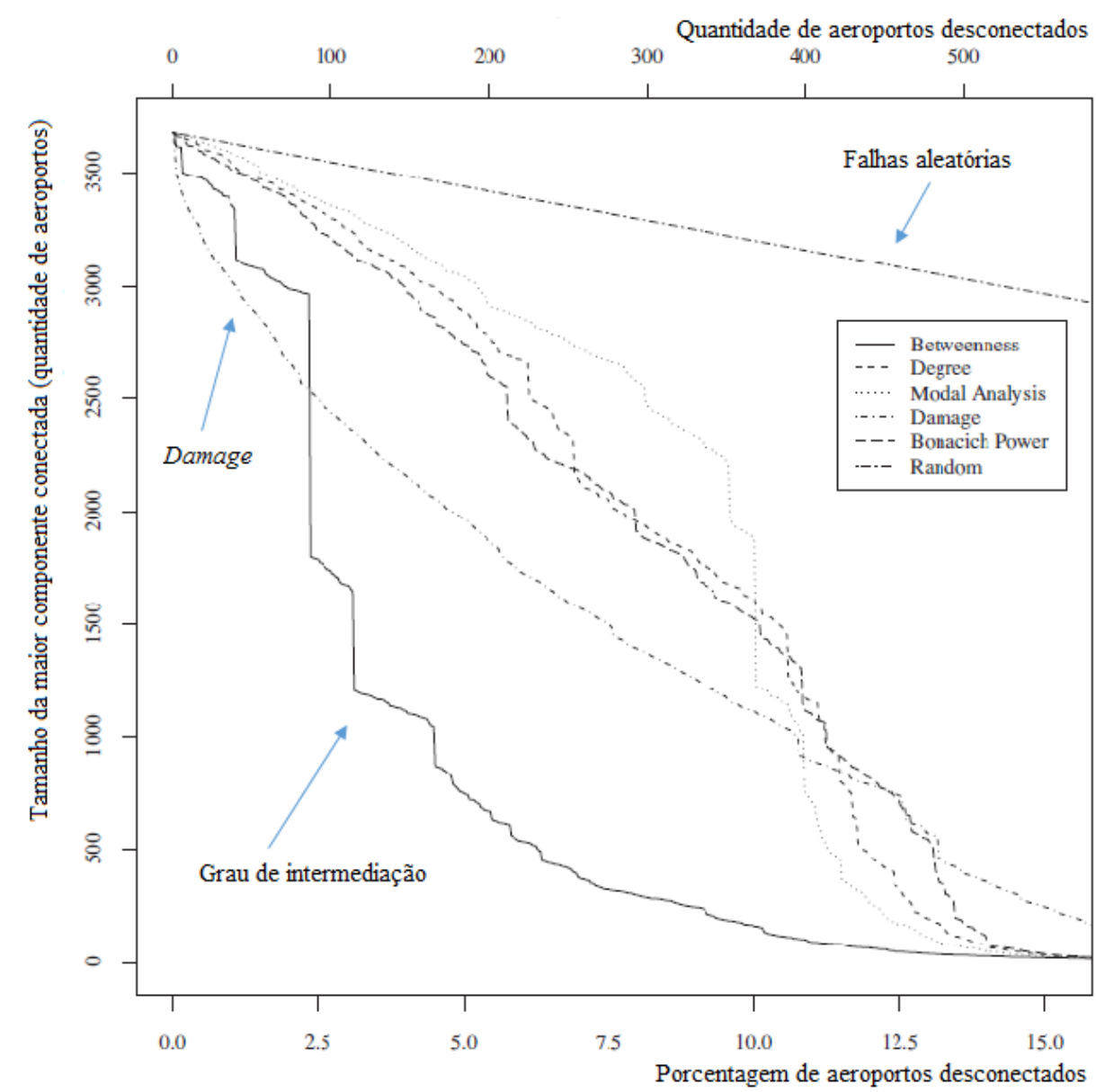

Figura 4.3. Vulnerabilidade da rede de transporte aéreo mundial (Fonte: adaptado de Lordan et al., 2014b). 
Apesar da variedade de estudos e aplicações com objetivos similares, uma avaliação comparativa dos resultados encontrados pelos pesquisadores fica, em certa medida, prejudicada devido às diferentes características de modelagem da rede, do processo de simulação e dos parâmetros utilizados como indicadores de vulnerabilidade. A proposta de desenvolvimento de um método estruturado pode permitir a avaliação comparativa entre resultados de análise de vulnerabilidade de redes de transporte aéreo.

\subsection{INTERVENÇÕES NA REDE DE TRANSPORTE AÉREO}

Chi \& Cai (2004), ao investigarem o comportamento da rede de aeroportos dos EUA, chegaram à conclusão de que a remoção de aeroportos de pequeno porte, ou seja, aqueles que apresentam poucas ligações com outro aeroporto, produziria uma rede mais bem conectada (com menor caminho mínimo médio e maior eficiência). No entanto, é claro que esta ação prejudicaria a acessibilidade das regiões que dispõe apenas desses pequenos aeroportos.

Mais recentemente, Zhao \& Xu (2009) sugeriram um caminho contrário. Em seus estudos, mostraram como aumentar a robustez de uma rede pela adição de novas arestas entre os vértices de baixo grau (aqueles que apresentam poucas conexões). Eles notaram que graças ao ciclo formado entre esses vértices, a rede mantém o seu funcionamento mesmo após a falha de um nó de alto grau (denominado de nó hub).

No contexto da rede de transporte aéreo, isso significaria a elaboração de uma estratégia para a oferta de rotas entre pequenos e médios aeroportos, podendo incluir a formação de aeroportos $h u b s$, de âmbito regional, contribuindo para a viabilidade econômica da operação. Esses aeroportos hubs regionais seriam caracterizados por parâmetros estruturais e funcionais de menor escala em comparação aos parâmetros dos aeroportos hubs de âmbito nacional ou internacional.

Sobre esse processo de expansão da rede de transporte, é importante destacar que desde a conclusão da desregulamentação econômica da aviação civil brasileira, em que se tornou vigente a liberdade de oferta e de tarifas dos serviços aéreos, o planejamento de rotas para compor a malha aérea das empresas ficou restrito aos fatores econômicos e operacionais levados em consideração pelas próprias empresas.

No entanto, pesquisas recentes já discutem a importância do papel que as instituições públicas responsáveis pela definição de políticas e de regulação da aviação civil podem exercer no 
âmbito do planejamento da rede de transporte aéreo. Ao investigar essa questão, Queiroz (2014) elaborou uma proposta metodológica para orientar e fundamentar os programas governamentais de incentivo à prestação de serviços aéreos, de maneira que promova o aumento da acessibilidade, através do crescimento da rede de transporte aéreo.

\subsection{TÓPICOS CONCLUSIVOS}

As empresas aéreas estruturam a sua rede de voos de forma a maximizar a eficiência econômica e operacional, resultando em malhas aéreas que se situam entre dois modelos básicos de rede: point-to-point e hub-and-spoke. Foram discutidos os elementos presentes em diversos estudos que buscaram investigar e entender melhor a vulnerabilidade resultantes dessas configurações, em especial aqueles que fizeram uso da teoria de redes complexas.

Pode-se observar que as aplicações se assemelham no sentido de usarem uma mesma base teórica para modelagem e análise das redes de transporte aéreo. No entanto, as decisões do pesquisador acerca das características, medições e indicadores a serem empregados, levam a resultados que, por vezes, não permitem uma avaliação comparativa. Assim, no próximo capítulo será proposta uma arquitetura geral padronizada para efetuar o processo de análise de vulnerabilidade de redes de transporte aéreo. 


\section{MÉTODO DE ANÁLISE DE VULNERABILIDADE DE REDES DE TRANSPORTE AÉREO}

\subsection{APRESENTAÇÃO}

A proposição do método para análise de vulnerabilidade de uma rede de transporte aéreo tem como principais objetivos a descrição topológica inicial da rede, a identificação da importância e criticidade dos aeroportos e a avaliação do grau de vulnerabilidade da própria rede. O método proposto permite gerar informações básicas sobre os elementos críticos da malha aérea, fornecendo parâmetros que podem ser inseridos no processo de gerenciamento de risco promovido por órgãos reguladores e empresas operadoras do sistema.

O presente capítulo apresenta, inicialmente, as considerações que foram adotadas para o desenvolvimento do método. Em seguida, é exposta a proposta geral do método, as etapas integrantes e as informações necessárias para aplicá-lo.

\subsection{CONSIDERAÇÕES SOBRE O MÉTODO}

A vulnerabilidade de sistemas em rede tem sido analisada sob diferentes abordagens metodológicas. Neste contexto, Murray et al. (2008) recomendam uma abordagem integrada, dado a riqueza de informações que poderia ser produzido no processo de análise.

O ferramental teórico e técnico da ciência das redes complexas tem se mostrado útil para essa integração, pois possibilita o emprego de uma modelagem com fundamentos matemáticos, associada a diferentes estratégias de simulação de cenários ou níveis de perturbação do sistema, além de fornecer indicadores representativos da performance do sistema (HOSSAIN et al., 2013).

Dessa forma, o método formulado oferece a conjugação de três abordagens metodológicas, dentre as definidas por Murray et al. (2008). As avaliações baseadas em simulação e em estratégias específicas são empregadas para a formação dos cenários de impacto considerados. A avaliação baseada em modelagem matemática também é empregada através da aplicação de métricas e indicadores provenientes da teoria de redes complexas.

O método proposto não pretende considerar e avaliar impactos de dimensão econômica ou que estejam relacionados ao gerenciamento operacional, isto é, ao controle de tráfego aéreo ou à operação aeroportuária, em decorrência de um cenário e período específicos de interrupção de 
um aeroporto. Sabe-se que a interrupção temporária de um aeroporto gera um prejuízo econômico e enseja a aplicação de diversos procedimentos operacionais, tais como: a interrupção de pousos e decolagens; o remanejamento de aeronaves em voo; o atendimento prolongado de aeronaves em solo; o remanejamento de passageiros e carga; dentre outras ações necessárias para minimizar as consequências e retornar à situação normal de funcionamento. Esses elementos, portanto, não estão sendo considerados no método formulado nesta dissertação. Para maiores detalhes sobre esse tipo de avaliação de cenário específico, podem ser vistos os estudos de Janic (2005) e Pejovik (2009).

\subsection{ESTRUTURAÇÃO DO MÉTODO}

O método foi desenvolvido a partir da abordagem da teoria de redes complexas aplicada na modelagem de redes de transporte aéreo, sendo composto por seis etapas, cada uma com suas respectivas entregas principais:

- Etapa I: Caracterização do sistema de transporte aéreo

- Etapa II: Processo de modelagem da rede de transporte aéreo (RTAer)

- Etapa III: Análise topológica da RTAer

- Etapa IV: Simulação de ataque sequencial à RTAer

○ Etapa V: Simulação de interrupção individual de aeroportos

○ Etapa VI: Análise dos resultados e conclusões finais

Visando atender aos objetivos propostos nesta pesquisa, a Figura 5.1 apresenta o diagrama das seis etapas que compõem a estruturação geral do método.

\subsubsection{ETAPA I: CARACTERIZAÇÃO DO SISTEMA DE TRANSPORTE AÉREO}

Um passo fundamental para efetuar uma análise de vulnerabilidade de um sistema está na descrição das características gerais do objeto a ser analisado, incluindo, dentre outros elementos julgados relevantes, seus aspectos institucionais, econômicos e operacionais (PIPICANO, 2014). Este passo, de caráter qualitativo, esteve relativamente ausente nos primeiros estudos elaborados com o objetivo de analisar a vulnerabilidade de redes de aeroportos, que restaram por focar em aspectos mais quantitativos ou metodológicos, conforme apontado por Lordan et $a l .,(2014 a)$. 


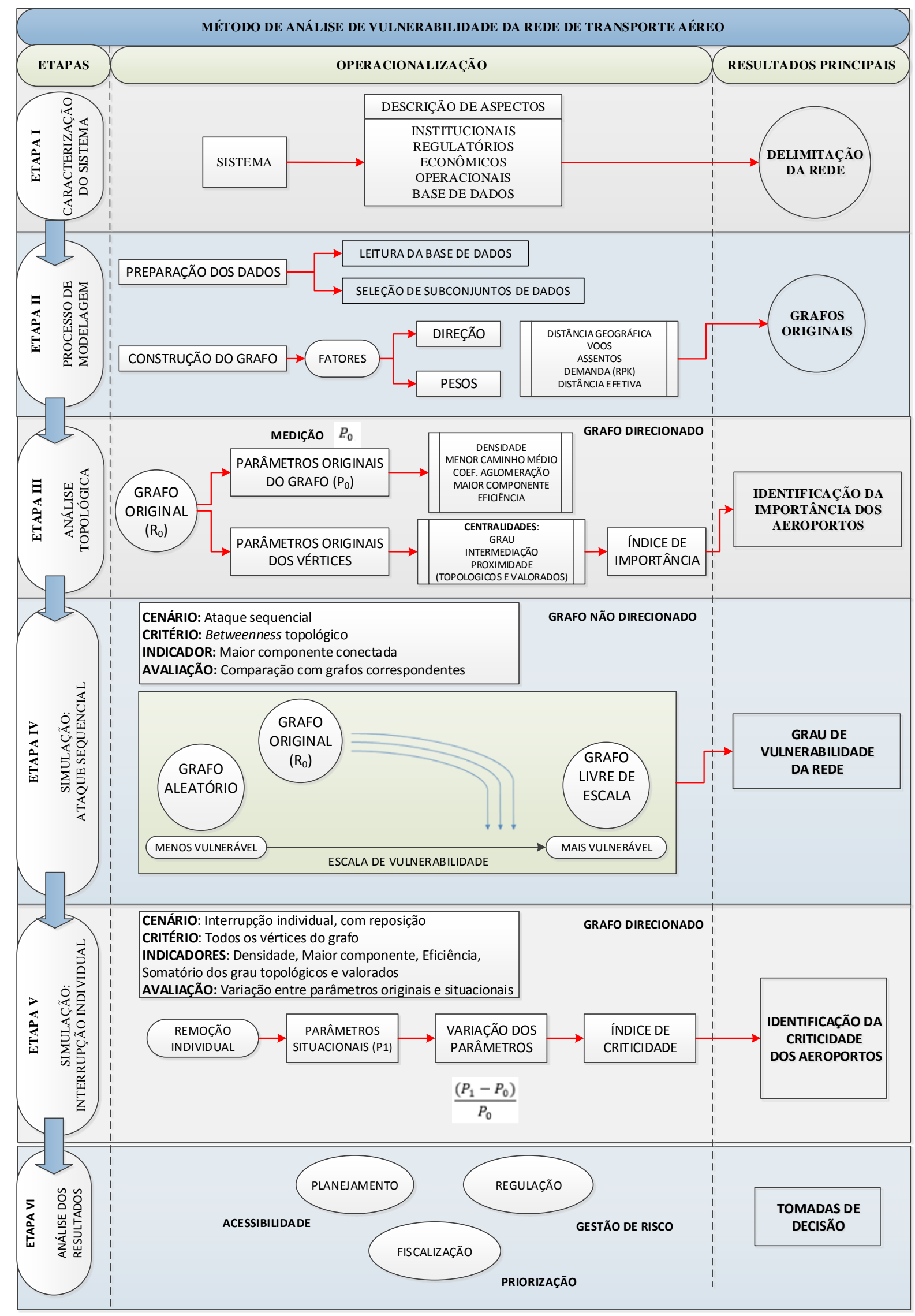

Figura 5.1. Estrutura geral do método (Fonte: elaborado pelo autor). 
Esta etapa também incluirá uma descrição explicativa da base de dados utilizada na análise, além das especificações dos aeroportos e voos que comporão a rede de transporte aéreo a ser investigada. Essas especificações incluem os aeroportos de origem e destino dos voos, o período de coleta dos dados, a natureza e tipo de voos (doméstico ou internacional e regular ou não regular), objetos de transporte (passageiros ou carga) e o grupo de empresas aéreas a serem incluídas na análise.

Após esses procedimentos, o resultado principal deverá ser uma definição clara do escopo de aplicação do método, através da delimitação da rede de transporte aéreo que será considerado o objeto a ser investigado.

\subsubsection{ETAPA II: PROCESSO DE MODELAGEM DA REDE DE TRANSPORTE AÉREO}

A modelagem é iniciada através da abstração da RTAer como um conjunto de vértices interligados por arestas, sendo representada um grafo. Os vértices representam os aeroportos e as arestas representam a presença de voos que ligam um par de aeroportos. Essa simples abstração já nos permite extrair a visualização e um entendimento básico da estrutura topológica da RTAer.

Continua-se o processo de modelagem por meio da agregação de outras informações capazes de representar a realidade operacional de maneira mais fiel. Assim, atribui-se pesos às arestas do grafo utilizando quatro características inerentes às redes de transporte aéreo, conforme Quadro 5.1: a distribuição espacial dos aeroportos por meio da distância geográfica; o tráfego de aeronaves entre os aeroportos representada pelo número de voos; a oferta de serviços aéreos refletida em termos de número de assentos disponíveis em cada rota e a demanda por transporte aéreo medida em termos de passageiro quilômetro pago transportado (RPK - Revenue Passenger Kilometer).

Quadro 5.1. Elementos de valoração nos grafos com pesos.

\begin{tabular}{lll}
\hline \multicolumn{2}{c}{ Caracterís ticas da RTAer } & \multicolumn{1}{c}{ Variável } \\
\hline 1 & Distribuição espacial & Distância geográfica (quilômetros) \\
2 & Tráfego de aeronaves & Número de voos \\
3 & Oferta de serviços aéreos & Número de assentos disponíveis \\
4 & Demanda por transporte aéreo & Passageiro quilômetro pago transportado (RPK) \\
\hline
\end{tabular}


Neste ponto, vale destacar que as arestas do grafo podem ser valoradas de acordo com a característica ou o atributo mais adequado para medir o parâmetro de interesse da rede ou dos seus componentes.

Como mostrado no Quadro 4.2 do Capítulo 4, as pesquisas anteriores fizeram uso de variáveis como o número de voos, de assentos ou de oferta de transporte aéreo (ASK - Available Seats Kilometer) como formas de representação da intensidade de tráfego na rede. Dentre essas variáveis, a medida de oferta (ASK) pode ser considerada a mais abrangente, pois considera os fatores da distância geográfica e da quantidade de assentos disponíveis numa determinada rota.

No entanto, além desses dois fatores já estarem sendo considerados isoladamente, a medida de ASK não reflete o que de fato é demandado da rede pelos usuários. Essa demanda por transporte aéreo é representada pela medida de RPK e, assim, pode ser mais apropriada para reconhecer a intensidade ou força das ligações entre pares de aeroportos.

Por fim, efetua-se a combinação dos atributos da distribuição espacial e da oferta de serviços aéreos para a construção de um terceiro atributo, denominado de "distância efetiva". Como apresentado no Capítulo 3, Dall'Asta et al., (2006) propuseram e empregaram o atributo da "distância efetiva" para calcular apenas o grau de intermediação valorado da rede de transporte aéreo mundial.

O método formulado nesta dissertação se propõe a ampliar a aplicabilidade desse atributo, empregando-o para a determinação qualquer parâmetro de rede que precise reconhecer o menor caminho entre um par de vértices.

O Quadro 5.2 resume as características operacionais consideradas no cálculo de parâmetros valorados para uma rede com pesos. Uma vantagem da utilização dessas características operacionais é que deve permitir capturar mais elementos da realidade operacional no processo de modelagem e simulação, trazendo resultados mais fiéis ao comportamento da rede. Por outro lado, parece haver a desvantagem de se perder a significação intuitiva ou física dos valores dos parâmetros.

Percorrido o processo de modelagem, é possível obter os grafos originais que representação a situação inicial da rede de transporte aéreo. 
Quadro 5.2. Característica operacional considerada na medição dos parâmetros.

\begin{tabular}{lc}
\hline Parâmetro (medida) valorado & $\begin{array}{c}\text { Característica operacional } \\
\text { (atributo) }\end{array}$ \\
\hline Centralidade de grau & $\begin{array}{c}\text { Distância geográfica } \\
\text { Voos }\end{array}$ \\
Centralidade de proximidade & Assentos \\
Centralidade de intermediação & Ristância efetiva \\
Menor caminho médio & Distância efetiva \\
Coeficiente de aglomeração global & Distância efetiva \\
Eficiência global & RPK \\
\hline
\end{tabular}

\subsubsection{ETAPA III: ANÁLISE TOPOLÓGICA DA REDE}

Lordan et al., (2014a) consideram que o estudo da vulnerabilidade de uma rede deve ser precedido de uma análise descritiva da sua topologia. A visualização gráfica da rede é um ponto de partida para esta análise, mas a caracterização estrutural e funcional é formalmente dada pela medição das propriedades originais da rede, tais como, o grau médio, o diâmetro, o menor caminho médio, a maior componente conectada, o coeficiente de aglomeração e a eficiência.

Os parâmetros dos vértices também fornecem informações acerca da topologia da rede, especialmente pela maneira como os valores dessas medidas se distribuem ao longo da rede. Serão considerados três principais medidas associadas à centralidade do vértice, medidos tanto sob o enfoque topológico quanto funcional da rede (modelo de grafo com pesos): o grau (degree), a proximidade (closeness) e a intermediação (betweenness).

A partir das medições dos parâmetros dos vértices, é possível ordenar os aeroportos segundo os valores encontrados, mas essa classificação pode variar de acordo com o parâmetro. O grau topológico, por exemplo, irá destacar os aeroportos com maior número de conexões (arestas), já o grau valorado pelas distâncias deverá considerar mais importante aquele aeroporto que proporcione ligações a pontos/regiões mais distantes.

Uma classificação final pode ser alcançada através de um indicador de importância do nó $i$ $\left(I_{I M P i}\right)$ que sintetize as informações das três métricas consideradas. $\mathrm{O}$ indicador pode ser 
formulado através da padronização das variáveis pelo método do escore $Z^{6}$, seguido pelo somatório dos valores para um determinado vértice, conforme mostrado na Equação 19:

$$
I_{I M P i}=\sum_{\text {par }} \text { parâmetro padronizado do vértice } i
$$

A descrição estrutural (topológica) da rede e a identificação da importância dos aeroportos, sob o ponto de vista de suas próprias características, são os resultados principais do estágio de análise topológica.

\subsubsection{ETAPA IV: SIMULAÇÃO DE ATAQUE SEQUENCIAL}

A quarta etapa abrange o processo de simulação de cenários de ataques à rede de transporte aéreo, causando a interrupção de aeroportos em sequência. Este tipo de cenário, conforme apontado na seção 4.5 e na Figura 4.3, foi explorado por Dall'Asta et al., (2006) e Lordan et al., (2014b) e ambos identificaram que o grau de intermediação dos vértices do grafo foi o critério de seleção de aeroportos mais eficaz para causar danos à rede, quando esse dano era associado ao decréscimo na componente conectada.

Assim, para efeitos práticos e de forma a simplificar a simulação, apenas esse critério de importância de aeroportos é considerado nesta etapa. Como indicador de impacto à rede, é utilizado a métrica da maior componente conectada, também considerada nos trabalhos citados.

A Figura 5.2 busca ilustrar como ocorrerá o procedimento de remoção sequencial dos vértices. Parte-se do grafo original e, a cada passo da simulação, elimina-se as conexões de um determinado vértice, selecionado pelo critério do grau de intermediação, e mede-se o tamanho da maior componente conectada restante. Os passos se seguem até a ausência total de conexões e o isolamento dos seus vértices, situação que configura a desintegração do grafo.

Sabe-se que em cenários de ataque à uma rede, os grafos aleatórios se mostram menos vulneráveis, enquanto que os grafos do tipo livre de escala (scale-free) caracterizam-se por uma alta vulnerabilidade (LEWIS, 2009). Assim, considerando a característica antagônica desses dois tipos de grafos teóricos, propõe-se avaliar o grau de vulnerabilidade da rede real original através da comparação entre o comportamento dessa rede real no cenário de ataque sequencial e os comportamentos demonstrados por grafos aleatórios e livres de escala correspondentes.

\footnotetext{
${ }^{6} \mathrm{O}$ escore $\mathrm{Z}$ corresponde à diferença entre um valor observado e a média aritmética das observações, dividida pelo desvio-padrão da amostra de dados (LEVINE, 2008)
} 

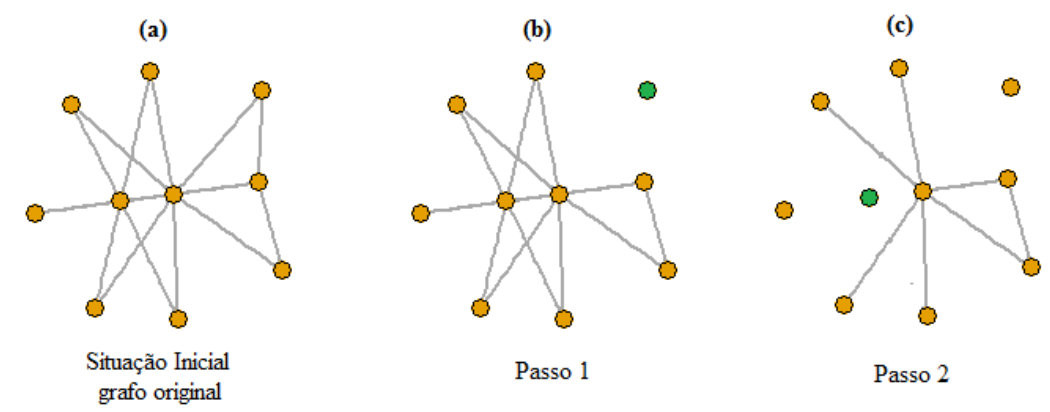

Figura 5.2. Ilustração do procedimento de remoção sequencial dos vértices.

Os grafos correspondentes serão gerados a partir de dois parâmetros originais da rede de transporte aéreo: número de vértices e número de arestas, ou seja, os grafos terão mecanismo de formação próprio, mas apresentarão densidade igual ou muito similar à rede real.

O comportamento ou o grau de vulnerabilidade das redes diante do cenário proposto será identificado por meio da curva gerada num gráfico que mostra a relação entre a proporção de aeroportos removidos e a maior componente conectada ainda restante na rede. Neste ponto, levanta-se a hipótese de que a curva da rede real ficará numa situação intermediária entre as curvas do grafo aleatório e do grafo livre de escala.

De forma complementar, o poder de dominância do ponto central $\left(C_{D}\right)$ de cada rede real original será medido e, então, seus resultados serão compatibilizados com aqueles demonstrados pelas curvas de impacto da componente conectada.

Por fim, é importante destacar que essa etapa do método busca avaliar tão somente o grau de vulnerabilidade das redes, baseando-se parcialmente na metodologia de análise de vulnerabilidade proposta por Lordan et al., (2014b).

Na proposição original dos autores, além da curva decrescente da componente conectada, em função dos aeroportos removidos, a metodologia prevê a identificação dos aeroportos críticos da rede. No entanto, essa identificação pode não refletir totalmente a realidade das infraestruturas críticas numa rede de transporte aéreo, principalmente devido a dois motivos. Primeiro, a criticidade de uma infraestrutura está associada ao potencial de impacto que a sua interrupção individual pode gerar ao sistema (BRASIL, 2010; YUSTA et al., 2011). Assim, a estratégia de remoção sequencial de vértices não reflete esse tipo cenário. Segundo, o monitoramento do impacto ocorre apenas pela maior componente conectada, deixando de lado outros parâmetros de rede que, também, sofrerão queda em seus valores. 
Assim, a próxima etapa do método deverá fornecer uma operacionalização mais adequada para o processo de identificação dos aeroportos críticos.

\subsubsection{ETAPA V: SIMULAÇÃO DE INTERRUPÇÃO INDIVIDUAL}

A quinta etapa abrange o processo de simulação do cenário de interrupção de um único aeroporto. Note que neste caso, as causas da interrupção não são relevantes. O que importa é o cenário de fechamento temporário das operações no aeroporto e os impactos gerados à rede.

Essa estratégia de remoção dos vértices, com reposição, permitirá a medição de parâmetros situacionais $\left(P_{1}, P_{2}, P_{3}\right.$, etc) e suas respectivas variações em relação aos parâmetros originais da rede $\left(\left(P_{1}-P_{0}\right) / P_{0}\right)$. Por parâmetros situacionais, entende-se o conjunto de medições de parâmetros do grafo na condição da rede perturbada (isto é, determinado nó removido).

A Figura 5.3 busca ilustrar como ocorrerá o procedimento de remoção de vértices, com reposição. Parte-se do grafo original, onde é medido todos os parâmetros de grafo considerados. A cada passo da simulação, elimina-se as conexões de um determinado vértice e mede-se os parâmetros do grafo correspondentes àquela situação específica. No passo seguinte, o vértice anteriormente removido é recolocado no grafo, juntamente com suas conexões originais, e um outro vértice é removido. Os passos se seguem até cada um dos vértices pertencentes ao grafo terem sido removidos uma vez.

(a)

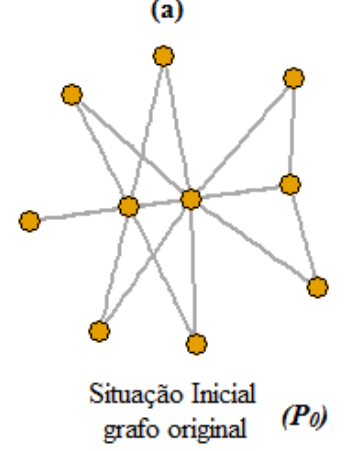

(b)

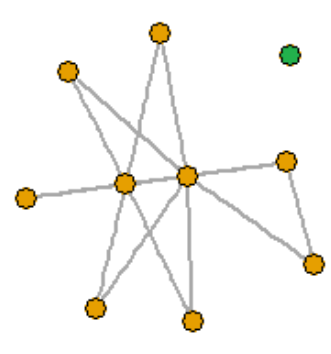

Passo $1 \quad\left(\boldsymbol{P}_{2}\right)$ (c)

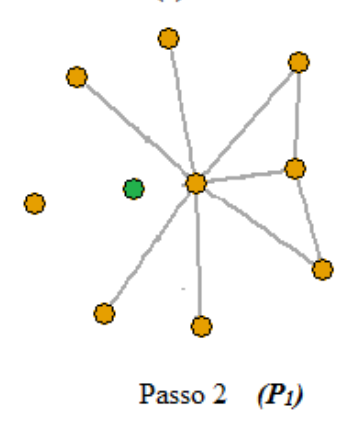

Figura 5.3. Procedimento de remoção dos vértices, com reposição.

A sistemática de simulação proposta nesta etapa (remoção de vértices com reposição) se diferencia da estratégia utilizada na pesquisas de Dall'Asta et al., (2006) e Lordan et al., (2014b), que empregaram a estratégia de remoção sequencial, mas apresenta similaridades com os métodos aplicados por Latora \& Marchiori (2005) e Hossain et al., (2013), que empregaram a estratégia de remoção com reposição. 
Nesta etapa, serão considerados oito parâmetros globais do grafo (originais e situacionais). A densidade, a maior componente conectada e a eficiência global são as três primeiras medidas básicas, também tratadas no estágio da análise topológica. As outras cinco medidas resultam do somatório dos valores de graus topológicos (conectividade) e dos graus valorados pelas distâncias, voos, assentos e RPK, que estão associados às características globais da rede no que se refere à acessibilidade (capacidade de acesso geográfico), ao tráfego de aeronaves, à oferta de serviços aéreos e à demanda por transporte aéreo, respectivamente.

A variação relativa entre um parâmetro original e um parâmetro situacional (para um determinado nó removido) indica o impacto causado no desempenho da rede, segundo aquele parâmetro. Para um mesmo aeroporto, o impacto causado à rede, devido a sua retirada, pode se diferenciar de acordo com o parâmetro de rede considerado.

Partindo do conceito de infraestrutura crítica, a identificação da criticidade de um elemento se dá através da avaliação das consequências negativas provocadas por uma eventual interrupção desse único elemento. Assim, a sintetização das diferentes variações dos parâmetros num indicador de impacto é útil para uma avaliação final da criticidade do aeroporto.

O indicador pode ser formulado através da padronização das variáveis pelo método do escore Z, seguido pelo somatório dos valores das variações associadas a um determinado vértice, conforme mostrado na Equação 20.

$$
I_{C R T i}=\sum_{\text {par }} \text { variação padronizada do parâmetro de rede }
$$

Esse processo de simulação fornecerá uma dimensão de impactos estruturais e funcionais à rede de transporte aéreo e permitirá a ordenação dos aeroportos em função do nível de variação negativa provocado nos parâmetros originais da rede.

Será possível, também, analisar a compatibilidade do indicador de criticidade com os resultados do indicador de importância dos aeroportos, identificados na Etapa III do método. Por fim, os aeroportos críticos identificados nesta quinta etapa poderão ser comparados com o conjunto preliminar de aeroportos críticos obtidos pelo método proposto por Lordan et al., (2014b).

\subsubsection{ETAPA VI: ANÁLISE DOS RESULTADOS}

Este último estágio do método objetiva realizar as análises finais dos resultados obtidos com a consecução das etapas anteriores do método e que podem servir de base de informação para 
melhorar a tomada de decisão nos processos de planejamento de políticas públicas, de investimentos no sistema aeroportuário, de atuação regulatória e de procedimentos operacionais.

\subsection{TÓPICOS CONCLUSIVOS}

Neste capítulo foi apresentada a estruturação do método por meio do delineamento dos processos, das formas de operacionalização e da descrição dos principais resultados associados a cada etapa. Basicamente, o método inclui a seguintes processos: (1) caracterização do sistema de transporte aéreo a ser analisado; (2) modelagem da rede de transporte aéreo; (3) análise topológica da rede; (4) simulação de cenários de interrupção operacional de aeroportos de rede e (5) análise dos resultados obtidos.

Após a definição da estrutura e funcionamento do método, é possível passar para a próxima fase da metodologia da dissertação que se refere à aplicação do método proposto para a análise da vulnerabilidade rede de transporte aéreo brasileira. 


\section{APLICAÇÃO DO MÉTODO NA MALHA AÉREA BRASILEIRA}

\subsection{APRESENTAÇÃO}

Para atingir os objetivos dessa dissertação, que inclui a validação do método de análise de vulnerabilidade proposto, procedeu-se a aplicação do método nas redes que formam a malha aérea brasileira, constituída de voos de passageiros domésticos e internacionais, com origem ou destino nos aeroportos brasileiros, sendo operados por empresas nacionais e estrangeiras.

A oferta e demanda do transporte aéreo público no Brasil cresceu significativamente nos últimos 15 anos. O aumento das operações pressionou as infraestruturas aeroportuárias existentes e forçou as organizações competentes a iniciarem novas políticas e ações no sentido de disponibilizar maior capacidade de processamento de voos e de melhorar a gestão aeroportuária. Neste contexto, a análise de vulnerabilidade da malha aérea brasileira gera informações que contribuirão no planejamento do papel a ser exercido pelas organizações públicas e privadas para garantir a qualidade dos serviços aéreos, especialmente no âmbito dos processos de gestão de riscos do setor.

Assim, o presente capítulo apresenta uma visão geral do sistema de transporte aéreo brasileiro e descreve a execução das etapas que contemplam o método proposto no capítulo anterior.

\subsection{SUPORTE COMPUTACIONAL}

\subsubsection{COLETA E MANIPULAÇÃO DOS DADOS}

O ambiente R (R CORE TEAM, 2015), versão 3.2.2, foi utilizado para tratamento, modelagem e simulação dos dados. O software R é, primordialmente, um aplicativo destinado à computação estatística e exibição gráfica, mas também é uma linguagem de programação (R CORE TEAM, 2015). A linguagem R é considerada um dialeto da linguagem $S$, projetada na década de 80 , e tem sido amplamente utilizada não só na comunidade estatística como em diversos outros campos do conhecimento.

Além de ser um aplicativo gratuito, um importante benefício do R é sua capacidade em permitir a reprodutibilidade de uma pesquisa (GANDRUD, 2014). O conceito de pesquisa reprodutível em $\mathrm{R}$ está relacionado à facilidade de transferência dos dados e do código de análise em $\mathrm{R}$ para uma pessoa interessada no estudo, permitindo que essa pessoa possa avaliar e reproduzir os 
resultados da pesquisa. Outra vantagem da elaboração de uma pesquisa reprodutível é a facilidade com que as análises podem ser refeitas quando se dispõe de uma nova base de dados. Isso é especialmente interessante quando a leitura dos dados é realizada a partir de uma base de dados online.

Para as finalidades de aplicação do método de análise de vulnerabilidade, essa ferramenta possibilita a criação do modelo de rede, a medição dos parâmetros de interesse, suas variações em decorrência da simulação de interrupção de um aeroporto e a estimação do grau de vulnerabilidade de determinada configuração de rede. A implementação de análise de modelos de redes complexas no $\mathrm{R}$ foi feita, principalmente, por meio de funções disponíveis no pacote denominado igraph. Informações mais detalhadas sobre o uso e aplicações desse pacote podem ser obtidas no manual do pacote igraph e em Kolaczyk \& Csárdi (2014).

\subsubsection{IMPLEMENTAÇÃO}

A seguir, no Quadro 6.1, são apresentados os principais códigos produzidos para a implementação do método de análise de vulnerabilidade e suas respectivas finalidades. Os códigos foram escritos e rodados no RStudio, que é um ambiente aberto e gratuito de desenvolvimento integrado para o aplicativo $\mathrm{R}$.

Quadro 6.1. Códigos produzidos no R para implementação do método.

\begin{tabular}{|c|c|c|}
\hline Códigos & Objetivos & Etapas do método \\
\hline airGraph.R & $\begin{array}{l}\text { Leitura da base de dados, preparação e seleção de } \\
\text { subconjuntos de dados e construção do grafo }\end{array}$ & Etapa II - Modelagem \\
\hline graphMetrics. $R$ & Cálculo dos parâmetros do grafo & \multirow{4}{*}{$\begin{array}{l}\text { Etapa III - Análise } \\
\text { Topológica }\end{array}$} \\
\hline nodeMetrics. $R$ & Cálculo dos parâmetros dos vértices & \\
\hline graphEfficiency.R & Cálculo da eficiência global & \\
\hline importanceIndex. $R$ & Cálculo do índice de importância dos vértices & \\
\hline seqRemoval.R & $\begin{array}{l}\text { Remoção sequencial dos vértices e monitoramento } \\
\text { da maior componente conectada }\end{array}$ & \multirow{3}{*}{$\begin{array}{l}\text { Etapa IV - } \\
\text { Simulação/Ataque } \\
\text { sequencial }\end{array}$} \\
\hline gnmSeqRemoval.R & $\begin{array}{l}\text { Geração de grafo aleatório correspondente e } \\
\text { remoção sequencial dos vértices }\end{array}$ & \\
\hline gbaSeqRemoval.R & $\begin{array}{l}\text { Geração de grafo livre de escala correspondente e } \\
\text { remoção sequencial dos vértices }\end{array}$ & \\
\hline criticalAirport. $R$ & $\begin{array}{l}\text { Remoção individual e com reposição dos vértices e } \\
\text { monitoramento dos parâmetros de grafo de } \\
\text { interesse }\end{array}$ & \multirow[t]{2}{*}{$\begin{array}{l}\text { Etapa V - } \\
\text { Simulação/Interrupção } \\
\text { individual }\end{array}$} \\
\hline criticalityIndex.R & Cálculo do índice de criticidade dos vértices & \\
\hline
\end{tabular}

Os códigos desenvolvidos para a aplicação do método, juntamente com a base de dados utilizada, estão armazenados num repositório disponibilizado pela página eletrônica 
bitbucket.org, na rede mundial de computadores. No APÊNDICE A - Principais códigos implementados no $\mathrm{R}$ - estão transcritos alguns desses principais códigos que viabilizaram a condução do estudo de caso.

\subsection{ETAPA I - CARACTERIZAÇÃO DO SISTEMA}

Para proceder a análise de vulnerabilidade é necessário caracterizar o sistema, ao menos sob seus aspectos gerais, de forma que seja possível delimitar a rede de transporte aéreo que será objeto do estudo e, assim, permitir reconhecer o alcance dos resultados e a abrangência das decisões que poderão ser adotadas para melhoria do próprio sistema. No caso desta pesquisa, a aplicação exige uma caracterização básica do sistema de aviação civil brasileiro.

\subsubsection{O SISTEMA DE AVIAÇÃO CIVIL BRASILEIRO}

\subsubsection{PANORAMA HISTÓRICO, INSTITUCIONAL E REGULATÓRIO}

As atividades de aviação civil no Brasil tiveram início em 1927, quando surgiram as primeiras empresas e linhas aéreas regulares (SILVA, 2008). Em 1931, o Governo criou o Departamento de Aeronáutica Civil, posteriormente denominado Departamento de Aviação Civil (DAC), órgão que ficou responsável pelo planejamento, controle e incentivo dessa nova atividade econômica. Em 1972, foi criada a INFRAERO, empresa estatal que ficou responsável pela administração dos aeroportos federais (SILVA, 2008).

Entre a década de 60 e os anos 2000, o setor de transporte aéreo no Brasil passou por duas grandes reformas regulatórias (SALGADO et al., 2010): a introdução da regulação estrita, que definiu a era da "competição controlada", entre o final dos anos 1960 e final da década 1980 e a Política de Flexibilização da Aviação Comercial, inaugurando a era do "livre mercado", introduzida no início da década de 1990. A partir desta segunda fase, diversas medidas foram tomadas no sentido de estimular a entrada de novas empresas, a exploração de novas linhas aéreas e a competição (SALGADO et al., 2010).

Em 2000, no contexto da flexibilização econômica setorial, instituiu-se o Conselho de Aviação Civil (CONAC), composto por um grupo de Ministros de Estado e incumbido de formular a política nacional de aviação civil, dentre outras diretrizes (SILVA, 2008). Em 2001, estabeleceu-se a liberdade tarifária, iniciando um regime de mercado em que as empresas 
poderiam praticar qualquer valor de tarifa, sujeitas apenas ao registro prévio e monitoramento do órgão regulador.

Em 2005, ainda sob os efeitos da reforma da administração pública federal, foi criada Agência Nacional de Aviação Civil (ANAC), uma organização pública independente do poder executivo central. O novo órgão foi instituído nos moldes das primeiras agências reguladoras brasileiras e recebeu a incumbência de, nos termos das políticas estabelecidas pelos Poderes Executivo e Legislativo, regular e fiscalizar as atividades de aviação civil e de infraestrutura aeronáutica e aeroportuária, em substituição às atividades do DAC.

A Lei de Criação da ANAC, instituiu, também, a liberdade de oferta no âmbito do mercado doméstico, permitindo às empresas selecionar as rotas mais convenientes economicamente, observando apenas as restrições de controle de tráfego e de capacidade aeroportuária.

Essas novas características do setor, juntamente com a melhora de outros fatores macroeconômicos, como a estabilização da moeda e o crescimento do PIB, proporcionaram uma dinamização do setor aéreo, levando ao crescimento da oferta e demanda, além da queda do valor médio das tarifas aéreas (BRASIL, 2014).

O crescimento das operações aéreas evidenciou a necessidade de investimentos na modernização e ampliação das infraestruturas aeroportuárias. Assim, buscando garantir tais investimentos, em 2011 o Governo Federal optou por iniciar uma política de concessão de aeroportos federais, dos quais, atualmente, seis já concluíram o processo e estão sob gestão de concessionários privados: aeroportos de São Gonçalo do Amarante/RN (SBSG), de Guarulhos/SP (SBGR), de Viracopos/SP (SBKP), de Brasília/DF (SBBR), do Galeão/RJ (SBGL) e de Confins/MG (SBCF).

Por fim, em linhas gerais, a atividade regulatória da ANAC atua sob o enfoque econômico e técnico (BRASIL, 2009). A regulação econômica tem como objetivo básico o estabelecimento de mecanismos para incentivar a competição saudável da indústria, manter a qualidade dos serviços aéreos prestados e preservar direitos dos usuários do sistema.

A regulação técnica preocupa-se com o desenvolvimento e a manutenção da segurança do transporte aéreo. De um lado, tem-se a regulação da segurança operacional (safety) que busca prevenir acidentes e incidentes aeronáuticos, provocados, em geral, por causas naturais ou não intencionais, como falha de equipamentos ou erro humano. De outro lado, há a regulação da 
segurança contra atos de interferência ilícita (aviation security) que objetiva prevenir a ocorrência de atos intencionais que possam gerar danos ao transporte aéreo, como atos criminosos ou terroristas.

\subsubsection{CENÁRIO MACROECONÔMICO}

Sabe-se que os fatores macroeconômicos impactam o desenvolvimento e a dinâmica de mercado dos serviços de transporte aéreo público (OLIVEIRA, 2009). As pesquisas na área da economia do setor aéreo investigam a evolução de variáveis e indicadores como o Produto Interno Bruto (PIB), o tamanho da população brasileira, a taxa de câmbio e o preço do barril de petróleo para ajudar a entender determinados efeitos percebidos na dinâmica do mercado como, por exemplo, a variação na demanda.

Ao observar o cenário brasileiro, no período de 2004 a 2014, verifica-se que o PIB apresentou um crescimento médio anual de $3,44 \%$, enquanto o crescimento médio populacional foi da ordem de 1\%, como pode ser visto na variação detalhada na Figura 6.1.

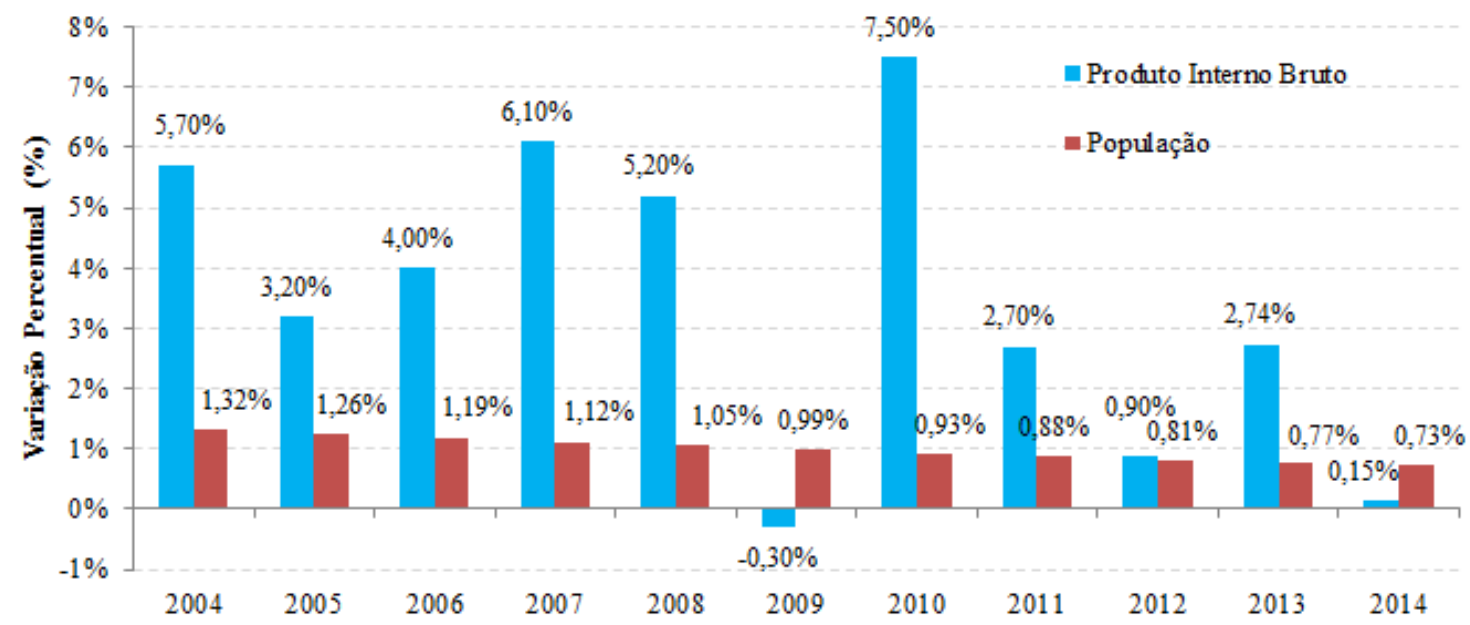

Figura 6.1. Variação anual do PIB brasileiro (Fonte: Brasil, 2014 e Brasil, 2015a).

Nesse mesmo período, a variação da demanda doméstica por transporte aéreo de passageiros aponta um crescimento muito mais significativo, apresentado na Figura 6.2, da ordem de 10\% ao ano. 


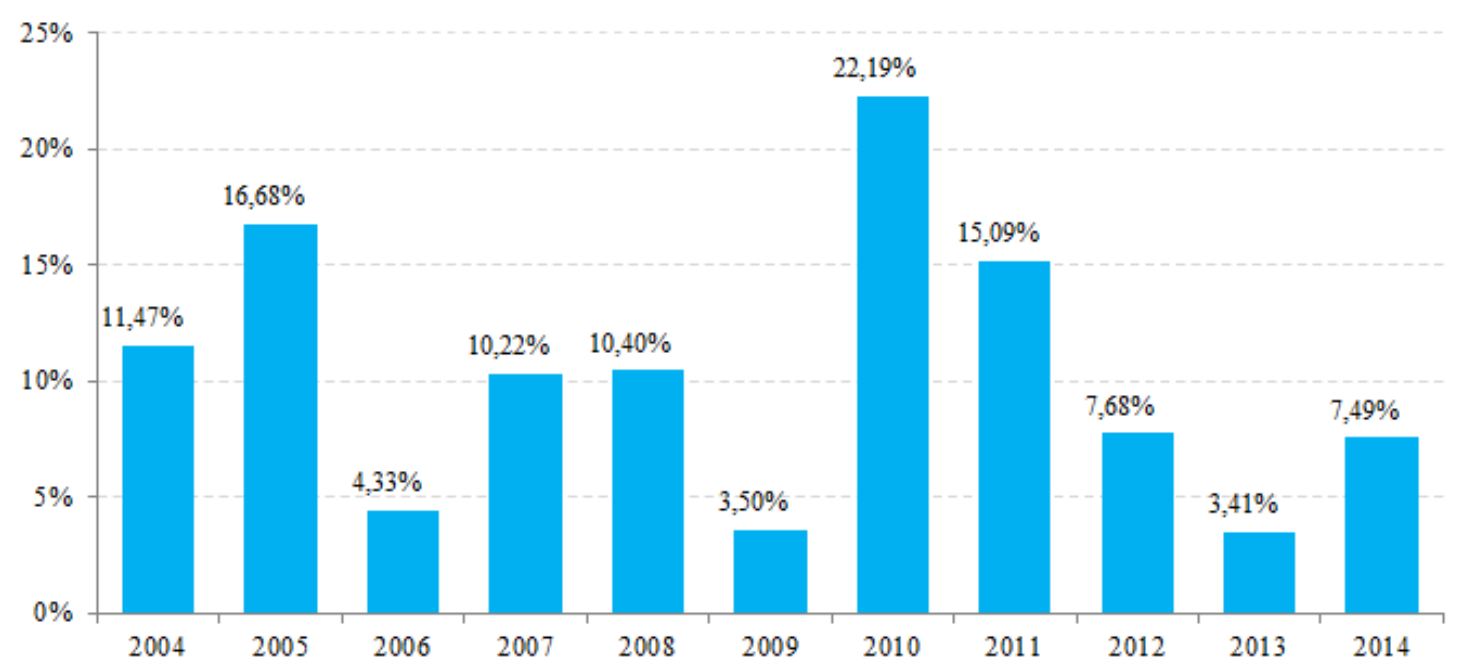

Figura 6.2. Variação anual da demanda por transporte aéreo (RPK), mercado doméstico e internacional (Fonte: Brasil, 2014 e Brasil, 2015a).

Nos últimos 12 anos, o setor de transporte aéreo passou por importantes consolidações regulatórias e institucionais, que promoveram mudanças na sua estrutura de mercado. Junto à liberalização econômica, em 2001, o setor foi impactado pela entrada de um importante player, a empresa aérea GOL, que iniciou a aplicação do modelo low cost low fare, proporcionando a prática de menores tarifas para o serviço de transporte. Em contrapartida, grandes empresas tradicionais, como TRANSBRASIL, VASP e VARIG, foram forçadas a encerrar suas atividades, o que causou uma concentração maior do mercado, essencialmente no período de 2007 a 2009. O duopólio das empresas TAM e GOL vivido nesse período foi se desfazendo nos últimos anos, principalmente devido ao crescimento da participação de mercado da empresa AZUL.

De acordo com o relatório mensal de Demanda e Oferta do Transporte Aéreo, de dezembro de 2014 (BRASIL, 2015b), a indústria produziu neste mês quase 11 milhões de assento quilômetro oferecido (Available Seats Kilometers - ASK) no mercado de transporte aéreo doméstico. Desse montante, 99,3\% foi devido à contribuição de quatro empresas principais: GOL, TAM, AZUL e AVIANCA. A participação de mercado (em RPK) de cada uma dessas empresas restou dividida conforme mostrado na Figura 6.3. 


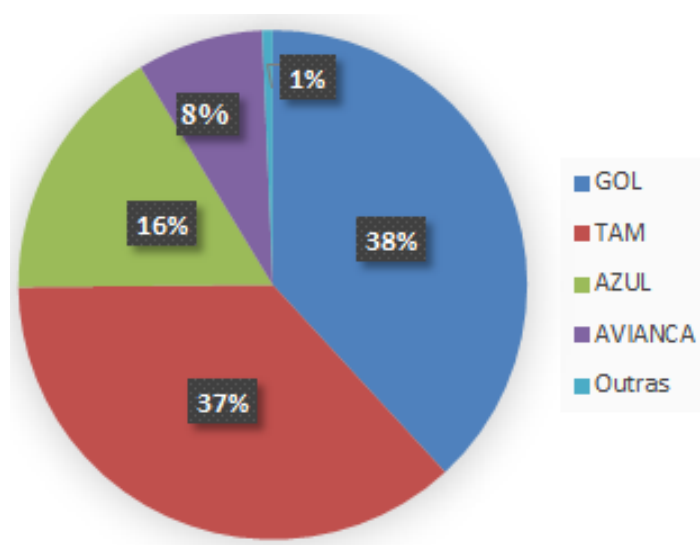

Figura 6.3. Participação no mercado doméstico, em RPK, das principais empresas aéreas brasileiras (Fonte: Brasil, 2015b).

\subsubsection{INFRAESTRUTURA AEROPORTUÁRIA}

No âmbito do sistema de aviação civil brasileiro, tem-se o denominado sistema aeroportuário, constituído pelo conjunto de aeródromos civis brasileiros, divididos em aeródromos privados e aeródromos públicos (BRASIL, 1986).

De acordo com a base cadastral disponibilizada pela ANAC (BRASIL, 2016a), o Brasil conta com 1.886 aeródromos privados e 654 aeródromos públicos. Dentre esses aeródromos públicos, apenas 108 recebem voos regulares atualmente (BRASIL, 2016b). É nesse conjunto relativamente restrito de aeródromos em que se opera a malha de voos domésticos e internacionais que constituem a rede de transporte aéreo brasileira.

\subsubsection{BASE DE DADOS}

A base de dados utilizada neste estudo advém das informações estatísticas do transporte aéreo do Brasil, disponibilizadas por meio de planilhas anuais, no sítio eletrônico da ANAC (BRASIL, 2015c). Os dados são gerados pelos operadores aéreos nacionais e estrangeiros, que prestam serviço de transporte aéreo público regular e não regular, exceto as empresas de táxi aéreo. O fornecimento dos dados ao órgão regulador é regulamentado pela Resolução $\mathrm{n}^{\circ}$ 191/2011 e pelas Portarias $n^{\circ} 1.189$ e 1.190/SRE/2011, que estabelecem o envio mensal dos dados à ANAC pelas empresas aéreas.

As empresas aéreas, nacionais ou estrangeiras, enviam informações associadas à etapa básica e à etapa combinada de seus voos. De acordo com a metodologia utilizada pela regulamentação e as orientações disponibilizadas pela Agência, a etapa básica do voo é "aquela realizada pela aeronave desde a sua decolagem até o próximo pouso, independentemente de onde tenha sido 
realizado o embarque ou o desembarque do objeto de transporte (passageiro elou cargas). Os dados estatísticos das etapas básicas representam o status da aeronave em cada etapa do voo, apresentando a movimentação de cargas e passageiros entre os aeródromos de origem e destino da aeronave. É a operação de uma aeronave entre uma decolagem e o próximo pouso, ou seja, é a ligação direta entre dois aeródromos" (BRASIL, 2015d).

Por outro lado, a etapa combinada do voo é "aquela que identifica os pares de aeródromos de origem, onde houve o embarque do objeto de transporte, e destino, onde houve o desembarque do objeto de transporte, independentemente da existência de aeródromos intermediários, atendidos por determinado voo. É a etapa de voo vista com foco no objeto de transporte (pessoas elou cargas), com base no embarque e desembarque nos aeródromos relacionados. Os dados estatísticos da etapa combinada informam a origem e destino no voo, dos passageiros e cargas transportadas, independente das suas escalas" (BRASIL, 2015d).

Para assimilar melhor esses conceitos, a Figura 6.4 a seguir traz a representação de um voo fictício que liga três pontos (A, B e C). Os deslocamentos entre A e B e entre B e C constituem as etapas básicas (voos diretos), enquanto que o deslocamento entre A e C constitui uma etapa combinada, ou seja, não há voo direto entre A e C, mas é possível deslocar-se entre esses dois pontos realizando duas etapas básicas. No ponto A, ocorre o embarque de 40 passageiros, sendo 15 deles direcionados para o destino B e os outros 25 se destinam ao ponto C. No ponto B, além do desembarque de 15 passageiros vindos de A, outros 32 passageiros são embarcados com destino ao ponto $\mathrm{C}$.

A base de dados dispõe de informações estatísticas associadas às duas etapas de voo (BRASIL, 2015d), isto é, uma mesma linha da base de dados pode se referir tanto à etapa básica como à etapa combinada. O que determina qual etapa está sendo descrita são as variáveis a serem consideradas.

Para a aplicação deste estudo é necessária apenas as estatísticas associadas à etapa básica do voo, ou seja, aquelas informações que caracterizam a ligação direta entre dois aeródromos, realizada por uma determinada empresa aérea. Neste caso, as variáveis consideradas estão indicadas no Quadro 6.2. 


\begin{tabular}{cccccc}
\hline \multirow{2}{*}{$N^{\mathbf{0}}$ do Voo } & \multirow{2}{*}{ Etapa } & \multirow{2}{*}{ Origem } & \multirow{2}{*}{ Destino } & \multicolumn{2}{c}{ Passageiros } \\
& & & & Embarques & A bordo \\
\hline 1524 & Básica & A & B & 15 & $40(15+25)$ \\
1524 & Combinada & A & C & 25 & \\
1524 & Básica & B & C & 7 & $32(25+7)$ \\
\hline
\end{tabular}

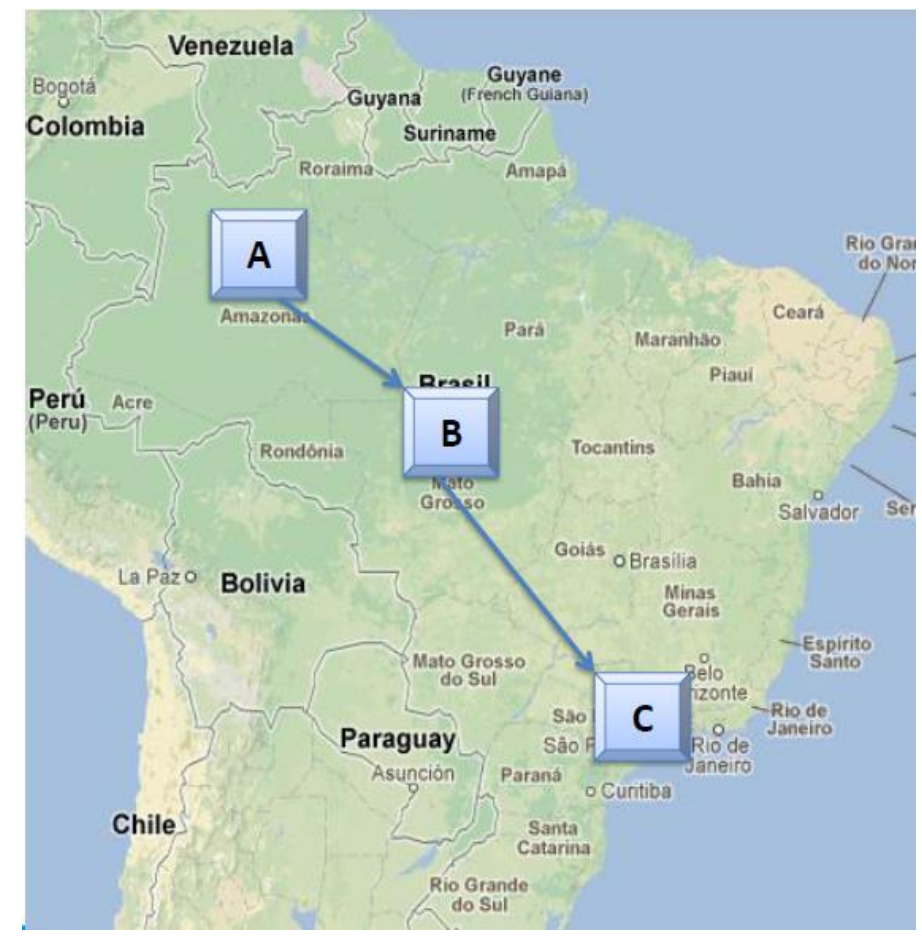

Figura 6.4. Exemplos de etapas básicas e etapa combinada de um voo (Fonte: adaptado de Caixeta e Sakai, 2013).

Considerando as informações referentes à etapa básica, cada linha da planilha eletrônica disponibilizada registra os dados dos voos realizados por uma determinada empresa aérea, entre um determinado par de aeroportos, para uma determinada natureza e grupo de voo, durante todo o período de um mês. Assim, a demanda por oferta de tráfego (RPK), a distância voada, as decolagens realizadas, os assentos disponíveis ou as horas voadas, por exemplo, são resultados dos voos realizados durante um determinado mês. Os dados de voo estão agrupados por mês, ou seja, cada variável numérica da base de dados refere-se a um somatório que representa todas as operações aéreas realizadas no período de um mês.

Quadro 6.2. Variáveis da base de dados utilizadas no estudo.

\begin{tabular}{llll}
\hline Empresa (Sigla) & Aeroporto de origem (Sigla) & Grupo de Voo & Decolagens \\
Ano & Aeroporto de destino (Sigla) & RPK & Assentos \\
Mês & Natureza do Voo & Distância Voada & \\
\hline
\end{tabular}

A variável "natureza do voo" refere-se à natureza das etapas e possui o valor "Doméstico", caso as etapas tenham o pouso e a decolagem realizados no Brasil e sejam operadas por empresas 
brasileiras, ou possuem o valor "Internacional", nos demais casos. A variável "grupo de voo" faz referência ao tipo de operação das etapas, recebendo os seguintes valores: (i) "Improdutivo" para representar etapas que não geraram receita à empresa aérea (como realização de treinamentos, voo para manutenção de aeronaves, etc); (ii) "Regular" para indicar etapas remuneradas, operadas regularmente e sob uma numeração de Horário de Transporte (HOTRAN) e; (iii) "Não Regular" para representar as etapas remuneradas, operadas de forma não continuada e sem contar com uma numeração de HOTRAN. As demais variáveis podem ser interpretadas de forma mais direta, mas a definição exata de cada variável presente no banco de dados pode ser encontrada no sítio eletrônico da ANAC e no Anexo 1 desta dissertação.

Para a aplicação do método, utilizou-se a planilha de dados do ano de 2014, que conta com um total de 46.436 linhas, referentes às etapas de voo, e 37 colunas, referentes às variáveis. Apesar da disponibilização de dados mais recentes, provenientes dos serviços aéreos providos no decorrer de 2015, optou-se por uma amostra do ano anterior, por considerar que houve mais tempo para aplicação de procedimentos de auditoria e validação dos dados pelo órgão regulador. Assim, pode-se dizer que é menor a probabilidade de haver inconsistências na base de dados de 2014. Por fim, o mês de dezembro de 2014 foi selecionado para a aplicação do método, tendo em vista o aumento sazonal da demanda por transporte aéreo nesse período, que é quando o sistema passa por uma prova maior de capacidade de atendimento da demanda. Isso torna mais necessária a garantia da operação adequada do sistema e mais interessante os resultados da análise proposta. A avaliação do grau de vulnerabilidade da rede e a identificação dos aeroportos críticos permitirão um melhor planejamento do papel a ser exercido pelas organizações públicas e privadas para garantir a qualidade dos serviços nesse período do ano.

\subsubsection{DELIMITAÇÃO DAS REDES DE TRANSPORTE AÉREO}

Considerando os recortes que podem ser feitos para definir o escopo de uma rede de transporte aéreo e considerando a disponibilidade de informações na base de dados sobre o transporte aéreo brasileiro, esta pesquisa buscou aplicar o método de análise de vulnerabilidade em 7 (sete) diferentes redes, apresentadas na Tabela 6.1. Para a formação das redes foram considerados apenas voos que processaram passageiros, tanto regulares como não regulares. As três primeiras redes abrangem os voos de todas as empresas em operação, ou seja, a rede doméstica inclui todas as empresas nacionais e a rede internacional inclui todas as empresas nacionais e estrangeiras que operaram no Brasil durante o mês de dezembro de 2014. As quatro últimas 
redes abrangem os voos realizados por uma única empresa brasileira, incluindo as operações domésticas e internacionais realizadas por elas.

A delimitação de diferentes níveis de redes proporciona uma aplicação abrangente do método, gerando resultados específicos que podem fundamentar decisões mais bem direcionadas nas esferas de planejamento, regulação e fiscalização do setor.

Tabela 6.1. Delimitação das redes de transporte aéreo.

\begin{tabular}{lll}
\hline & \multicolumn{1}{c}{ Delimitação das redes } & Denominação recebida \\
\hline 1 & Rede de voos domésticos no Brasil & R_bra_dom \\
2 & Rede de voos internacionais no Brasil & R_bra_int \\
3 & Rede de voos totais (domésticos e internacionais) no Brasil & R_bra_tot \\
4 & Rede de voos totais (domésticos e internacionais) da TAM & R_tam \\
5 & Rede de voos totais (domésticos e internacionais) da GOL & R_glo \\
6 & Rede de voos totais (domésticos e internacionais) da AZUL & R_azu \\
7 & Rede de voos totais (domésticos e internacionais) da AVIANCA & R_one \\
\hline
\end{tabular}

\subsection{ETAPA II - MODELAGEM DA REDE}

\subsubsection{PREPARAÇÃO DA BASE DE DADOS}

Como mencionado, a aplicação limitou-se às estatísticas de transporte aéreo referentes ao mês de dezembro de 2014, composta por 4.134 linhas de etapas de voo. A partir desta base de dados, eliminou-se as informações referente às etapas de voo improdutivas, isto é, aquelas que não geraram receita à empresa aérea. Assim, os grafos formulados representam a rede formada, exclusivamente, por voos regulares e não regulares.

As linhas da base de dados cujo valor da variável "RPK" era zero ou vazio foram eliminadas, de forma a garantir que fossem consideradas apenas as etapas básicas de voos que processaram passageiros. Cabe ressaltar que esse filtro não gera perda de informação às variáveis consideradas neste estudo. A ocorrência de valores zero ou faltantes na coluna da variável RPK é resultado do método escolhido pelo órgão regulador para a disponibilização dos dados, que conjuga etapa básica com etapa combinada de voos ${ }^{7}$.

Após essa delimitação, foi necessário proceder dois filtros na base para eliminar dados faltantes (zero ou vazio) nas variáveis "Distância" e "Decolagens". Nesse caso, os dados faltantes ocorrem somente para etapas de voo realizadas por empresas estrangeiras. Segundo

\footnotetext{
${ }^{7}$ Informação obtida no sítio eletrônico da Agência Nacional de Aviação Civil e confirmada na área técnica do órgão.
} 
informações obtidas com a área técnica da ANAC, as empresas estrangeiras, diferentemente das brasileiras, informam um valor de RPK para as etapas combinadas, conforme procedimento estabelecido pela regulamentação. Esse procedimento acaba produzindo os dados faltantes na coluna de "Distância" e "Decolagens" e, também, acaba gerando um decréscimo nos valores de RPK das etapas básicas que compõem essa etapa combinada. Como o processo de modelagem utiliza apenas dados das etapas básicas, há uma perda relativamente pequena de informação quando se considera os voos internacionais realizados por empresas estrangeiras. A Tabela 6.2 abaixo indica a representatividade dos dados considerados na formação de cada rede, após a realização dos recortes e delimitações mencionados.

Tabela 6.2. Representatividade das amostras da base delimitada e da base final.

\begin{tabular}{|c|c|c|c|c|c|c|c|c|c|}
\hline \multirow{2}{*}{$\begin{array}{l}\text { Malhas aéreas da } \\
\text { RTAer brasileira }\end{array}$} & \multirow{2}{*}{\begin{tabular}{|c|} 
Base primária \\
Linhas \\
\end{tabular}} & \multicolumn{2}{|c|}{ Base secundária $($ RPK > 0) } & \multicolumn{3}{|c|}{ Base delimitada } & \multicolumn{3}{|c|}{ Base final } \\
\hline & & Linhas & $R P K$ & Linhas & $R P K$ & $R P K(\%)$ & Linhas & $R P K$ & $R P K(\%)$ \\
\hline R_bra_dom & 4134 & 2405 & $2,02 \mathrm{E}+10$ & 1905 & $8,87 \mathrm{E}+09$ & $43,9 \%$ & 1905 & $8,87 \mathrm{E}+09$ & $100 \%$ \\
\hline R_bra_int & 4134 & 2405 & $2,02 \mathrm{E}+10$ & 500 & $1,13 \mathrm{E}+10$ & $56,1 \%$ & 482 & $1,10 \mathrm{E}+10$ & $96,7 \%$ \\
\hline R_bra_tot & 4134 & 2405 & $2,02 \mathrm{E}+10$ & 2405 & $2,02 \mathrm{E}+10$ & $100 \%$ & 2387 & $1,98 \mathrm{E}+10$ & $98,2 \%$ \\
\hline R_tam & 4134 & 2405 & $2,02 \mathrm{E}+10$ & 486 & $5,36 \mathrm{E}+09$ & $26,6 \%$ & 486 & $5,36 \mathrm{E}+09$ & $100 \%$ \\
\hline R_glo & 4134 & 2405 & $2,02 \mathrm{E}+10$ & 622 & $3,80 \mathrm{E}+09$ & $18,8 \%$ & 622 & $3,80 \mathrm{E}+09$ & $100 \%$ \\
\hline R_azu & 4134 & 2405 & $2,02 \mathrm{E}+10$ & 701 & $1,60 \mathrm{E}+09$ & $7,9 \%$ & 701 & $1,60 \mathrm{E}+09$ & $100 \%$ \\
\hline R_one & 4134 & 2405 & $2,02 \mathrm{E}+10$ & 118 & $7,14 \mathrm{E}+08$ & $3,5 \%$ & 118 & $7,14 \mathrm{E}+08$ & $100 \%$ \\
\hline \multicolumn{10}{|l|}{ Legenda: } \\
\hline \multicolumn{10}{|c|}{ Base primária: base com as etapas de voo do mês de dezembro de 2014} \\
\hline \multicolumn{10}{|c|}{ Base secundária: base resultante do filtro na variável RPK para retirar valores zerados ou vazios } \\
\hline \multicolumn{10}{|c|}{$\begin{array}{l}\text { Base delimitada: base resultante dos filtros nas variáveis "empresa", "natureza do voo" e "grupo de voo", para delimitar o escopo da } \\
\text { malha aérea }\end{array}$} \\
\hline \multicolumn{10}{|c|}{ Base final: base resultante dos filtros nas variáveis "decolagens" e "distância", para eliminar dados faltantes } \\
\hline
\end{tabular}

\subsubsection{CONSTRUÇÃO DOS GRAFOS}

Após a preparação inicial da base de dados, foi possível criar os grafos representativos da rede de transporte aéreo brasileira. Os grafos são denominados nesta dissertação conforme indicado na Tabela 6.3, que também apresenta o índice de reciprocidade para os respectivos grafos na forma direcionada.

O uso de grafos sem direção foi comum na maioria dos estudos discutidos no capítulo 4, pois os autores observaram que a maioria das rotas formadoras da rede de transporte aéreo dispunha de voos de ida e volta, ou seja, havia pouca ocorrência de voos circulares. De fato, essa característica é comum no transporte aéreo, no entanto, considerando que a reciprocidade dos grafos gerados não apresentou valores relativamente elevados para todas as redes $(78 \%$ para a rede de voos da TAM), e considerando a oportunidade de representação mais fiel da realidade operacional, optou-se também pelo uso do modelo de grafo direcionado na aplicação do 
método. Apenas na etapa III, de simulação de ataque sequencial, devido às suas particularidades, fez-se uso do modelo não direcionado.

Tabela 6.3. Medida da reciprocidade dos grafos direcionados.

\begin{tabular}{lc}
\hline \multicolumn{1}{c}{ Rede } & Reciprocidade \\
\hline R_bra_dom & $88 \%$ \\
R_bra_int & $87 \%$ \\
R_bra_tot & $88 \%$ \\
R_tam & $78 \%$ \\
R_glo & $90 \%$ \\
R_azu & $95 \%$ \\
R_one & $93 \%$ \\
\hline
\end{tabular}

Para a designação de pesos às arestas do grafo foram considerados cinco atributos (edges attributes): distância geográfica, distância efetiva, quantidade de voos processados, número de assentos disponíveis e demanda por transporte aéreo entre cada par de aeródromos conectado. A demanda por transporte aéreo é medida em passageiro quilômetro pago transportado (Revenue Passenger Kilometer - RPK). Cada um desses atributos pode ser utilizado para valorar as arestas do grafo antes de se realizar a medição de algum parâmetro valorado.

\subsection{ETAPA III - ANÁLISE TOPOLÓGICA}

\subsubsection{VISUALIZAÇÃO DOS GRAFOS}

Como ponto de partida, pode-se ter uma noção da estrutura topológica dos grafos gerados a partir da sua projeção esquemática, como mostrado na Figura 6.5 para as redes de voos domésticos, internacionais e voos totais e, na Figura 6.6, para as redes de voos exclusivos das empresas aéreas brasileiras.
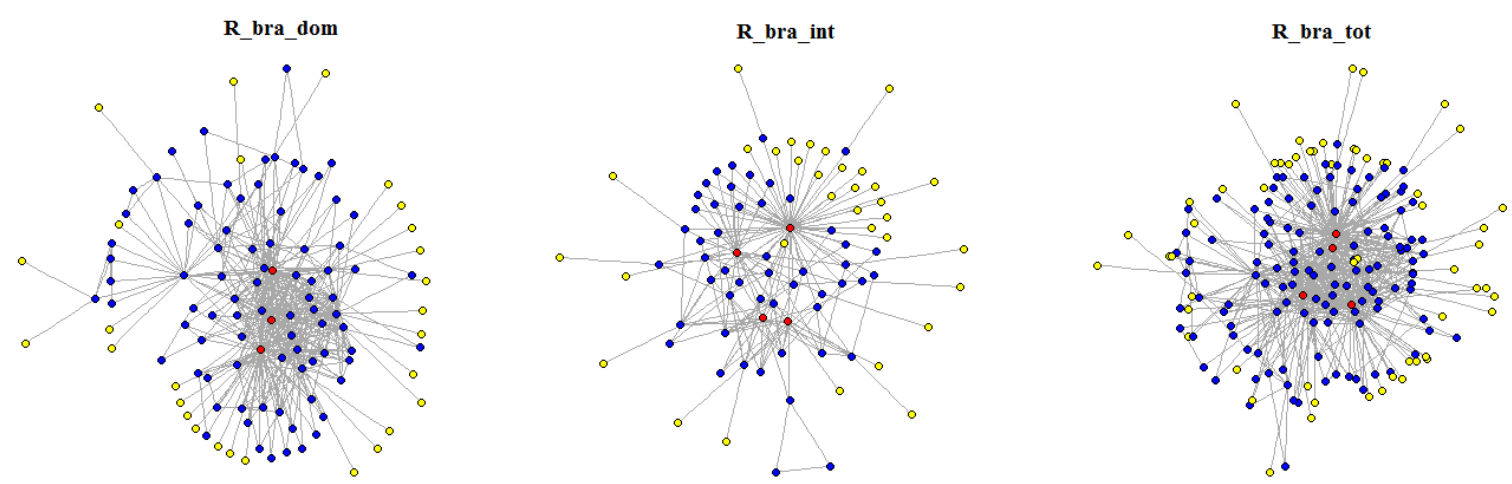

Figura 6.5. Representação visual das redes de voos domésticos e internacionais do Brasil.

Esse tipo de visualização não reflete a disposição espacial dos aeroportos, mas apenas fornece uma informação intuitiva sobre a posição central ou periférica dos vértices formadores do grafo. 
Os vértices destacados em vermelho e localizados numa região mais central do grafo possuem maior número de arestas, representando os aeroportos mais bem conectados, ou seja, aqueles que oferecem mais possibilidades de rotas. Os vértices dispostos na região mais periférica do grafo ou mais afastada da região central estão menos conectados e destacados em amarelo. Em geral, esses vértices apresentam apenas uma conexão, equivalendo-se aos aeroportos que oferecem uma única rota direta aos usuários.
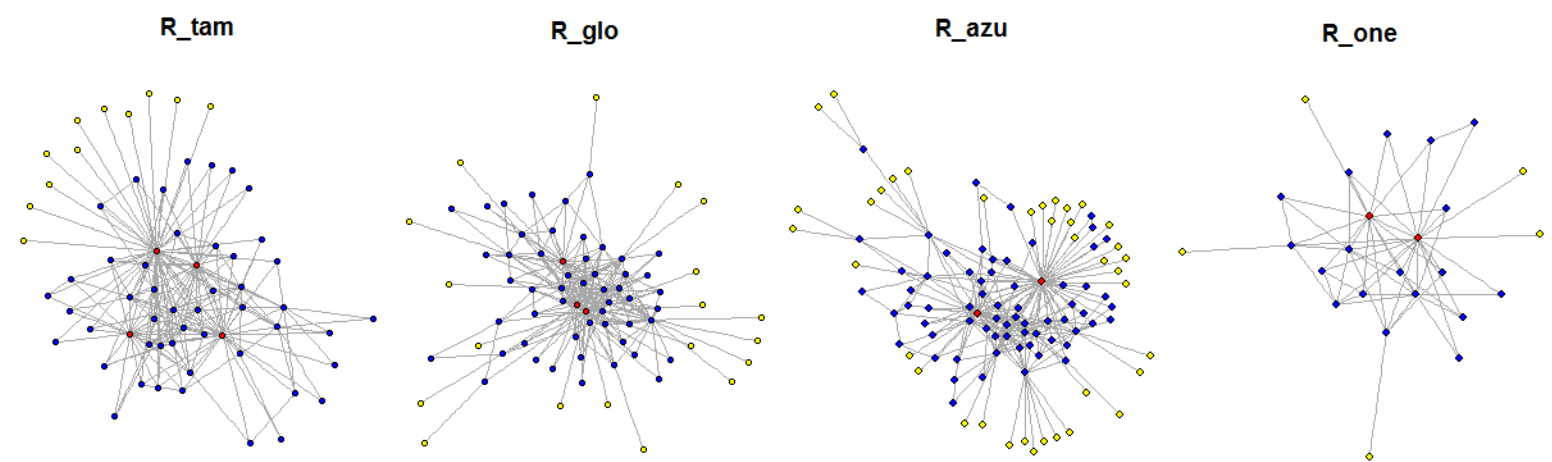

Figura 6.6. Representação visual das redes de voos das empresas aéreas brasileiras.

\subsubsection{PARÂMETROS ORIGINAIS DOS GRAFOS}

\subsubsection{GRAFOS NÃO DIRECIONADOS}

A medição dos parâmetros originais $\left(\mathrm{P}_{0}\right)$ dos modelos de grafos não direcionados é importante para que seja possível realizar uma comparação inicial com os parâmetros de outras redes de transporte aéreo já estudadas na literatura. A Tabela 6.4 apresenta os resultados de algumas medidas básicas para os grafos gerados neste estudo e a Tabela 6.5 apresenta os resultados coletados de algumas referências bibliográficas. As métricas são: número de vértices $(N)$, número de arestas $(E)$, grau médio $(\langle k\rangle)$, menor caminho médio $(L)$ e coeficiente de aglomeração $(C)$.

É interessante notar que as duas redes de abrangência mundial da Tabela 6.5, apesar de possuírem uma quantidade de vértices e arestas bastante superior às redes de âmbito nacional (USA, China, Índia, Austrália e Brasil), apresentam propriedades de grandeza similar a essas mesmas redes. O grau médio, o menor caminho médio e o coeficiente de aglomeração da rede mundial são comparáveis aos valores obtidos para as demais redes. Isso sugere que as redes de transporte aéreo, independente da sua abrangência, tendem a apresentar propriedades semelhantes. 
Tabela 6.4. Parâmetros originais de grafos não direcionados da rede brasileira.

\begin{tabular}{lccccc}
\hline \multicolumn{1}{c}{ Redes } & $\boldsymbol{N}$ & $\boldsymbol{E}$ & $\langle\boldsymbol{k}\rangle$ & $\boldsymbol{L}$ & $\boldsymbol{C}$ \\
\hline R_bra_dom & 114 & 437 & 7,67 & 2,54 & 0,35 \\
\hline R_bra_int & 87 & 173 & 3,98 & 2,63 & 0,03 \\
\hline R_bra_tot & 184 & 609 & 6,62 & 2,57 & 0,23 \\
\hline R_tam & 63 & 210 & 6,67 & 2,02 & 0,26 \\
\hline R_glo & 74 & 252 & 6,81 & 2,33 & 0,33 \\
\hline R_azu & 106 & 258 & 4,87 & 2,60 & 0,19 \\
\hline R_one & 25 & 59 & 4,72 & 1,97 & 0,34 \\
\hline
\end{tabular}

Tabela 6.5. Parâmetros de grafos não direcionados obtidos na literatura pesquisada.

\begin{tabular}{lcccccr}
\hline \multicolumn{1}{c}{ Redes } & $\boldsymbol{N}$ & $\boldsymbol{E}$ & $\langle\boldsymbol{k}\rangle$ & $\boldsymbol{L}$ & $\boldsymbol{C}$ & \multicolumn{1}{c}{ Fonte } \\
\hline Mundo & 3880 & 18880 & 9,70 & 4,37 & - & Dall'Asta et al. (2004) \\
\hline Mundo & 3712 & 24848 & - & 3,94 & 0,64 & Lordan et al (2014) \\
\hline USA & 215 & - & 13,94 & 2,40 & 0,62 & CHI Li Ping et al. (2003) \\
\hline China & 128 & 1165 & 14,00 & 2,07 & 0,60 & W. Li e X. Cai (2003) \\
\hline Índia & 84 & 512 & 3,00 & 2,23 & 0,63 & Sapre (2011) \\
\hline Austrália & 131 & 596 & 9,10 & 2,90 & 0,50 & Hoss ain et al. (2013) \\
\hline Brasil & 142 & - & 10,28 & 2,34 & 0,63 & Rocha (2008) \\
\hline
\end{tabular}

Todas as redes das Tabelas 6.4 e 6.5 caracterizam-se por um pequeno caminho médio $(L)$. Para se deslocar entre quaisquer dois aeroportos da rede mundial (origem e destino), por exemplo, é necessário, em média, passar por no máximo outros três aeroportos, ou seja, apenas três escalas farão parte da viagem. Nas redes domésticas, a média de escalas dos voos indiretos varia de uma a duas escalas.

As redes constituídas pelo transporte aéreo brasileiro possuem um coeficiente de aglomeração relativamente baixo (entre 0,03 e 0,35 ) em comparação às redes de países da literatura apontada (entre 0,5 a 0,64 ), indicando tratar-se de redes com menos incidência de ciclos de ordem três, ou seja, menor ocorrência de conexões conjuntas entre três aeroportos. Isso, também, sugere que a morfologia das redes que compõem a malha aérea brasileira está mais próxima de um formato do tipo hub-and-spoke. Dentre as empresas aéreas, a TAM e a AZUL possuem menores coeficientes de aglomeração e, possivelmente, operam sob uma estrutura mais associada ao modelo hub-and-spoke.

Por meio das informações extraídas dos grafos não direcionados já é possível obter uma base acerca da estrutura e funcionamento dessas redes de transporte aéreo. No entanto, conforme discutido anteriormente, explorou-se, também, os modelos de grafos direcionados, já que refletem mais adequadamente o direcionamento das rotas entre pares de aeroportos. 


\subsubsection{GRAFOS DIRECIONADOS}

Os parâmetros originais dos grafos direcionados estão apresentados na Tabela 6.6. Através do parâmetro do número de vértices, observa-se que no período considerado para a formação dos grafos (mês de dezembro de 2014), um total de 114 aeródromos brasileiros atenderam operações domésticas, formando a malha aérea de voos domésticos no Brasil (R_bra_dom). Desse conjunto, apenas 17 aeródromos também atenderam operações internacionais que, somado a outros 70 aeroportos estrangeiros, formam a rede de voos internacionais com origem ou destino no Brasil, composta por um total de 87 aeroportos (R_bra_int).

Tabela 6.6. Parâmetros originais de grafos direcionados da rede brasileira.

\begin{tabular}{|c|c|c|c|c|c|c|c|c|c|c|c|c|c|}
\hline \multirow[b]{2}{*}{ Grafos } & \multicolumn{5}{|c|}{ Parte 1} & \multicolumn{8}{|c|}{ Parte 2} \\
\hline & $N$ & $E$ & Dens & Comp & $\langle k\rangle$ & $D$ & $D^{w}$ & $L$ & $L^{w}$ & $C$ & $C^{w}$ & $E f f$ & $E f f^{w}$ \\
\hline R_bra_dom & 114 & 823 & 0,06 & 114 & 7,22 & 5 & 13,13 & 2,58 & 0,73 & 0,35 & 0,50 & 0,44 & 7,83 \\
\hline R_bra_int & 87 & 324 & 0,04 & 87 & 3,72 & 6 & 499,29 & 2,63 & 15,98 & 0,03 & 0,10 & 0,43 & 0,71 \\
\hline R_bra_tot & 184 & 1146 & 0,03 & 184 & 6,23 & 5 & 52,65 & 2,61 & 2,48 & 0,23 & 0,47 & 0,42 & 3,88 \\
\hline R_tam & 63 & 373 & 0,10 & 63 & 5,92 & 4 & 18,33 & 2,08 & 1,04 & 0,26 & 0,59 & 0,53 & 6,05 \\
\hline R_glo & 74 & 478 & 0,09 & 74 & 6,46 & 5 & 18,81 & 2,36 & 1,17 & 0,33 & 0,48 & 0,48 & 5,92 \\
\hline $\mathrm{R}$ _azu & 106 & 503 & 0,05 & 106 & 4,75 & 5 & 8,41 & 2,63 & 0,73 & 0,19 & 0,36 & 0,43 & 3,40 \\
\hline R_one & 25 & 114 & 0,19 & 25 & 4,56 & 4 & 8,45 & 1,98 & 0,92 & 0,34 & 0,52 & 0,57 & 5,29 \\
\hline
\end{tabular}

\section{Legenda:}

$\boldsymbol{N}$ - número de vértices $\boldsymbol{E}$ - número de arestas $\boldsymbol{D e n s}$ - densidade da rede

Comp - maior componente conectada $\langle\boldsymbol{k}\rangle$ - grau médio $\boldsymbol{D}$ - diâmetro
$\boldsymbol{L}$ - menor caminho médio
$\boldsymbol{C}$ - coeficiente de aglomeração
$\boldsymbol{E} \boldsymbol{f}$ - eficiência
$\underline{w}$ - weight - indica que o parâmetro foi calculado a partir da rede com pesos (parâmetro valorado)

Os aeroportos brasileiros que processam voos domésticos e internacionais, como mostrado na Tabela 6.7 desempenham um papel importante na manutenção do funcionamento normal da rede de transporte aéreo. Além de serem os únicos pontos de entrada e saída de voos internacionais, esses aeroportos atendem à demanda do Distrito Federal e das capitais do País (única exceção é o aeroporto de Foz do Iguaçu (SBFI), localizado no município de Foz do Iguaçu/PR).

Dentre as empresas aéreas, a maior rede é aquela formada pela AZUL, constituída de 106 aeroportos, enquanto que a AVIANCA opera em apenas 25 pontos. Os grafos apresentam baixíssima densidade (valor máximo seria 1) e, portanto, caracterizam-se como grafos esparsos, ou seja, possuem relativamente pequeno número de arestas quando comparado com a quantidade possível (LEWIS, 2009). Essa característica é esperada, tendo em vista a inviabilidade econômica de se ofertar transporte aéreo em cada uma ou mesmo na maioria das rotas possíveis entre os vários pares de aeroportos. Em geral, as redes do tipo point-to-point tendem a ser mais densas, com conexões entre pares de aeroportos de forma direta. Enquanto 
que as redes do tipo hub-and-spoke se mostram menos densas, concentrando as rotas entre o aeroporto $h u b$ e os aeroportos periféricos. De qualquer forma, uma maior densidade da rede indica uma proporção maior de arestas e, por conseguinte, uma melhor conectividade.

Tabela 6.7. Lista de 17 aeroportos brasileiros que atenderam voos domésticos e internacionais.

\begin{tabular}{cllc}
\hline $\begin{array}{c}\text { SIGLA } \\
\text { OACI }\end{array}$ & \multicolumn{1}{c}{ NOME } & MUNICÍPIO & UF \\
\hline SBBE & VAL DE CANS - JÚLIO CEZAR RIBEIRO & BELÉM & PA \\
\hline SBBR & PRESIDENTE JUSCELINO KUBITSCHEK & BRASÍLIA & DF \\
\hline SBCF & TANCREDO NEVES & CONFINS & MG \\
\hline SBCG & CAMPO GRANDE & CAMPO GRANDE & MS \\
\hline SBCT & AFONSO PENA & CURITIBA & PR \\
\hline SBEG & EDUARDO GOMES & MANAUS & AM \\
\hline SBFI & CATARATAS & FOZ DO IGUAÇU & PR \\
\hline SBFL & HERCÍLIO LUZ & FLORIANÓPOLIS & SC \\
\hline SBFZ & PINTO MARTINS & FORTALEZA & CE \\
\hline SBGL & GALEÃO - ANTONIO CARLOS JOBIM & RIO DE JANEIRO & RJ \\
\hline SBGR & GUARULHOS - GOVERNADOR ANDRÉ FRANCO MONTORO & GUARULHOS & SP \\
\hline SBKP & VIRACOPOS & CAMPINAS & SP \\
\hline SBMO & ZUMBI DOS PALMARES & RIO LARGO & AL \\
\hline SBPA & SALGADO FILHO & PORTO ALEGRE & RS \\
\hline SBRF & GUARARAPES - GILBERTO FREYRE & RECIFE & PE \\
\hline SBSG & GOVERNADOR ALUIZIO ALVES & SÃO GONÇALO DO AMARANTE & RN \\
\hline SBSV & DEPUTADO LUÍS EDUARDO MAGALHÃES & SALVADOR & BA \\
\hline
\end{tabular}

Todos os grafos originais estão completamente conectados, ou seja, não há componentes isoladas, indicando que nas diversas redes é possível partir de um aeroporto e chegar a qualquer outro aeroporto após algumas escalas. A situação de componentes isoladas existiu durante o ano de 1999 (ROCHA, 2009) e, possivelmente, em anos anteriores à desregulamentação setorial, devido à prática de reserva de rotas e destinos que eram explorados.

A parte 2 da Tabela 6.6 contém valores de parâmetros calculados tanto para os grafos sem pesos, sob um ponto de vista estritamente topológico, quanto para as versões de grafos com pesos. É interessante notar os resultados provenientes de cada uma das abordagens e as razões das diferenças encontradas.

O diâmetro $(D)$ de um grafo conectado qualquer é definido como o maior dos menores caminhos ou maior caminho geodésico entre qualquer par de vértices (LEWIS, 2009). Nas redes das empresas, a TAM e a AVIANCA constituem redes com os menores diâmetros, indicando que uma viagem entre o par mais distante de aeroportos consome, no máximo, três escalas ou 
conexões $^{8}$. A rede de voos internacionais possui o maior diâmetro. A Tabela 6.8 indica os aeroportos mais distantes em cada uma das redes brasileiras.

Tabela 6.8. Diâmetro e ligações entre aeroportos mais distantes das redes.

\begin{tabular}{lcr}
\hline \multicolumn{1}{c}{ Grafos } & Diâmetro & \multicolumn{1}{c}{ Aeroportos mais distantes } \\
\hline R_bra_dom & 5 & Alta Floresta/MT (SBAT) - Oriximina/PA (SBTB) \\
R_bra_int & 6 & Fort Lauderdale/Estados Unidos (KFLL) - Concepción/Chile (SCIE) \\
R_bra_tot & 5 & San José/Costa Rica (MROC) - Tucuruí/PA (SBTU) \\
R_tam & 4 & Boa Vista/RR (SBBV) - Ilhéus/BA (SBIL) \\
R_glo & 5 & Miami/Estados Unidos (KMIA) - Cruzeiro do Sul/AC (SBCZ) \\
R_azu & 5 & Alta Floresta/MT (SBAT) - Itaituba/PA (SBIH) \\
R_one & 4 & Chapecó/SC (SBCH) - Bogotá/Colômbia (SKBO) \\
\hline
\end{tabular}

Verifica-se, ainda, na Tabela 6.6 que os tamanhos do menor caminho médio (L) das redes de voos domésticos $\left(R \_b r a \_d o m\right)$ e internacionais $\left(R \_b r a \_i n t\right)$ apresentam valores próximos, mas o correspondente parâmetro valorado $\left(L^{w}\right)$ indica uma diferença significativa. O parâmetro $L$ indica que, do ponto de vista estritamente topológico, o número médio de escalas/paradas necessárias para partir de um aeroporto $i$ para qualquer outro aeroporto $j$ varia de uma a duas escalas. No entanto, quando observamos os valores do parâmetro valorado, apesar de não conseguirmos extrair um significado físico, é possível perceber o grau de diferenças que é proporcionado pela simples consideração do peso nas arestas. A grande diferença entre as duas redes citadas, deve-se aos fatores da distância geográfica e da oferta de assentos disponíveis, que são combinados para formar o atributo da distância efetiva $(l=d / w)$. Na rede de voos domésticos, a distância geográfica menor entre os pares de aeroportos e a maior oferta de assentos faz com que o resultado do caminho valorado pela distância efetiva seja muito pequeno quando comparado com a rede de voos internacionais, que conta com distâncias geográficas maiores e menor oferta de assentos.

Esse efeito provocado nos valores do menor caminho médio $(L)$ das redes indica que o método da distância efetiva para a valoração das arestas dos grafos com peso é apropriado, pois é razoável esperar que a distância média ou, de outra forma, a dificuldade média para deslocarse entre dois pontos de uma rede de transporte aéreo doméstica seja menor que numa rede de transporte aéreo internacional.

\footnotetext{
${ }^{8} \mathrm{O}$ termo conexão está sendo empregado aqui no sentido da operação de troca de voo por um passageiro num aeroporto intermediário entre sua origem e seu destino final.
} 
Quanto ao coeficiente de aglomeração, observa-se um aumento no parâmetro valorado para todas as redes. Esses resultados indicam que nos subgrafos abrangidos pelo conjunto de aeroportos mais fortemente conectados, ou seja, que atendem a maior proporção de demanda por transporte aéreo (em RPK), existe uma maior probabilidade da presença de loops de ordem três (triângulos fechados). A estrutura desses subgrafos, portanto, são próximas à morfologia point-to-point.

No caso da eficiência das redes, observa-se um efeito semelhante ao ocorrido com o menor caminho médio e que também se justifica pelo emprego do atributo da distância efetiva. Se considerarmos apenas o ponto de vista topológico, a eficiência da rede de voos domésticos é praticamente a mesma que aquela conseguida pela rede de voos internacionais. No entanto, ao considerarmos a valoração das arestas do grafo, é possível constatar a diferença na grandeza da eficiência de cada rede.

\subsubsection{PARÂMETROS DOS VÉRTICES}

A análise topológica da rede também inclui a descrição dos parâmetros que caracterizam seus vértices. No método proposto está previsto o cálculo de parâmetros que indicam a centralidade do vértice, quais sejam, o grau (degree centrality), a proximidade (closeness centrality) e a intermediação (betweenness centrality).

Os três tipos de centralidade são medidos tanto sob o ponto de vista topológico, considerando os grafos sem pesos, quanto sob o ponto de vista funcional da rede, por meio da alocação de pesos nas arestas do grafo. Então, obtêm-se medidas topológicas e valoradas. No caso do grau valorado, que busca reconhecer a intensidade das ligações entre pares de aeroportos, utilizouse quatro versões, cada uma com um atributo específico: distância geográfica, voos, assentos e demanda por transporte aéreo (em RPK). Para o caso da centralidade de proximidade e de intermediação, que são medidas baseadas no menor caminho entre dois aeroportos, fez-se uso do atributo da distância efetiva.

\subsubsection{DISTRIBUIÇÕES DAS MEDIDAS DE CENTRALIDADE}

A rede brasileira de voos domésticos (R_bra_dom) apresenta uma distribuição de grau topológico similar a curva definida por uma lei de potência (Figura 6.7), demonstrando uma variabilidade significativa do grau topológico, típica de vários outros sistemas reais considerados como redes complexas do tipo livre de escala. Verifica-se a ocorrência de muitos 
aeroportos com baixo número de conexões e poucos aeroportos com uma quantidade grande de conexões. Aproximadamente $80 \%$ dos aeroportos possuem entre 2 a 20 conexões $\left(k_{\text {total }}=k_{\text {in }}+\right.$ $\left.k_{\text {out }}\right)$. Os $20 \%$ restantes possuem entre 21 , caso dos aeroportos de Campo Grande (SBCG) e Uberlândia (SBUL), e 116 conexões, caso do aeroporto de Campinas (SBKP).

Além do histograma do grau topológico da rede $R \_b r a \_$dom, a Figura 6.7 disponibiliza as três formas usuais de apresentação da sua distribuição de probabilidade. A distribuição do grau topológico representa a probabilidade de um vértice escolhido aleatoriamente possuir um valor de grau igual a $k$. Normalmente a distribuição do grau é mostrada por meio de um gráfico denominado $\log$-log, de onde é possível identificar uma tendência de relação linear negativa entre o $\log (P(>k))$ e $\log k$.

Ao analisar o histograma dos quatro tipos de graus valorados considerados nesta pesquisa, para a rede de voos domésticos, verifica-se uma variabilidade similar à disposta pelo grau topológico, como mostrado na Figura 6.8. Assim, a rede caracteriza-se pela presença de poucos aeroportos que proporcionam alta capacidade de acesso geográfico (grau valorado pelas distâncias), com intenso tráfego de aeronaves (grau valorado pelos voos), com significativa oferta de serviços aéreos (grau valorado pelos assentos) e grande participação no atendimento da demanda do mercado (grau valorado pelo RPK). Ao passo que há muitos outros aeroportos que possuem baixos valores dessas mesmas dimensões.

A distribuição típica encontrada para os parâmetros dos vértices da rede de voos domésticos também foi vista nas demais redes consideradas nesta pesquisa. 

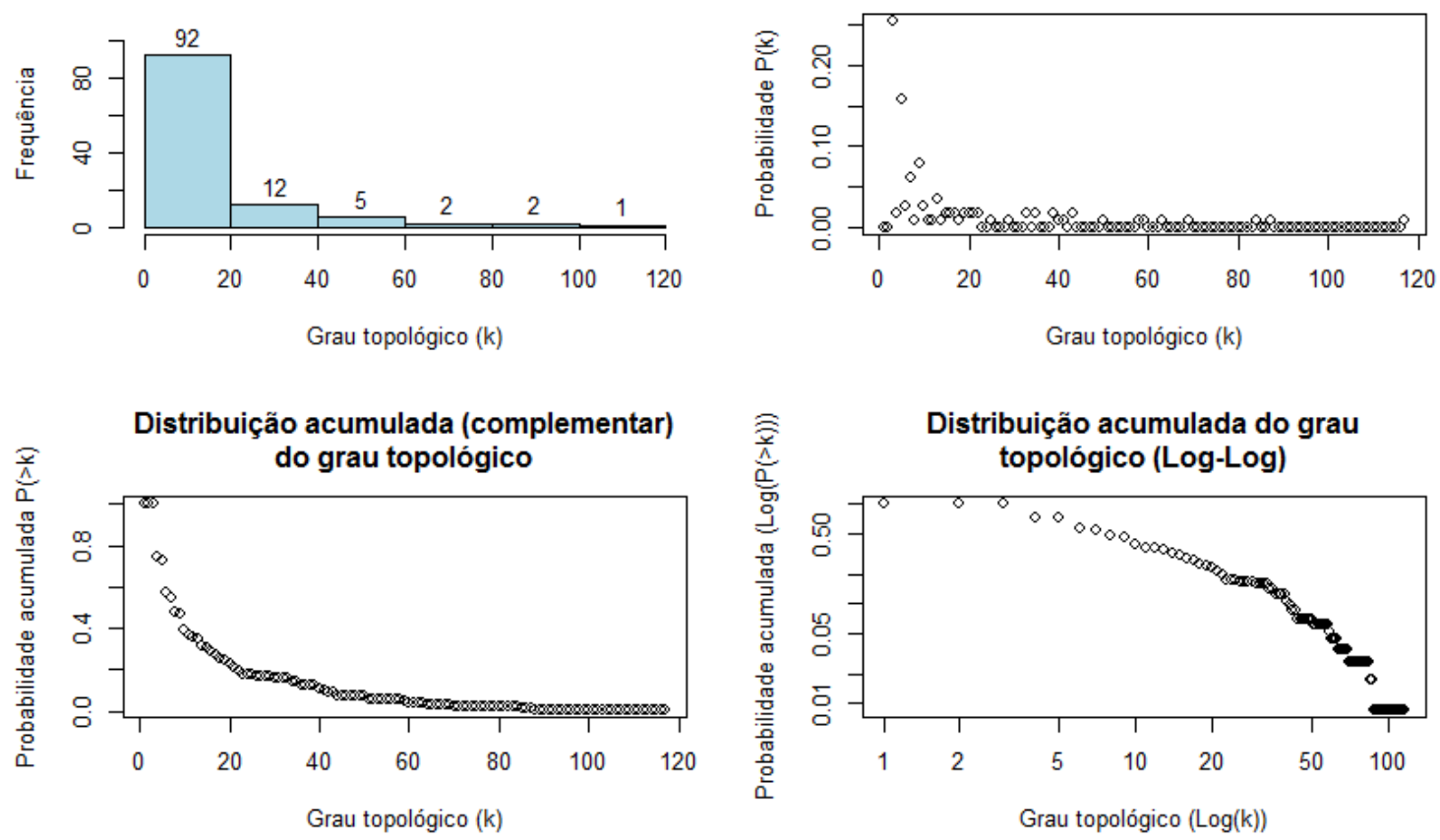

Figura 6.7. Histograma e distribuições do grau topológico da rede $R \_b r a \_d o m$.
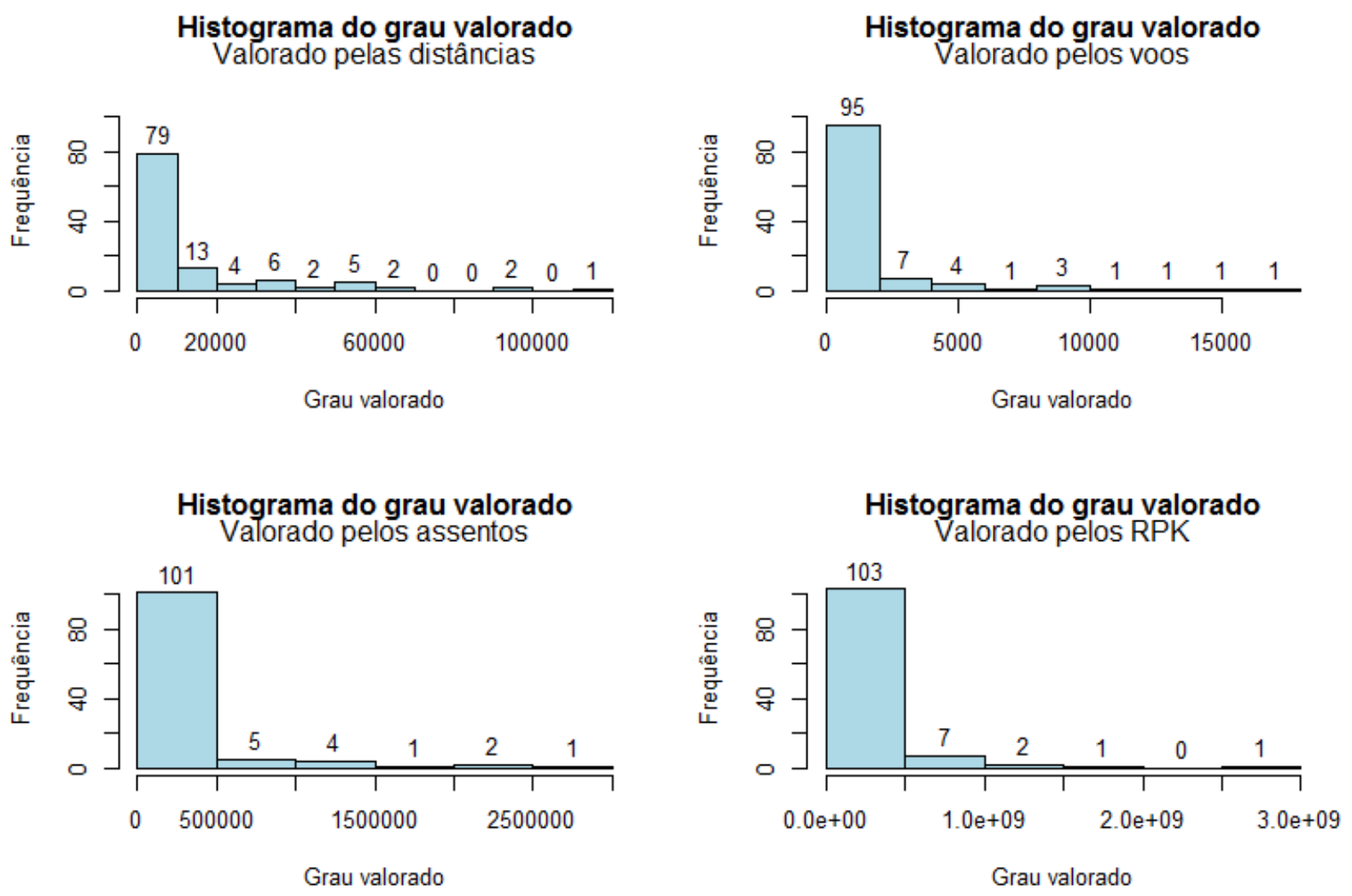

Figura 6.8. Histogramas dos graus valorados pelas distâncias, voos, assentos e RPK da rede $R \_b r a \_d o m$. 


\subsubsection{EXAME BIVARIADO DOS PARÂMETROS DE VÉRTICES}

A análise bivariada das variáveis é importante para buscar entender as possíveis inter-relações existentes. Na Figura 6.9 visualiza-se os diagramas de dispersão entre o grau topológico da rede de voos domésticos e os respectivos graus valorados (pelos atributos da distância, voos, assentos e demanda por transporte aéreo, em RPK).

Nos quatro casos, observa-se algum grau de correlação positiva, sendo mais forte na relação entre o grau topológico e o grau valorado pelas distâncias. A relação é um pouco mais fraca nos três demais gráficos de dispersão. Observa-se, por exemplo, que há uma tendência de aumento do grau valorado pelos voos, na medida em que cresce o grau topológico. No entanto, há pontos que se afastam da curva de relação linear.

Nota-se que o aeroporto de Campinas (SBKP), o mais bem conectado à rede (maior grau topológico) não é o aeroporto que processa mais voos (grau valorado), caso do aeroporto de Guarulhos (SBGR). Na verdade, há aeroportos com tráfego de voos relativamente intensa, apesar de um grau de conectividade bem menor. Isso pode ser explicado pela concentração de tráfego em poucas rotas e entre alguns poucos pares de aeroportos, a exemplo, da ponte aérea Rio-São Paulo, formada pelos aeroportos de Santos Dumont/RJ (SBRJ) e Congonhas/SP (SBSP).
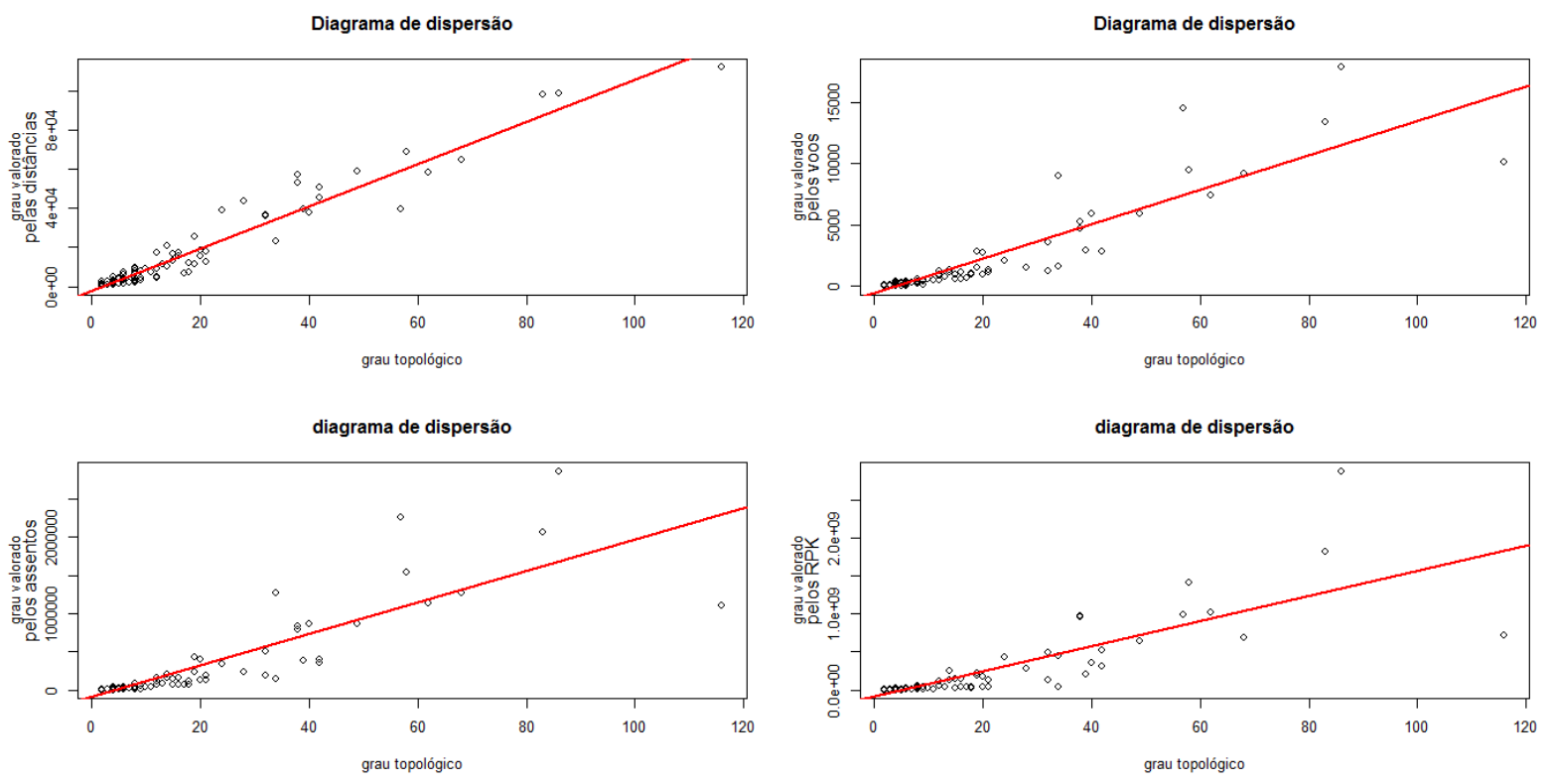

Figura 6.9. Diagramas de dispersão entre grau topológicos e os graus valorados para a rede $R \_b r a \_d o m$.

Um panorama mais geral do grau de relação linear entre cada uma das medidas de centralidade dos aeroportos que compõem a rede de voos domésticos pode ser observado na Tabela 6.9 e na 
Figura 6.10, a seguir. A tabela fornece os valores de correlação linear, enquanto que a figura dispõe de uma matriz de correlação composta por elipses cujos formatos fornecem uma forma mais prática e intuitiva de visualização da mesma relação entre as variáveis. As elipses com forma mais aberta indicam uma relação linear mais fraca, enquanto que as elipses com forma mais fechada estão associadas a uma relação linear mais forte entre duas variáveis. A elipse totalmente fechada apresenta o formato de uma linha reta, que indica uma correlação igual a 1.

Tabela 6.9. Correlação linear entre os parâmetros de vértices da rede $R \_b r a \_d o m$.

\begin{tabular}{|c|c|c|c|c|c|c|c|c|c|}
\hline & $k$ & $k_{\text {distância }}^{w}$ & $k^{w}{ }_{v o o}$ & $k^{w}$ assentos & $k_{R P K}^{w}$ & $C l$ & $C l_{\text {distância efetiva }}^{w}$ & $B$ & $\boldsymbol{B}^{w}{ }_{\text {distância efetiva }}$ \\
\hline $\boldsymbol{k}$ & 1,00 & 0,97 & 0,90 & 0,86 & 0,82 & 0,86 & 0,50 & 0,81 & 0,79 \\
\hline$k^{w}$ distância & 0,97 & 1,00 & 0,87 & 0,85 & 0,86 & 0,85 & 0,47 & 0,79 & 0,74 \\
\hline$k^{w}$ voo & 0,90 & 0,87 & 1,00 & 0,99 & 0,92 & 0,74 & 0,42 & 0,64 & 0,89 \\
\hline$k^{w}$ assentos & 0,86 & 0,85 & 0,99 & 1,00 & 0,94 & 0,72 & 0,40 & 0,58 & 0,88 \\
\hline$k^{w}{ }_{R P K}$ & 0,82 & 0,86 & 0,92 & 0,94 & 1,00 & 0,69 & 0,36 & 0,58 & 0,80 \\
\hline$C l$ & 0,86 & 0,85 & 0,74 & 0,72 & 0,69 & 1,00 & 0,65 & 0,63 & 0,63 \\
\hline$C l^{w}$ distância efetiva & 0,50 & 0,47 & 0,42 & 0,40 & 0,36 & 0,65 & 1,00 & 0,27 & 0,33 \\
\hline $\boldsymbol{B}$ & 0,81 & 0,79 & 0,64 & 0,58 & 0,58 & 0,63 & 0,27 & 1,00 & 0,71 \\
\hline $\boldsymbol{B}^{w}{ }_{\text {distância efetiva }}$ & 0,79 & 0,74 & 0,89 & 0,88 & 0,80 & 0,63 & 0,33 & 0,71 & 1,00 \\
\hline
\end{tabular}

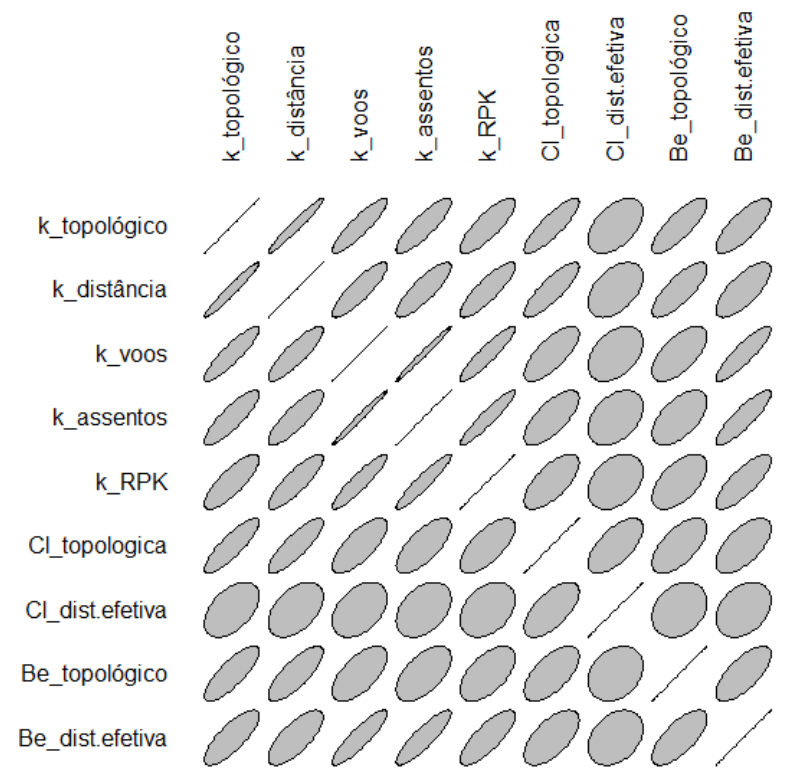

Figura 6.10. Visualização da relação de linearidade entre os parâmetros de vértices.

Verifica-se que nem todas as medidas de centralidade possuem correlação linear significativa. A correlação entre o grau de intermediação topológico $(B)$ e o grau de proximidade valorado pela distância efetiva foi de apenas 0,27 , um valor baixo quando comparado aos demais casos. O próprio grau de proximidade valorado é a medida que menos apresenta relação linear com as demais. As relações de linearidade encontradas entre os parâmetros de vértices da rede de voos 
domésticos também foram detectadas de forma similar nas demais redes consideradas nesta pesquisa.

\subsubsection{IDENTIFICAÇÃO DA IMPORTÂNCIA DOS AEROPORTOS}

A literatura atribui um nível de importância aos vértices a partir da observação dos seus parâmetros. Entretanto, a importância dada a um vértice de um grafo se modifica de acordo com o parâmetro que esteja sendo considerado na análise. Esse comportamento já pode ser notado a partir dos gráficos de dispersão mostrados anteriormente, mas pode ser analisado de forma mais detalhada com base nos resultados da Tabela 6.10, que apresenta os valores dos parâmetros de 25 aeroportos mais importantes da rede de voos domésticos ( $\left.R \_b r a \_d o m\right)$.

$\mathrm{Na}$ tabela estão incluídas as medidas encontradas para as centralidades de grau topológico $(k)$, centralidades de proximidade $(C l)$ e de intermediação $(B)$ e suas respectivas medidas valoradas $\left(k^{w}, C l^{w}, B^{w}\right)$. As duas últimas colunas da tabela informam o resultado do cálculo do indicador de importância proposto para a etapa III do método de análise de vulnerabilidade. O primeiro valor do indicador $\left(I_{I M P}\right)$ é aquele obtido pela fórmula de cálculo da Equação 19, apresentada na seção 5.3.3. O segundo valor do indicador $\left(I_{I M P(\%)}\right)$ foi obtido com o emprego da função denominada "ordem.porcentual" do software Excel, que retorna a posição de um valor em um conjunto de dados na forma de uma porcentagem do conjunto de dados. Em cinza, estão destacados os maiores valores de cada parâmetro, de onde é possível notar que o aeroporto mais importante ou a ordenação da importância dos aeroportos varia de acordo com o parâmetro considerado.

Através da observação dos resultados da Tabela 6.10, verifica-se que o aeroporto de Viracopos/SP (SBKP) se destaca sob o ponto de vista de quatro diferentes parâmetros. Possui o maior grau topológico $(k)$, resultando em 116 conexões com outros aeroportos que, no caso da rede direcionada, incluem ligações (rotas) de saída $\left(k \_o u t=60\right)$ e de entrada $\left(k \_i n=56\right)$. Ou seja, há voos partindo do aeroporto de Viracopos para 60 destinos diferentes e os voos de chegada são provenientes de 56 pontos de origem. Isso faz de Viracopos, o aeroporto que mais contribui para a conectividade da rede.

Pode-se afirmar, também, que a rede proporciona maior acessibilidade geográfica aos usuários através do aeroporto de Viracopos, tendo em vista o maior valor obtido no grau valorado pelas distâncias. Isso demonstra que as rotas oferecidas pelo aeroporto conectam cidades brasileiras mais distantes. 
Tabela 6.10. Parâmetros de 25 aeroportos mais importantes da rede $R \_b r a \_d o m$.

\begin{tabular}{|c|c|c|c|c|c|c|c|c|c|c|c|c|c|}
\hline & Aeroporto & Sigla & $\boldsymbol{k}$ & $\boldsymbol{k}_{\text {distância }}^{\boldsymbol{w}}$ & $k^{w}{ }_{\text {voo }}$ & $k_{\text {assentos }}^{w}$ & $k_{R P K}^{w}$ & $\mathrm{Cl}$ & $\mathrm{Cl}_{\text {distância efetiva }}^{w}$ & $B$ & $\boldsymbol{B}^{w}{ }_{\text {distância efetiva }}$ & $I_{I M P}$ & $I_{I M P(\%)}$ \\
\hline 1 & Guarulhos/SP & SBGR & 86 & 98813,65 & 17846 & 2864104 & 2871742074 & 0,61081 & 0,02351 & 0,10667 & 4048 & 30,4632 & 1,00 \\
\hline 2 & Brasîlia/DF & SBBR & 83 & 98246,05 & 13383 & 2068069 & 1809627934 & 0,60753 & 0,02349 & 0,17359 & 4831 & 25,3364 & 0,99 \\
\hline 3 & Congonhas/SP & SBSP & 57 & 39781,47 & 14491 & 2257020 & 993163926 & 0,51131 & 0,02357 & 0,03223 & 4762 & 19,9825 & 0,98 \\
\hline 4 & Viracopos/SP & SBKP & 116 & 112010,25 & 10086 & 1104345 & 719609975 & 0,66082 & 0,02328 & 0,32047 & 2631 & 19,2902 & 0,97 \\
\hline 5 & Galeão/RJ & SBGL & 58 & 68848,68 & 9447 & 1547232 & 1409435926 & 0,55941 & 0,02340 & 0,04538 & 590 & 14,6177 & 0,96 \\
\hline 6 & Confins/MG & SBCF & 68 & 64776,61 & 9157 & 1267510 & 689758937 & 0,57071 & 0,02342 & 0,12452 & 1342 & 13,2696 & 0,95 \\
\hline 7 & Salvador/BA & SBSV & 62 & 58466,05 & 7432 & 1140888 & 1017101337 & 0,50901 & 0,02310 & 0,08850 & 1849 & 13,1920 & 0,94 \\
\hline 8 & Santos Dumont/RJ & SBRJ & 34 & 23315,16 & 8985 & 1273310 & 442432544 & 0,47479 & 0,02356 & 0,02188 & 3433 & 11,3351 & 0,93 \\
\hline 9 & Fortaleza/CE & SBFZ & 38 & 56891,88 & 4720 & 787608 & 970659114 & 0,52558 & 0,02264 & 0,02905 & 1194 & 9,3575 & 0,92 \\
\hline 10 & Porto Alegre/RS & SBPA & 49 & 59131,85 & 5894 & 862507 & 637877377 & 0,49345 & 0,02319 & 0,04574 & 666 & 9,2178 & 0,92 \\
\hline 11 & Recife/PE & SBRF & 38 & 53340,18 & 5264 & 831194 & 964118872 & 0,47881 & 0,02284 & 0,01245 & 859 & 9,1088 & 0,91 \\
\hline 12 & Manaus/AM & SBEG & 42 & 50968,69 & 2819 & 398311 & 519542894 & 0,51598 & 0,02140 & 0,22091 & 2652 & 8,1215 & 0,90 \\
\hline 13 & Curitiba/PR & SBCT & 40 & 37649,81 & 5955 & 865503 & 362597302 & 0,48707 & 0,02347 & 0,00617 & 882 & 7,3992 & 0,89 \\
\hline 14 & Belém/PA & SBBE & 32 & 36585,85 & 3603 & 510727 & 484133620 & 0,50000 & 0,02183 & 0,06247 & 1742 & 6,4238 & 0,88 \\
\hline 15 & Cuiabá/MT & SBCY & 42 & 45491,85 & 2835 & 357736 & 307688476 & 0,48498 & 0,02231 & 0,09671 & 1326 & 5,9357 & 0,87 \\
\hline 16 & Goiânia/GO & SBGO & 39 & 39709,00 & 2957 & 391192 & 207672765 & 0,49561 & 0,02327 & 0,00838 & 0 & 4,0651 & 0,86 \\
\hline 17 & Natal/RN & SBSG & 24 & 38778,70 & 2109 & 334621 & 435777690 & 0,46502 & 0,02182 & 0,00814 & 0 & 3,2020 & 0,85 \\
\hline 18 & Maceió/AL & SBMO & 28 & 43927,37 & 1529 & 241595 & 284958599 & 0,47679 & 0,02183 & 0,00244 & 0 & 2,8749 & 0,84 \\
\hline 19 & Porto Seguro/BA & SBPS & 32 & 35792,40 & 1237 & 189678 & 131190850 & 0,47280 & 0,02221 & 0,00235 & 0 & 2,1782 & 0,84 \\
\hline 20 & Florianópolis/SC & SBFL & 19 & 11405,90 & 2861 & 432008 & 185442272 & 0,44488 & 0,02316 & 0,00129 & 224 & 1,9935 & 0,83 \\
\hline 21 & Ribeirão Preto/SP & SBRP & 34 & 23382,67 & 1614 & 147259 & 43837346 & 0,47479 & 0,02268 & 0,00774 & 224 & 1,8538 & 0,82 \\
\hline 22 & Vitória/ES & SBVT & 20 & 15590,33 & 2763 & 400855 & 176613766 & 0,45935 & 0,02294 & 0,00017 & 0 & 1,8273 & 0,81 \\
\hline 23 & São Luís/MA & SBSL & 19 & 25306,90 & 1529 & 235707 & 226414664 & 0,46694 & 0,02193 & 0,00209 & 213 & 1,6650 & 0,80 \\
\hline 24 & Campo Grande/MS & SBCG & 21 & 17835,58 & 1341 & 187402 & 130001861 & 0,45200 & 0,02186 & 0,01818 & 224 & 1,0195 & 0,79 \\
\hline 25 & João Pessoa/PB & SBJP & 14 & 20660,22 & 1111 & 166701 & 244990207 & 0,44488 & 0,02002 & 0,00270 & 112 & 0,5308 & 0,78 \\
\hline
\end{tabular}


Outras duas medidas topológicas, o grau de proximidade e de intermediação, encontram seus maiores valores no aeroporto de Viracopos. Isso indica que, ao menos sob a ótica topológica, esse aeroporto possibilita deslocamentos de forma mais facilitada aos outros aeroportos da rede, além de ser ponto de parada/conexão para voos indiretos, ou seja, atua como aeroporto hub

Quando se observa os parâmetros valorados, outros três diferentes aeroportos se destacam: aeroporto de Congonhas (SBSP), de Brasília (SBBR) e de Guarulhos (SBGR). O aeroporto de Congonhas é o aeroporto mais bem posicionado da rede, devido ao seu alto grau de proximidade valorada pela distância efetiva. Isso indica que, apesar de oferecer uma quantidade de rotas bem menor em relação as existentes em Viracopos, os voos operados em Congonhas permitem um deslocamento mais facilitado dos usuários entre pontos da rede. Essa facilidade é dada por menores tamanhos de distância efetiva associada aos deslocamentos. Essas pequenas distâncias efetivas se manifestam devido as características do próprio aeroporto de Congonhas que conecta pontos geográficos menos distantes e, ao mesmo tempo, possui uma alta oferta de assentos nessas ligações. Uma rota típica com essas características seria a ligação entre Congonhas (SBSP) e Santos Dumont (SBRJ), também conhecida como Ponte Aérea.

O aeroporto de Brasília (SBBR) apresentou o maior valor de grau de intermediação valorado pela distância efetiva. Esse resultado coloca Brasília como o aeroporto hub mais característico da rede de voos domésticos, pois é por esse aeroporto que passa a maioria dos menores caminhos valorados entre pares de aeroportos. Isto é, os voos indiretos que ligam o ponto de origem ao ponto de destino de forma mais rápida (menor trajeto geográfico) e que ofertam maior número de assentos passam pelo aeroporto de Brasília, como ponto intermediário.

Por fim, tem-se o aeroporto de Guarulhos (SBGR) que foi considerado o mais importante da rede quanto ao tráfego de aeronaves $\left(k_{\text {voos }}\right)$, oferta de assentos em voos diretos ( $\left.k_{\text {assentos }}\right)$ e participação de mercado em termos de demanda atendida $\left(k_{R P K}\right)$. Esses resultados são alcançados devido ao elevado volume de operações que são realizadas no aeroporto, isto é, há muitas frequências de voos no âmbito das rotas disponibilizadas.

Essa mesma característica também pode ser notada, comparando o parâmetro da conectividade topológica, no qual mostra que os aeroportos de Guarulhos, Brasília e Congonhas são menos conectados à rede do que o aeroporto de Viracopos. Apesar desses aeroportos oferecerem menos opções de destinos, as rotas que existem são operadas com maior frequência de voos e maior oferta de assentos, resultando numa maior participação de mercado. 
Verificando o resultado geral proporcionado pelo indicador de importância $\left(I_{I M P}\right)$, que leva em conta as medidas dos aeroportos segundo cada um dos parâmetros, o aeroporto de Guarulhos mantém-se na primeira posição, seguido pelos aeroportos de Brasília (SBBR), Congonhas (SBSP), Viracopos (SBKP), Galeão (SBGL), dentre outros. Por meio do indicador de importância obtém-se uma ordenação final dos aeroportos segundo os seus próprios atributos.

A Tabela 6.11 seguinte traz um resultado parcial de cada uma das redes estudadas, mostrando a ordenação dos cinco primeiros aeroportos, segundo o indicador de importância calculado. Como pode-se verificar na tabela, o indicador de importância de Guarulhos permanece máximo em seis das sete redes consideradas. Tem-se um resultado diferente apenas na rede de voos da empresa AZUL, na qual aparecem os aeroportos de Viracopos e Confins como mais importantes, antes do aeroporto de Guarulhos.

É interessante observar, também, que, seguidos por dois aeroportos brasileiros (Guarulhos e Galeão), três aeroportos estrangeiros se destacam na rede de voos internacionais: aeroporto de Miami (KMIA), nos Estados Unidos, de Lisboa (LPPT), em Portugal, e o aeroporto de Buenos Aires (SAEZ), na Argentina. Assim, tem-se três aeroportos estrangeiros que apresentam nível de importância para a rede de voos internacionais brasileira maior que outros 15 aeroportos brasileiros que atendem voos internacionais (ver Tabela 6.7, que lista esses aeroportos).

Os resultados completos dos parâmetros de vértices para cada um dos grafos considerados neste estudo estão dispostos no Apêndice B, com ordenação baseada no indicador de importância. 
Tabela 6.11. Os cinco aeroportos com maiores indicadores de importância em cada rede.

\begin{tabular}{|c|c|c|c|c|c|c|c|}
\hline & Aeroporto & Sigla & $k$ & $k_{\text {voo }}^{w}$ & $\boldsymbol{B}^{w}$ distância efetiva & $I_{I M P}$ & $I_{I M P(\%)}$ \\
\hline \multicolumn{8}{|c|}{$\underline{R}$ bra_dom } \\
\hline 1 & Guarulhos/SP & SBGR & 86 & 17846 & 4048 & 30,4632 & 1,00 \\
\hline 2 & Brasília/DF & SBBR & 83 & 13383 & 4831 & 25,3364 & 0,94 \\
\hline 3 & Congonhas/SP & SBSP & 57 & 14491 & 4762 & 19,9825 & 0,89 \\
\hline 4 & Campinas/SP & SBKP & 116 & 10086 & 2631 & 19,2902 & 0,84 \\
\hline 5 & Galeão/SP & SBGL & 58 & 9447 & 590 & 14,6177 & 0,78 \\
\hline \multicolumn{8}{|c|}{$R \_b r a \_i n t$} \\
\hline 1 & Guarulhos/SP & SBGR & 110 & 6472 & 6466,0000 & 50,0859 & 1,00 \\
\hline 2 & Galeão/SP & SBGL & 57 & 2125 & 201,0000 & 15,5769 & 0,98 \\
\hline 3 & Miami/Estados Unidos & KMIA & 25 & 1113 & 1424,0000 & 8,7662 & 0,97 \\
\hline 4 & Lisboa/Portugal & LPPT & 23 & 544 & 1076,0000 & 7,2472 & 0,96 \\
\hline 5 & Buenos Aires/Argentina & SAEZ & 17 & 1129 & 1053,0000 & 4,6706 & 0,95 \\
\hline \multicolumn{8}{|c|}{ R_bra_tot } \\
\hline 1 & Guarulhos/SP & SBGR & 195 & 24318 & 22247 & 58,982 & 1,00 \\
\hline 2 & Galeão/SP & SBGL & 115 & 11572 & 1814 & 23,2813 & 0,99 \\
\hline 3 & Brasilia/DF & SBBR & 100 & 13759 & 8645 & 22,1298 & 0,98 \\
\hline 4 & Campinas/SP & SBKP & 131 & 10353 & 4666 & 16,9184 & 0,98 \\
\hline 5 & Congonhas/SP & SBSP & 57 & 14491 & 6711 & 16,3831 & 0,97 \\
\hline \multicolumn{8}{|c|}{$R \_$tam } \\
\hline 1 & Guarulhos/SP & SBGR & 100 & 7371 & 2603 & 35,632 & 1,00 \\
\hline 2 & Brasilia/DF & SBBR & 67 & 5165 & 1046 & 15,9478 & 0,98 \\
\hline 3 & Congonhas/SP & SBSP & 47 & 6432 & 1713 & 15,3173 & 0,96 \\
\hline 4 & Galeão/SP & SBGL & 53 & 3837 & 155 & 11,7444 & 0,95 \\
\hline 5 & Fortaleza/CE & SBFZ & 23 & 1728 & 502 & 4,95219 & 0,93 \\
\hline \multicolumn{8}{|c|}{ R_glo } \\
\hline 1 & Guarulhos/SP & SBGR & 96 & 7873 & 3179 & 34,3867 & 1,00 \\
\hline 2 & Brasília/DF & SBBR & 60 & 4719 & 1136 & 16,6474 & 0,98 \\
\hline 3 & Congonhas/SP & SBSP & 49 & 6123 & 1475 & 15,4283 & 0,97 \\
\hline 4 & Galeão/SP & SBGL & 66 & 4425 & 218 & 15,3437 & 0,95 \\
\hline 5 & Confins/MG & SBCF & 45 & 3255 & 341 & 8,92217 & 0,94 \\
\hline \multicolumn{8}{|c|}{$\underline{R \_a z u}$} \\
\hline 1 & Campinas/SP & SBKP & 118 & 9158 & 8968 & 50,2655 & 1,00 \\
\hline 2 & Confins/MG & SBCF & 66 & 4324 & 2863 & 21,7221 & 0,99 \\
\hline 3 & Guarulhos/SP & SBGR & 38 & 2732 & 0 & 11,1147 & 0,98 \\
\hline 4 & Cuiabá/MT & SBCY & 34 & 1448 & 3194 & 9,902 & 0,97 \\
\hline 5 & Santos Dumont/RJ & SBRJ & 30 & 2425 & 552 & 8,34498 & 0,96 \\
\hline \multicolumn{8}{|c|}{ R_one } \\
\hline 1 & Guarulhos/SP & SBGR & 29 & 1995 & 328 & 18,4163 & 1,00 \\
\hline 2 & Brasília/DF & SBBR & 40 & 1820 & 162 & 14,9981 & 0,95 \\
\hline 3 & Salvador/BA & SBSV & 21 & 1245 & 208 & 9,14994 & 0,91 \\
\hline 4 & Galeão/SP & SBGL & 18 & 984 & 60 & 5,57659 & 0,87 \\
\hline 5 & Congonhas/SP & SBSP & 11 & 1203 & 46 & 3,45501 & 0,83 \\
\hline
\end{tabular}




\subsection{ETAPA IV - SIMULAÇÃO DE ATAQUE SEQUENCIAL}

\subsubsection{GRAFOS CORRESPONDENTES}

A implementação da etapa 3 depende da geração de grafos aleatórios e livres de escala que sejam correspondentes aos grafos representativos da malha aérea brasileira. A Figura 6.11 mostra exemplos da representação visual dos grafos correspondentes à rede de voos domésticos $\left(R \_b r a \_d o m\right)$. Pode-se perceber que a estrutura do grafo livre de escala é caracterizada por uma concentração de conexões em quatro vértices que se localizam na região central do esquema gráfico.
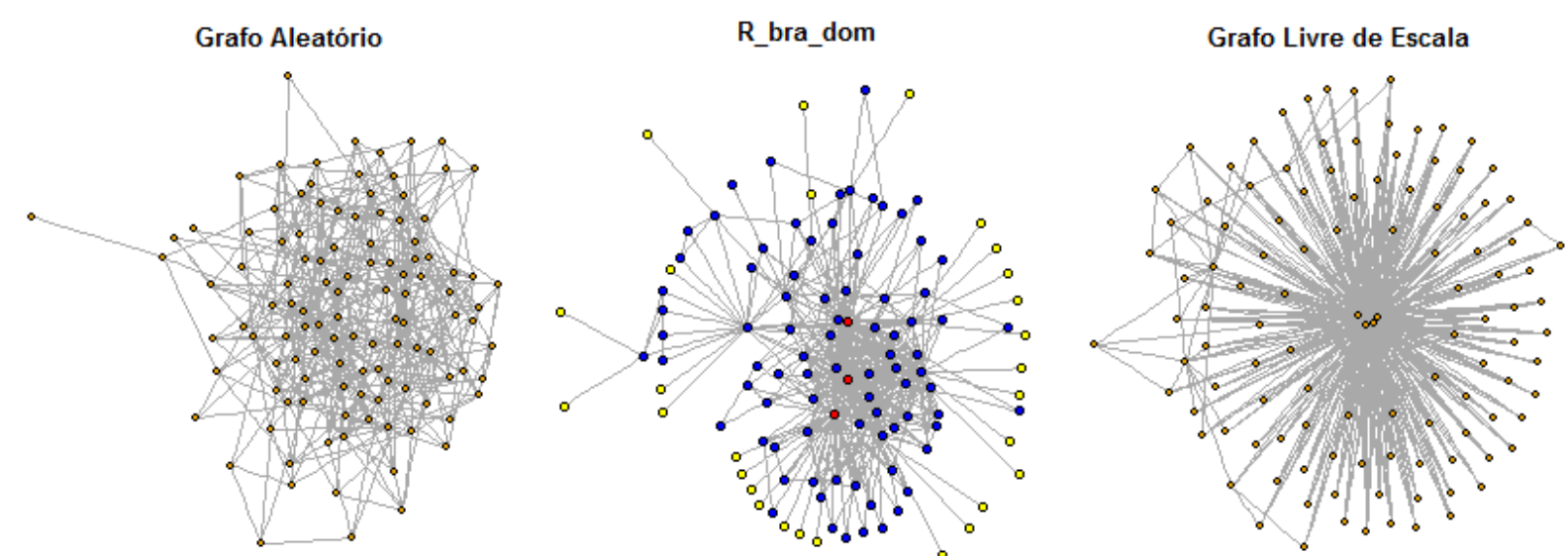

Figura 6.11. Representação visual dos grafos correspondentes à rede $R \_b r a \_d o m$.

A geração dos grafos aleatórios e livres de escala foi implementada através de um processo repetitivo (10 repetições), no qual os parâmetros finais resultam da média das repetições realizadas. Nesse processo, buscou assegurar que os grafos correspondentes tivessem o mesmo número de vértices e arestas ao da rede original. Isso foi alcançado para o grafo aleatório, mas para o grafo livre de escala resultou numa pequena diferença no número de arestas, devido ao mecanismo teórico de construção de grafo livre de escala.

Como pode ser visto na Tabela 6.12, na maioria dos casos obteve-se um grafo livre de escala com uma maior quantidade de arestas, consequentemente uma maior densidade. Essa característica poderia ser um elemento de vantagem durante o processo de simulação de ataque sequencial, pois um grafo com maior densidade seria impactado de forma mais lenta que outro de menor densidade. Assumiu-se que essa diferença não traria prejuízos para os objetivos da pesquisa. 
Tabela 6.12. Comparação dos parâmetros dos grafos originais e dos grafos correspondentes.

\begin{tabular}{|c|c|c|c|c|c|c|c|c|c|}
\hline & \multicolumn{3}{|c|}{$\begin{array}{c}\text { Parâmetros das redes } \\
\text { originais }\end{array}$} & \multicolumn{6}{|c|}{ Parâmetros das redes correspondentes } \\
\hline & \multirow{2}{*}{$\mathbf{N}$} & \multirow{2}{*}{$\mathbf{E}$} & \multirow{2}{*}{ Densidade } & \multicolumn{3}{|c|}{ Grafo aleatório } & \multicolumn{3}{|c|}{ Grafo livre de escala } \\
\hline & & & & $\mathbf{N}$ & $\mathbf{E}$ & Densidade & $\mathbf{N}$ & $\mathbf{E}$ & Densidade \\
\hline R_bra_dom & 114 & 437 & 0,0678 & 114 & 437 & 0,0678 & 114 & 446 & 0,0692 \\
\hline R_bra_int & 87 & 173 & 0,0462 & 87 & 173 & 0,0462 & 87 & 171 & 0,0457 \\
\hline R_bra_tot & 184 & 609 & 0,0362 & 184 & 609 & 0,0361 & 184 & 726 & 0,0431 \\
\hline R_tam & 63 & 210 & 0,1075 & 63 & 210 & 0,1075 & 63 & 242 & 0,1239 \\
\hline R_glo & 74 & 252 & 0,0933 & 74 & 252 & 0,0932 & 74 & 286 & 0,1058 \\
\hline R_azu & 106 & 258 & 0,0464 & 106 & 258 & 0,0463 & 106 & 312 & 0,0560 \\
\hline R_one & 25 & 59 & 0,1967 & 25 & 59 & 0,1966 & 25 & 69 & 0,2300 \\
\hline
\end{tabular}

\subsubsection{GRAU DE VULNERABILIDADE}

Conforme proposto pelo método, o grau de vulnerabilidade da rede de transporte aéreo é avaliado por meio de uma abordagem comparativa do comportamento da rede frente a ataques sequenciais aos seus aeroportos. Esse comportamento é refletido por meio da curva gerada no gráfico que associa a maior componente conectada e a porcentagem de aeroportos removidos.

A Figura 6.12 e a Figura 6.13 apresentam os gráficos resultantes das simulações realizadas em cada rede. A medida que a número de aeroportos removidos aumenta, cai o tamanho da maior componente conectada, até chegar ao ponto de desintegração total da rede, ou seja, a situação de aeroportos isolados.

Verifica-se que a desintegração dos grafos aleatórios ocorre a partir de $40 \%$ de aeroportos removidos. Enquanto que os grafos originais ou livres de escala já chegam à essa desintegração numa faixa entre 20 a 30\%. Como esperado, o comportamento dos grafos aleatórios, representados pelas curvas em azul, indicam grafos menos vulneráveis aos ataques sequenciais.

Todas as redes de transporte aéreo consideradas resultaram em curvas próximas ao comportamento registrado para os grafos livres de escala. Isso confirma os resultados empíricos encontrados em outras redes de transporte aéreo, de onde se verificou, também, comportamentos similares. 

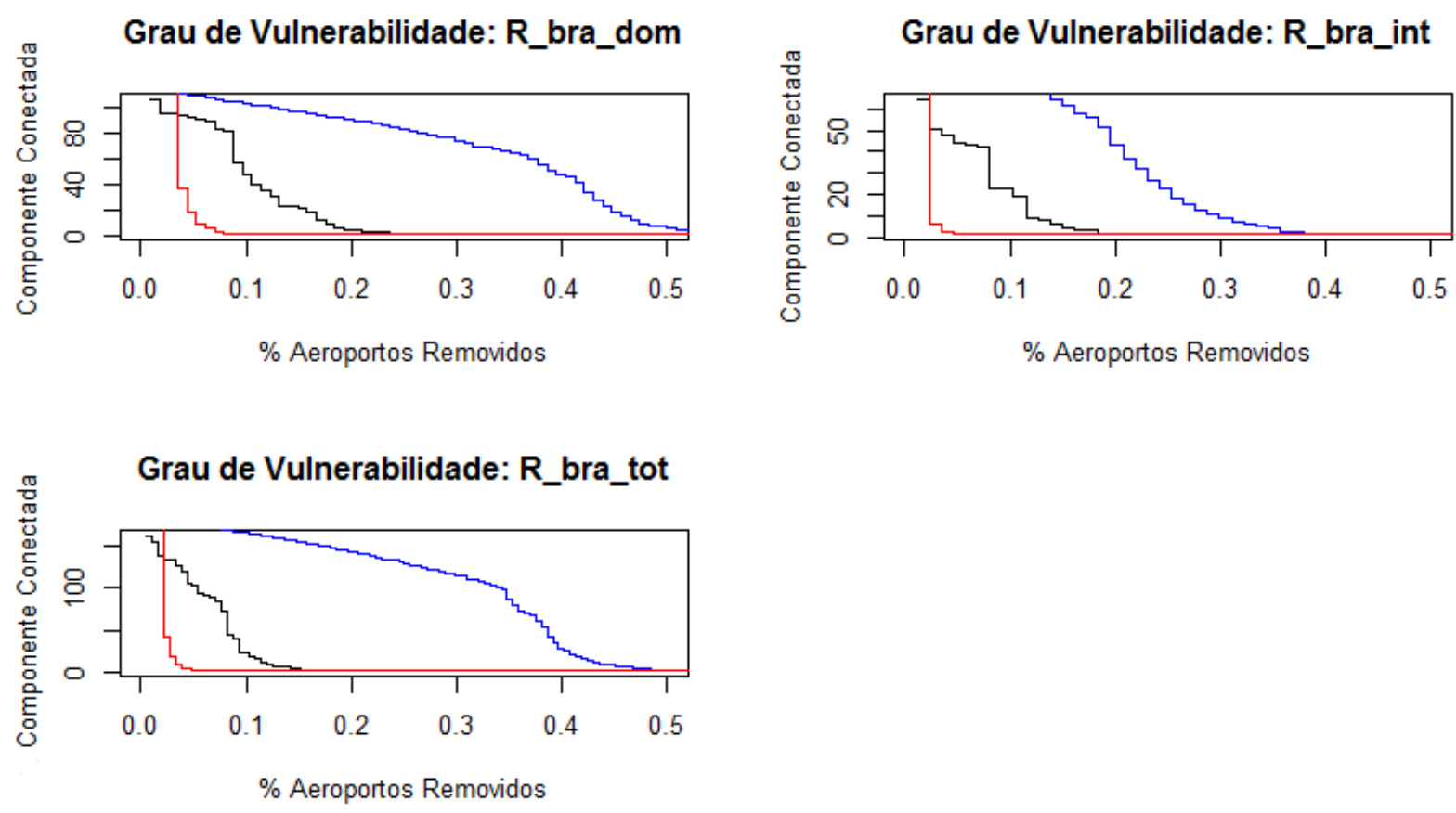

Figura 6.12. Resultados da simulação de ataque sequencial. Cores das curvas: preto para a rede original, azul para a rede aleatória e vermelho para a rede livre de escala.
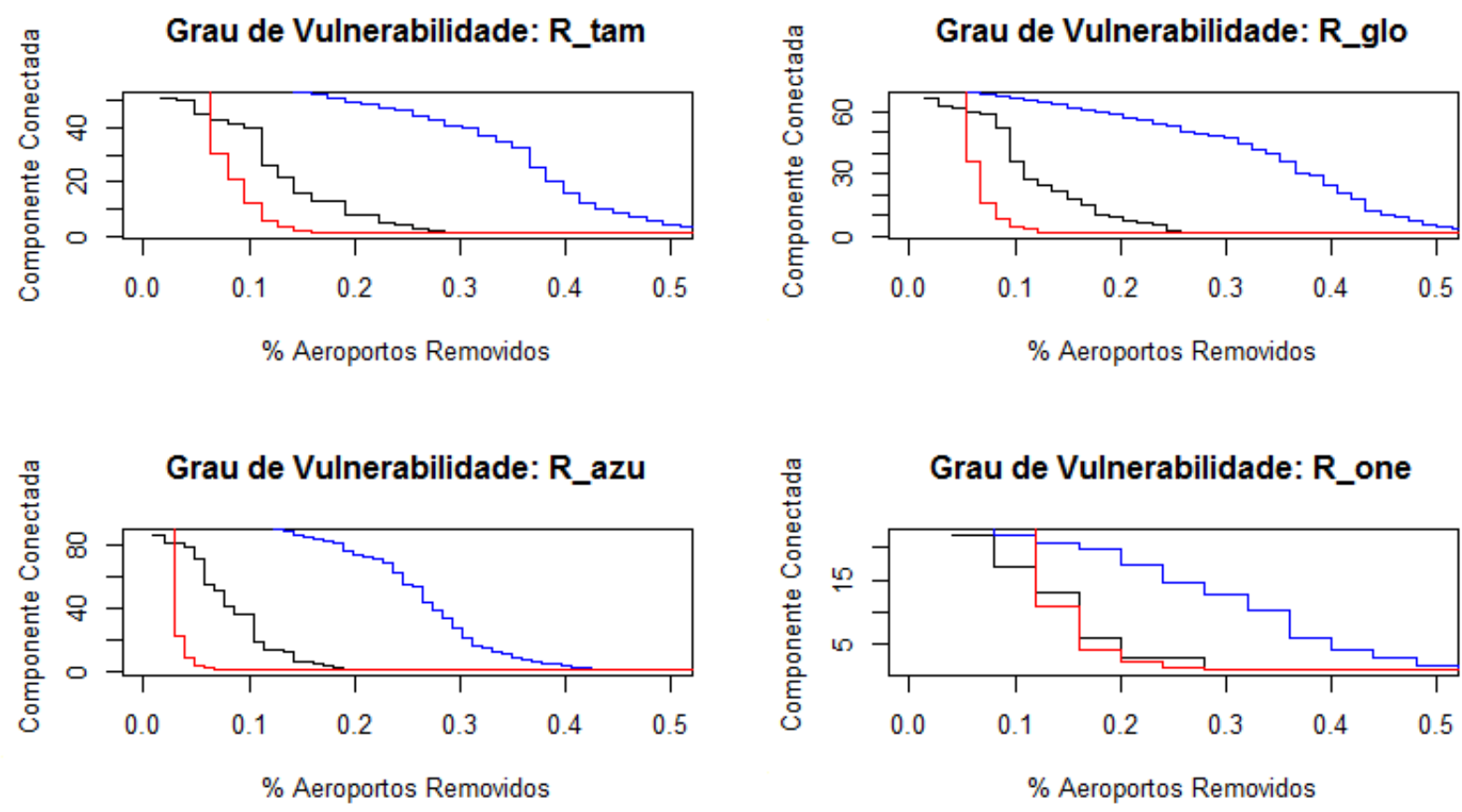

Figura 6.13. Resultados da simulação de ataque sequencial. Cores das curvas: preto para a rede original, azul para a rede aleatória e vermelho para a rede livre de escala. 
A Tabela 6.13 apresentam os resultados encontrados para a dominância do ponto central de cada uma das redes de transporte aéreo. Essa medida reflete a dependência da rede em relação ao aeroporto mais central, segundo a medida do grau de intermediação topológico. A rede de voos internacionais apresentou a maior dominância do ponto central, com valor de 0,68 , seguida pela rede de voos da TAM.

Tabela 6.13. Dominância do ponto central das RTAer.

\begin{tabular}{ll}
\hline \multicolumn{1}{c}{ Redes } & $\boldsymbol{C}_{\boldsymbol{D}}$ \\
\hline R_bra_dom & 0,31 \\
R_bra_int & 0,68 \\
R_bra_tot & 0,43 \\
R_tam & 0,58 \\
R_glo & 0,42 \\
R_azu & 0,57 \\
R_one & 0,47 \\
\hline
\end{tabular}

\subsubsection{AEROPORTOS CRÍTICOS DETERMINADOS PELA LITERATURA}

Essa etapa do método, que busca avaliar tão somente o grau de vulnerabilidade das redes, baseia-se parcialmente na metodologia de análise de vulnerabilidade proposta por Lordan et al., (2014b). Assim, para fins de comparação com os resultados finais que serão obtidos com a aplicação da etapa IV do método proposto nesta dissertação, foram listados na Tabela 6.14 os primeiros seis aeroportos que seriam considerados como críticos pela literatura, para cada uma das redes de transporte estudadas.

Observa-se na Tabela 6.14 que, segundo o método da literatura, o aeroporto de Viracopos (SBKP) seria considerado o mais crítico para a rede de voos domésticos ( $\left.R \_b r a \_d o m\right)$, enquanto que o aeroporto de Guarulhos (SBGR) assumiria a quarta posição. Nas redes que possuem voos internacionais ( $R \_b r a \_i n t, R \_b r a \_t o t, R \_t a m$ e $R \_g l o$ ) o aeroporto de Guarulhos se destacaria, possivelmente devido ao papel que o aeroporto exerce como principal porta de entrada de voos internacionais no Brasil. 
Tabela 6.14. Ordenação dos aeroportos que seriam críticos, segundo Lordan et al., $(2014 b)$.

\begin{tabular}{|c|c|c|c|c|c|c|c|c|c|}
\hline \multirow{2}{*}{ SIGLA } & \multirow{2}{*}{ Nome } & \multirow{2}{*}{$\mathbf{U F}$} & \multicolumn{7}{|c|}{ Redes } \\
\hline & & & bra_dom & bra_int & bra_tot & tam & glo & azu & one \\
\hline SBBE & Val de Cans & $\mathrm{PA}$ & & & & & & $6^{\circ}$ & \\
\hline SBBR & Presidente Juscelino Kubitschek & $\mathrm{DF}$ & $3^{\circ}$ & & $4^{\mathrm{o}}$ & $2^{\mathrm{o}}$ & $3^{\circ}$ & $3^{\circ}$ & $1^{\circ}$ \\
\hline SBCF & Tancredo Neves & MG & $5^{\circ}$ & & $5^{\circ}$ & & $4^{\circ}$ & $2^{\circ}$ & \\
\hline SBCY & Marechal Rondon & MT & & & & & & $5^{\circ}$ & \\
\hline SBEG & Eduardo Gomes & $\mathrm{AM}$ & $2^{\circ}$ & & & & & & \\
\hline SBFL & Hercílio Luz & $\mathrm{SC}$ & & & & & & & $5^{\circ}$ \\
\hline SBFZ & Pinto Martins & $\mathrm{CE}$ & & & & $5^{\circ}$ & $5^{\circ}$ & & $6^{\circ}$ \\
\hline SBGL & Galeão & RJ & $6^{\circ}$ & $2^{\mathrm{o}}$ & $3^{\circ}$ & $3^{\circ}$ & $2^{o}$ & & $4^{\circ}$ \\
\hline SBGR & Guarulhos & SP & $4^{\circ}$ & $1^{\mathrm{o}}$ & $1^{\mathrm{o}}$ & $1^{\mathrm{o}}$ & $1^{\mathrm{o}}$ & $4^{\circ}$ & $2^{\circ}$ \\
\hline SBKP & Viracopos & $\mathrm{SP}$ & $1^{\mathrm{o}}$ & & $2^{\mathrm{o}}$ & & & $1^{\mathrm{o}}$ & \\
\hline SBSP & Congonhas & $\mathrm{SP}$ & & & & $4^{\circ}$ & $6^{\circ}$ & & \\
\hline SBSV & Dep. Luís Eduardo Magalhões & $\mathrm{BA}$ & & & $6^{\circ}$ & & & & $3^{\circ}$ \\
\hline KMIA & Miami / Estados Unidos & - & & $4^{\circ}$ & & $6^{\circ}$ & & & \\
\hline LPPT & Lisboa / Portugal & - & & $3^{\circ}$ & & & & & \\
\hline МРТO & Tocumen / Panamá & - & & $6^{\circ}$ & & & & & \\
\hline SAEZ & Ezeiza / Argentina & - & & $5^{\circ}$ & & & & & \\
\hline
\end{tabular}

\subsection{ETAPA V - SIMULAÇÃO DE INTERRUPÇÃO INDIVIDUAL}

O último estágio de aplicação do método envolve o processo de remoção individual, com reposição, de vértices dos grafos construídos, de forma a simular uma interrupção operacional ou o fechamento temporário de um único aeroporto da rede e ser possível avaliar os impactos estruturais e funcionais causados. O tipo de evento adverso que leva à interrupção do aeroporto, seja de natureza aleatória (falhas) ou determinística (ataque), não foi relevante para esta etapa. A simples consideração da interrupção foi considerada suficiente para que fossem avaliados os possíveis impactos gerados e o nível de criticidade do aeroporto.

Os impactos gerados à rede foram avaliados através da variação relativa entre um parâmetro original e situacional do grafo. Os parâmetros originais $\left(\mathrm{P}_{0}\right)$ foram medidos para o grafo em seu estado inicial. Os parâmetros situacionais ( $\mathrm{P}_{i}$, sendo $i$ um determinado vértice) foram medidos em cada uma das simulações de um aeroporto removido. A diferença relativa $\left(\left(\mathrm{P}_{\mathrm{i}}-\mathrm{P}_{0}\right) / \mathrm{P}_{0}\right)$ foi associada ao impacto provocado ao grafo, devido à remoção do vértice $i$.

No processo de simulação, oito parâmetros foram monitorados, sendo três parâmetros de caráter estrutural, definidos pela densidade, maior componente conectada e conectividade global da rede $\left(\sum k\right)$, e outros cinco parâmetros funcionais: eficiência, acessibilidade global $\left(\sum k^{w} D I S T A \hat{N} C I A\right)$, 
tráfego de aeronaves global ( $\left.\sum \mathrm{k}^{\mathrm{w}} \mathrm{voo}\right)$, oferta de assentos global $\left(\sum \mathrm{k}^{\mathrm{w}}\right.$ ASSENTOS $)$ e demanda global atendida $\left(\sum \mathrm{k}^{\mathrm{w}}{ }_{\mathrm{RPK}}\right)$.

Na Tabela 6.15 estão indicados os 25 aeroportos que causaram maiores impactos na rede de voos domésticos ( $\left.R \_b r a \_d o m\right)$, ordenados segundo o resultado do indicador de criticidade $\left(I_{C R I}\right)$. O primeiro valor do indicador é aquele obtido pela fórmula de cálculo da Equação 20, apresentada na seção 5.3.5. O segundo valor do indicador $\left(I_{C R I(\%)}\right)$ foi obtido com o emprego da função denominada “ordem.porcentual” do software Excel, que retorna a posição de um valor em um conjunto de dados na forma de uma porcentagem do conjunto de dados.

Os resultados completos das variações nos parâmetros de cada um dos grafos considerados neste estudo estão dispostos no Apêndice C. Mais à frente, a Tabela 6.16 relaciona os cincos aeroportos que obtiveram os maiores indicadores de criticidade em cada uma das redes.

A ordenação dos aeroportos pelo indicador de criticidade se diferencia, em certa medida, da ordenação alcançada pelo indicador de importância, medido na etapa de análise topológica da rede. Como já discutido, o indicador de importância reflete características próprias do aeroporto, tais como, a quantidade de rotas disponíveis, de voos realizados, de assentos ofertados, dentre outros atributos operacionais. Em geral, os aeroportos que apresentam valores elevados para esses atributos são considerados essenciais para o bom funcionamento da rede de transporte aéreo. No entanto, o processo de simulação da interrupção individual de aeroportos permite quantificar, de fato, os possíveis impactos gerados à rede e determinar, o real nível de criticidade que deve ser atribuído a um aeroporto. Desse modo, a ordenação baseada no indicador de criticidade resulta numa melhor precisão acerca da essencialidade do aeroporto para o funcionamento normal da rede. 
Tabela 6.15. Impactos dos 25 aeroportos mais críticos da rede $R \_b r a \_d o m$.

\begin{tabular}{|c|c|c|c|c|c|c|c|c|c|c|c|c|}
\hline & & \multirow[b]{2}{*}{ Sigla } & \multicolumn{3}{|c|}{ Impactos Es truturais } & \multicolumn{5}{|c|}{ Impactos Funcionais } & \multicolumn{2}{|c|}{ Indicador } \\
\hline & & & Densidade & Componente & $\sum k$ & Eficiência $\sum \boldsymbol{k}^{w}$ & & $\sum \boldsymbol{k}_{v}^{w}$ & $\sum \boldsymbol{k}_{a}^{w}$ & $\sum k_{R P K}^{w}$ & $I_{C R I}$ & $I_{C R I(\%)}$ \\
\hline 2 & Viracopos/SP & SBKP & $-0,1409$ & $-0,0702$ & $-0,1409$ & $-0,0925$ & $-0,1456$ & $-0,1218$ & $-0,0937$ & $-0,0811$ & 28,82 & 0,99 \\
\hline 4 & Congonhas/SP & SBSP & $-0,0693$ & $-0,0088$ & $-0,0693$ & $-0,1375$ & $-0,0517$ & $-0,1750$ & $-0,1915$ & $-0,1120$ & 20,40 & 0,97 \\
\hline 5 & Salvador/BA & SBSV & $-0,0753$ & $-0,0351$ & $-0,0753$ & $-0,0900$ & $-0,0760$ & $-0,0898$ & $-0,0968$ & $-0,1147$ & 17,67 & 0,96 \\
\hline 6 & Confins/MG & SBCF & $-0,0826$ & $-0,0175$ & $-0,0826$ & $-0,0885$ & $-0,0842$ & $-0,1106$ & $-0,1075$ & $-0,0778$ & 16,94 & 0,96 \\
\hline 9 & Porto Alegre/RS & SBPA & $-0,0595$ & $-0,0263$ & $-0,0595$ & $-0,0728$ & $-0,0769$ & $-0,0712$ & $-0,0732$ & $-0,0719$ & 12,89 & 0,93 \\
\hline 10 & Santos Dumont/RJ & SBRJ & $-0,0413$ & $-0,0175$ & $-0,0413$ & $-0,1053$ & $-0,0303$ & $-0,1085$ & $-0,1080$ & $-0,0499$ & 11,59 & 0,92 \\
\hline 11 & Cuiabá/MT & SBCY & $-0,0510$ & $-0,0526$ & $-0,0510$ & $-0,0681$ & $-0,0591$ & $-0,0342$ & $-0,0304$ & $-0,0347$ & 10,82 & 0,91 \\
\hline 12 & Recife/PE & SBRF & $-0,0462$ & $-0,0088$ & $-0,0462$ & $-0,0521$ & $-0,0693$ & $-0,0636$ & $-0,0705$ & $-0,1087$ & 9,71 & 0,90 \\
\hline 13 & Fortaleza/CE & SBFZ & $-0,0462$ & $-0,0088$ & $-0,0462$ & $-0,0466$ & $-0,0739$ & $-0,0570$ & $-0,0668$ & $-0,1095$ & 9,40 & 0,89 \\
\hline 14 & Curitiba/PR & SBCT & $-0,0486$ & $-0,0088$ & $-0,0486$ & $-0,0842$ & $-0,0489$ & $-0,0719$ & $-0,0734$ & $-0,0409$ & 9,21 & 0,88 \\
\hline 19 & Porto Seguro/BA & SBPS & $-0,0389$ & $-0,0088$ & $-0,0389$ & $-0,0262$ & $-0,0465$ & $-0,0149$ & $-0,0161$ & $-0,0148$ & 2,52 & 0,84 \\
\hline 20 & Florianópolis/SC & SBFL & $-0,0231$ & $-0,0088$ & $-0,0231$ & $-0,0557$ & $-0,0148$ & $-0,0346$ & $-0,0367$ & $-0,0209$ & 2,42 & 0,83 \\
\hline 21 & Ribeirão Preto/SP & SBRP & $-0,0413$ & $-0,0088$ & $-0,0413$ & $-0,0328$ & $-0,0304$ & $-0,0195$ & $-0,0125$ & $-0,0049$ & 2,23 & 0,82 \\
\hline 22 & Vitória/ES & SBVT & $-0,0243$ & $-0,0088$ & $-0,0243$ & $-0,0371$ & $-0,0203$ & $-0,0334$ & $-0,0340$ & $-0,0199$ & 1,87 & 0,81 \\
\hline 23 & Campo Grande/MS & SBCG & $-0,0255$ & $-0,0175$ & $-0,0255$ & $-0,0292$ & $-0,0232$ & $-0,0162$ & $-0,0159$ & $-0,0147$ & 1,51 & 0,81 \\
\hline 24 & São Luís/MA & SBSL & $-0,0231$ & $-0,0088$ & $-0,0231$ & $-0,0250$ & $-0,0329$ & $-0,0185$ & $-0,0200$ & $-0,0255$ & 1,12 & 0,80 \\
\hline 25 & Londrina/PR & SBLO & $-0,0243$ & $-0,0088$ & $-0,0243$ & $-0,0292$ & $-0,0240$ & $-0,0119$ & $-0,0109$ & $-0,0052$ & 0,21 & 0,79 \\
\hline
\end{tabular}


Tabela 6.16. Os cinco aeroportos com maiores indicadores de criticidade em cada rede.

\begin{tabular}{|c|c|c|c|c|c|c|c|c|}
\hline \multirow[b]{2}{*}{ Aeroporto } & \multirow[b]{2}{*}{ Sigla } & \multicolumn{3}{|c|}{ Impactos Estruturais } & \multicolumn{2}{|c|}{ Impactos Funcionais } & \multicolumn{2}{|c|}{ Indicador } \\
\hline & & Densidade & Componente & $\sum k$ & Eficiência & $\sum \boldsymbol{k}^{w}{ }_{v o o}$ & $I_{C R I}$ & $I_{C R I(\%)}$ \\
\hline \multicolumn{9}{|l|}{ R_bra_dom } \\
\hline 1 Guarulhos/SP & SBGR & $-0,1045$ & $-0,0088$ & $-0,1045$ & $-0,0934$ & $-0,2156$ & 31,44 & 1,00 \\
\hline 2 Viracopos/SP & SBKP & $-0,1409$ & $-0,0702$ & $-0,1409$ & $-0,0925$ & $-0,1218$ & 28,82 & 0,99 \\
\hline 3 Brasilia/DF & SBBR & $-0,1009$ & $-0,0088$ & $-0,1009$ & $-0,0830$ & $-0,1617$ & 24,89 & 0,98 \\
\hline 4 Congonhas/SP & SBSP & $-0,0693$ & $-0,0088$ & $-0,0693$ & $-0,1375$ & $-0,1750$ & 20,40 & 0,97 \\
\hline 5 Salvador/BA & SBSV & $-0,0753$ & $-0,0351$ & $-0,0753$ & $-0,0900$ & $-0,0898$ & 17,67 & 0,96 \\
\hline \multicolumn{9}{|l|}{$R \_b r a \_i n t$} \\
\hline 1 Guarulhos/SP & SBGR & $-0,3395$ & $-0,2529$ & $-0,3395$ & $-0,6879$ & $-0,5732$ & 65,9789 & 1,00 \\
\hline 2 Galeão/SP & SBGL & $-0,1759$ & $-0,0230$ & $-0,1759$ & $-0,0673$ & $-0,1882$ & 19,1394 & 0,99 \\
\hline 3 Miami/Estados Unidos & KMIA & $-0,0772$ & $-0,0115$ & $-0,0772$ & $-0,0780$ & $-0,0986$ & 7,9396 & 0,98 \\
\hline 4 Lisboa/Portugal & LPPT & $-0,0710$ & $-0,0345$ & $-0,0710$ & $-0,0531$ & $-0,0482$ & 7,5131 & 0,97 \\
\hline 5 Buenos Aires/Argentina & SAEZ & $-0,0525$ & $-0,0115$ & $-0,0525$ & $-0,1257$ & $-0,1000$ & 4,3639 & 0,95 \\
\hline \multicolumn{9}{|c|}{$R \_b r a \_t o t$} \\
\hline 1 Guarulhos/SP & SBGR & $-0,1702$ & $-0,1196$ & $-0,1702$ & $-0,2158$ & $-0,2585$ & 74,2325 & 1,00 \\
\hline 2 Galeão/SP & SBGL & $-0,1003$ & $-0,0109$ & $-0,1003$ & $-0,0555$ & $-0,1230$ & 28,1044 & 0,99 \\
\hline 3 Campinas/SP & SBKP & $-0,1143$ & $-0,0489$ & $-0,1143$ & $-0,0850$ & $-0,1100$ & 25,9245 & 0,99 \\
\hline 4 Brasilia/DF & SBBR & $-0,0873$ & $-0,0054$ & $-0,0873$ & $-0,0684$ & $-0,1462$ & 22,9077 & 0,98 \\
\hline 5 Congonhas/SP & SBSP & $-0,0497$ & $-0,0054$ & $-0,0497$ & $-0,1118$ & $-0,1540$ & 18,1093 & 0,98 \\
\hline \multicolumn{9}{|l|}{$R \_$tam } \\
\hline 1 Guarulhos/SP & SBGR & $-0,2681$ & $-0,1905$ & $-0,2681$ & $-0,2631$ & \begin{tabular}{|l|}
$-0,3086$ \\
\end{tabular} & 46,2049 & 1,00 \\
\hline 2 Brasilia/DF & SBBR & $-0,1796$ & $-0,0159$ & $-0,1796$ & $-0,1454$ & $-0,2162$ & 18,0693 & 0,98 \\
\hline 3 Congonhas/SP & SBSP & $-0,1260$ & $-0,0159$ & $-0,1260$ & $-0,3097$ & $-0,2692$ & 17,7126 & 0,97 \\
\hline 4 Galeão/SP & SBGL & $-0,1421$ & $-0,0159$ & $-0,1421$ & $-0,0826$ & $-0,1606$ & 13,8714 & 0,95 \\
\hline 5 Fortaleza/CE & SBFZ & $-0,0617$ & $-0,0159$ & $-0,0617$ & $-0,0611$ & $-0,0723$ & 4,2423 & 0,94 \\
\hline \multicolumn{9}{|l|}{ R_glo } \\
\hline 1 Guarul & GR & $-0,2008$ & $-0,0946$ & $-0,2008$ & $-0,1881$ & \begin{tabular}{l|l|}
$-0,2703$ \\
\end{tabular} & 41,7870 & 1,00 \\
\hline 2 Congonhas/SP & SBSP & $-0,1025$ & $-0,0676$ & $-0,1025$ & $-0,2408$ & $-0,2102$ & 22,9023 & 0,99 \\
\hline 3 Galeão/SP & SBGL & $-0,1381$ & $-0,0135$ & $-0,1381$ & $-0,0813$ & $-0,1519$ & 18,2883 & 0,97 \\
\hline 4 Brasília/DF & SBBR & $-0,1255$ & $-0,0135$ & $-0,1255$ & $-0,1148$ & $-0,1620$ & 18,0360 & 0,96 \\
\hline 5 Confins/MG & SBCF & $-0,0941$ & $-0,0270$ & $-0,0941$ & $-0,0997$ & $-0,1118$ & 11,9298 & 0,95 \\
\hline \multicolumn{9}{|l|}{ R_azu } \\
\hline 1 Campinas/SP & SBKP & $-0,2346$ & $-0,1792$ & $-0,2346$ & $-0,4622$ & $-0,3746$ & 65,3293 & 1,00 \\
\hline 2 Confins/MG & SBCF & $-0,1312$ & $-0,0283$ & $-0,1312$ & $-0,1080$ & $-0,1769$ & 23,9736 & 0,99 \\
\hline 3 Cuiabá/MT & SBCY & $-0,0676$ & $-0,0660$ & $-0,0676$ & $-0,1128$ & $-0,0592$ & 12,2066 & 0,98 \\
\hline 4 Guarulhos/SP & SBGR & $-0,0755$ & $-0,0094$ & $-0,0755$ & $-0,0434$ & $-0,1118$ & 12,1129 & 0,97 \\
\hline 5 Porto Alegre/RS & SBPA & $-0,0636$ & $-0,0283$ & $-0,0636$ & $-0,0803$ & $-0,0855$ & 9,8543 & 0,96 \\
\hline \multicolumn{9}{|l|}{ R_one } \\
\hline 1 Brasîlia/DF & SBBR & $-0,3509$ & $-0,1200$ & $-0,3509$ & $-0,1961$ & $-0,2965$ & 20,9522 & 1,00 \\
\hline 2 Guarulhos/SP & SBGR & $-0,2544$ & $-0,0800$ & $-0,2544$ & $-0,3026$ & $-0,3250$ & 20,1659 & 0,96 \\
\hline 3 Salvador/BA & SBSV & $-0,1842$ & $-0,0400$ & $-0,1842$ & $-0,2458$ & $-0,2028$ & 8,9577 & 0,92 \\
\hline 4 Galeão/RJ & SBGL & $-0,1579$ & $-0,0400$ & $-0,1579$ & $-0,1572$ & $-0,1603$ & 5,6779 & 0,88 \\
\hline 5 Fortaleza/CE & SBFZ & $-0,1053$ & $-0,0800$ & $-0,1053$ & $-0,0955$ & $-0,0823$ & 4,0165 & 0,83 \\
\hline
\end{tabular}

\subsection{TÓPICOS CONCLUSIVOS}

Inicialmente, o objetivo deste capítulo foi apresentar os recursos utilizados e os instrumentos produzidos para alcançar a implementação do método proposto no capítulo anterior. Em seguida, tratou-se da aplicação das etapas do método, no qual a primeira etapa envolveu uma caracterização básica do sistema de aviação civil brasileiro, dando ênfase na descrição das características da base de dados utilizada na etapa de modelagem da rede de transporte aéreo. 
Observou-se que no processo de modelagem é necessária uma especificação clara dos elementos que constituem o modelo, de forma a permitir a interpretação adequada dos resultados gerados tanto na análise topológica quanto nos processos de simulação de interrupções dos aeroportos.

O primeiro processo de simulação (ataque sequencial) gerou os resultados que permitem avaliar o grau de vulnerabilidade das redes. Efetuou-se, também, o segundo processo de simulação, obtendo-se dados que permitirão avaliar a criticidades dos aeroportos que compõem a rede.

Assim, efetuada a aplicação, o capítulo seguinte abrange a análise dos resultados, que constitui a última etapa do método proposto. 


\section{ANÁLISE DOS RESULTADOS}

\subsection{APRESENTAÇÃO}

Este capítulo tem como objetivo efetuar a última etapa do método de análise de vulnerabilidade, analisando os resultados e propondo direcionamentos paras as esferas de planejamento, regulação e fiscalização do setor. As aplicações das etapas I e II do método proposto forneceram resultados que não carecem de uma análise adicional específica.

A aplicação da etapa III, devido a sua própria forma de operacionalização, já enseja a realização de uma análise topológica da rede que, para os objetivos desta dissertação, já foi suficientemente efetuada no capítulo anterior. Assim, a seguir foi feita apenas uma breve recapitulação dos resultados das três primeiras etapas do método. Em seguida, fez-se a análise dos resultados das últimas duas etapas, que constituem os processos de simulação de interrupção de aeroportos.

\subsection{ETAPA I - CARACTERIZAÇÃO DO SISTEMA}

O sistema de aviação civil brasileiro tem uma longa trajetória de desenvolvimento. Especificamente a respeito do transporte aéreo público, a evolução desse mercado passou por ao menos duas fases características, antes e depois das medidas de desregulamentação gradual do setor, também conhecida como liberalização econômica.

Esta política de liberalização proporcionou diversos efeitos positivos ao mercado e aos usuários dos serviços. Por outro lado, quando conjugada à falta de planejamento e execução de investimentos na infraestrutura aeroportuária e aos interesses econômicos das empresas, os serviços de transporte aéreo público passaram a servir menos localidades. Viveu-se um processo de concentração de voos em poucos aeroportos, especificamente naqueles utilizados como hubs pelas empresas aéreas.

Essa estrutura concentrada de voos tende a ser mais sensível a eventos de interrupção dos aeroportos, o que reforça a justificativa para a realização de uma análise de vulnerabilidade sistemática do sistema para compor um processo mais amplo de gerenciamento de riscos.

Assim, através das informações disponíveis na base de dados do transporte aéreo brasileiro, foi possível delimitar sete redes de transporte aéreo de passageiros: rede de voos domésticos, rede de voos internacionais, rede de voos totais (domésticos e internacionais), e redes individuais de 
voos das empresas aéreas brasileiras com maiores participações de mercado (TAM, GOL, AZUL e AVIANCA). A partir daí, aplicou-se o método em cada uma delas, com foco na rede de voos domésticos.

\subsection{ETAPA II - MODELAGEM DA REDE DE TRANSPORTE}

Para a criação dos modelos de rede, realizou-se uma preparação preliminar da base de dados. Devido a forma de recebimento e armazenamento dos dados pela ANAC, esse procedimento resultou numa perda de informação de voos internacionais realizados por empresas estrangeiras de aproximadamente $3,3 \%$ da demanda por transporte aéreo atendida por essas empresas. No entanto, o valor não foi considerado significativo para prejudicar a aplicação do método na rede de voos internacionais ou totais. De fato, as análises seguintes demonstram o levantamento de resultados coerentes, mesmo com essa ausência de dados.

Tendo sido preparada a base de dados, foram gerados no ambiente computacional os grafos representativos das redes de transporte, delimitadas na etapa anterior. Criou-se modelos direcionados e não direcionados para atender aos objetivos específicos das análises intermediárias, de acordo com a proposta do método. Os modelos direcionados evidenciaram um nível de reciprocidade (presença de voos diretos de ida e volta) relativamente mais baixo na rede da empresa TAM. Enquanto que sua rede apresentou uma reciprocidade de $78 \%$ das rotas, as outras três empresas aéreas operam redes com valores de reciprocidade entre 90 e $95 \%$. Isso sugere que a operação de voos circulares é mais comum na rede da empresa TAM.

\subsection{ETAPA III - ANÁLISE TOPOLÓGICA DA REDE}

Com os modelos de rede estabelecidos, procedeu-se a análise topológica dos sete grafos constituídos e que representam diferentes níveis da rede de transporte aéreo brasileira. A visualização esquemática dos grafos conseguiu fornecer uma primeira noção sobre a estrutura topológica das redes, destacando a presença de vértices centrais e periféricos.

Os resultados dos parâmetros dos grafos demonstraram a presença do efeito de mundo pequeno (small-world) na estrutura das redes, tendo em vista os baixos valores relativos de caminho geodésico médio e valores significativos de coeficiente de aglomeração, similares a resultados de outros estudos. O grau topológico dos vértices apresentou uma curva de distribuição do tipo lei de potência, que é característico de redes complexas do tipo livre de escala. Assim, 
confirmou-se, mais uma vez, a presença das propriedades de mundo pequeno e de livre de escala na rede de transporte aéreo brasileira.

A medição das centralidades dos vértices permitiu identificar o nível de importância que os aeroportos apresentam de acordo com suas próprias propriedades. Existe uma correlação linear relativamente forte entre algumas medidas de centralidade, mas que não se mostra suficiente para a adoção de apenas um critério de importância. Cada aeroporto possui características operacionais próprias que lhe fazem destacar em determinados parâmetros. Assim, o emprego de um indicador que conjugue os resultados de cada media foi útil para alcançar uma ordenação final dos aeroportos quanto ao nível de importância.

\subsection{ETAPA IV - SIMULAÇÃO DE ATAQUES SEQUENCIAIS}

O processo de simulação de ataques sequenciais teve como objetivo permitir uma avaliação do grau de vulnerabilidade das redes. Esta avaliação ocorreu por meio de uma verificação comparativa do comportamento da rede real com o comportamento de redes fictícias sob o cenário de interrupção definido.

O comportamento foi descrito por meio do monitoramento da variação da maior componente conectada na medida em que os vértices do grafo eram removidos um a um. A maior componente conectada é um parâmetro de grafo que mede o número de vértices que estão conectados formando a maior componente presente no grafo.

Os grafos originais de todas as redes estudadas eram completamente conectados, ou seja, é possível partir de qualquer aeroporto e chegar a qualquer outro aeroporto da rede, mas sob um cenário de ataques sequenciais, alguns aeroportos passam a ficar isolados do sistema, sem conexões, e o tamanho da maior componente conectada decresce.

O grau de vulnerabilidade de todos os grafos se situou na situação intermediária esperada, conforme mostrado pela Figura 6.12 e Figura 6.13 da seção 6.6.2. Trata-se de um comportamento intermediário entre o apresentado por um grafo aleatório e um grafo livre de escala correspondentes, mas bem próximo ao nível de vulnerabilidade apresentado por esse último.

Comparando os resultados associados a cada rede de transporte, verificou-se que a estrutura da rede de voos domésticos é menos vulnerável que àquela formada por voos internacionais. A 
primeira rede se desintegra quando aproximadamente $25 \%$ dos aeroportos são removidos. A desintegração da segunda rede já ocorre antes da faixa de $20 \%$ de aeroportos removidos.

A susceptibilidade à interrupção do aeroporto central (maior grau de intermediação) da rede de voos internacionais também é indicada pelo parâmetro da dominância do ponto central (Tabela 6.13), que resultou em 0,68 , o maior valor dentre todas as sete redes consideradas.

No âmbito do transporte aéreo doméstico, as redes das empresas TAM, GOL e AVIANCA se comportaram de forma similar, com uma desintegração total ocorrendo somente próximo da faixa de $30 \%$ de aeroportos removidos. A rede da AZUL resultou na pior situação de vulnerabilidade, podendo ser desintegrada com a proporção de $20 \%$ de remoção de aeroportos.

No que se refere à dominância do ponto central, presentes na Tabela 6.13, as redes da TAM e da AZUL apresentam praticamente o mesmo nível de dependência do aeroporto de maior grau de intermediação. Esse nível é maior que o medido para as redes das empresas GOL e AVIANCA.

Desta forma, os eventos adversos de natureza intencional que causem a interrupção operacional de aeroportos têm potencial de gerar maior dano à rede de voos internacionais e às redes de voos das empresas AZUL e TAM, principalmente se a interrupção ocorrer em aeroportos considerados centrais para essas redes, como provavelmente ocorreria num cenário de ataque planejado.

Apesar das diferenças quanto ao grau de vulnerabilidade, todas as redes apresentaram uma vulnerabilidade significativamente elevada, devido à proximidade com o comportamento demonstrado pelo grafo teórico do tipo livre de escala. Essa característica é presente em redes de transporte aéreo com estrutura fortemente associada à morfologia do tipo hub-and-spoke. A constatação do grau de vulnerabilidade das redes pode ser empregada como um fator adicional a ser considerado no planejamento da expansão da rede atendida pelos serviços aéreos.

Nesse sentido, a literatura de redes complexas tem identificado ser possível mitigar a vulnerabilidade de redes do tipo livre de escala através da adição de ligações entre vértices de baixo grau topológico (ZHAO; XU, 2009). Ou seja, numa rede de transporte aéreo isso corresponderia a fomentar a conexão entre pequenos e médios aeroportos. Esse tipo de estratégia também se alinha às pesquisas que propõem soluções para o crescimento da oferta de serviços aéreos para novas localidades, de forma a ampliar a acessibilidade promovida pela rede 
de transporte aéreo e contribuir para o desenvolvimento econômico e social das regiões a serem atendidas (QUEIROZ, 2014).

Como último resultado desta quarta etapa do método, tem-se uma listagem preliminar de aeroportos considerados críticos, segundo a metodologia proposta por Lordan et al., (2014b), conforme mostrado na Tabela 6.14 da seção 6.6.3. Na rede de voos domésticos, por exemplo, o aeroporto de Viracopos/SP (SBKP) foi tido como o mais crítico, seguido pelos aeroportos de Manaus/AM (SBEG), Brasília/DF (SBBR), Guarulhos/SP (SBGR), Confins/MG (SBCF) e Galeão/RJ (SBGL), nesta ordem apresentada.

Como discutido no capítulo 5, considera-se que esse processo de determinação da criticidade dos aeroportos apresenta algumas desvantagens que foram tratadas através da operacionalização da etapa $\mathrm{V}$ do método proposto nesta dissertação, cujos resultados serão analisados a seguir.

\subsection{ETAPA V - SIMULAÇÃO DE INTERRUPÇÕES OPERACIONAIS INDIVIDUAIS}

Nesta etapa do método, levantou-se os impactos estruturais e funcionais gerados às redes de transporte aéreo, em virtude da interrupção operacional de um único aeroporto, e ao final, foi possível determinar o nível de criticidade dos aeroportos que formavam as redes estudadas.

Primeiramente, avaliou-se o comportamento da variabilidade dos impactos. A seguir, estão apresentados os histogramas das variáveis que representam os impactos levantados. Na Figura 7.1 tem-se os gráficos da variação na densidade, na maior componente conectada, na conectividade e na eficiência da rede de voos domésticos. Na Figura 7.2, são mostrados os gráficos da variação nos parâmetros globais de acessibilidade, oferta de assentos, tráfego de aeronaves e de demanda atendida na mesma rede de voos domésticos.

A eficiência da rede foi o parâmetro que se mostrou com a variabilidade menos acentuada, dentre todos os parâmetros monitorados, mas de uma maneira geral, todos os tipos de impactos demonstram uma variabilidade acentuada e similar, onde muitos aeroportos possuem baixo potencial de impacto, da ordem de, no máximo, $5 \%$ de queda nos parâmetros originais da rede. Ao passo que um pequeno grupo de aeroportos apresenta características que, numa situação de interrupção operacional, podem provocar quedas de, aproximadamente, 5 a $35 \%$ nos parâmetros originais da rede. 
(a)

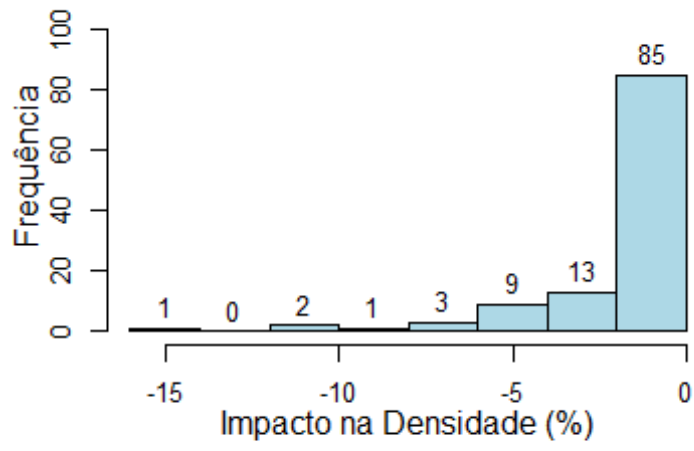

(c)

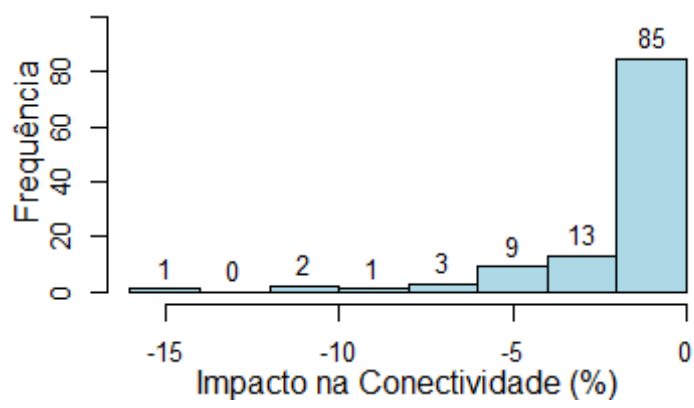

(b)

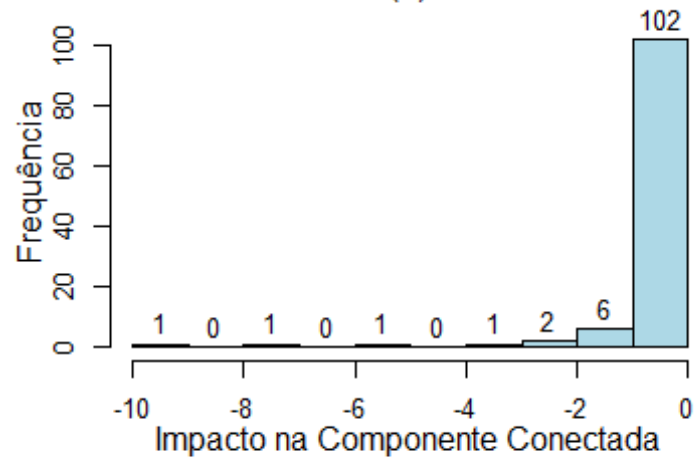

(d)

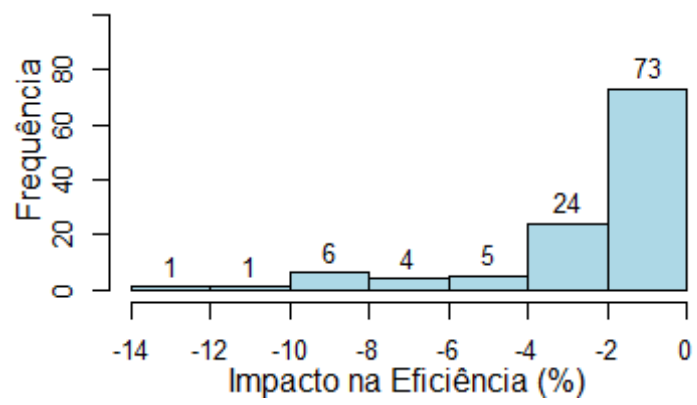

Figura 7.1. Histogramas das variações nos parâmetros do grafo da rede de voos domésticos.

(a) histograma do impacto na densidade; (b) histograma do impacto na componente conectada; (c) histograma do impacto na conectividade da rede e (d) histograma do impacto na eficiência.

(a)

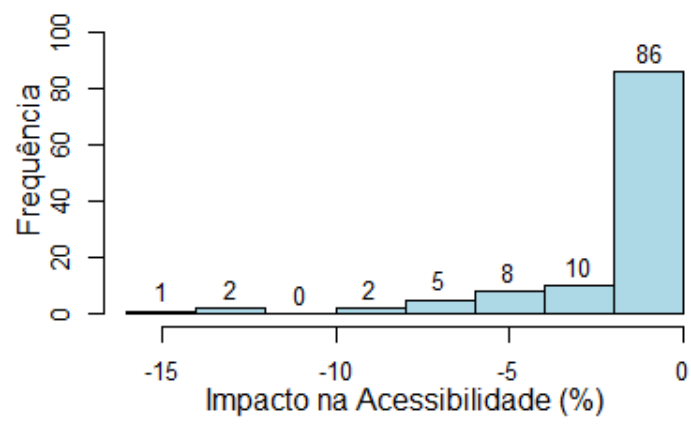

(c)

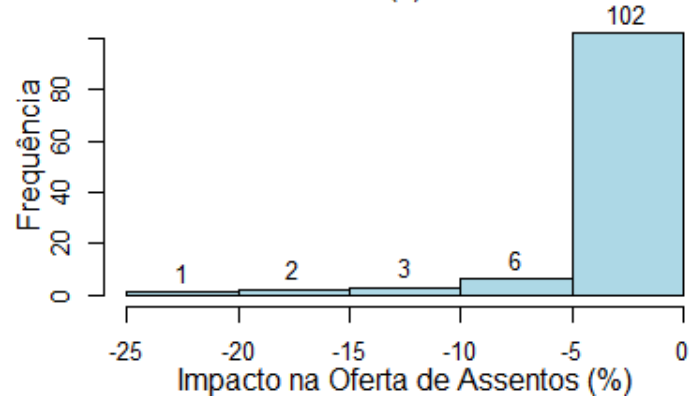

(b)

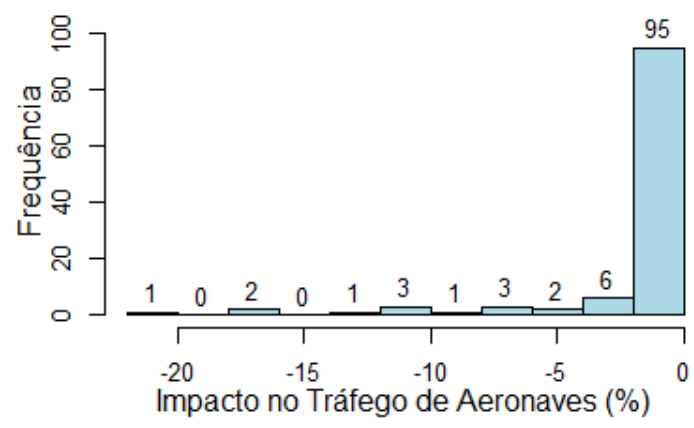

(d)

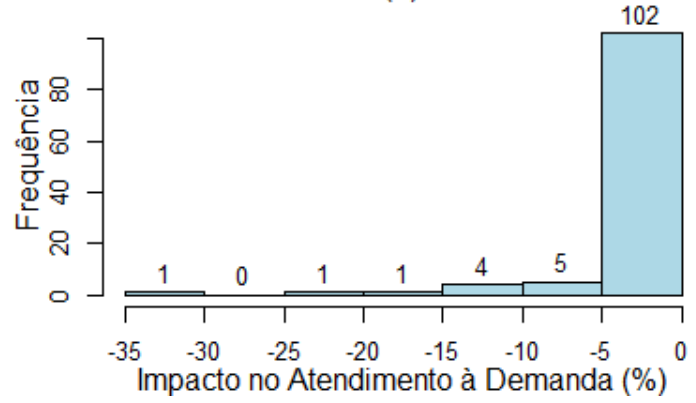

Figura 7.2. Histogramas das variações nos parâmetros do grafo da rede de voos domésticos.

(a) histograma do impacto na acessibilidade; (b) histograma do impacto no tráfego de aeronaves; (c) histograma do impacto na oferta de assentos e (d) histograma do impacto no atendimento à demanda. 
As variações nos parâmetros de rede monitorados podem apresentar algum tipo de relação. Isso pode ser inicialmente avaliado pelos coeficientes de correlação apresentados na Tabela 7.1. Uma forma de visualização que permite uma intepretação mais facilitada da matriz de correlação é mostrada na Figura 7.3.

Tabela 7.1. Matriz de correlação das variações nos parâmetros do grafo que representa a rede de voos domésticos $\left(R \_b r a \_d o m\right)$.

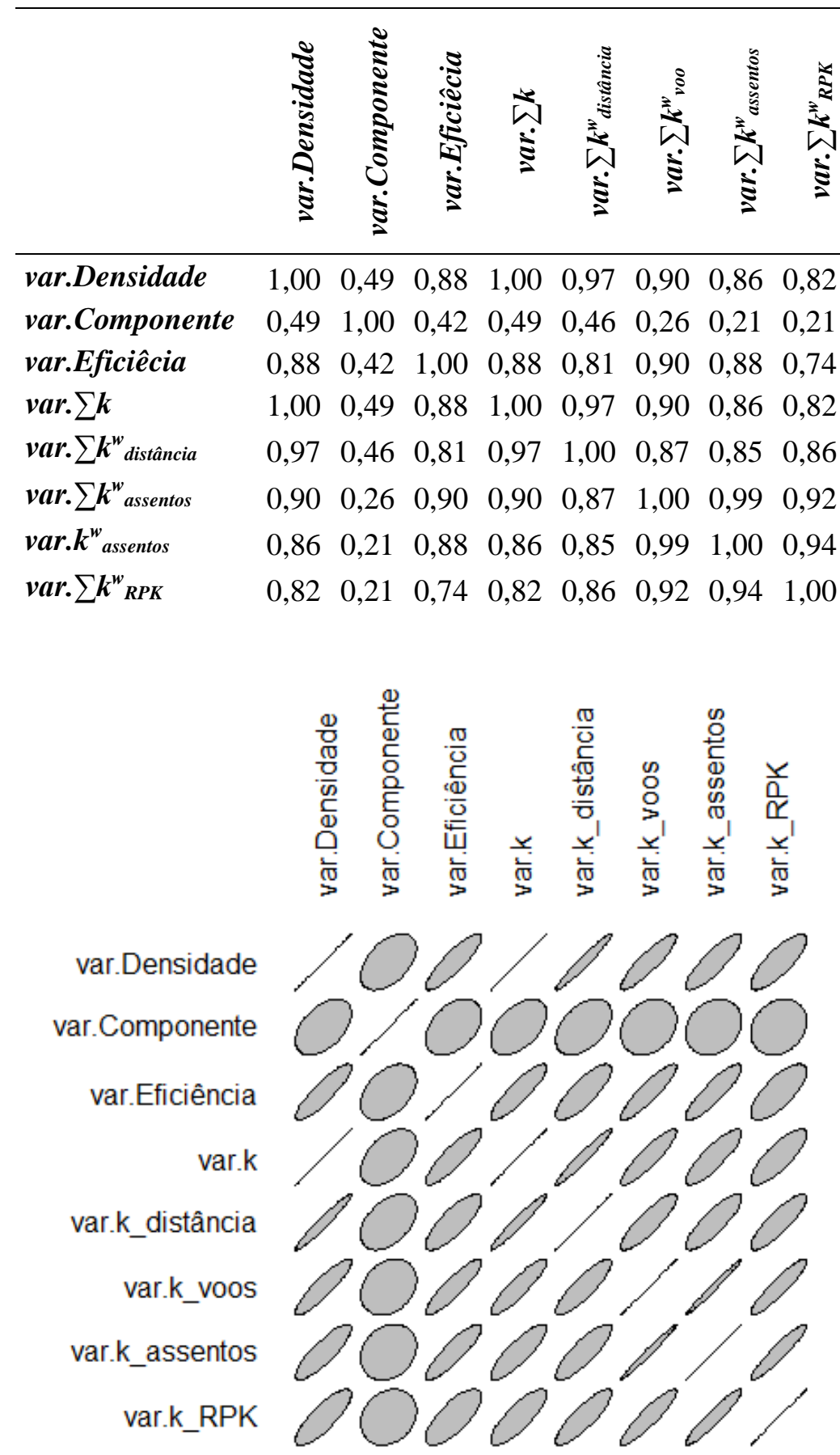

Figura 7.3. Representação em elipses dos coeficientes da matriz de correlação das variações nos parâmetros do grafo que representa a rede de voos domésticos $\left(R \_b r a \_d o m\right)$. 
Verifica-se que a densidade e a conectividade apresentam correlação igual a 1. Isso significa que o método pode ser implementado considerando apenas uma dessas variáveis, sem prejuízo aos resultados a serem alcançados. A componente conectada foi o parâmetro que menos apresentou correlação com todos os demais parâmetros.

Além de conhecer o nível de impacto que pode ser gerado à rede em decorrência da interrupção de aeroportos, é importante determinar os aeroportos que podem causar os maiores impactos.

A Tabela 6.15 disposta na seção 6.7, apresentam os resultados da simulação para a rede de voos domésticos. O aeroporto de Viracopos/SP (SBKP) foi o que mais impactou a densidade, a conectividade e a disponibilidade de acesso geográfico, causando quedas de 14,09\% nos dois primeiros parâmetros, que são estruturais, e queda 14,56\% no último, que é de natureza funcional. Os impactos na densidade e na conectividade da rede são iguais não só para o aeroporto de Viracopos, mas também para todos os demais aeroportos. Mais uma vez confirmase a redundância na consideração desses dois parâmetros no método proposto.

O aeroporto de Manaus/AM (SBEG) foi o mais crítico quando se observa a variação da componente conectada. Isso significa que a interrupção do aeroporto da capital amazonense acarreta no isolamento de uma maior quantidade de aeroportos. Ressalta-se que essa situação se torna mais agravante no contexto da frágil mobilidade na qual os moradores de alguns municípios da região norte enfrentam.

Quanto ao parâmetro de eficiência da rede, o impacto é maior no caso de interrupções do aeroporto de Congonhas/SP. Verifica-se que o aeroporto de Guarulhos/SP (SBGR) gerou maiores danos em parâmetros funcionais, tal como, no tráfego de aeronaves, na oferta de assentos e no atendimento da demanda de mercado. Esses últimos resultados se mostram coerentes com aqueles obtidos pela análise da importância dos aeroportos.

Um resumo do nível de criticidade geral dos aeroportos é alcançado pelo cálculo do indicador de criticidade $\left(I_{C R I}\right)$, também apresentado na Tabela 6.15, do Capítulo 6. No caso da rede de voos domésticos, os seis primeiros aeroportos críticos são: Guarulhos/SP (SBGR), Viracopos/SP (SBKP), Brasília/DF (SBBR), Congonhas/SP (SBSP), Salvador/BA (SBSV) e Confins/MG (SBCF). Nota-se que esse resultado se diferencia, em certa medida, do alcançado pela abordagem adotada por Lordan et al., (2014b), cujos resultados estão na Tabela 6.14, da seção 6.6.3. 
A aplicação do método em diferentes níveis de redes de transporte aéreo possibilitou determinar os aeroportos críticos de forma específica para cada rede. A Tabela 6.16, da seção 6.7, traz esses resultados parciais - cinco primeiros aeroportos - de onde é possível perceber que na rede de voos internacionais alguns aeroportos estrangeiros apresentam nível de criticidade maior que os aeroportos brasileiros. Essa indicação é útil, pois pode direcionar a atuação das organizações públicas e privadas para esse conjunto de aeroportos, principalmente quando a preocupação estiver focada no funcionamento normal da rede de voos internacionais.

A adequada identificação da criticidade dos aeroportos é relevante para o processo de gestão de risco que as organizações públicas e privadas do setor de aviação civil implementam para apoiar, especialmente, as suas decisões quanto à regulação, fiscalização e operação do sistema.

No processo regulatório, por exemplo, é comum o estabelecimento de uma classificação do conjunto de empresas reguladas, agrupando-as de acordo com suas similaridades operacionais. Isso possibilita que os requisitos definidos numa norma técnica sejam aplicados de forma mais adequada e direcionada, de acordo com as subdivisões de grupos ou classes de empresas previamente estabelecidos, a partir dos critérios de classificação.

A análise de agrupamento é uma técnica multivariada cujo principal objetivo é agrupar objetos, levando em consideração as características que possuem (HAIR et al, 2009). Essa técnica foi empregada para análise do conjunto de dados obtidos com a aplicação do método, especificamente para os dados de impacto gerados na simulação de interrupção individual de aeroportos da rede de voos domésticos.

A técnica de análise de agrupamento foi empregada utilizando a medida de distância euclidiana, dados padronizados para medição da similaridade e método hierárquico de agrupamento. $\mathrm{O}$ gráfico de dendrograma, normalmente gerado ao final de um processo de análise de agrupamento, foi substituído pela Tabela 7.2, com vistas a proporcionar uma melhor visualização e interpretação dos resultados. O dendrograma original gerado encontra-se disponível no Apêndice D.

Verifica-se que os aeroportos foram separados em cinco grupos. O primeiro grupo é composto por 4 integrantes, Guarulhos, Brasília, Congonhas e Galeão, que apresentam um indicador de criticidade médio do grupo de 23,40. Em seguida, tem-se outros dois grupos, relativamente ainda pequenos, no qual vale destacar a presença dos aeroportos de Manaus e Cuiabá, integrando segundo grupo de aeroportos críticos. 
Há um grupo intermediário, composto por 7 aeroportos, com criticidade média de 12,49. Ao final da tabela, há dois grupos maiores, onde são apresentados, apenas a título ilustrativo, os três primeiros aeroportos de cada grupo. $\mathrm{O}$ indicador de criticidade médio desses grupos é bem inferior aos três primeiros grupos definidos.

Tabela 7.2. Grupos de aeroportos da rede de voos domésticos $\left(R \_b r a \_d o m\right)$ definidos pela análise de agrupamento.

\begin{tabular}{|c|c|c|c|c|c|}
\hline \multirow[t]{2}{*}{ Grupo } & \multicolumn{2}{|c|}{$\begin{array}{l}\text { Tamanho do } \\
\text { Grupo }\end{array}$} & \multicolumn{2}{|c|}{ Integrantes do Grupo } & \multirow[t]{2}{*}{$\begin{array}{l}\text { Indicador de criticidade } \\
\text { médio do grupo }\end{array}$} \\
\hline & Qtde. & Proporção & Aeroporto & Siglas & \\
\hline & \multirow{4}{*}{4} & \multirow{4}{*}{$3,5 \%$} & Guarulhos/SP & SBGR & \multirow{4}{*}{23,40} \\
\hline & & & Brasi1lia/DF & SBBR & \\
\hline & & & Congonhas/SP & SBSP & \\
\hline & & & Galeão/RJ & SBGL & \\
\hline & \multirow{3}{*}{3} & \multirow{3}{*}{$2,6 \%$} & Viracopos/SP & SBKP & \multirow{3}{*}{18,36} \\
\hline$<$ & & & Manaus/AM & SBEG & \\
\hline & & & Cuiabá/MT & SBCY & \\
\hline & \multirow{7}{*}{7} & \multirow{7}{*}{$6,1 \%$} & Salvador/BA & SBSV & \multirow{7}{*}{12,49} \\
\hline & & & Confins/MG & SBCF & \\
\hline & & & Porto Alegre/RS & SBPA & \\
\hline & & & Santos Dumont/RJ & SBRJ & \\
\hline & & & Recife/PE & SBRF & \\
\hline & & & Fortaleza/CE & SBFZ & \\
\hline & & & Curitiba/PR & SBCT & \\
\hline & \multirow{4}{*}{23} & \multirow{4}{*}{$20,2 \%$} & Belém/PA & SBBE & \multirow{4}{*}{0,96} \\
\hline & & & Goiânia/GO & SBGO & \\
\hline & & & Natal/RN & SBSG & \\
\hline & & & Outros & Outros & \\
\hline & \multirow{4}{*}{77} & \multirow{4}{*}{$67,5 \%$} & Marabá/PA & SBMA & \multirow{4}{*}{$-3,35$} \\
\hline & & & Santarém/PA & SBSN & \\
\hline & & & Imperatriz/MA & SBIZ & \\
\hline & & & Outros & Outros & \\
\hline
\end{tabular}

A gestão de risco, em geral, é um processo cíclico que envolve estágios de identificação, avaliação, mitigação e monitoramento dos riscos associados a uma determinada atividade. Conforme discutido no capítulo 2 desta dissertação, acerca das abordagens conceituais na literatura de transportes, um dos elementos usados para a estimação do risco são as consequências ou a severidade das consequências advindas de um evento adverso que provoque a interrupção de instalações ou componentes de um sistema.

O nível de criticidade obtido com a aplicação do método de análise de vulnerabilidade está associado ao potencial de consequências, de natureza estrutural e funcional, que a interrupção 
de um determinado aeroporto pode gerar à funcionalidade da rede. Portanto, o indicador de criticidade pode ser utilizado como uma informação de entrada para estimação dos riscos inerentes ao funcionamento da rede de transporte aéreo.

No exercício da atividade regulatória da aviação civil, podem ser estabelecidos requisitos que promovam a adoção de soluções organizacionais e planos de resposta eficazes para mitigar o grau de vulnerabilidade e o nível de criticidade dos aeroportos. 


\section{CONCLUSÕES}

\subsection{CONSIDERAÇÕES INICIAIS}

Essa dissertação apresentou o problema de como avaliar a vulnerabilidade de redes de transporte aéreo no contexto de interrupção operacional de aeroportos. A investigação desse problema é relevante, pois há a necessidade atual de levantamento de informações acerca dos potenciais impactos que esse tipo de cenário pode gerar ao funcionamento normal da rede de transporte aéreo. Tais informações podem contribuir para embasar a tomada de decisão dos gestores, especialmente em relação aos processos de planejamento da malha aérea, de gestão de risco e de proteção de infraestruturas críticas.

Após o desenvolvimento da pesquisa, tanto pela fundamentação teórica apresentada quanto pela análise empírica efetuada, pode-se afirmar que os objetivos traçados no primeiro capítulo da dissertação foram alcançados. Primeiramente, com base na revisão bibliográfica, estruturou-se um método para analisar a vulnerabilidade de redes de transporte aéreo utilizando a abordagem disponibilizada pelas redes complexas. Em seguida, o método foi aplicado na rede de transporte aéreo brasileira, permitido a quantificação de impactos estruturais e funcionais em decorrência dos cenários adversos definidos. Por meio dessa quantificação de impactos, foi possível avaliar o grau de vulnerabilidade da rede de transporte aéreo e identificar seus aeroportos críticos.

A delimitação de diferentes níveis de redes - no âmbito de voos domésticos, internacionais e de empresas aéreas - proporcionou uma aplicação abrangente do método, gerando resultados específicos que podem fundamentar decisões de planejamento, de regulação e de fiscalização do setor que sejam melhor direcionadas aos elementos críticos do subsistema que esteja sob avaliação dos gestores.

As decisões nas esferas de planejamento, regulação e de fiscalização deveriam ser capazes de promover a diminuição da probabilidade de ocorrência de interrupções operacionais decorrentes de eventos adversos. O planejamento de investimentos em infraestrutura aeroportuária, por exemplo, pode preocupar-se com a instalação de equipamentos modernos que garantam a continuidade normal das operações de um aeroporto, mesmo em condições meteorológicas severas. Os requisitos regulatórios, também, podem direcionar o desenvolvimento de uma estrutura de gestão aeroportuária com capacidade para responder adequadamente às eventuais interrupções, mitigando os impactos associados à ocorrência, sejam elas de natureza acidental ou proposital (como atos de interferência ilícita). 
Acredita-se que, além dos resultados práticos, a pesquisa trouxe contribuições nos seguintes aspectos: (1) a avaliação comparativa da literatura sobre análise de vulnerabilidade de redes de transporte aéreo; (2) a inserção de diferentes atributos operacionais no processo de modelagem da rede, incluindo a ampliação do uso do conceito de "distância efetiva"; (3) a formulação de indicadores de importância e de criticidade dos aeroportos, levando em consideração diferentes critérios de importância e de impactos na rede; (4) a crítica acerca da metodologia de identificação de aeroportos críticos proposta por Lordan et al., (2014b) e, finalmente, (5) a própria estruturação de um método para efetuar a análise de vulnerabilidade de redes de transporte aéreo.

\subsection{CONCLUSÕES}

Através da condução desta pesquisa foi possível chegar as seguintes conclusões:

(1) As redes que compõem a rede de transporte aéreo brasileira possuem propriedades típicas de redes complexas, apresentando pequeno valor de caminho geodésico, coeficiente de aglomeração significativo e distribuição de grau do tipo lei de potência;

(2) Os parâmetros de centralidade dos vértices de um grafo que modela uma rede de transporte aéreo demonstram ter correlação linear significativa, mas não o suficiente para permitir o emprego de apenas uma dessas medidas como critério de importância dos vértices. O nível de importância dos aeroportos varia de acordo com a característica estrutural ou funcional que esteja sendo avaliada, justificando a formação de um indicador que sumarize as variáveis consideradas;

(3) O mesmo ocorreu em relação ao monitoramento das variações dos parâmetros originais dos grafos, isto é, apesar de uma correlação linear considerável entre a maioria das variáveis de impacto, elas estão associadas a diferentes características globais do sistema, que devem ser avaliadas em conjunto para a estimação dos impactos e a determinação do nível de criticidade dos aeroportos. Essa conclusão só não é aplicável para os parâmetros de densidade e de conectividade global da rede, que apresentaram variações idênticas e, portanto, uma delas foi redundante na análise efetuada;

(4) As redes que formam a rede de transporte aéreo brasileira possuem uma organização fortemente associada à estrutura hub-and-spoke, tornando-as significativamente vulneráveis a interrupções de seus aeroportos centrais (com maior grau de intermediação). A rede de voos 
internacionais operados no Brasil e as redes das empresas aéreas TAM e AZUL foram as que demonstraram maior grau de vulnerabilidade e de dependência do aeroporto central. Essa situação sugere que uma estratégia de planejamento de expansão da malha aérea que combine a necessidade de mitigação de potenciais impactos com os fatores econômicos e operacionais, tradicionalmente considerados, pode trazer benefícios ao sistema;

(5) A maioria dos casos de interrupção de um único aeroporto tem baixo potencial de impacto. No entanto, a interrupção de alguns aeroportos específicos pode gerar impactos da ordem de 5 a $35 \%$ na estrutura e na funcionalidade da rede de transporte aéreo, justificando a realização de uma determinação clara do nível de criticidade desses aeroporto;.

(6) No âmbito da rede de voos domésticos, há três grupos de aeroportos que deveriam ser priorizados no que se refere ao planejamento de investimentos e à atuação regulatória e fiscalizatória, tendo em vista os indicadores de criticidade. Esses três grupos abrange um universo de 14 aeroportos, apresentados na Tabela 7.2 da seção 7.6. Os investimentos e a atuação do órgão regulador deveriam ser orientados no sentido de promover a diminuição da probabilidade de ocorrência de interrupções ou a mitigação das consequências, caso tais interrupções se concretizem; e

(7) No âmbito da rede de voos internacionais, os eventos que causem interrupção de alguns aeroportos estrangeiros - como os de Miami (KMIA), de Lisboa (LPPT) e de Buenos Aires (SAEZ) - apresentam potencial significativo de impacto na rede brasileira. Isso indica que o monitoramento da operação desses aeroportos pode auxiliar no gerenciamento das ações de resposta das entidades brasileiras frente a concretização de eventos adversos.

\subsection{LIMITAÇÕES DA PESQUISA}

O desenvolvimento desta pesquisa apresenta algumas limitações, dentre as quais se destacam as seguintes:

(1) A avalição dos impactos à rede de transporte aéreo não considerou danos de natureza econômica e ambiental, que também se manifestam em cenários de interrupção de aeroportos;

(2) O método proposto, apesar de ter se mostrado adequado às redes de âmbito nacional e individual de empresas aéreas, pode não se apresentar eficaz para a avaliação da rede de transporte aéreo mundial ou a nível continental. Em redes dessa abrangência, aparecem outros 
fatores, como restrições geopolíticas (GUIMERA et al., 2005), que influenciam a organização estrutural da rede e podem gerar particularidades para a análise de vulnerabilidade;

(3) A aplicação do método foi feita apenas em redes de transporte aéreo constituídas por voos que processaram passageiros (domésticos e internacionais), ou seja, não foram considerados os voos cargueiros, que transportam exclusivamente cargas ou malas postais; e

(4) Ainda em relação à aplicação do método, utilizou-se dados agregados referentes ao mês de dezembro de 2014. É possível efetuar a aplicação do método utilizando dados mais recentes e, ainda, fazendo uso de dados referentes a um intervalo de tempo mais curto, de semanas ou dias. Isso pode permitir o levantamento de resultados mais precisos e ações ainda mais direcionadas.

\subsection{RECOMENDAÇÕES PARA PESQUISAS FUTURAS}

O delineamento de futuras pesquisas pode considerar os tópicos apresentados a seguir:

- No método apresentado, o fator temporal para o deslocamento pela rede é levado em consideração por estar associado ao atributo da distância geográfica entre os aeroportos da rede. No entanto, o fator da tarifa de deslocamento, que comporia uma representação do custo total de viagem, não foi inserido no modelo. Essa inserção poderia aprimorar o método e tornar os resultados sensíveis à variação da tarifa média praticada em cada rota da rede de transporte aéreo;

- A investigação de processos dinâmicos que ocorrem pela rede de transporte aéreo, como a propagação de atrasos após a ocorrência de eventos adversos, podem contribuir para o gerenciamento do tráfego aéreo e das operações aeroportuárias. A literatura internacional já tem apresentado estudos sobre esse tipo de problema, a partir da abordagem dada pela teoria de redes complexas; e

- $\quad$ O método de análise de vulnerabilidade proposto nesta dissertação pode ser aplicado em outros sistemas tecnológicos que operam sob uma estrutura de rede ou ainda é possível investigar o comportamento de dois ou mais sistemas que atuem de forma interdependente. Ademais, caso haja a disponibilidade de dados para a estimação da probabilidade de ocorrência de eventos adversos que causem interrupções operacionais nos componentes de um sistema, essa estimação de probabilidade pode ser combinada com os resultados de criticidade 
fornecidos pelo método proposto e, assim, ser possível quantificar um nível de risco das operações do sistema. 


\section{REFERÊNCIAS BIBLIOGRÁFICAS}

ALBERT, R. \& BARABÁSI, A-L. (2002) Statistical mechanics of complex networks. Reviews of Modern Physics, v. 74, p. 47.

ALBERT, R.; JEONG, H.; BARABÁSI, A-L. (2000) Error and attack tolerance of complex networks. Nature, v. 406, p. 378-382.

ABNT (2009) Associação Brasileira de Normas Técnicas. Gestão de Riscos - Princípios e Diretrizes. Norma Brasileira, ABNT NBR ISO 31000. Rio de Janeiro, RJ, 24 p.

AZIZI, N.; CHAUHAN, S.; SAHLI, S.; VIDYARTHI, N. (2016) The impact of hub failure in hub-and-spoke networks: Mathematical formulations and solution techniques. Computers \& Operations Research, v. 65, p. 174-188.

BAGLER, G. (2008a) Complex Network view of performance and risks on Airport Networks. Physica A: Statistical Mechanics and its Applications, v. 387, n. 12, p. 2972-2980.

BAGLER, G. (2008b) Analysis of the airport network of India as a complex weighted network. Physics and Society, Disponível em: <http://arxiv.org/abs/0805.0924>. Acesso em: 18 mar. 2015.

BARABÁSI, A-L. (2009) Linked (Conectado): A Nova Ciência dos Networks. Leopardo Editora. Tradução: Jonas Pereira dos Santos, 241 p.

BARABÁSI, A-L. (2012) Network Science. Disponível em: <http://barabasilab.neu.edu/networksciencebook/>. Acesso em 07 mar. 2015.

BARRAT, A.; BARTHELEMY, M.; PASTOR-SATORRAS, R.; VESPIGNANI, A. (2004) The architecture of complex weighted networks. Proceedings of the National Academy of Sciences of the United States of America, v. 101, n. 11, p. 3747-3752.

BERDICA, K. (2002) An introduction to road vulnerability: what has been done, is done and should be done. Transport Policy, v. 9, n. 2, p. 117-127.

BRASIL (1986) Código Brasileiro de Aeronáutica. Lei n 7.565. Presidência da República, Brasília, Brasil.

BRASIL (2008) Estratégia Nacional de Defesa. Publicação. Ministério da Defesa. Brasília, DF. Disponível em: <http://www.defesa.gov.br/projetosweb/estrategia/arquivos/estrategia_defesa_nacional_portu gues.pdf $>$. Acesso em: 12 nov. 2014

BRASIL (2009) Política Nacional de Aviação Civil. Decreto n 6.780. Presidência da República, Brasília, Brasil.

BRASIL (2010) Guia de Referência para a Segurança das Infraestruturas Críticas da Informação. Livro. Presidência da República. Gabinete de Segurança Institucional. Departamento de Segurança da Informação e Comunicações. Organização: Claudia Canongia, Admilson Gonçalves Júnior e Raphael Mandarino Junior. Brasília, DF, Versão 01, 151 p. 
BRASIL (2014) Anuário Estatístico do Transporte Aéreo de 2013. Publicação. Agência Nacional de Aviação Civil. Brasília, DF. Disponível em: <http://www2.anac.gov.br/estatistica/anuarios.asp>. Acesso em: 18 set. 2015.

BRASIL (2014b) Regulamento Brasileiro da Aviação Civil - RBAC n 139 - Emenda n 02. Regulamentação, Resolução n 307, de 06 de março de 2014. Agência Nacional de Aviação Civil, DF. Disponível em: <http://www.anac.gov.br/assuntos/legislacao>. Acesso em: 15 mai. 2016.

BRASIL (2015a) Anuário Estatístico do Transporte Aéreo de 2014. Publicação. Agência Nacional de Aviação Civil. Brasília, DF. Disponível em: <http://www2.anac.gov.br/estatistica/anuarios.asp>. Acesso em: 18 set. 2015.

BRASIL (2015b) Demanda e Oferta do Transporte Aéreo. Publicação. Agência Nacional de Aviação Civil. Brasília, DF. Disponível em: <http://www2.anac.gov.br/estatistica/demandaeoferta/DemandaeOferta.asp>. Acesso em: 18 set. 2015 .

BRASIL (2015c) Dados Estatísticos do Transporte Aéreo do Brasil. Publicação. Agência Nacional de Aviação Civil. Brasília, DF. Disponível em: <http://www2.anac.gov.br/Estatistica/DadosEstatisticos/>. Acesso em: 10 set. 2015.

BRASIL (2015d) Descrição de Variáveis. Página eletrônica. Agência Nacional de Aviação Civil. Brasília, DF. Disponível em: <http://www2.anac.gov.br/Estatistica/DadosEstatisticos/descricao.asp>. Acesso em: 10 set. 2015.

BRASIL (2016a) Lista de Aeródromos Públicos e Privados. Planilha de dados. Agência Nacional de Aviação Civil. Brasília, DF. Disponível em: <http://www.anac.gov.br/Area.aspx?ttCD_CHAVE=8>. Acesso em: 28 fev. 2016

BRASIL (2016b) Voos autorizados vigentes (HOTRAN). Planilha de dados. Agência Nacional de Aviação Civil. Brasília, DF. Disponível em: <http://www2.anac.gov.br/hotran/>. Acesso em: 28 fev. 2016

CAIXETA, V. \& SAKAI, M. (2013) Dados estatísticos: empresas brasileiras. Semana da Qualidade da Informação do Transporte Aéreo. São Paulo, SP. Disponível em: <http://www2.anac.gov.br/estatistica/1_semana/1_semana.asp>. Acesso em: 2 mar. 2015

CANADA (2014) National Strategy for Critical Infrastructure. Publication. Government of Canada. ISBN: 978-1-100-11248-0. Disponível em: <http://www.publicsafety.gc.ca/cnt/rsrcs/pblctns/srtg-crtcl-nfrstrctr/index-eng.aspx>. Acesso em: 12 nov. 2014.

CARDILLO, A.; ZANIN, M.; GÓMEZ-GARDEÑES, J.; ROMANCE, M.; RAMO, A. J. G.; BOCCALETTI, S. (2013) Modeling the multi-layer nature of the European Air Transport Network: Resilience and passengers re-scheduling under random failures. The European Physical Journal Special Topics, v. 215, n. 1, p. 23-33.

CAVAlCANTE, G. V. (2009) Ciência das Redes: Aspectos Epistemológicos. Tese de Doutorado. Universidade de Brasília. Brasília, DF, 151 p. 
CHEN, L. \& MILLER-HOOKS, E. (2012) Resilience: an indicator of recovery capability in intermodal freight transport. Transportation Science, v. 46, n. 1, p. 109-123.

CHEUNG, D. P. \& GUNES, M. H. (2012) A complex network analysis of the united states air transportation. Proceedings of the 2012 International Conference on Advances in Social Networks Analysis and Mining (ASONAM 2012). IEEE Computer Society, Washington, DC, USA, p. 699-701.

CHI, L. P. \& CAI, X. (2004) Structural changes caused by error and attack tolerance in us airport network. International Journal of Modern Physics B, v. 18, n. 17n19, p. 2394-2400.

CHO, D. J. (2002) Three papers on measuring the reliability and flexibility of transportation system capacity. Dissertations available from ProQuest. Paper AAI3043858. Disponível em: <http://repository.upenn.edu/dissertations/AAI3043858>.

CLAUSEN, J.; LARSEN, A.; LARSEN, J.; REZANOVA, N. (2010) Disruption management in the airline industry - Concepts, models and methods. Computers \& Operations Research, v. 37, n. 5, p. 809-821.

COLIZZA, V.; BARRAT, A.; BARTHÉLEMY, M.; VESPIGNANI, A. (2006) The role of the airline transportation network in the prediction and predictability of global epidemics. Proceedings of the National Academy of Sciences of the United States of America, v. 103, n. 7, p. 2015-2020.

CONTI, E.; CAO, S.; THOMAS, A. J. (2013) Disruptions in the US Airport Network. Physics and Society. Disponível em: <http://arxiv.org/abs/1301.2223? context=physics >. Acesso em: 31 ago. 2015.

COOK, A.; BLOM, H.; MANTEGNA, R. N.; MICCICHÈ, S.; RIVAS, D.; VÁZQUEZ, R.; ZANIN, M. (2015) Applying complexity science to air traffic management. Journal of Air Transport Management, v. 42, p. 149-158.

COSTA, L. F.; OLIVEIRA JUNIOR, O. N.; TRAVIESO, G.; RODRIGUES, F. A.; BOAS, P. R. V., ANTIQUEIRA, L.; VIANA, M. P.; ROCHA, L. E. C. (2011) Analyzing and Modeling Real-World Phenomena with Complex Networks: A Survey of Applications. Advances in Physics, v. 60, n. 3, p. 329-412.

CRUCITTI, P.; LATORA, V.; MARCHIORI, M.; RAPISARDA, A. (2003) Efficiency of scale-free networks: error and attack tolerance. Physica A: Statistical Mechanics and its Applications, v. 320, p. 622-642.

CUNHA FILHO, M. S. (2014) Avaliação da vulnerabilidade da rede de transporte rodoviário de carga no Brasil. Dissertação de Mestrado em Transportes, Publicação: T.DM: 011A/2014, Departamento de Engenharia Civil e Ambiental, Universidade de Brasília, Brasilia, DF, 150p.

DALL'ASTA, L.; BARRAT, A.; BARTHÉLEMY, M.; VESPIGNANI, A. (2006) Vulnerability of Weighted Networks. Journal of Statistical Mechanics: Theory and Experiment, v. 2006, n. 04.

DANG, Y. \& LI, W. (2011) Comparative analysis on weighted network structure of air passenger flow of China and US. Journal of Transportation Systems Engineering and Information Technology, v. 11, n. 3, p. 156-162. 
DANG, Y.; DING, F.; GAO, F. (2012) Empirical Analysis on Flight Flow Network Survivability of China. Journal of Transportation Systems Engineering and Information Technology, v. 12, n. 6, p. 177-185.

DESLANDES, S. F. (2007) O projeto de pesquisa como exercício científico e artesanato intelectual. Pesquisa social: teoria, método e criatividade. M. C. S. Minayo; S. F. Deslandes; R. Gomes (eds). 25ª ed. Revista e atualizada. Petrópolis, RJ, Vozes, pp. 31-60.

D'ESTE, G. M.; TAYLOR, M. A. P. (2001) Modelling network vulnerability at the level of the national strategic transport network. Journal of the Eastern Asia Society for Transportation Studies, v. 4, n. 2, p. 1-14.

ERATH, A; BIRDSALL, J.; AXHAUSEN, K.; HAJDIN, R. (2009) Vulnerability assessment methodology for Swiss road network. Transportation Research Record: Journal of the Transportation Research Board, n. 2137, p. 118-126.

ERATH, A. L. (2011) Vulnerability assessment of road transport infrastructure. Dissertation for the degree of Doctor of Science. Department of Civil, Environmental and Geomatic Engineering, Eidgenössische Technische Hochschule ETH Zürich, Nr. 19671.

ERICH, W. (2012) Análise de Vulnerabilidade em Redes de Transporte Público Urbano. Monografia de Projeto Final em Transportes. Departamento de Engenharia Civil e Ambiental, Universidade de Brasília, Brasília, DF, 58 p.

EUROPEAN UNION (2005) Livro Verde: Relativo a um Programa Europeu de Proteção das Infraestruturas Críticas. Disponível em: <http://eur-lex.europa.eu/legalcontent/EN/TXT/?uri=URISERV:133259>. Acesso em: 18 set. 2015.

FLEURQUIN, P.; RAMASCO, J. J.; EGUÍLUZ, V. M. (2014) Characterization of delay propagation in the US air transportation network. Transportation Journal, v. 53, n. 3, p. 330344.

FREEMAN, L. C. (1977) A set of measures of centrality based on betweenness. Sociometry, v. 40, n. 1 , p. 35-41.

FREEMAN, L. C. (1979) Centrality in social networks conceptual clarification. Social Networks, v. 1, n. 3, p. 215-239.

FROHN, R. (2012) Robustness in the Air Transportation Network. Econometrics Bachelor's Thesis, University of Amsterdam. Disponível em: < http://dare.uva.nl/cgi/arno/show.cgi?fid=484496>. Acesso em: 22 dez. 2105.

GANDRUD, C. (2014) Reproducible Research with R and R Studio. Chapman and Hall/CRC, Florida, United States, 294 p.

GAUTREAU, A.; BARRAT, A.; BARTHÉLEMY, M. (2009) Microdynamics in stationary complex networks. Proceedings of the National Academy of Sciences, v. 106, n. 22, p. 88478852 .

GUIDA, M. \& MARIA, F. (2007) Topology of the italian airport network: a scale-free smallworld network with a fractal structure? Chaos, Solitons and Fractals, v. 31, n. 3, p. 527-536. 
GUIMERA, R. \& AMARAL, L. (2004) Modeling the world-wide airport network. European Physical Journal B, v. 38, n. 2, p. 381-385.

GUIMERA, R.; MOSSA, S.; TURTSCHI, A.; AMARAL, L. (2005) The worldwide air transportation network: Anomalous centrality, community structure, and cities' global roles. Proceedings of the National Academy of Sciences of the United States of America, v. 102, n. 22, p. 7794-7799.

HAN, D-D.; QIAN, J-H.; LIU, J-G. (2009) Network topology and correlation features affiliated with European airline companies. Physica A: Statistical Mechanics and its Applications, v. 388, n. 1 , p. $71-81$.

HOLMGREN, Â. J. (2007) A framework for vulnerability assessment of electric power systems. Critical Infrastructure: Reliability and Vulnerability. A. T Murray \& T. H. Grubesic (eds), Springer, pp. 31-55.

HOSSAIN, M.; ALAM, S.; REES, T.; ABBASS, H. (2013) Australian airport network robustness analysis: a complex network approach. Australian Transport Research Forum 2013 Proceedings, publication website: http://www.patrec.org/atrf.aspx.

IPEA (2015) Instituto de Pesquisa Econômica Aplicada. Modelagem de Sistemas Complexos para Políticas Públicas. Publicação. Bernardo, A. F., Patrícia A. M. S., Mariana H. T. (eds). Brasília, DF, 436 p.

IZAWA, M. M. (2010) Modelagem do sistema de transporte urbano do Distrito Federal por redes complexas. Dissertação de Mestrado em Física. Departamento de Física, Universidade de Brasília, DF, 64 p.

JANIĆ, M. (2005) Modeling the large scale disruptions of an airline network. Journal of transportation engineering, v. 131, n. 4, p. 249-260.

JORNAL DA GLOBO. (2012) Pista do aeroporto de Viracopos volta a operar em Campinas (SP). Jornal da Globo, 16 out. 2012. Disponível em: <http://g1.globo.com/jornal-daglobo/noticia/2012/10/pista-do-aeroporto-de-viracopos-volta-operar-em-campinas-sp.html >

Acesso em: 28 fev. 2016.

KAI-QUAN, C.; JUN, Z.; WEN-BO, D.; XIAN-BIN, C. (2012) Analysis of the Chinese air route network as a complex network. Chinese Physics B, v. 21, n. 2.

KOLACZYK, E. D. \& CSÁRDI, G. (2014) Statistical Analysis of Network Data with R. Springer.

LACASA, L.; CEA, M.; ZANIN, M. (2009) Jamming transition in air transportation networks. Physica A: Statistical Mechanics and its Applications, v. 388, n. 18, p. 3948-3954.

LATORA, V. \& MARCHIORI, M. (2001) Efficient behavior of small-world networks. Physical Review Letters, v. 87, n. 19.

LATORA, V. \& MARCHIORI, M. (2005) Vulnerability and protection of infrastructure networks. Physical Review E, v. 71, n. 1, p. 015103. 
LEVINE, D. M.; STEPHAN, D. F.; KREHBIEL, T. C.; BERENSON, M. L. (2008) Estatística: teoria e aplicações. Editora LTC, Tradução: Teresa Cristina Padilha de Souza, Rio de Janeiro, RJ, 752p.

LEWIS, T. G. (2009) Network science: Theory and applications. John Wiley \& Sons, Hoboken, New Jersey, EUA, 512 p.

BEI-JIE, L.; WEN-BO, D.; CHEN, L.; KAI-QUAN, C. Topologic and dynamic resilience model of Chinese airport network. Control and Automation (ICCA), 11th IEEE International Conference on. IEEE, Taichung, Taiwan, p. 1460-1465.

LI, W. \& CAI, X. (2004) Statistical analysis of airport network of China. Physical Review E, v. 69, n. 4.

LILLO, F.; POZZI, S.; TEDESCHI, A.; FERRARA, G.; MATRELLA, G.; LUCAT, B.; LICU, A. (2009) Coupling and complexity of interaction of stca networks. Eurocontrol 8th Innovative Research Workshop \& Exhibition. Disponível em: <https://www.eurocontrol.int/sites/default/files/field_tabs/content/documents/nm/safety/safety -asmt-ino-2009.pdf>. Acesso em: 27 fev. 2016.

LILLO, F.; MICCICHE, S.; MANTEGNA, R. N.; BEATO, V.; POZZI, S. (2011) ELSA Project: Toward a complex network approach to ATM delays analysis. Proceedings on the INO 2011 Conference. Disponível em: <http://complexworld.eu/wiki/images/3/3c/ELSA__SID2011_-_Lillo_et_al.pdf>. Acesso em: 23 set. 2015.

LIN, J. (2012) Network analysis of China's aviation system, statistical and spatial structure. Journal of Transport Geography, v. 22, p. 109-117.

LIN, J. \& BAN, Y. (2014) The evolving network structure of US airline system during 19902010. Physica A: Statistical Mechanics and its Applications, v. 410, p. 302-312.

LI-PING, C.; RU, W.; HANG, S.; XIN-PING, X.; JIN-SONG, Z.; WEI, L.; XU, C. (2003) Structural properties of US flight network. Chinese physics letters, v. 20, n. 8, p. 1393.

LIU, H.; HU, X-B.; YANG, S.; ZHANG, K.; PAOLO, E. (2011) Application of complex network theory and genetic algorithm in airline route networks. Journal of the Transportation Research Board, v. 2214, n.1, p. 50-58.

LORDAN, O.; SALLAN, J. M.; SIMO, P. (2014a) Study of the topology and robustness of airline route networks from the complex network approach: a survey and research agenda. Journal of Transport Geography, v. 37, p. 112-120.

LORDAN, O.; SALLAN, J. M.; SIMO, P.; GONZALEZ-PRIETO, D. (2014b) Robustness of the air transport network. Transportation Research Part E: Logistics and Transportation Review, v. 68, p. 155-163.

LORDAN, O.; SALLAN, J. M.; SIMO, P.; PIETRO, D. G. (2015) Robustness of airline alliance route networks. Communications in Nonlinear Science and Numerical Simulation, v. 22, n. 13 , p. 587-595.

MAERTENS, S. (2013) Airport business interruptions: Developing and applying a scheme for the estimation of resulting cost impacts. Journal of Airport Management, v. 7, n. 4, p. 383-406. 
METZ, J.; CALVO, R.; SENO, E. R. M.; ROMERO, R. R. F.; LIANG, Z. (2007) Redes Complexas: conceitos e aplicações. Relatórios Técnicos do ICMC-USP São Carlos, SP, 33 p.

MO, H. \& WANG, J. (2011) Structural evolution of China's air transport network. Transportation, Mechanical, and Electrical Engineering (TMEE), 2011 International Conference on, IEEE Publisher, p. 21-24.

MONECHI, B. (2015) Complex Networks and Transport Systems: Application to Air Transport and Urban Mobility. Thesis, Faculty of Mathematical, Physical and Natural Sciences, Dipartimento di Fisica, Università degli studi di Roma "La Sapienza", 161 p.

MORAES, T. M. \& GONÇALVES, G. E. (2013) Estudo da Vulnerabilidade do Sistema de Transporte Aéreo Nacional com base no Arcabouço da Ciência das Redes. XIII Jornada de Ensino, Pesquisa e Extensão - JEPEX 2013, Pernambuco, RE.

MURRAY, A. T. \& GRUBESIC, T. H. (2007) Overview of reliability and vulnerability in critical infrastructure. Critical Infrastructure: Reliability and Vulnerability. A. T Murray \& T. H. Grubesic (eds), Springer, p. 1-8.

MURRAY, A. T.; MATISZIW, T. C.; GRUBESIC, T. H. (2008) A methodological overview of network vulnerability analysis. Growth and Change, v. 39, n. 4, p. 573-592.

NAGARAJAN, H.; WEI, P.; RATHINAM, S.; SUN, D. (2012) Air transportation network robustness optimization under limited legs itinerary constraint. The 5th International Conference on Research in Air Transportation (ICRAT 2012), Berkeley, CA, USA.

NICHOLSON, A. (2003) Transport network reliability measurement and analysis. Transportes, v. 11, n. 2.

OKAMOTO, K.; CHEN, W.; LI, X.-Y. (2008) Ranking of closeness centrality for large-scale social networks. Frontiers in Algorithmics. Franco, P. P., Xiaodong, W., Jianping, Y. (eds), Springer, p. 186-195.

OLIVEIRA, A. (2009) Transporte Aéreo: Economia e Políticas Públicas. 1. ed., Pezco, São Paulo, SP 197 p.

PEJOVIC, T.; NOLAND, R. B.; WILLIAMS, V.; TOUMI, R. (2009) A tentative analysis of the impacts of an airport closure. Journal of Air Transport Management, v. 15, n. 5, p. 241248.

PIPICANO, E. F. M. (2014) Análise da vulnerabilidade da rede de transporte de Sistemas de Operação Exclusiva em Corredores de Ônibus-BRT com base na medida da centralidade. Dissertação de Mestrado em Transportes. Departamento de Engenharia Civil e Ambiental, Universidade de Brasília, Brasília, DF, 103 p.

PRICINOTE, M. A. (2008) Metodologia para identificação da confiabilidade topológica da rede de transporte público urbano. Dissertação de Mestrado em Transportes, Publicação T.DM. 007A/2008. Departamento de Engenharia Civil e Ambiental, Universidade de Brasília, Brasília, DF, $92 \mathrm{p}$.

QUARTIERI, J.; GUIDA, M.; GUARNACCIA, C.; D'AMBROSIO, S.; GUADAGNUOLO, D. (2008) Topological properties of the italian airport network studied via multiple addendials 
and graph theory. International Journal of Mathematical Models and Methods in Applied Sciences, n. 2, p. 312-316.

QUEIROZ, M. P. (2014) Definição de diretrizes para autorizações de voos para as empresas aéreas. Tese de Doutorado em Transportes, Publicação T.D. 004A/2014. Departamento de Engenharia Civil e Ambiental, Universidade de Brasília, Brasília, DF, 146 p.

R CORE TEAM. (2015) The $\mathrm{R}$ Project for Statistical Computing. Disponível em: <https://www.r-project.org/foundation/>. Acesso em: 12 nov. 2014.

REGGIANI, A.; NIJKAMP, P.; CENTO, A (2010). Connectivity and concentration in airline networks: a complexity analysis of Lufthansa's network. European Journal of Information Systems, v. 19, n. 4, p. 449-461.

ROCHA, L. E. (2009) Structural evolution of the Brazilian airport network. Journal of Statistical Mechanics: Theory and Experiment, v. 2009, n. 04.

RODRIGUE, J.-P. (2013) The Geography of Transport Systems. Disponível em: <https://people.hofstra.edu/geotrans/>. Acesso em: 31 ago. 2015.

RODRIGUES, F. A. (2007) Caracterização, Classificação e Análise de Redes Complexas. Tese de Doutorado em Física, Instituto de Física de São Carlos, Departamento de Física e Informática, Universidade de São Paulo, São Carlos, SP, 157 p.

ROSSANO, A \& MANO, J. P. (2010) Vulnerabilidade de redes complexas. XVIII Seminário de Iniciação Científica da PUC-RIO, de 24 a 27 de agosto de 2010. Disponível em: < http://www.puc-rio.br/pibic/relatorio_resumo2010/>.

ROSSANO, A \& COLOMBO, E. H. F. (2011) Vulnerabilidade de redes complexas. XIX Seminário de Iniciação Científica da PUC-RIO, de 23 a 26 de agosto de 2011. Disponível em: <http://www.puc-rio.br/pibic/relatorio_resumo2011/>.

RU, W. \& XU, C. (2005) Hierarchical Structure, Disassortativity and Information Measures of the US Flight Network. Chinese Physics Letters, v. 22, n. 10, p. 2715-2718.

SALGADO, L. H.; VASSALLO, M. D.; OLIVEIRA, A. V. M. DE. (2010) Regulação, Políticas Setoriais, Competitividade e Formação de Preços: Considerações sobre o Transporte Aéreo no Brasil. Journal of Transport Literature, v. 4, n. 1, p. 7-48.

SAPRE, M. S. (2011) Topological Analysis of Air Transportation Networks. Thesis for the degree of Master of Sciencce. Center for Computational Natural Sciences and Bioinformatics, International Institute of Information Technology Hyderabad, India, 108 p.

SHANMEI, L. \& XIAOHAO, X. (2015) Vulnerability analysis for airport networks based on fuzzy soft sets: From the structural and functional perspective. Chinese Journal of Aeronautics. v. 28 , n. 3, p. 780-788.

SILVA, A. R. \& OTAZU, V. J. O. (2011) Redes Complexas: Medidas e Métricas. Projeto Final de Graduação, Coordenadoria do Curso de Ciência da Computação, Universidade Estadual de Mato Grosso do Sul, MS, 60 p. 
SILVA, T. H. C. (2008) Re-regulação no Mercado de Aviação Civil: necessária ou não? Monografia. Ministério da Fazenda, Secretaria de Acompanhamento Econômico. Disponível em: <http://www.seae.fazenda.gov.br/premio-seae/edicoes-anteriores/edicao2008/Est_Tema2_2.pdf>. Acesso em: 28 fev. 2016

SNELDER, M.; VAN ZUYLEN, H. J.; IMMERS, L. H. (2012) A framework for robustness analysis of road networks for short term variations in supply. Transportation Research Part A: Policy and Practice, v. 46, n. 5, p. 828-842.

SOUTELINO, A. L. D. (2006) Desmistificando o Sistema Hub-and-Spoke. Disponível em: <http://www.oaviao.com.br/materias_comunidade/imagens/Hub_and_spoke.pdf >. Acesso em: 09 set 2015.

TAYLOR, M. A. P. \& D'ESTE, G. M. (2007) Transport Network Vulnerability: A Method for Diagnosis of Critical Locations in Transport Infrastructure Systems. Critical Infrastructure: Reliability and Vulnerability. A. T Murray \& T. H. Grubesic (eds), Springer, pp. 17 - 38.

TEIXEIRA JUNIOR, L. A. R. (2015) Método para Análise da Vulnerabilidade dos Nós Intermodais da Rede de Transportes de Carga Brasileira. Dissertação de Mestrado em Transportes. Departamento de Engenharia Civil e Ambiental, Universidade de Brasília, Brasília, DF, 131 p.

UNITED STATES (2013) U. S. Department of Homeland Security National Infrastructure Protection Plan. Publication, EUA. Disponível em: <http://www.dhs.gov/nationalinfrastructure-protection-plan>. Acesso em: 12 nov. 2014.

WANG, J.; MO, H.; WANG, F.; JIN, F. (2011) Exploring the network structure and nodal centrality of China's air transport network: A complex network approach. Journal of Transport Geography, v.19, n. 4, p. 712-721.

WANG, Z.; CHAN, A. P. C.; YUAN, J.; XIA, B.; SKITMORE, M.; LI, Q. (2015) Recent Advances in Modeling the Vulnerability of Transportation Networks. Journal of Infrastructure Systems, v. 21, n. 2.

WILKINSON, S. M.; DUNN, S.; MA, S. (2012) The vulnerability of the European air traffic network to spatial hazards. Natural hazards, v. 60, n. 3, p. 1027-1036.

WUELLNER, D. R.; ROY, S.; D'SOUZA, R. M. (2010) Resilience and rewiring of the passenger airline networks in the United States. Physical Review E, v. 82, n. 5.

YUSTA, J. M.; CORREA, G. J.; LACAL-ARÁNTEGUI, R. (2011) Methodologies and applications for critical infrastructure protection: State-of-the-art. Energy Policy, v. 39, n. 10, p. 6100-6119.

ZANIN, M. Network analysis reveals patterns behind air safety events. (2014) Physica A: Statistical Mechanics and its Applications, v. 401, p. 201-206.

ZANIN, M. \& LILLO, F. (2013) Modelling the air transport with complex networks: A short review. The European Physical Journal Special Topics, v. 215, n. 1, p. 5-21. 
ZENG, X.; TANG, X.; JIANG, K. (2011) Empirical Study of Chinese Airline Network Structure Based on Complex Network Theory. Journal of Transportation Systems Engineering and Information Technology, v. 11, n. 6, p. 175-181.

ZHANG, J.; CAO, X-B., DU, W-B., CAI, K-Q. (2010) Evolution of chinese airport network. Physica A: Statistical Mechanics and its Applications, v. 389, n. 18, p. 3922-3931.

ZHAO, J. \& XU, K. (2009) Enhancing the robustness of scale-free networks. Journal of Physics A: Mathematical and Theoretical, v. 42, n. 19. 


\section{APÊNDICE A - Principais códigos implementados no $R$ airGraph.R}

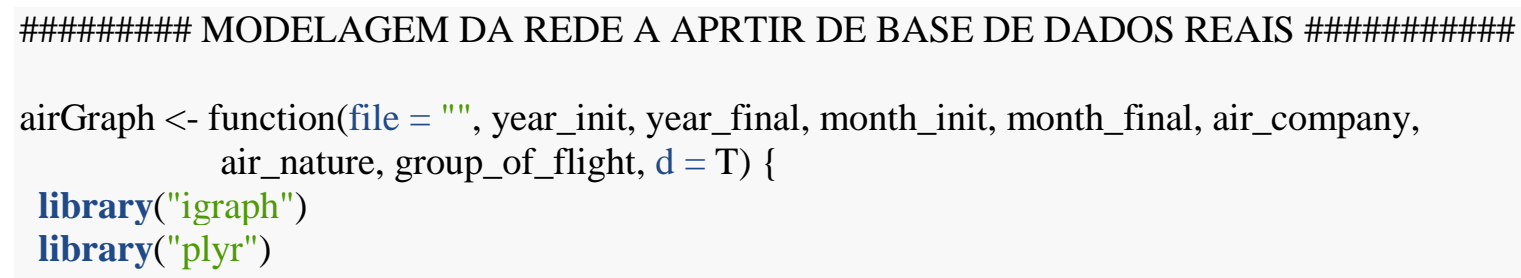


\# Filtra o grupo do voo. Se group_of_flight for vazio, ie. "'", então não há filtro.

if (group_of_flight $==$ "'") \{

data.flights <- data.flights[data.flights\$GRUPO.DE.VOO != "Improdutivo", ]

\} else $\{$ data.flights $<-$ data.flights[data.flights\$GRUPO.DE.VOO == group_of_flight, ] \}

\# quantidade de dados apos a filtragem de empresa, natureza e grupo de voo quant_universe <- nrow(data.flights)

sum_demand_universe <- sum(as.numeric(data.flights\$RPK), na.rm=T)

\# remove todos os dados cuja decolagens é vazia ou 0

data.flights <- subset(data.flights, DECOLAGENS != "")

data.flights <- subset(data.flights, DECOLAGENS != 0)

\# remove todos os dados cuja distancia e vazia ou 0

data.flights <- subset(data.flights, DISTANCIA.VOADA.KM != "")

data.flights <- subset(data.flights, DISTANCIA.VOADA.KM !=0)

\# quantidade de dados apos a filtragem de dados faltantes (VOOS INTERNACIONAIS). quant_missing <- nrow(data.flights)

sum_demand_missing <-sum(as.numeric(data.flights\$RPK), na.rm=T)

\#\#\#\#\#\#\#\# PARTE 2 - GERAÇÃO DO GRAFO REPRESENTATIVO \#\#\#\#\#\#\#\#\#\#

from.airports <- data.flights \$AEROPORTO.DE.ORIGEM..SIGLA. \#\# factor object' to.airports <- data.flights\$AEROPORTO.DE.DESTINO..SIGLA. \#\# factor object'

airline <- data.flights\$EMPRESA..SIGLA. \# codigo IATA da empresa aerea

takeoff <- as.numeric(data.flights\$DECOLAGENS) \# decolagens totais no mês.

flowndistance <- as.numeric(data.flights\$DISTANCIA.VOADA.KM) \# distância total voada no mê $s$.

distance <- flowndistance/takeoff \# distância média da rota.

hours <- as.numeric(data.flights\$HORAS.VOADAS) \# horas voadas totais no mês.

time <- hours/takeoff \# tempo médio de voo na rota.

ASK <- as.numeric(data.flights\$ASK) \# oferta de tráfego total no mês.

RPK <- as.numeric(data.flights\$RPK) \# demanda de tráfego total no mês.

flights <- as.numeric(data.flights\$DECOLAGENS) \# decolagens totais no mês.

seats <- as.numeric(data.flights\$ASSENTOS) \# assentos totais no mês.

paxPerFlight <- RPK/flowndistance \#\# passageiro médio por voo.

pax <- takeoff*paxPerFlight \#\# passageiros totais no mês.

df <- data.frame(from=from.airports, to=to.airports, company=airline, $\mathrm{d}=$ distance, $\mathrm{f}=$ flights, $\mathrm{s}=$ seats, pax. $\mathrm{km}=\mathrm{RPK}$, seats. $\mathrm{km}=\mathrm{ASK}, \mathrm{EDS}=$ distance/seats, $\mathrm{EDF}=$ distance/flights)

aero.net <- ddply(df, .(from, to), summarize, distance=mean(d), flights=sum(f), seats=sum(s), $\mathrm{RPK}=\mathrm{sum}($ pax.km), ASK=sum(seats.km), EDS=mean(d)/sum(s), EDF=mean(d)/sum(f)

)

g <- graph.data.frame(aero.net, directed=TRUE)

$\mathrm{g}<-\operatorname{simplify}(\mathrm{g}$, remove.multiple $=\mathrm{F})$

\#\# Reciprocity: defines the proporsion of mutual connections in a directed graph.

\#\# Referência: ROCHA(2009) e Igraph Package. Circular paths (LORDAN)

R.default <- reciprocity (g, mode='default') 


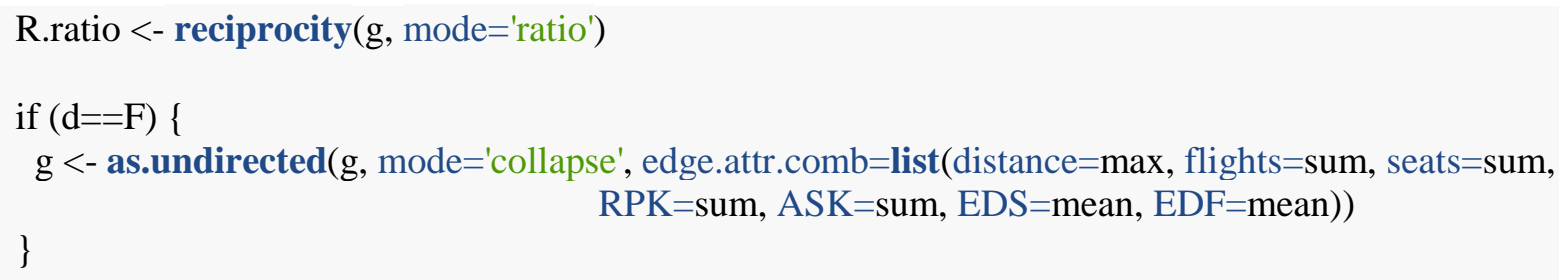


print(paste("Medida de reciprocidade (R.dafault):", round(R.default, digits=2), sep=""))

print(paste("Medida de reciprocidade (R.ratio):", round(R.ratio, digits=2), sep="'"))

print("Graph")

$\operatorname{print}(\mathrm{g})$

\}

$\operatorname{return}(\mathrm{g})$

\section{seqRemoval.R}

\#\#\#\#\# ETAPA 3 - REMOÇÃO SEQUENCIAL DOS VERTICES (MÉTODO LORDAN, 2014) \#\#\#\#\# \#\#\#\#\#

\#\#\#\#\# Considera apenas o betweenness como critério de seleção dos vértices \#\#\#\#\#

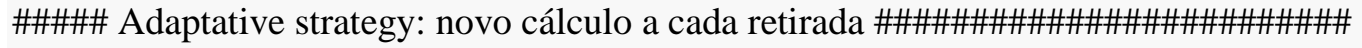

seqRemoval <- function (graph, direction=F) \{

$\mathrm{N}=\operatorname{vcount}($ graph $)$

be $<-$ betweenness (graph, directed=direction, normalized=T) \#\# Vetor de betweenness

central.point <- $(\operatorname{sum}(\max (\mathrm{be})-\mathrm{be})) /(\mathrm{N}-1)$ \# dominancia do ponto central

$\mathrm{q}=\operatorname{seq}(1, \mathrm{~N})$

$\mathrm{Cg}=$ NULL \#\# armazena o 'giant componet size' a cada 'rodada' de simulação.

$\mathrm{x}=0$ \#\# ável medirá porcentagem de aeroportos retirados a cada 'rodada' de simulaçao.Coc

Disconnected = NULL \#\# vetor armazenará a porcentagem de aeroportos retirados a cada 'rodada'.

critical.airports = NULL \#\# vetor para gravar os aeroportos criticos (segundo LORDAN)

for $(\mathrm{z}$ in $\mathrm{q})$

\{

$\mathrm{i}=\operatorname{names}(\mathrm{be}[\mathrm{which}(\mathrm{be}==\max (\mathrm{be}))])$

critical.airports $=\mathbf{c}($ critical.airports, $\mathrm{i})$ \#\# formação do vetor com aeroportos críticos

graph = delete.edges(graph,E(graph)[from(i)]) \#\# Observação: tive que deixar de usar o 'gtemp'.

graph $=$ delete.edges $($ graph, $\mathrm{E}($ graph $)[$ to(i) $])$

$\mathrm{x}=((\mathrm{z}) / \mathrm{N})$ \#\# para medir,a cada rodada, a porcentagem de aeroportos retirados.

$\mathrm{Cg}=\mathbf{c}(\mathrm{Cg}, \max (\mathbf{c l u s t e r s}($ graph $) \$ c s i z e)) \# \#$ Vetor de giant components size.

Disconnected $=\mathbf{c}($ Disconnected, $\mathrm{x}) \# \#$ vetor de quantos aeroportos foram retirados

be <- betweenness(graph, directed=direction) \#\# recalcula o betweenness cada 'rodada' de simulação. \}

plot(Disconnected,Cg, type="s", xlab="\% Aeroportos Removidos",

ylab="Maior Componente Conectada", $\operatorname{xlim}=\mathbf{c}(0,0.5)) \quad \# x \lim =c(0,0.25)$

critical.airports <- cbind(critical.airports) \#\# transforma o vetor em uma matriz de uma coluna colnames(critical.airports) <- "critical airports" \#\# nomeia a coluna da matriz

$\operatorname{print}($ head(critical.airports, 15)) 
print(paste("Dominancia do ponto central:", round(central.point, 2), sep = "'))

\#\# o código gera o gráfico do Lordan conforme esperado, mas gera um "vetor" muito grande. \#\# Se uso head(vetor) dá pra ver os resultados iniciais, mas pq está dando um vetor grande. \}

\section{criticalAirport.R}

\#\# Codigo para simular a retirada de um nó e medir a variaçao nos parametros do grafo \#\# (Impacto à Rede e Criticidade dos Aeroportos)

criticalAirportPlus <- function(graph) \{

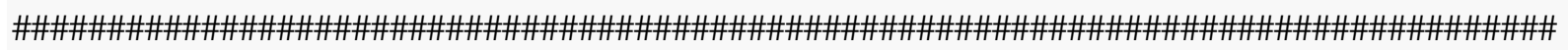
\#\#\#\#\#\#\#\#\#\#

\#\# PARAMETROS ORIGINAIS DA REDE AEREA (Po)

$\mathrm{N}<-$ vcount(graph)

E <- ecount(graph)

Density <- graph.density(graph) \# densidade

GC <- $(\max (\mathbf{c l u s t e r s}($ graph, mode='weak')\$csize $))$ \# maior componente conectada

Eff <- graphEfficiencyLatoraMarchiori(graph, weights=T) \# eficiencia global

par.dr <- sum(degree(graph, mode='all')) \#\# conectividade total

par.wdr.d<-sum(graph.strength(graph, mode='all', weights=E(graph)\$distance)) \# acessibilidade tot al

par.wdr.f<- sum(graph.strength(graph, mode='all', weights=E(graph)\$flights)) \# trafego de voos tota $l$

par.wdr.s $<-\operatorname{sum}($ graph.strength(graph, mode='all', weights=E(graph)\$seats)) \# trafego de assentos $t$ otal

par.wdr.r<- sum(graph.strength(graph, mode='all', weights=E(graph)\$RPK))\# tamanho de mercado

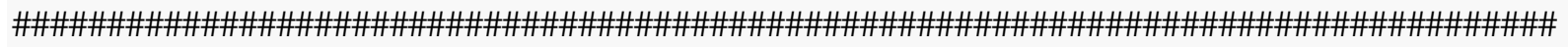
\#\#\#\#\#\#\#\#\#

\#\# SIMULACAO DE RETIRADA DE NOS E CALCULO DE PARAMETROS SITUACIONAIS D

A REDE.

$\mathrm{q}=\operatorname{seq}(1, \mathrm{~N})$

$\mathrm{Dg}=\mathrm{NULL}$

$\mathrm{Cg}=\mathrm{NULL}$

$\mathrm{Eg}=\mathrm{NULL}$

$\mathrm{dr}=$ NULL

wdr.d $=$ NULL

wdr.f $=$ NULL

wdr.s $=$ NULL

wdr.r $=$ NULL

for (i in q)

\{

gtemp $=$ delete.edges $($ graph,E(graph) $[$ from(i)])

gtemp $=$ delete.edges (gtemp,E(gtemp)[to(i)])

$\mathrm{Dg}=\mathbf{c}(\mathrm{Dg}, \mathrm{graph}$.density $(\mathrm{gtemp}))$ \#\# Vetor de variacao de densidades.

$\mathrm{Cg}=\mathbf{c}(\mathrm{Cg}, \max ($ clusters $($ gtemp, mode='weak' $) \$ c$ csize $))$ \#\# Vetor de variacao de giant component. 
$\mathrm{Eg}=\mathbf{c}($ Eg,graphEfficiencyLatoraMarchiori (gtemp, weights=T $)) \# \#$ vetor de variacao de eficienci as.

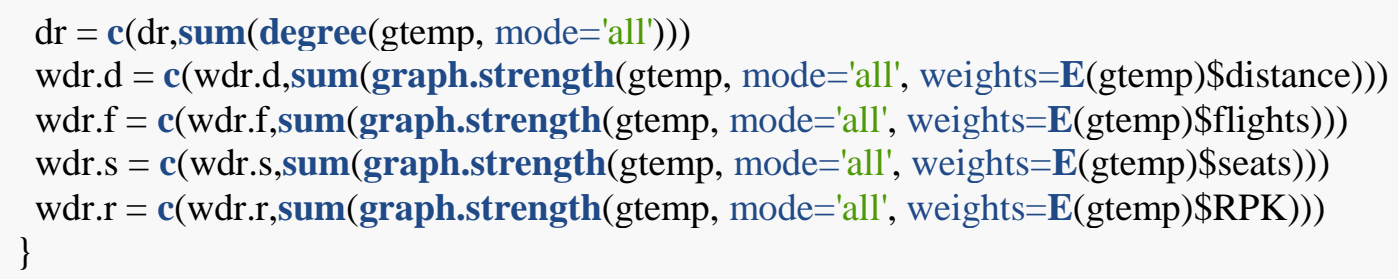




\section{APÊNDICE B - Resultados dos parâmetros de vértices}

Resultados dos 25 (vinte e cinco) primeiros aeroportos

1. Rede de voos internacionais $\left(R_{-} b r a \_i n t\right)$ :

\begin{tabular}{|c|c|c|c|c|c|c|c|c|c|c|c|c|}
\hline & Sigla & $k$ & $\boldsymbol{k}_{\text {distância }}^{\boldsymbol{w}}$ & $k_{v o o}^{w}$ & $k^{w}{ }_{\text {assentos }}$ & $k_{R P K}^{w}$ & $\mathrm{Cl}$ & $C l^{w}{ }_{\text {distância efetiva }}$ & $B$ & $\boldsymbol{B}^{w}$ distância efetiva & $I_{I M P}$ & $I_{I M P(\%)}$ \\
\hline 1 & SBGR & 110 & 697044,1 & 6472 & 1462545 & 6872121439 & 0,6880 & 0,00144 & 0,66157 & 6466,00000 & 50,0859 & 1,00 \\
\hline 2 & SBGL & 57 & 359364,2 & 2125 & 449814 & 2213905140 & 0,4751 & 0,00142 & 0,13963 & 201,00000 & 15,5769 & 0,98 \\
\hline 3 & KMIA & 25 & 140273,0 & 1113 & 263393 & 1333075943 & 0,4971 & 0,00142 & 0,10303 & 1424,00000 & 8,7662 & 0,97 \\
\hline 4 & LPPT & 23 & 267904,7 & 544 & 144791 & 833772121 & 0,5000 & 0,00136 & 0,08606 & 1076,00000 & 7,2472 & 0,96 \\
\hline 5 & SAEZ & 17 & 31859,6 & 1129 & 201295 & 217368537 & 0,4649 & 0,00143 & 0,05898 & 1053,00000 & 4,6706 & 0,95 \\
\hline 6 & МРTO & 16 & 75977,8 & 764 & 117302 & 438606472 & 0,4550 & 0,00139 & 0,03056 & 0,00000 & 2,7802 & 0,94 \\
\hline 7 & SBBR & 17 & 91325,0 & 376 & 75107 & 342790690 & 0,3857 & 0,00133 & 0,01147 & 0,00000 & 1,9232 & 0,93 \\
\hline 8 & SPIM & 13 & 37632,9 & 471 & 81218 & 196009329 & 0,4365 & 0,00141 & 0,03849 & 408,00000 & 1,8396 & 0,91 \\
\hline 9 & SCEL & 8 & 24444,1 & 778 & 150461 & 320263642 & 0,4388 & 0,00143 & 0,03105 & 0,00000 & 1,7946 & 0,90 \\
\hline 10 & LEMD & 8 & 67158,4 & 316 & 89428 & 623388430 & 0,4300 & 0,00139 & 0,02575 & 165,00000 & 1,7665 & 0,89 \\
\hline 11 & SABE & 10 & 13661,6 & 888 & 123204 & 154093243 & 0,4365 & 0,00143 & 0,01066 & 0,00000 & 1,5969 & 0,88 \\
\hline 12 & KJFK & 7 & 53096,4 & 398 & 94552 & 574845700 & 0,4300 & 0,00140 & 0,01657 & 83,00000 & 1,5364 & 0,87 \\
\hline 13 & LFPG & 6 & 56111,4 & 314 & 97961 & 789856650 & 0,4216 & 0,00138 & 0,00223 & 0,00000 & 1,4904 & 0,86 \\
\hline 14 & SBKP & 15 & 93034,0 & 267 & 59768 & 279044647 & 0,3629 & 0,00126 & 0,02766 & 165,00000 & 1,4638 & 0,84 \\
\hline 15 & EDDF & 10 & 90033,0 & 190 & 69318 & 521396206 & 0,4433 & 0,00136 & 0,01331 & 0,00000 & 1,4285 & 0,83 \\
\hline 16 & SBPA & 14 & 47637,0 & 437 & 67562 & 149985881 & 0,3755 & 0,00142 & 0,00941 & 0,00000 & 1,2948 & 0,82 \\
\hline 17 & SBFZ & 17 & 89639,7 & 106 & 25574 & 122518273 & 0,3789 & 0,00126 & 0,04293 & 248,00000 & 1,0381 & 0,81 \\
\hline 18 & KMCO & 9 & 41011,0 & 231 & 51017 & 243768999 & 0,4343 & 0,00136 & 0,00550 & 0,00000 & 0,3865 & 0,80 \\
\hline 19 & SBEG & 10 & 39180,4 & 191 & 29177 & 86937890 & 0,3675 & 0,00135 & 0,02456 & 246,00000 & 0,3676 & 0,79 \\
\hline 20 & SBSV & 12 & 80938,0 & 144 & 36224 & 188316689 & 0,3739 & 0,00124 & 0,00840 & 0,00000 & 0,3583 & 0,77 \\
\hline 21 & $\mathrm{SBCF}$ & 10 & 52142,3 & 234 & 43811 & 212077722 & 0,3644 & 0,00132 & 0,00381 & 0,00000 & 0,3507 & 0,76 \\
\hline 22 & SUMU & 8 & 8648,0 & 429 & 70796 & 78604260 & 0,4503 & 0,00143 & 0,00255 & 0,00000 & 0,3475 & 0,75 \\
\hline 23 & MDSD & 10 & 37820,0 & 248 & 43896 & 113358893 & 0,4624 & 0,00138 & 0,00599 & 15,00000 & 0,3252 & 0,74 \\
\hline 24 & SKBO & 7 & 28429,0 & 256 & 49318 & 191742485 & 0,4343 & 0,00140 & 0,01745 & 84,00000 & 0,2869 & 0,73 \\
\hline 25 & EGLL & 4 & 37458,8 & 187 & 59149 & 437656999 & 0,4175 & 0,00136 & 0,00056 & 0,00000 & 0,2102 & 0,72 \\
\hline
\end{tabular}


2. Rede de voos totais ( $\left.R \_b r a \_t o t\right)$

\begin{tabular}{|c|c|c|c|c|c|c|c|c|c|c|c|c|}
\hline & Sigla & $\boldsymbol{k}$ & $k_{\text {distância }}^{w}$ & $k^{w}{ }_{\text {voo }}$ & $k^{w}$ assentos & $k_{R P K}^{w}$ & $\mathrm{Cl}$ & $\mathrm{Cl}_{\text {distância efetiva }}^{w}$ & $B$ & $\boldsymbol{B}^{w}$ distância efetiva & $I_{I M P}$ & $I_{I M P(\%)}$ \\
\hline 1 & SBGR & 195 & 794949,8787 & 24318 & 4326649 & 9743863513 & 0,67778 & 0,00437 & 0,41815 & 22247 & 58,98195 & 1,00 \\
\hline 2 & SBGL & 115 & 428212,8745 & 11572 & 1997046 & 3623341066 & 0,57911 & 0,00436 & 0,11087 & 1814 & 23,28131 & 0,99 \\
\hline 3 & SBBR & 100 & 189571,0315 & 13759 & 2143176 & 2152418624 & 0,56656 & 0,00436 & 0,10671 & 8645 & 22,12983 & 0,98 \\
\hline 4 & SBKP & 131 & 205044,2042 & 10353 & 1164113 & 998654622 & 0,59416 & 0,00435 & 0,19529 & 4666 & 16,91839 & 0,98 \\
\hline 5 & SBSP & 57 & 39781,47385 & 14491 & 2257020 & 993163926 & 0,45865 & 0,00437 & 0,01536 & 6711 & 16,38305 & 0,97 \\
\hline 6 & SBCF & 78 & 116918,9288 & 9391 & 1311321 & 901836659 & 0,53666 & 0,00436 & 0,07266 & 2159 & 12,07863 & 0,97 \\
\hline 7 & SBSV & 74 & 139404,0451 & 7576 & 1177112 & 1205418026 & 0,52286 & 0,00435 & 0,06296 & 3007 & 12,06930 & 0,96 \\
\hline 8 & SBRJ & 34 & 23315,1614 & 8985 & 1273310 & 442432544 & 0,47044 & 0,00437 & 0,01489 & 6964 & 10,56177 & 0,96 \\
\hline 9 & SBFZ & 55 & 146531,5702 & 4826 & 813182 & 1093177387 & 0,51841 & 0,00431 & 0,03877 & 3608 & 9,73132 & 0,95 \\
\hline 10 & SBPA & 63 & 106768,8612 & 6331 & 930069 & 787863258 & 0,49459 & 0,00435 & 0,03336 & 1074 & 8,70623 & 0,95 \\
\hline 11 & SBRF & 46 & 104854,1789 & 5417 & 862045 & 1117957512 & 0,47781 & 0,00433 & 0,00889 & 1326 & 7,99923 & 0,94 \\
\hline 12 & SBEG & 52 & 90149,07609 & 3010 & 427488 & 606480784 & 0,51404 & 0,00421 & 0,15382 & 4808 & 7,28513 & 0,93 \\
\hline 13 & SBCT & 46 & 56279,81443 & 6069 & 883577 & 411960154 & 0,48413 & 0,00437 & 0,00451 & 1426 & 6,83270 & 0,93 \\
\hline 14 & SBBE & 39 & 55629,84513 & 3669 & 523139 & 516258926 & 0,49459 & 0,00424 & 0,06448 & 3405 & 5,91500 & 0,92 \\
\hline 15 & SBCY & 42 & 45491,85002 & 2835 & 357736 & 307688476 & 0,47656 & 0,00429 & 0,06090 & 2142 & 4,41198 & 0,92 \\
\hline 16 & KMIA & 25 & 140273,0329 & 1113 & 263393 & 1333075943 & 0,48930 & 0,00400 & 0,00204 & 358 & 4,25867 & 0,91 \\
\hline 17 & LPPT & 23 & 267904,6598 & 544 & 144791 & 833772121 & 0,48930 & 0,00292 & 0,00079 & 0 & 3,66568 & 0,91 \\
\hline 18 & SBMO & 29 & 161076,3667 & 1530 & 241838 & 313425806 & 0,47044 & 0,00427 & 0,00140 & 0 & 3,60074 & 0,90 \\
\hline 19 & SBFL & 27 & 27684,0625 & 2978 & 451716 & 210287185 & 0,45636 & 0,00435 & 0,02415 & 1074 & 3,17681 & 0,90 \\
\hline 20 & SBGO & 39 & 39709,00482 & 2957 & 391192 & 207672765 & 0,48285 & 0,00435 & 0,00444 & 0 & 3,16910 & 0,89 \\
\hline 21 & SBSG & 26 & 46837,2 & 2141 & 343067 & 462352506 & 0,46565 & 0,00426 & 0,00516 & 0 & 2,55845 & 0,89 \\
\hline 22 & SBVT & 20 & 15590,33333 & 2763 & 400855 & 176613766 & 0,45865 & 0,00433 & 0,00034 & 0 & 1,93455 & 0,88 \\
\hline 23 & SBRP & 34 & 23382,66667 & 1614 & 147259 & 43837346 & 0,46803 & 0,00432 & 0,00663 & 360 & 1,68859 & 0,87 \\
\hline 24 & SBPS & 32 & 35792,4 & 1237 & 189678 & 131190850 & 0,46684 & 0,00429 & 0,00141 & 0 & 1,63133 & 0,87 \\
\hline 25 & SBSL & 19 & 25306,90476 & 1529 & 235707 & 226414664 & 0,46803 & 0,00426 & 0,00209 & 349 & 1,40448 & 0,86 \\
\hline
\end{tabular}


3. Rede de voos da TAM (R_tam)

\begin{tabular}{|c|c|c|c|c|c|c|c|c|c|c|c|c|}
\hline & Sigla & $\boldsymbol{k}$ & $\boldsymbol{k}_{\text {distância }}$ & $k^{w}{ }_{v o o}$ & $k^{w}{ }_{\text {assentos }}$ & $k_{R P K}^{w}$ & $\mathrm{Cl}$ & $\mathrm{Cl}_{\text {distância efetiva }}^{w}$ & $\boldsymbol{B}$ & $\boldsymbol{B}^{w}$ distância efetiva & $I_{I M P}$ & $I_{I M P}(\%)$ \\
\hline 1 & SBGR & 100 & 279004 & 7371 & 1454863 & 2986143261 & 0,87324 & 0,03035 & 0,57727 & 2603 & 35,63199 & 1,00 \\
\hline 2 & SBBR & 67 & 91002 & 5165 & 876604 & 856214957 & 0,68889 & 0,02974 & 0,21180 & 1046 & 15,94783 & 0,98 \\
\hline 3 & SBSP & 47 & 33458 & 6432 & 1015302 & 467530857 & 0,55357 & 0,03017 & 0,07481 & 1713 & 15,31731 & 0,96 \\
\hline 4 & SBGL & 53 & 107016 & 3837 & 683882 & 837514794 & 0,64583 & 0,02999 & 0,08004 & 155 & 11,74442 & 0,95 \\
\hline 5 & SBFZ & 23 & 38886 & 1728 & 330416 & 451131152 & 0,55357 & 0,02858 & 0,00533 & 502 & 4,95219 & 0,93 \\
\hline 6 & SBCT & 20 & 13102 & 1592 & 270782 & 118525099 & 0,54867 & 0,03019 & 0,00585 & 1068 & 4,49003 & 0,91 \\
\hline 7 & SBSV & 23 & 23933 & 1719 & 319370 & 334100901 & 0,55856 & 0,02910 & 0,01937 & 0 & 3,12772 & 0,90 \\
\hline 8 & SBBE & 21 & 32429 & 1104 & 196128 & 229087237 & 0,54386 & 0,02630 & 0,03318 & 364 & 2,50902 & 0,88 \\
\hline 9 & SBCF & 19 & 25372 & 1584 & 261521 & 134641698 & 0,53913 & 0,02977 & 0,00422 & 45 & 2,30475 & 0,87 \\
\hline 10 & SBRJ & 15 & 10817 & 2195 & 316080 & 116085926 & 0,53448 & 0,02998 & 0,01147 & 0 & 2,20319 & 0,85 \\
\hline 11 & SBPA & 17 & 21640 & 1521 & 271812 & 213480138 & 0,53913 & 0,02957 & 0,00324 & 0 & 2,14585 & 0,83 \\
\hline 12 & SBRF & 12 & 14572 & 1376 & 262234 & 351794640 & 0,52101 & 0,02874 & 0,00114 & 122 & 2,03169 & 0,82 \\
\hline 13 & KMIA & 15 & 85502 & 362 & 98768 & 536797213 & 0,52991 & 0,02116 & 0,00145 & 0 & 1,81829 & 0,80 \\
\hline 14 & SBEG & 19 & 35579 & 896 & 165206 & 270632543 & 0,54386 & 0,02526 & 0,04359 & 122 & 1,59781 & 0,79 \\
\hline 15 & SBFL & 13 & 11828 & 781 & 130986 & 69070284 & 0,52991 & 0,02932 & 0,00252 & 0 & 0,18654 & 0,77 \\
\hline 16 & SBVT & 12 & 8639 & 734 & 123666 & 63023381 & 0,52542 & 0,02894 & 0,00177 & 0 & $-0,08662$ & 0,75 \\
\hline 17 & SBGO & 14 & 11357 & 572 & 98208 & 50439106 & 0,53913 & 0,02916 & 0,00517 & 0 & $-0,10800$ & 0,74 \\
\hline 18 & SBSG & 10 & 16142 & 644 & 121598 & 194131487 & 0,52101 & 0,02635 & 0,00011 & 0 & $-0,12151$ & 0,72 \\
\hline 19 & SBPS & 20 & 21599 & 302 & 51480 & 41491684 & 0,54386 & 0,02576 & 0,01144 & 0 & $-0,34783$ & 0,70 \\
\hline 20 & SBSL & 13 & 17420 & 524 & 88626 & 91867393 & 0,52542 & 0,02611 & 0,00744 & 18 & $-0,36385$ & 0,69 \\
\hline 21 & SBMO & 12 & 22182 & 379 & 73716 & 106930078 & 0,52101 & 0,02595 & 0,00083 & 0 & $-0,48847$ & 0,67 \\
\hline 22 & SBKP & 14 & 14927 & 345 & 59900 & 33160324 & 0,54386 & 0,02825 & 0,00061 & 0 & $-0,49357$ & 0,66 \\
\hline 23 & SBRP & 15 & 10198 & 306 & 49788 & 13404306 & 0,54386 & 0,02928 & 0,00242 & 0 & $-0,52774$ & 0,64 \\
\hline 24 & SBFI & 9 & 7391 & 495 & 84556 & 55068518 & 0,49206 & 0,02774 & 0,00041 & 0 & $-0,80803$ & 0,62 \\
\hline 25 & SBCY & 8 & 9579 & 344 & 58098 & 52231602 & 0,51667 & 0,02669 & 0,00063 & 0 & $-1,17563$ & 0,61 \\
\hline
\end{tabular}


4. Rede de voos da GOL $\left(R \_g l o\right)$

\begin{tabular}{|c|c|c|c|c|c|c|c|c|c|c|c|c|}
\hline & Sigla & $k$ & $\boldsymbol{k}_{\text {distância }}$ & $k^{w}{ }_{v o o}$ & $\boldsymbol{k}_{\text {assentos }}$ & $k_{R P K}^{w}$ & $\mathrm{Cl}$ & $C l_{\text {distância efetiva }}^{w}$ & $B$ & $B^{w}{ }_{\text {distância efetiva }}$ & $I_{I M P}$ & $I_{I M P(\%)}$ \\
\hline 1 & SBGR & 96 & 163970 & 7873 & 1335734 & 1388317937 & 0,72277 & 0,02278 & 0,42132 & 3179 & 34,38672 & 1,00 \\
\hline 2 & SBBR & 60 & 82358 & 4719 & 789641 & 690051665 & 0,61864 & 0,02239 & 0,17252 & 1136 & 16,64744 & 0,98 \\
\hline 3 & SBSP & 49 & 33376 & 6123 & 994500 & 421798585 & 0,52899 & 0,02271 & 0,14859 & 1475 & 15,42830 & 0,97 \\
\hline 4 & SBGL & 66 & 99769 & 4425 & 745713 & 703500818 & 0,64035 & 0,02259 & 0,12666 & 218 & 15,34365 & 0,95 \\
\hline 5 & SBCF & 45 & 54025 & 3255 & 542800 & 286203165 & 0,57031 & 0,02250 & 0,06815 & 341 & 8,92217 & 0,94 \\
\hline 6 & SBSV & 40 & 44084 & 2732 & 467352 & 400007403 & 0,54478 & 0,02204 & 0,02869 & 509 & 8,40978 & 0,93 \\
\hline 7 & SBFZ & 32 & 58764 & 1864 & 320843 & 348610695 & 0,52518 & 0,02116 & 0,01218 & 488 & 6,84898 & 0,91 \\
\hline 8 & SBRF & 27 & 38749 & 1865 & 315613 & 356929661 & 0,50694 & 0,02160 & 0,05736 & 700 & 6,34708 & 0,90 \\
\hline 9 & SBRJ & 16 & 7895 & 3447 & 581298 & 180636859 & 0,50000 & 0,02272 & 0,00382 & 830 & 6,32463 & 0,89 \\
\hline 10 & SBPA & 34 & 52061 & 2117 & 360599 & 280405186 & 0,54074 & 0,02212 & 0,01623 & 143 & 6,11768 & 0,87 \\
\hline 11 & SBCT & 30 & 28612 & 2209 & 366388 & 163516652 & 0,51773 & 0,02257 & 0,00872 & 421 & 5,19439 & 0,86 \\
\hline 12 & SBBE & 23 & 25995 & 1365 & 226863 & 202505571 & 0,50000 & 0,02043 & 0,05473 & 657 & 3,85390 & 0,84 \\
\hline 13 & SBEG & 18 & 31863 & 819 & 140133 & 179513157 & 0,48993 & 0,01881 & 0,04702 & 420 & 2,12143 & 0,83 \\
\hline 14 & SBKP & 27 & 39964 & 713 & 121131 & 83664901 & 0,53285 & 0,02209 & 0,01867 & 0 & 2,00195 & 0,82 \\
\hline 15 & SBSG & 20 & 33656 & 839 & 145305 & 165989406 & 0,49324 & 0,02037 & 0,00049 & 0 & 1,61798 & 0,80 \\
\hline 16 & SBGO & 21 & 23024 & 931 & 144392 & 70886632 & 0,51773 & 0,02213 & 0,00411 & 0 & 1,17964 & 0,79 \\
\hline 17 & SBFL & 14 & 9058 & 1264 & 199008 & 78197387 & 0,46795 & 0,02233 & 0,02902 & 143 & 1,06681 & 0,78 \\
\hline 18 & SBSL & 15 & 20230 & 675 & 114678 & 105306478 & 0,48344 & 0,02041 & 0,00795 & 318 & 0,98658 & 0,76 \\
\hline 19 & SBMO & 18 & 31248 & 598 & 105148 & 118904452 & 0,48344 & 0,02105 & 0,00039 & 0 & 0,96758 & 0,75 \\
\hline 20 & SBVT & 14 & 10052 & 1083 & 174648 & 72636787 & 0,47712 & 0,02210 & 0,00224 & 0 & 0,49254 & 0,73 \\
\hline 21 & SBPS & 20 & 20296 & 596 & 104562 & 68253377 & 0,50000 & 0,02147 & 0,00648 & 0 & 0,48880 & 0,72 \\
\hline 22 & SBCY & 16 & 20450 & 633 & 109389 & 108474680 & 0,49660 & 0,02088 & 0,01284 & 6 & 0,40444 & 0,71 \\
\hline 23 & SBCG & 15 & 12063 & 422 & 71264 & 49771241 & 0,48993 & 0,02057 & 0,00191 & 0 & $-0,63513$ & 0,69 \\
\hline 24 & SAEZ & 12 & 22440 & 366 & 64632 & 62420224 & 0,45062 & 0,01906 & 0,00034 & 0 & $-0,68449$ & 0,68 \\
\hline 25 & SBFI & 10 & 7932 & 519 & 84727 & 56057678 & 0,45912 & 0,02127 & 0,00102 & 0 & $-0,81419$ & 0,67 \\
\hline
\end{tabular}




\begin{tabular}{|c|c|c|c|c|c|c|c|c|c|c|c|c|}
\hline & Sigla & $k$ & $\boldsymbol{k}_{\text {distância }}^{w}$ & $k_{\text {voo }}^{w}$ & $\boldsymbol{k}_{\text {assentos }}^{w}$ & $k_{R P K}^{w}$ & $\mathrm{Cl}$ & $\mathrm{Cl}_{\text {distância efetiva }}^{w}$ & $B$ & $\boldsymbol{B}^{w}{ }_{\text {distância efetiva }}$ & $I_{I M P}$ & $I_{I M P(\%)}$ \\
\hline 1 & SBKP & 118 & 138483,0288 & 9158 & 954991 & 766809253 & 0,68627 & 0,02486 & 0,57757 & 8968 & 50,26551 & 1,00 \\
\hline 2 & SBCF & 66 & 64082,31048 & 4324 & 467326 & 300234357 & 0,57692 & 0,02426 & 0,20349 & 2863 & 21,72214 & 0,99 \\
\hline 3 & SBGR & 38 & 38644,8861 & 2732 & 304185 & 192919539 & 0,45852 & 0,02355 & 0,02651 & 0 & 11,11474 & 0,98 \\
\hline 4 & SBCY & 34 & 31649,05928 & 1448 & 149997 & 119026353 & 0,48165 & 0,02202 & 0,11909 & 3194 & 9,90200 & 0,97 \\
\hline 5 & SBRJ & 30 & 19664,42538 & 2425 & 258548 & 100444174 & 0,47297 & 0,02432 & 0,02879 & 552 & 8,34498 & 0,96 \\
\hline 6 & SBSV & 38 & 29195,79407 & 1506 & 147348 & 116126147 & 0,47511 & 0,02152 & 0,07076 & 1258 & 7,98970 & 0,95 \\
\hline 7 & SBPA & 32 & 19900,96942 & 2089 & 217022 & 130246306 & 0,46053 & 0,02300 & 0,04878 & 615 & 7,98238 & 0,94 \\
\hline 8 & SBCT & 26 & 17795,72787 & 2134 & 227202 & 79291213 & 0,45652 & 0,02418 & 0,00759 & 764 & 7,35147 & 0,93 \\
\hline 9 & SBRF & 28 & 36188,54286 & 1345 & 147595 & 136398666 & 0,46460 & 0,01982 & 0,01515 & 994 & 7,25790 & 0,92 \\
\hline 10 & SBBR & 31 & 30204,63717 & 1389 & 150718 & 99326418 & 0,50725 & 0,02277 & 0,06708 & 192 & 6,46422 & 0,91 \\
\hline 11 & SBEG & 22 & 25546,11531 & 849 & 87644 & 93592528 & 0,48837 & 0,01621 & 0,15382 & 1851 & 4,91291 & 0,90 \\
\hline 12 & SBGO & 22 & 23361,88371 & 925 & 102318 & 67304971 & 0,47511 & 0,02230 & 0,01194 & 410 & 4,34058 & 0,89 \\
\hline 13 & SBBE & 23 & 21196,71204 & 937 & 82882 & 63441374 & 0,48165 & 0,01573 & 0,07440 & 818 & 3,28036 & 0,88 \\
\hline 14 & SBFZ & 22 & 25249,45588 & 647 & 68791 & 75148697 & 0,46256 & 0,01752 & 0,01848 & 365 & 3,07328 & 0,87 \\
\hline 15 & SBMO & 22 & 30462 & 370 & 35999 & 32539810 & 0,47297 & 0,01823 & 0,00476 & 14 & 2,11226 & 0,86 \\
\hline 16 & SBPV & 8 & 9514,578947 & 398 & 45196 & 32878615 & 0,44492 & 0,01784 & 0,02207 & 2019 & 1,95983 & 0,85 \\
\hline 17 & SBVT & 10 & 6314 & 946 & 102541 & 40953598 & 0,44304 & 0,02306 & 0,00020 & 0 & 1,94695 & 0,84 \\
\hline 18 & SBPS & 22 & 23940 & 339 & 33636 & 21445789 & 0,45652 & 0,02005 & 0,00493 & 0 & 1,85587 & 0,83 \\
\hline 19 & SBRP & 18 & 15146 & 410 & 33491 & 11165775 & 0,45064 & 0,02363 & 0,00179 & 0 & 1,65440 & 0,82 \\
\hline 20 & SBBH & 18 & 7212 & 899 & 61668 & 16396383 & 0,44304 & 0,02181 & 0,01352 & 0 & 1,61298 & 0,81 \\
\hline 21 & SBSG & 16 & 19876 & 470 & 44090 & 38482047 & 0,45652 & 0,01864 & 0,00927 & 0 & 1,36784 & 0,80 \\
\hline 22 & SBSP & 8 & 4116,912681 & 733 & 86170 & 35071679 & 0,38889 & 0,02297 & 0,00000 & 0 & 1,25124 & 0,80 \\
\hline 23 & SBLO & 14 & 13004,51447 & 437 & 39140 & 16049973 & 0,43750 & 0,02180 & 0,00209 & 0 & 1,05674 & 0,79 \\
\hline 24 & SBCG & 10 & 8700 & 427 & 44584 & 30807204 & 0,42857 & 0,02131 & 0,01937 & 207 & 0,86047 & 0,78 \\
\hline 25 & SBSR & 12 & 12068 & 324 & 26227 & 9598943 & 0,43750 & 0,02294 & 0,00146 & 0 & 0,77825 & 0,77 \\
\hline
\end{tabular}


6. Rede de voos da AVIANCA (R_one)

\begin{tabular}{|c|c|c|c|c|c|c|c|c|c|c|c|c|}
\hline & Sigla & $\boldsymbol{k}$ & $\boldsymbol{k}_{\text {distância }}$ & $k^{w}{ }_{v o o}$ & $k_{\text {assentos }}^{w}$ & $k_{R P K}^{w}$ & $\mathrm{Cl}$ & $C l^{w}$ distância efetiva & $B$ & $\boldsymbol{B}^{w}{ }_{\text {distância efetiva }}$ & $I_{I M P}$ & $I_{I M P(\%)}$ \\
\hline 1 & SBGR & 29 & 39861 & 1995 & 285738 & 342199381 & 0,72727 & 0,08388 & 0,22870 & 328 & 18,41633 & 1,00 \\
\hline 2 & SBBR & 40 & 45074 & 1820 & 240940 & 197861905 & 0,85714 & 0,07824 & 0,51861 & 162 & 14,99807 & 0,95 \\
\hline 3 & SBSV & 21 & 17840 & 1245 & 191114 & 161617574 & 0,63158 & 0,08082 & 0,06840 & 208 & 9,14994 & 0,91 \\
\hline 4 & SBGL & 18 & 21378 & 984 & 133846 & 114159402 & 0,61538 & 0,08192 & 0,04563 & 60 & 5,57659 & 0,87 \\
\hline 5 & SBSP & 11 & 7942 & 1203 & 161048 & 68762805 & 0,54545 & 0,07891 & 0,01024 & 46 & 3,45501 & 0,83 \\
\hline 6 & SBFZ & 12 & 23248 & 505 & 71814 & 108052896 & 0,55814 & 0,06994 & 0,08575 & 90 & 3,04066 & 0,79 \\
\hline 7 & SBRF & 10 & 13786 & 678 & 105752 & 118995905 & 0,53333 & 0,07524 & 0,00466 & 0 & 2,06396 & 0,75 \\
\hline 8 & SBFL & 12 & 7698 & 492 & 71076 & 33668882 & 0,55814 & 0,07865 & 0,09388 & 46 & 0,67774 & 0,70 \\
\hline 9 & SBRJ & 6 & 3872 & 918 & 117384 & 45265585 & 0,52174 & 0,07775 & 0,00060 & 0 & 0,55902 & 0,66 \\
\hline 10 & SBPA & 6 & 4698 & 300 & 36534 & 24337550 & 0,46154 & 0,07235 & 0,00000 & 0 & $-2,07448$ & 0,62 \\
\hline 11 & SBGO & 7 & 4955 & 242 & 28440 & 11211798 & 0,53333 & 0,07557 & 0,00060 & 0 & $-2,12533$ & 0,58 \\
\hline 12 & SBCY & 6 & 5528 & 296 & 32412 & 24387058 & 0,51064 & 0,06370 & 0,00453 & 32 & $-2,16873$ & 0,54 \\
\hline 13 & SBMO & 6 & 7756 & 182 & 26732 & 26584259 & 0,51064 & 0,06855 & 0,00000 & 0 & $-2,33491$ & 0,50 \\
\hline 14 & SBJU & 6 & 7278 & 246 & 28484 & 24481977 & 0,52174 & 0,06522 & 0,00000 & 0 & $-2,46076$ & 0,45 \\
\hline 15 & SBPL & 6 & 4346 & 189 & 30246 & 15614655 & 0,48980 & 0,06934 & 0,00000 & 0 & $-2,66810$ & 0,41 \\
\hline 16 & SBAR & 4 & 3086 & 124 & 14800 & 8483882 & 0,48000 & 0,07271 & 0,00000 & 0 & $-3,20111$ & 0,37 \\
\hline 17 & SBIL & 4 & 2368 & 112 & 13552 & 5907251 & 0,48000 & 0,07194 & 0,00000 & 0 & $-3,37806$ & 0,33 \\
\hline 18 & SBSG & 4 & 8126 & 156 & 23628 & 37174750 & 0,50000 & 0,05216 & 0,00000 & 0 & $-3,42999$ & 0,29 \\
\hline 19 & SBJP & 6 & 11704 & 155 & 19336 & 30217506 & 0,51064 & 0,04374 & 0,00000 & 0 & $-3,53315$ & 0,25 \\
\hline 20 & $\mathrm{SBCH}$ & 2 & 818 & 115 & 17106 & 5341949 & 0,36364 & 0,07244 & 0,00000 & 0 & $-3,65929$ & 0,20 \\
\hline 21 & SBCG & 4 & 2870 & 176 & 17960 & 9813968 & 0,48000 & 0,05786 & 0,00000 & 0 & $-3,93669$ & 0,16 \\
\hline 22 & $\mathrm{SBCT}$ & 2 & 2164 & 62 & 8526 & 6918308 & 0,47059 & 0,05379 & 0,00000 & 0 & $-4,81339$ & 0,12 \\
\hline 23 & SBPF & 2 & 1584 & 48 & 4800 & 2756952 & 0,42857 & 0,05125 & 0,00000 & 0 & $-5,13675$ & 0,08 \\
\hline 24 & $\mathrm{SBCF}$ & 2 & 1180 & 25 & 2540 & 1198290 & 0,47059 & 0,04477 & 0,00000 & 0 & $-5,63972$ & 0,04 \\
\hline 25 & SKBO & 2 & 8128 & 8 & 1056 & 2040128 & 0,36364 & 0,00523 & 0,00000 & 0 & $-7,37685$ & 0,00 \\
\hline
\end{tabular}




\section{APÊNDICE C - Resultados das variações dos parâmetros dos grafos}

Resultados dos 25 (vinte e cinco) primeiros aeroportos

1. Rede de voos internacionais $\left(R \_b r a \_i n t\right)$ :

\begin{tabular}{|c|c|c|c|c|c|c|c|c|c|c|c|}
\hline & Sigla & Densidade & Componente & $\sum k$ & Eficiência $\sum \boldsymbol{k}^{w}$ & & $\sum k^{w}{ }_{v o o}$ & $\sum \boldsymbol{k}_{a}^{w}$ & $\sum_{R}^{w}$ & $I_{C R I}$ & $\overline{I_{C R I(\%)}}$ \\
\hline 1 & SBGR & $-0,3395$ & $-0,2529$ & $-0,3395$ & $-0,6879$ & $-0,3703$ & $-0,5732$ & $-0,6040$ & $-0,6267$ & 65,98 & 1,00 \\
\hline 2 & SBGL & $-0,1759$ & $-0,0230$ & $-0,1759$ & $-0,0673$ & $-0,1909$ & $-0,1882$ & $-0,1858$ & $-0,2019$ & 19,14 & 0,99 \\
\hline 3 & KMIA & $-0,0772$ & $-0,0115$ & $-0,0772$ & $-0,0780$ & $-0,0745$ & $-0,0986$ & $-0,1088$ & $-0,1216$ & 7,94 & 0,98 \\
\hline 4 & LPPT & $-0,0710$ & $-0,0345$ & $-0,0710$ & $-0,0531$ & $-0,1423$ & $-0,0482$ & $-0,0598$ & $-0,0760$ & 7,51 & 0,97 \\
\hline 5 & SAEZ & $-0,0525$ & $-0,0115$ & $-0,0525$ & $-0,1257$ & $-0,0169$ & $-0,1000$ & $-0,0831$ & $-0,0198$ & 4,36 & 0,95 \\
\hline 6 & МРТO & $-0,0494$ & $-0,0115$ & $-0,0494$ & $-0,0346$ & $-0,0404$ & $-0,0677$ & $-0,0484$ & $-0,0400$ & 2,78 & 0,94 \\
\hline 7 & SBBR & $-0,0525$ & $-0,0115$ & $-0,0525$ & $-0,0216$ & $-0,0485$ & $-0,0333$ & $-0,0310$ & $-0,0313$ & 2,02 & 0,93 \\
\hline 8 & SPIM & $-0,0401$ & $-0,0230$ & $-0,0401$ & $-0,0793$ & $-0,0200$ & $-0,0417$ & $-0,0335$ & $-0,0179$ & 2,00 & 0,92 \\
\hline 9 & SBFZ & $-0,0525$ & $-0,0345$ & $-0,0525$ & $-0,0214$ & $-0,0476$ & $-0,0094$ & $-0,0106$ & $-0,0112$ & 1,93 & 0,91 \\
\hline 10 & SBKP & $-0,0463$ & $-0,0230$ & $-0,0463$ & $-0,0264$ & $-0,0494$ & $-0,0236$ & $-0,0247$ & $-0,0254$ & 1,92 & 0,90 \\
\hline 11 & SABE & $-0,0309$ & $-0,0115$ & $-0,0309$ & $-0,0717$ & $-0,0073$ & $-0,0786$ & $-0,0509$ & $-0,0141$ & 1,50 & 0,88 \\
\hline 12 & SCEL & $-0,0247$ & $-0,0115$ & $-0,0247$ & $-0,0675$ & $-0,0130$ & $-0,0689$ & $-0,0621$ & $-0,0292$ & 1,50 & 0,87 \\
\hline 13 & LEMD & $-0,0247$ & $-0,0230$ & $-0,0247$ & $-0,0391$ & $-0,0357$ & $-0,0280$ & $-0,0369$ & $-0,0569$ & 1,44 & 0,86 \\
\hline 14 & SBPA & $-0,0432$ & $-0,0115$ & $-0,0432$ & $-0,0546$ & $-0,0253$ & $-0,0387$ & $-0,0279$ & $-0,0137$ & 1,31 & 0,85 \\
\hline 15 & KJFK & $-0,0216$ & $-0,0230$ & $-0,0216$ & $-0,0391$ & $-0,0282$ & $-0,0352$ & $-0,0390$ & $-0,0524$ & 1,21 & 0,84 \\
\hline 16 & EDDF & $-0,0309$ & $-0,0115$ & $-0,0309$ & $-0,0268$ & $-0,0478$ & $-0,0168$ & $-0,0286$ & $-0,0476$ & 0,97 & 0,83 \\
\hline 17 & LFPG & $-0,0185$ & $-0,0115$ & $-0,0185$ & $-0,0311$ & $-0,0298$ & $-0,0278$ & $-0,0405$ & $-0,0720$ & 0,73 & 0,81 \\
\hline 18 & SBSV & $-0,0370$ & $-0,0115$ & $-0,0370$ & $-0,0138$ & $-0,0430$ & $-0,0128$ & $-0,0150$ & $-0,0172$ & 0,31 & 0,80 \\
\hline 19 & SBEG & $-0,0309$ & $-0,0230$ & $-0,0309$ & $-0,0298$ & $-0,0208$ & $-0,0169$ & $-0,0120$ & $-0,0079$ & 0,07 & 0,79 \\
\hline 20 & SUMU & $-0,0247$ & $-0,0115$ & $-0,0247$ & $-0,0647$ & $-0,0046$ & $-0,0380$ & $-0,0292$ & $-0,0072$ & 0,02 & 0,78 \\
\hline 21 & SKBO & $-0,0216$ & $-0,0230$ & $-0,0216$ & $-0,0392$ & $-0,0151$ & $-0,0227$ & $-0,0204$ & $-0,0175$ & $-0,03$ & 0,77 \\
\hline 22 & SBCF & $-0,0309$ & $-0,0115$ & $-0,0309$ & $-0,0201$ & $-0,0277$ & $-0,0207$ & $-0,0181$ & $-0,0193$ & $-0,04$ & 0,76 \\
\hline 23 & SBFL & $-0,0247$ & $-0,0345$ & $-0,0247$ & $-0,0438$ & $-0,0086$ & $-0,0104$ & $-0,0081$ & $-0,0023$ & $-0,10$ & 0,74 \\
\hline 24 & KMCO & $-0,0278$ & $-0,0115$ & $-0,0278$ & $-0,0275$ & $-0,0218$ & $-0,0205$ & $-0,0211$ & $-0,0222$ & $-0,14$ & 0,73 \\
\hline 25 & MDSD & $-0,0309$ & $-0,0115$ & $-0,0309$ & $-0,0320$ & $-0,0201$ & $-0,0220$ & $-0,0181$ & $-0,0103$ & $-0,15$ & 0,72 \\
\hline
\end{tabular}


2. Rede de voos totais $\left(R \_b r a \_t o t\right)$ :

\begin{tabular}{|c|c|c|c|c|c|c|c|c|c|c|c|}
\hline & Sigla & ensidade & Componente & $\sum k$ & Eficiência & $\sum \boldsymbol{k}_{\text {dist }}^{w}$ & $\sum k^{w}{ }_{v o o}$ & $\sum \boldsymbol{k}_{a}^{w}$ & $\sum k_{R P K}^{w}$ & $I_{C R I}$ & $I_{C R I(\%)}$ \\
\hline 1 & SBGR & $-0,1702$ & $-0,1196$ & $-0,1702$ & $-0,2158$ & $-0,2999$ & $-0,2585$ & $-0,3045$ & $-0,4913$ & 74,23 & $\overline{1,00}$ \\
\hline 2 & SBGL & $-0,1003$ & $-0,0109$ & $-0,1003$ & $-0,0555$ & $-0,1615$ & $-0,1230$ & $-0,1406$ & $-0,1827$ & 28,10 & 0,99 \\
\hline 3 & SBKP & $-0,1143$ & 0489 & $-0,1143$ & $-0,0850$ & $-0,0774$ & $-0,1100$ & $-0,0819$ & $-0,0504$ & 25,92 & 0,99 \\
\hline 4 & SBBR & $-0,0873$ & $-0,0054$ & $-0,0873$ & $-0,0684$ & $-0,0715$ & $-0,1462$ & $-0,1508$ & $-0,1085$ & 22,91 & 0,98 \\
\hline 5 & SBSP & $-0,0497$ &, 0054 & $-0,0497$ & $-0,1118$ & $-0,0150$ & $-0,1540$ & $-0,1589$ & $-0,0501$ & 18,11 & 0,98 \\
\hline 6 & SBSV & $-0,0646$ & $-0,0217$ & $-0,0646$ & $-0,0772$ & $-0,0526$ & $-0,0805$ & $-0,0829$ & $-0,0608$ & 16,52 & 0,97 \\
\hline 7 & SBCF & $-0,0681$ & $-0,0109$ & $-0,0681$ & $-0,0743$ & $-0,0441$ & $-0,0998$ & $-0,0923$ & $-0,0455$ & 15,94 & 0,97 \\
\hline 8 & SBEG & $-0,0454$ & 0652 & $-0,0454$ & $-0,0616$ & $-0,0340$ & $-0,0320$ & $-0,0301$ & $-0,0306$ & 13,54 & 0,96 \\
\hline 9 & SBPA & $-0,0550$ & $-0,0163$ & $-0,0550$ & $-0,0633$ & $-0,0403$ & $-0,0673$ & $-0,0655$ & $-0,0397$ & 12,53 & 0,96 \\
\hline 10 & SBFZ & $-0,0480$ & $-0,0163$ & $-0,0480$ & $-0,0405$ & $-0,0553$ & $-0,0513$ & $-0,0572$ & $-0,0551$ & 11,01 & 0,95 \\
\hline 11 & SBRJ & $-0,0297$ & 09 & $-0,0297$ & -0 & $-0,0088$ & $-0,0955$ & $-0,0896$ & $-0,0223$ & 10,70 & 0,95 \\
\hline 12 & SBRF & $-0,0401$ & $-0,0054$ & $-0,0401$ & -0 & $-0,0396$ & $-0,0576$ & $-0,0607$ & $-0,0564$ & 9,13 & 0,94 \\
\hline 13 & SBCT & $-0,0401$ & $-0,0054$ & $-0,0401$ & $-0,0694$ & $-0,0212$ & $-0,0645$ & $-0,0622$ & $-0,0208$ & 8,95 & 0,93 \\
\hline 14 & SBCY & $-0,0366$ & $-0,0326$ & $-0,0366$ & $-0,0623$ & $-0,0172$ & $-0,0301$ & $-0,0252$ & $-0,0155$ & 8,38 & 0,93 \\
\hline 15 & SBBE & $-0,0340$ & $-0,0163$ & $-0,0340$ & $-0,0479$ & $-0,0210$ & $-0,0390$ & $-0,0368$ & $-0,0260$ & 6,99 & 0,92 \\
\hline 16 & SBFL & $-0,0236$ & $-0,0163$ & $-0,0236$ & $-0,0472$ & $-0,0104$ & $-0,0317$ & $-0,0318$ & $-0,0106$ & 4,78 & 0,92 \\
\hline 17 & SBGO & $-0,0340$ & $-0,0054$ & $-0,0340$ & $-0,0362$ & $-0,0150$ & $-0,0314$ & $-0,0275$ & $-0,0105$ & 4,32 & 0,91 \\
\hline 18 & LPPT & $-0,0201$ & $-0,0054$ & $-0,0201$ & $-0,0029$ & $-0,1011$ & $-0,0058$ & $-0,0102$ & $-0,0420$ & 3,99 & 0,91 \\
\hline 19 & KMIA & $-0,0218$ & $-0,0054$ & $-0,0218$ & $-0,0114$ & $-0,0529$ & $-0,0118$ & $-0,0185$ & $-0,0672$ & 3,89 & 0,90 \\
\hline 20 & SBMO & $-0,0253$ & $-0,0054$ & $-0,0253$ & $-0,0205$ & $-0,0608$ & $-0,0163$ & $-0,0170$ & $-0,0158$ & 3,73 & 0,90 \\
\hline 21 & SBSG & $-0,0227$ & $-0,0054$ & $-0,0227$ & $-0,0205$ & $-0,0177$ & $-0,0228$ & $-0,0241$ & $-0,0233$ & 2,56 & 0,89 \\
\hline 22 & SBRP & $-0,0297$ & $-0,0054$ & $-0,0297$ & $-0,0282$ & $-0,0088$ & $-0,0172$ & $-0,0104$ & $-0,0022$ & 2,13 & 0,89 \\
\hline 23 & SBVT & $-0,0175$ & $-0,0054$ & $-0,0175$ & $-0,0314$ & $-0,0059$ & $-0,0294$ & $-0,0282$ & $-0,0089$ & 2,08 & 0,88 \\
\hline 24 & SBPS & $-0,0279$ & $-0,0054$ & $-0,0279$ & $-0,0227$ & $-0,0135$ & $-0,0131$ & $-0,0134$ & $-0,0066$ & 1,96 & 0,87 \\
\hline 25 & SBCG & $-0,0192$ & $-0,0109$ & $-0,0192$ & $-0,0262$ & $-0,0077$ & $-0,0143$ & $-0,0132$ & $-0,0066$ & 1,60 & 0,87 \\
\hline
\end{tabular}


3. Rede de voos da TAM (R_tam):

\begin{tabular}{|c|c|c|c|c|c|c|c|c|c|c|c|}
\hline & Sigla & Densidade & Componente & $\sum k$ & Eficiência & $\sum \boldsymbol{k}_{\text {dist }}^{w}$ & $\sum k_{v o o}^{w}$ & $\sum \boldsymbol{k}_{a s}^{w}$ & $\sum k_{R P K}^{w}$ & $I_{C R I}$ & $I_{C R I(\%)}$ \\
\hline 1 & $\begin{array}{l}\text { SBGR } \\
\text { SB }\end{array}$ & $-0,2681$ & $-0,1905$ & $-0,2681$ & $-0,2631$ & $-0,4301$ & $-0,3086$ & $-0,3446$ & $-0,5567$ & 46,20 & 1,00 \\
\hline 2 & SBBR & $-0,1796$ & $-0,0159$ & $-0,1796$ & $-0,1454$ & $-0,1403$ & $-0,2162$ & $-0,2077$ & $-0,1596$ & 18,07 & 0,98 \\
\hline 3 & SBSP & $-0,1260$ & $-0,0159$ & $-0,1260$ & $-0,3097$ & $-0,0516$ & $-0,2692$ & $-0,2405$ & $-0,0872$ & 17,71 & 0,97 \\
\hline 4 & SBGL & $-0,1421$ & $-0,0159$ & $-0,1421$ & $-0,0826$ & $-0,1650$ & $-0,1606$ & $-0,1620$ & $-0,1561$ & 13,87 & 0,95 \\
\hline 5 & SBFZ & $-0,0617$ & $-0,0159$ & $-0,0617$ & $-0,0611$ & $-0,0599$ & $-0,0723$ & $-0,0783$ & $-0,0841$ & 4,24 & 0,94 \\
\hline 6 & SBSV & $-0,0617$ & $-0,0159$ & $-0,0617$ & $-0,0496$ & $-0,0369$ & $-0,0720$ & $-0,0757$ & $-0,0623$ & 3,30 & 0,92 \\
\hline 7 & SBCT & $-0,0536$ & $-0,0159$ & $-0,0536$ & $-0,1051$ & $-0,0202$ & $-0,0666$ & $-0,0641$ & $-0,0221$ & 2,88 & 0,90 \\
\hline 8 & SBRJ & $-0,0402$ & $-0,0159$ & $-0,0402$ & $-0,1025$ & $-0,0167$ & $-0,0919$ & $-0,0749$ & $-0,0216$ & 2,76 & 0,89 \\
\hline 9 & SBCF & $-0,0509$ & $-0,0159$ & $-0,0509$ & $-0,0741$ & $-0,0391$ & $-0,0663$ & $-0,0620$ & $-0,0251$ & 2,49 & 0,87 \\
\hline 10 & SBPA & $-0,0456$ & $-0,0159$ & $-0,0456$ & $-0,0627$ & $-0,0334$ & $-0,0637$ & $-0,0644$ & $-0,0398$ & 2,13 & 0,85 \\
\hline 11 & SBBE & $-0,0563$ & $-0,0159$ & $-0,0563$ & $-0,0481$ & $-0,0500$ & $-0,0462$ & $-0,0465$ & $-0,0427$ & 2,07 & 0,84 \\
\hline & KMIA & $-0,0402$ & $-0,0159$ & $-0,0402$ & $-0,0138$ & $-0,1318$ & $-0,0152$ & $-0,0234$ & $-0,1001$ & 1,94 & 0,82 \\
\hline 13 & SBEG & $-0,0509$ & $-0,0159$ & $-0,0509$ & $-0,0407$ & $-0,0548$ & $-0,0375$ & $-0,0391$ & $-0,0505$ & 1,61 & 0,81 \\
\hline 14 & SBRF & $-0,0322$ & $-0,0159$ & $-0,0322$ & $-0,0501$ & $-0,0225$ & $-0,0576$ & $-0,0621$ & $-0,0656$ & 1,31 & 0,79 \\
\hline 15 & SBFL & $-0,0349$ & $-0,0159$ & $-0,0349$ & $-0,0580$ & $-0,0182$ & $-0,0327$ & $-0,0310$ & $-0,0129$ & $-0,12$ & 0,77 \\
\hline 16 & SBGO & $-0,0375$ & $-0,0159$ & $-0,0375$ & $-0,0586$ & $-0,0175$ & $-0,0239$ & $-0,0233$ & $-0,0094$ & $-0,32$ & 0,76 \\
\hline 17 & SBPS & $-0,0536$ & $-0,0159$ & $-0,0536$ & $-0,0252$ & $-0,0333$ & $-0,0126$ & $-0,0122$ & $-0,0077$ & $-0,35$ & 0,74 \\
\hline & SBVT & $-0,0322$ & $-0,0159$ & $-0,0322$ & $-0,0495$ & $-0,0133$ & $-0,0307$ & $-0,0293$ & $-0,0117$ & $-0,56$ & 0,73 \\
\hline 19 & SBRP & $-0,0402$ & $-0,0159$ & $-0,0402$ & $-0,0614$ & $-0,0157$ & $-0,0128$ & $-0,0118$ & $-0,0025$ & $-0,65$ & 0,71 \\
\hline 20 & SBSG & $-0,0268$ & $-0,0159$ & $-0,0268$ & $-0,0278$ & $-0,0249$ & $-0,0270$ & $-0,0288$ & $-0,0362$ & $-0,77$ & 0,69 \\
\hline & SBSL & $-0,0349$ & $-0,0159$ & $-0,0349$ & $-0,0294$ & $-0,0269$ & $-0,0219$ & $-0,0210$ & $-0,0171$ & $-0,81$ & 0,68 \\
\hline 22 & SBKP & $-0,0375$ & $-0,0159$ & $-0,0375$ & $-0,0401$ & $-0,0230$ & $-0,0144$ & $-0,0142$ & $-0,0062$ & $-0,93$ & 0,66 \\
\hline 23 & SBMO & $-0,0322$ & $-0,0159$ & $-0,0322$ & $-0,0257$ & $-0,0342$ & $-0,0159$ & $-0,0175$ & $-0,0199$ & $-1,00$ & 0,65 \\
\hline 24 & SBFI & $-0,0241$ & $-0,0159$ & $-0,0241$ & $-0,0357$ & $-0,0114$ & $-0,0207$ & $-0,0200$ & $-0,0103$ & $-1,56$ & 0,63 \\
\hline 25 & SBJP & $-0,0214$ & $-0,0159$ & $-0,0214$ & $-0,0183$ & $-0,0203$ & $-0,0175$ & $-0,0169$ & $-0,0204$ & $-1,83$ & 0,61 \\
\hline
\end{tabular}




\section{Rede de voos da GOL $\left(R \_g l o\right)$ :}

\begin{tabular}{|c|c|c|c|c|c|c|c|c|c|c|c|c|}
\hline & Sigla & Densidade & Componente & $\sum k$ & Eficiência & $\sum \boldsymbol{k}^{w}$ & distância & $\sum k^{w}{ }_{\text {voo }}$ & $\sum \boldsymbol{k}_{a}^{w}$ & $\sum k^{w}{ }_{R P K}$ & $I_{C R I}$ & $I_{C R I(\%)}$ \\
\hline 1 & SBGR & $-0,2008$ & $-0,0946$ & $-0,2008$ & $-0,1881$ & & $-0,2560$ & $-0,2703$ & $-0,2747$ & $-0,3650$ & 41,79 & 1,00 \\
\hline 2 & SBSP & $-0,1025$ & $-0,0676$ & $-0,1025$ & $-0,2408$ & & $-0,0521$ & $-0,2102$ & $-0,2045$ & $-0,1109$ & 22,90 & 0,99 \\
\hline 3 & SBGL & $-0,1381$ & $-0,0135$ & $-0,1381$ & $-0,0813$ & & $-0,1558$ & $-0,1519$ & $-0,1534$ & $-0,1849$ & 18,29 & 0,97 \\
\hline 4 & SBBR & $-0,1255$ & $-0,0135$ & $-0,1255$ & $-0,1148$ & & $-0,1286$ & $-0,1620$ & $-0,1624$ & $-0,1814$ & 18,04 & 0,96 \\
\hline 5 & SBCF & $-0,0941$ & $-0,0270$ & $-0,0941$ & $-0,0997$ & & $-0,0843$ & $-0,1118$ & $-0,1116$ & $-0,0752$ & 11,93 & 0,95 \\
\hline 6 & SBSV & $-0,0837$ & $-0,0135$ & $-0,0837$ & $-0,0800$ & & $-0,0688$ & $-0,0938$ & $-0,0961$ & $-0,1052$ & 9,23 & 0,93 \\
\hline 7 & SBRF & $-0,0565$ & $-0,0405$ & $-0,0565$ & $-0,0748$ & & $-0,0605$ & $-0,0640$ & $-0,0649$ & $-0,0938$ & 8,16 & 0,92 \\
\hline 8 & SBPA & $-0,0711$ & $-0,0135$ & $-0,0711$ & $-0,0557$ & & $-0,0813$ & $-0,0727$ & $-0,0742$ & $-0,0737$ & 6,79 & 0,90 \\
\hline 9 & SBFZ & $-0,0669$ & $-0,0135$ & $-0,0669$ & $-0,0455$ & & $-0,0917$ & $-0,0640$ & $-0,0660$ & $-0,0916$ & 6,55 & 0,89 \\
\hline 10 & SBRJ & $-0,0335$ & $-0,0135$ & $-0,0335$ & $-0,1259$ & & $-0,0123$ & $-0,1184$ & $-0,1196$ & $-0,0475$ & 6,00 & 0,88 \\
\hline 11 & SBCT & $-0,0628$ & $-0,0135$ & $-0,0628$ & $-0,0959$ & & $-0,0447$ & $-0,0758$ & $-0,0754$ & $-0,0430$ & 5,91 & 0,86 \\
\hline 12 & SBBE & $-0,0481$ & $-0,0270$ & $-0,0481$ & $-0,0685$ & & $-0,0406$ & $-0,0469$ & $-0,0467$ & $-0,0532$ & 4,46 & 0,85 \\
\hline 13 & SBKP & $-0,0565$ & $-0,0135$ & $-0,0565$ & $-0,0506$ & & $-0,0624$ & $-0,0245$ & $-0,0249$ & $-0,0220$ & 2,46 & 0,84 \\
\hline 14 & SBEG & $-0,0377$ & $-0,0270$ & $-0,0377$ & $-0,0311$ & & $-0,0497$ & $-0,0281$ & $-0,0288$ & $-0,0472$ & 2,33 & 0,82 \\
\hline 15 & SBFL & $-0,0293$ & $-0,0270$ & $-0,0293$ & $-0,0840$ & & $-0,0141$ & $-0,0434$ & $-0,0409$ & $-0,0206$ & 2,32 & 0,81 \\
\hline 16 & SBSG & $-0,0418$ & $-0,0135$ & $-0,0418$ & $-0,0268$ & & $-0,0525$ & $-0,0288$ & $-0,0299$ & $-0,0436$ & 1,39 & 0,79 \\
\hline 17 & SBGO & $-0,0439$ & $-0,0135$ & $-0,0439$ & $-0,0538$ & & $-0,0359$ & $-0,0320$ & $-0,0297$ & $-0,0186$ & 1,35 & 0,78 \\
\hline 18 & SBMO & $-0,0377$ & $-0,0135$ & $-0,0377$ & $-0,0322$ & & $-0,0488$ & $-0,0205$ & $-0,0216$ & $-0,0313$ & 0,63 & 0,77 \\
\hline 19 & SBPS & $-0,0418$ & $-0,0135$ & $-0,0418$ & $-0,0364$ & & $-0,0317$ & $-0,0205$ & $-0,0215$ & $-0,0179$ & 0,29 & 0,75 \\
\hline 20 & SBVT & $-0,0293$ & $-0,0135$ & $-0,0293$ & $-0,0513$ & & $-0,0157$ & $-0,0372$ & $-0,0359$ & $-0,0191$ & 0,19 & 0,74 \\
\hline 21 & MDSD & $-0,0209$ & $-0,0270$ & $-0,0209$ & $-0,0092$ & & $-0,0590$ & $-0,0085$ & $-0,0090$ & $-0,0298$ & $-0,03$ & 0,73 \\
\hline 22 & SBSL & $-0,0314$ & $-0,0135$ & $-0,0314$ & $-0,0336$ & & $-0,0316$ & $-0,0232$ & $-0,0236$ & $-0,0277$ & $-0,09$ & 0,71 \\
\hline 23 & SBCY & $-0,0335$ & $-0,0135$ & $-0,0335$ & $-0,0281$ & & $-0,0319$ & $-0,0217$ & $-0,0225$ & $-0,0285$ & $-0,14$ & 0,70 \\
\hline 24 & SBCG & $-0,0314$ & $-0,0135$ & $-0,0314$ & $-0,0266$ & & $-0,0188$ & $-0,0145$ & $-0,0147$ & $-0,0131$ & $-1,20$ & 0,68 \\
\hline 25 & SAEZ & $-0,0251$ & $-0,0135$ & $-0,0251$ & $-0,0190$ & & $-0,0350$ & $-0,0126$ & $-0,0133$ & $-0,0164$ & $-1,35$ & 0,67 \\
\hline
\end{tabular}


5. Rede de voos da AZUL $\left(R \_a z u\right)$ :

\begin{tabular}{|c|c|c|c|c|c|c|c|c|c|c|c|}
\hline & Sigla & Densidade & Componente & $\sum \boldsymbol{k}$ & Eficiência & $\sum \boldsymbol{k}^{w}{ }_{\text {dist }}$ & $\sum k^{w}{ }_{v o o}$ & $\sum \boldsymbol{k}_{a}^{w}$ & $\sum k_{R P K}^{w}$ & $I_{C R I}$ & $I_{C R I(\%)}$ \\
\hline 1 & SBKP & $-0,2346$ & $-0,1792$ & $-0,2346$ & $-0,4622$ & $-0,3146$ & $-0,3746$ & $-0,3893$ & $-0,4799$ & 65,33 & 1,00 \\
\hline 2 & SBCF & 312 & 283 & $-0,1312$ & 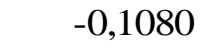 & $-0,1456$ & $-0,1769$ & $-0,1905$ & $-0,1879$ & 23,97 & 0,99 \\
\hline 3 & SBCY & $-0,0676$ & 0660 & $-0,0676$ & 1128 & $-0,0719$ & $-0,0592$ & $-0,0612$ & $-0,0745$ & 12,21 & 0,98 \\
\hline 4 & SBGR & $-0,0755$ & $-0,0094$ & $-0,0755$ & $-0,0434$ & $-0,0878$ & $-0,1118$ & $-0,1240$ & $-0,1207$ & 12,11 & 0,97 \\
\hline 5 & SBPA & $-0,0636$ & $-0,0283$ & $-0,0636$ & 0803 & $-0,0452$ & $-0,0855$ & $-0,0885$ & $-0,0815$ & 9,85 & 0,96 \\
\hline 6 & SBRJ & $-0,0596$ & $-0,0189$ & $-0,0596$ & $-0,0977$ & $-0,0447$ & $-0,0992$ & $-0,1054$ & $-0,0629$ & 9,77 & 0,95 \\
\hline 7 & SBSV & 5 & 3 & $-0,0755$ & 10 & $-0,0663$ & $-0,0616$ & -0, & $-0,0727$ & 9,48 & 0,94 \\
\hline 8 & SBEG & 437 & 0755 & $-0,0437$ & 87 & $-0,0580$ & $-0,0347$ & $-0,0357$ & $-0,0586$ & 8,18 & 0,93 \\
\hline 9 & SBRF & $-0,0557$ & $-0,0094$ & $-0,0557$ & $-0,0449$ & $-0,0822$ & $-0,0550$ & $-0,0602$ & $-0,0854$ & 7,31 & 0,92 \\
\hline 10 & SBCT & $-0,0517$ & $-0,0094$ & $-0,0517$ & $-0,0644$ & $-0,0404$ & $-0,0873$ & $-0,0926$ & $-0,0496$ & 7,11 & 0,91 \\
\hline 11 & SBBR & -( & $-0,0094$ & $-0,0616$ & -1 & $-0,0686$ & $-0,0568$ & -0, & $-0,0622$ & 6,79 & 0,90 \\
\hline 12 & SBBE & $-0,0457$ & $-0,0189$ & $-0,0457$ & $-0,0316$ & $-0,0482$ & $-0,0383$ & $-0,0338$ & $-0,0397$ & 4,14 & 0,90 \\
\hline 13 & SBGO & $-0,0$ & $-0,0094$ & $-0,0437$ & $-0,0421$ & $-0,0531$ & $-0,0378$ & $-0,0417$ & $-0,0421$ & 4,06 & 0,89 \\
\hline 14 & SBFZ & $-0,0437$ & $-0,0094$ & $-0,0437$ & $-0,0186$ & $-0,0574$ & $-0,0265$ & $-0,0280$ & $-0,0470$ & 3,21 & 0,88 \\
\hline 15 & SBMO & $-0,043$ & $-0,0094$ & $-0,0437$ & $-0,0$ & $-0,0692$ & $-0,0151$ & $-0,0147$ & $-0,0204$ & 2,50 & 0,87 \\
\hline 16 & SBPS & -0 & -0 & $-0,0437$ & 21 & $-0,0544$ & $-0,0139$ & $-0,0137$ & $-0,0134$ & 1,97 & 0,86 \\
\hline 17 & SBSG & $-0,0318$ & $-0,0094$ & $-0,0318$ & $-0,0204$ & $-0,0452$ & $-0,0192$ & $-0,0180$ & $-0,0241$ & 1,31 & 0,85 \\
\hline 18 & SBBH & $-0,0358$ & $-0,0094$ & $-0,0358$ & $-0,0297$ & $-0,0164$ & $-0,0368$ & $-0,0251$ & $-0,0103$ & 1,30 & 0,84 \\
\hline 19 & SBRP & $-0,03$ & $-0,0094$ & $-0,0358$ & -1 & $-0,0344$ & $-0,0168$ & $-0,0137$ & $-0,0070$ & 1,26 & 0,83 \\
\hline 20 & SBVT & $-0,0199$ & -0 , & $-0,0199$ & -0 & 43 & $-0,0387$ & 118 & $-0,0256$ & 1,04 & 0,82 \\
\hline 21 & SBCG & $-0,0199$ & $-0,0189$ & $-0,0199$ & $-0,0384$ & $-0,0198$ & $-0,0175$ & $-0,0182$ & $-0,0193$ & 0,59 & 0,81 \\
\hline 22 & SBLO & $-0,0278$ & $-0,0094$ & $-0,0278$ & $-0,02$ & $-0,0295$ & $-0,0179$ & $-0,0160$ & $-0,0100$ & 0,47 & 0,80 \\
\hline 23 & SBPV & $-0,01$ & $-0,0189$ & $-0,0159$ & & $-0,0216$ & $-0,0163$ & $-0,0184$ & $-0,0206$ & 0,26 & 0,79 \\
\hline 24 & SBSP & $-0,0159$ & $-0,0094$ & $-0,0159$ & $-0,03$ & $-0,0094$ & $-0,0300$ & $-0,0351$ & $-0,0219$ & 0,22 & 0,78 \\
\hline 25 & SBSN & $-0,0199$ & $-0,0283$ & $-0,0199$ & $-0,0273$ & $-0,0093$ & $-0,0157$ & $-0,0106$ & $-0,0061$ & 0,12 & 0,77 \\
\hline
\end{tabular}


6. Rede de voos da AVIANCA (R_one):

\begin{tabular}{|c|c|c|c|c|c|c|c|c|c|c|c|}
\hline & Sigla & Densidade & Componente & $\sum k$ & Eficiência & $\sum \boldsymbol{k}_{\text {dist }}^{w}$ & $\sum k^{w}{ }_{v o o}$ & $\sum \boldsymbol{k}^{w}{ }_{a}$ & $\sum k_{R P K}^{w}$ & $I_{C R I}$ & $\overline{I_{C R I(\%)}}$ \\
\hline 1 & SBBR & $-0,3509$ & $-0,1200$ & $-0,3509$ & $-0,1961$ & $-0,3504$ & $-0,2965$ & $-0,2860$ & $-0,2773$ & 20,95 & 1,00 \\
\hline 2 & SBGR & 2544 & 0800 & $-0,2544$ & 3026 & $-0,3099$ & $-0,3250$ & $-0,3392$ & $-0,4796$ & 20,17 & 0,96 \\
\hline 3 & SBSV & 42 & 0 & $-0,1842$ & 8 & $-0,1387$ & $-0,2028$ & $-0,2269$ & $-0,2265$ & 8,96 & 0,92 \\
\hline 4 & SBGL & 579 & 9400 & $-0,1579$ & 72 & $-0,1662$ & $-0,1603$ & $-0,1589$ & $-0,1600$ & 5,68 & 0,88 \\
\hline 5 & SBFZ & $-0,1053$ & $-0,0800$ & $-0,1053$ & 0955 & $-0,1807$ & $-0,0823$ & $-0,0852$ & $-0,1514$ & 4,02 & 0,83 \\
\hline 6 & SBSP & $-0,0965$ & $-0,0400$ & $-0,0965$ & ,2089 & $-0,0617$ & $-0,1960$ & $-0,1912$ & $-0,0964$ & 3,81 & 0,79 \\
\hline 7 & SBFL & & & $-0,1053$ & & $-0,0$ & $-0,0802$ & & $-0,0472$ & 2,75 &, 75 \\
\hline 8 & SBRF & 7 & $-c$ & $-0,0877$ & 57 & $-0,1072$ & $-0,1105$ & $-0,1255$ & $-0,1668$ & 1,64 & 0,71 \\
\hline 9 & SBRJ & $-0,0526$ & $-0,0400$ & $-0,0526$ & 00 & $-0,0301$ & $-0,1496$ & $-0,1393$ & $-0,0634$ & 0,51 & 0,67 \\
\hline 10 & SBGO & $-0,0614$ & $-0,0400$ & $-0,0614$ & 47 & $-0,0385$ & $-0,0394$ & $-0,0338$ & $-0,0157$ & $-2,79$ & 0,63 \\
\hline 11 & SBPA & & & $-0,0526$ & & $-0,0365$ & -0 , & 34 & $-0,0341$ & $-3,03$ & 0,58 \\
\hline 12 & SBJU & 6 & -( & $-0,0526$ & 77 & $-0,0566$ & 401 & 338 & $-0,0343$ & $-3,20$ & 0,54 \\
\hline 13 & SBMO & $-0,0526$ & $-0,0400$ & $-0,0526$ & $-0,0647$ & $-0,0603$ & $-0,0297$ & $-0,0317$ & $-0,0373$ & $-3,22$ & 0,50 \\
\hline 14 & SBCY & $-0,0526$ & 0400 & $-0,0526$ & 4 & $-0,0430$ & $-0,0482$ & $-0,0$ & $-0,0342$ & $-3,26$ & 0,46 \\
\hline 15 & SBJP & 6 & 0 & $-0,0526$ & & $-0,0910$ & $-0,0253$ & 30 & $-0,0423$ & $-3,50$ & 0,42 \\
\hline 16 & SBPL & & $-0,0400$ & $-0,0526$ & & $-0,0338$ & $-0,0308$ & 159 & $-0,0219$ & $-3,51$ & 0,38 \\
\hline 17 & SBSG & $-0,0351$ & $-0,0400$ & $-0,0351$ & $-0,0320$ & $-0,0632$ & $-0,0254$ & $-0,0280$ & $-0,0521$ & $-4,00$ & 0,33 \\
\hline 18 & SBAR & $-0,0351$ & $-0,0400$ & $-0,0351$ & $-0,0803$ & $-0,0240$ & $-0,0202$ & $-0,0176$ & $-0,0119$ & $-4,34$ & 0,29 \\
\hline 19 & SBIL & $-0,0$ & $-0,0400$ & $-0,0351$ & $-0,0$ & $-0,0184$ & $-0,0182$ & $-0,0161$ & $-0,0083$ & $-4,52$ & 0,25 \\
\hline 20 & SBCG & $-0,0351$ & $-0,0400$ & $-0,0351$ & $-0,0431$ & $-0,0223$ & $-0,0287$ & $-0,0213$ & $-0,0138$ & $-4,69$ & 0,21 \\
\hline 21 & $\mathrm{SBCH}$ & $-0,0175$ & $-0,0400$ & $-0,0175$ & $-0,0$ & $-0,0064$ & $-0,0187$ & $-0,0203$ & $-0,0075$ & $-5,00$ & 0,17 \\
\hline 22 & SBCT & $-0,0175$ & $-0,0400$ & $-0,0175$ & $-0,0$ & $-0,0168$ & $-0,0101$ & $-0,0101$ & $-0,0097$ & $-5,66$ & 0,13 \\
\hline 23 & SKBO & $-0,0175$ & $-0,0400$ & $-0,0175$ & $-0,0019$ & $-0,0632$ & $-0,0013$ & $-0,0013$ & $-0,0029$ & $-5,81$ & 0,08 \\
\hline 24 & SBPF & $-0,0175$ & $-0,0400$ & $-0,0175$ & $-0,0313$ & $-0,0123$ & $-0,0078$ & $-0,0057$ & $-0,0039$ & $-5,88$ & 0,04 \\
\hline 25 & $\mathrm{SBCF}$ & $-0,0175$ & $-0,0400$ & $-0,0175$ & $-0,0248$ & $-0,0092$ & $-0,0041$ & $-0,0030$ & $-0,0017$ & $-6,09$ & 0,00 \\
\hline
\end{tabular}




\section{APÊNDICE D - Dendrograma da análise de agrupamento}

\section{Dendograma}

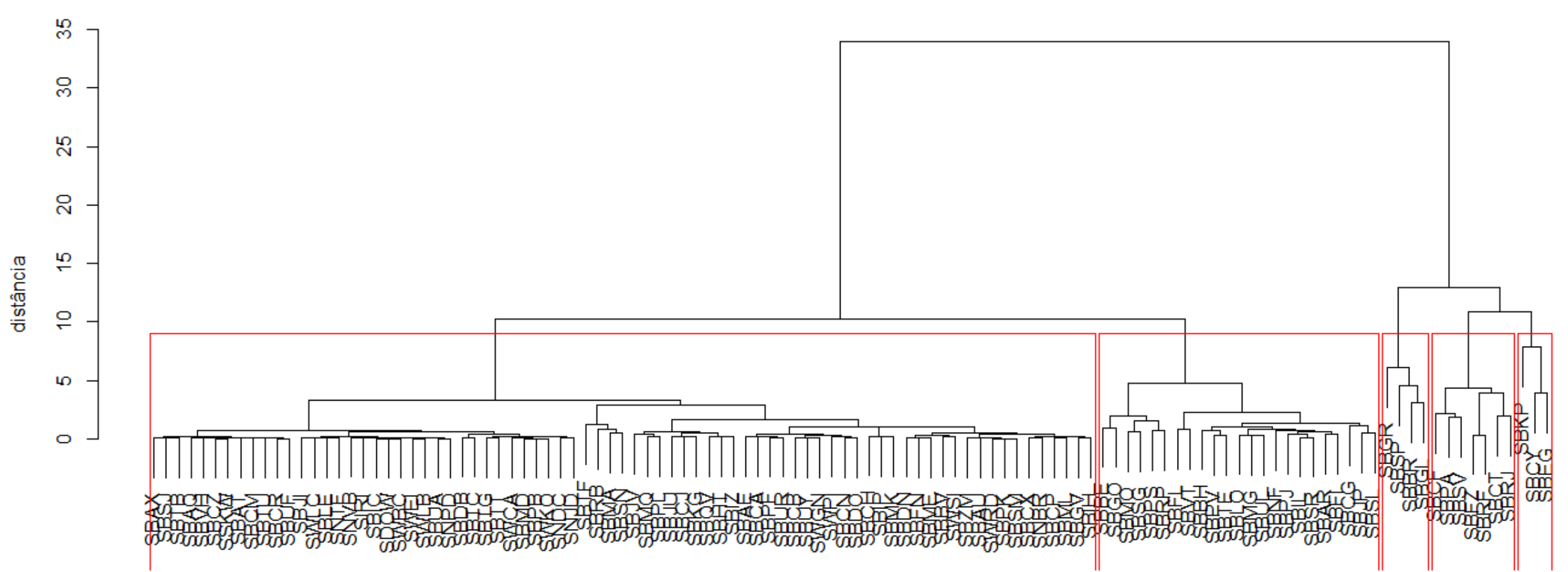

aeroportos 


\title{
ANEXO 1 - Descrição de variáveis da base de dados do
}

\section{transporte aéreo brasileiro}

\author{
Conteúdo transcrito da fonte: \\ http://www2.anac.gov.br/Estatistica/DadosEstatisticos/descricao.asp \\ Última atualização: 19/05/2015.
}

Etapa Básica: As etapas básicas são aquelas realizadas pela aeronave desde a sua decolagem até o próximo pouso, independente de onde tenha sido realizado o embarque ou o desembarque do objeto de transporte. Os dados estatísticos das etapas básicas representam o status da aeronave em cada etapa do voo, apresentando a movimentação de cargas e passageiros entre os aeródromos de origem e destino da aeronave. É a operação de uma aeronave entre uma decolagem e o próximo pouso, ou seja, é a ligação direta entre dois aeródromos.

- Empresa Aérea: Empresa Aérea responsável por operar as etapas;

- Natureza do Voo: Refere-se à natureza das etapas, e possui o valor "Doméstico" caso as etapas tenham o pouso e a decolagem realizadas no Brasil e sejam operadas por Empresas brasileiras ou possuem o valor "Internacional" caso contrário;

- Tipo de Voo: Faz referência ao tipo de operação das etapas:

- Improdutivas: etapas que não geraram receita à empresa aérea (como realização de treinamentos, voo para manutenção de aeronaves,...);

- Regulares: etapas remuneradas que são realizadas sob uma numeração de Horário de Transporte (HOTRAN). Recebem esse nome, pois possuem a característica de serem realizadas regularmente; e

- Não Regulares: etapas remuneradas que não são realizadas sob uma numeração de Horário de Transporte (HOTRAN). Recebem esse nome, pois possuem a característica de serem realizadas de forma não continuada. Aqui estão os voos Charters, Fretamentos,...

- ASK: Refere-se ao volume de Assentos Quilômetros Oferecidos, ou seja, a soma do produto entre o número de assentos oferecido e a distância das etapas;

- RPK: Refere-se ao volume de Passageiros Quilômetros Transportados, ou seja, a soma do produto entre o número de passageiros pagos e a distâncias das etapas;

- ATK: Refere-se ao volume de Tonelada Quilômetro Oferecida, ou seja, a soma do produto entre o payload, que é a capacidade total de peso disponível na aeronave, expressa em quilogramas, disponível para efetuar o transporte de passageiros, carga e correio, e a distância das etapas, dividido por 1.000;

- RTK: Refere-se ao volume de Toneladas Quilômetros Transportadas, ou seja, a soma do produto entre os quilogramas carregados pagos, onde cada passageiros possui o peso estimado de $75 \mathrm{Kg}$, e a distância das etapas, dividido por 1.000;

- Combustível: Refere-se à quantidade, em litros, de combustível consumida pela aeronave na execução da referida etapa. Informação disponível apenas para empresas brasileiras;

- Distância: Refere-se à distância, expressa em quilômetros, entre os aeródromos de origem e destino da etapa, considerando a curvatura do planeta Terra;

- Horas Voadas: Refere-se ao número de horas de voo entre os aeródromos de origem e destino da etapa; e 
- Decolagens: Refere-se ao número de decolagens que ocorreram entre os aeródromos de origem e destino da etapa;

- Carga Paga Km: Refere-se ao volume de Carga Paga (kg) em cada quilômetro, ou seja, a soma do produto entre a quantia $(\mathrm{kg})$ de carga paga e a distâncias das etapas;

- Carga Grátis Km: Refere-se ao volume de Carga Grátis (kg) em cada quilômetro, ou seja, a soma do produto entre a quantia $(\mathrm{kg})$ de carga grátis e a distâncias das etapas;

- Correio Km: Refere-se ao volume de Correio (kg) em cada quilômetro, ou seja, a soma do produto entre a quantia $(\mathrm{kg})$ de correio e a distâncias das etapas;

- Assentos: é o número de assentos disponíveis em cada etapa de voo de acordo com a configuração da aeronave na execução da etapa; e

- Payload (Kg): é a capacidade total de peso na aeronave, expressa em quilogramas, disponível para efetuar o transporte de passageiros, carga e correio.

Etapa Combinada: As etapas combinadas identificam os pares de aeródromos de origem, onde houve o embarque do objeto de transporte, e destino, onde houve o desembarque do objeto de transporte, independente da existência de aeródromos intermediários, atendidos por determinado voo. É a etapa de voo vista com foco no objeto de transporte (pessoas e/ou cargas), com base no embarque e desembarque nos aeródromos relacionados. Os dados estatísticos da etapa combinada informam a origem e destino no voo, dos passageiros e cargas transportadas, independente das suas escalas.

- Empresa Aérea: Empresa Aérea responsável por operar as etapas;

- Natureza do Voo: Refere-se à natureza das etapas, e possui o valor "Doméstico" caso as etapas tenham o pouso e a decolagem realizadas no Brasil e sejam operadas por Empresas brasileiras ou possuem o valor "Internacional" caso contrário;

- Tipo de Voo: Faz referência ao tipo de operação das etapas:

- Improdutivas: etapas que não geraram receita à empresa aérea (como realização de treinamentos, voo para manutenção de aeronaves,...);

- Regulares: etapas remuneradas que são realizadas sob uma numeração de Horário de Transporte (HOTRAN). Recebem esse nome, pois possuem a característica de serem realizadas regularmente; e

- Não Regulares: etapas remuneradas que não são realizadas sob uma numeração de Horário de Transporte (HOTRAN). Recebem esse nome, pois possuem a característica de serem realizadas de forma não continuada. Aqui estão os voos Charters, Fretamentos,...

- Passageiros Pagos: Refere-se aos passageiros que ocupam assentos comercializados ao público e que geram receita, com a compra de assentos, para a empresa de transporte aéreo. Incluem-se nesta definição as pessoas que viajam em virtude de ofertas promocionais, as que se valem dos programas de fidelização de clientes, as que se valem dos descontos concedidos pelas empresas, as que viajam com tarifas preferenciais, as pessoas que compram passagem no balcão ou através do site de empresa de transporte aéreo e as pessoas que compram passagem em agências de viagem;

- Passageiros Grátis: Refere-se aos passageiros que ocupam assentos comercializados ao público mas que não geram receita, com a compra de assentos, para a empresa de transporte aéreo. Incluem-se nesta definição as pessoas que viajam gratuitamente, as que se valem dos descontos de funcionários das empresas aéreas e seus agentes, os funcionários de empresas aéreas que viajam a negócios pela própria empresa e os tripulantes ou quem estiver ocupando assento destinado a estes; 
- Carga Paga: Refere-se à quantidade total, expressa em quilogramas, de todos os bens que tenham sido transportados na aeronave, exceto correio e bagagem, e tenham gerado receitas direta ou indireta para a empresa aérea;

- Carga Grátis: Refere-se à quantidade total, expressa em quilogramas, de todos os bens que tenham sido transportados na aeronave, exceto correio e bagagem, e não tenha gerado receitas diretas ou indiretas para a empresa aérea;

- Correio: Refere-se à quantidade de objetos transportados de rede postal em cada trecho de voo realizado, expresso em quilogramas. 